Political institutions, leaders, and public spending

\author{
Haakon Gjerløw
}

June 17, 2019

Thesis submitted for the degree of Philosophiæ Doctor 
(C) Haakon Gjerløw, 2019

Series of dissertations submitted to the

Faculty of Social Sciences, University of Oslo

No. 764

ISSN 1564-3991

All rights reserved. No part of this publication may be

reproduced or transmitted, in any form or by any means, without permission.

Cover: Hanne Baadsgaard Utigard.

Print production: Reprosentralen, University of Oslo. 


\section{Acknowledgements}

First, I want to thank my two supervisors, Carl Henrik Knutsen and Tore Wig. They are both world-class scholars and winners of HM The King's golden medal. They have taught me everything I know about the informal rules of academia, connected me with excellent research groups around the world and had high ambitions on my behalf. As part of the core team administrating the collection of the Historical Varieties of Democracy data, we have had extensive cooperation in the past four years. Safe to say, I have dealt more with Carl Henrik over the years than can be expected from a supervisor-supervisee relationship. He has always had thorough comments to any draft presented to him, and his grasp of the literature is astounding. I have (highly) appreciated our informal tone and friendly relationship. Tore, infamously known for regarding me as the comic relief of the research group, is admirably constructive in his feedback, as his critical comments are always followed by a state-of-the-art solution. Thank you both.

Second, I am grateful to a number of friends and colleagues. Peter Egge Langsæther has been an invaluable colleague and friend since BA. He has contributed greatly to this dissertation, not least by commenting on the whole dissertation(!), but he has also been important to my general intellectual development throughout the years. Martin G. Søyland has been a great friend and partner-in-crime in spending too much time on programming. Bjørn Høyland has been my main methodological mentor since my MA and I have always appreciated his high ambitions and his encouragement towards my career. I would also like to thank Jon Hovi and Scott Gates for commenting on an earlier draft of this dissertation. Magnus Rasmussen has had excellent comments to my papers, but his existence has not really been that fruitful for the expedient delivery of this dissertation, as he has instead dragged me into a series of new side projects requiring hours of data-collection and which are never finished. I would like to thank Øyvind Stiansen for keeping the office lively, and Tarald Laudal Berge for walking around with me. I would also like to mention Zoltan Fazekas, Sirianne Dahlum, Andreas Kokkvoll Tveit, Karl Bjurstrøm, Kjersti Skarstad, Solveig Hillesund, Simen Sørbøe Solbakken, Atle Haugsgjerd, my fellow Phd students, conference participants, and anonymous reviewers for helpful feedback and encouragement.

Third, I would like to thank the Historical Varieties of Democracy team. I would especially like to mention John Gerring, who is also a co-author to chapter 2. Cooperating with this international team of excellent scholars has been extremely rewarding.

I would also like to thank Professor Wilhelm Keilhaus Minnefond and Ingegerd og Arne Skaugs Forskningsfond for financial support.

I spent the spring of 2018 at the Department of Political Science at Emory College of Arts and Sciences. It is difficult overstate how impressive I found this academic community. I am very grateful to Jeffrey Staton for inviting me over, and to Marcella Morris for taking care of me with food, beer (where Steven Webster also helped a lot), and exercise 
(where Dr. Webster didn't help at all). I want to thank Gray Barrett, Siv Cheruvu, Pearce and Kathryn Edwards, Patrick Pierson, Daniel Arnon and the rest of the graduates for all the great conversations. Not least, I am very grateful to Jennifer Gandhi for all the intellectual conversations, and for letting me join her class and overrun it with weird norwegian-english.

Finally, I would like to thank Ingebjørg Finnbakk. Although she has been in the DR Congo for most of the time and not really had much to do with this dissertation, she always reminds me of why I should bother with studying economic development at all.

Haakon Gjerløw

Blindern, Oslo, Norway

June 2019 


\section{Contents}

1 Political institutions and public expenditures 17

1.1 Introduction . . . . . . . . . . . . . . . . . . . . 17

1.2 Political institutions and public expenditures: The case for a more nuanced

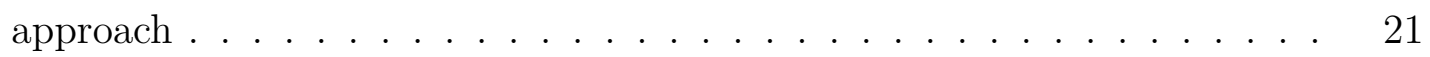

1.2.1 Shortcomings of the existing literature . . . . . . . . . 26

1.3 Key concepts . . . . . . . . . . . . . . . . . . . . . . 30

1.3.1 Democracy versus autocracy . . . . . . . . . . . . . 30

1.3.2 Public expenditures . . . . . . . . . . . . . . . . . 35

1.4 Theoretical framework . . . . . . . . . . . . . . . 38

1.4.1 Political institutions . . . . . . . . . . . . . . 39

1.4.2 Motivation . . . . . . . . . . . . . . . . . 40

1.4 .3 Capacities .......................... 41

1.5 Reaching conclusions: Philosophy of science . . . . . . . . . . . . . . 42

1.5.1 Causal inference . . . . . . . . . . . . . . . . . 43

1.5.2 Statistical inference . . . . . . . . . . . . . . . . . 44

1.6 The structure of the dissertation . . . . . . . . . . . . . . . 45

1.6.1 Regimes and industrialization ... . . . . . . . . . 45

1.6.2 Democracy and public services: Evidence from postal services . . 47

1.6.3 Leaders, private interests, and socially wasteful projects: Skyscrapers in democracies and autocracies . . . . . . . . . . . . 48

1.6.4 Presidents, parliaments, and the allocation of public investments during elections . . . . . . . . . . . . . . . . . 49

1.7 Implications . . . . . . . . . . . . . . . . . . . . . . 52

2 Regimes and Industrialization $\quad 55$

2.1 Introduction . . . . . . . . . . . . . . . . 56

2.2 Industrialization and Politics . . . . . . . . . . . . 57

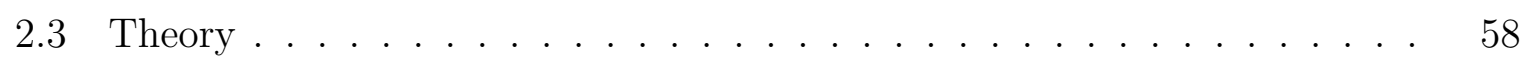

2.3.1 Clarifications and Caveats . . . . . . . . . . . . 62

2.4 Data and model specification . . . . . . . . . . . . . . 63

2.5 Results . . . . . . . . . . . . . . . . . . 66

2.6 Conclusion . . . . . . . . . . . . . . . . . . . . 73 
3 Democracy and public services: Evidence from postal services $\quad 75$

3.1 Introduction . . . . . . . . . . . . . . . . . 76

3.2 Literature review . . . . . . . . . . . . . . . . . . . . 77

3.2 .1 My contribution . . . . . . . . . . . . . . 81

3.3 Postal services . . . . . . . . . . . . . . . . . . . . . . . . . . . 82

3.4 Data and design . . . . . . . . . . . . . . . . . . . . . . . . . . . . . . . . . . . . .

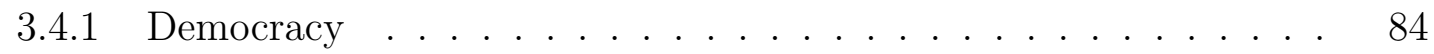

3.4 .2 Confounders . . . . . . . . . . . . . . . . 84

3.5 Analysis . . . . . . . . . . . . . . . . . 85

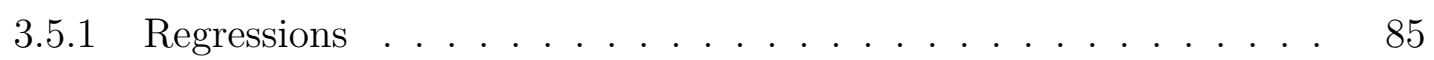

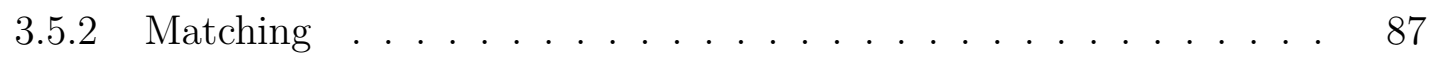

3.5.3 Alternative historical explanations . . . . . . . . . . . . . . . 90

3.6 Conclusion . . . . . . . . . . . . . . . . . . . . . . . . . 92

4 Leaders, private interests, and socially wasteful projects: Skyscrapers in democracies and autocracies $\quad \mathbf{9 5}$

4.1 Introduction . . . . . . . . . . . . . . . . . . . 96

4.2 Argument . . . . . . . . . . . . . . . . . . . . . . 98

4.2.1 Why democracies may build fewer and less expensive skyscrapers than autocracies: Potential mechanisms . . . . . . . . . . . . . 99

4.3 Data . . . . . . . . . . . . . . . . . . . 103

4.4 Empirical Analysis . . . . . . . . . . . . . . . . . 105

4.4.1 Tests on numbers of skyscrapers and skyscraper meters . . . . . 106

4.4.2 Which types of skyscrapers do autocrats build and in what contexts do autocrats build skyscrapers? . . . . . . . . . . . . . 109

4.4 .3 Investigating mechanisms . . . . . . . . . . . . . . . . . . 113

4.5 Conclusion . . . . . . . . . . . . . . . . . . . . 117

5 Presidents, parliaments and the allocation of public investments during $\begin{array}{lr}\text { elections. } & 119\end{array}$

5.1 Introduction . . . . . . . . . . . . . . . . . . 120

5.2 Legislatures, elections, and resource allocation . . . . . . . . . . . . 121

5.2 .1 Theory . . . . . . . . . . . . . . . . . 123

5.3 Empirical design . . . . . . . . . . . . . . . . . . . 126

5.4 Chinese official finance $(\mathrm{COF})$ to Africa . . . . . . . . . . . . 127

5.4 Data . . . . . . . . . . . . . . . . . 129

5.4 .2 Confounders . . . . . . . . . . . . . . . . 131

5.5 Analysis . . . . . . . . . . . . . . . . . . . . . 132

5.5 .1 Democracy and autocracy . . . . . . . . . . . . . . . 135

5.5 .2 Timing . . . . . . . . . . . . . . . . 136

5.5 .3 Placebo analyses . . . . . . . . . . . . . . . . . . . . . . . . . . . . . . . 136

5.5.4 Proportional versus majoritarian systems . . . . . . . . . . . . . 139 
5.6 Conclusion . . . . . . . . . . . . . . . . . . . . . . 140

6 Appendix for Chapter 2 145

6.1 Summary . . . . . . . . . . . . . . . . . . . 145

6.2 Data descriptions . . . . . . . . . . . . . . . . . . . . 146

6.3 Robustness tests of depreciation and lag . . . . . . . . . . 156

6.4 Different jackknife-estiamtions . . . . . . . . . . . . . . . . 156

6.5 Robustness tests of models with 5- and 10-year averages . . . . . . . 156

6.6 Alternative samples . . . . . . . . . . . . . . . . . . 157

7 Appendix for Chapter $3 \quad 161$

7.1 Summary . . . . . . . . . . . . . . . . . . . . . . . . . 161

7.2 Descriptive statistics . . . . . . . . . . . . . . . . . . 161

7.3 Robustness test: Jackknife and regional exclusion . . . . . . . . . . . 164

7.4 Robustness test: Changing the included covariates. . . . . . . . . . . 165

7.5 Robustness test: Alternative measures . . . . . . . . . . . . . 166

7.6 Robustness test: Letter-level analyses . . . . . . . . . . . . . . . . . . . . 169

8 Appendix for Chapter $4 \quad 171$

8.1 Summary . . . . . . . . . . . . . . . . . . . 171

8.2 Skyscraper data collection . . . . . . . . . . . . . . . . . 172

8.3 Descriptive statistics and sample . . . . . . . . . . . . . . . . 173

8.4 Alternative dependent variable specifications . . . . . . . . . . . . 176

8.5 Alternative independent variable specifications . . . . . . . . . . . . . . 182

8.6 Alternative lag- and sample specifications . . . . . . . . . . . . . . . . 188

8.7 First stage of zero-inflated negative binomial model (second stage reported as Model 5 in Table 4.1 of the paper $)$. . . . . . . . . . . . . . . . 193

8.8 Outliers and influential observations . . . . . . . . . . . . . . . . . . 194

8.9 Alternative mediators . . . . . . . . . . . . . . . . . . . . . 197

8.10 Alternative specifications for "vanity height" . . . . . . . . . . . . . 198

8.11 Robustness test of skyscraper excessiveness: Entropy Balancing models . 204

8.12 Alternative proxies of skyscraper excessiveness (Height/ground-floor area and Height/number of floors). CEM results, with building as unit of analysis.206

8.13 Interaction between Polyarchy and Urbanization/GDP per capita . . . . 207

9 Appendix for Chapter $5 \quad 209$

9.1 Summary . . . . . . . . . . . . . . . . . . . . . . . . . 209

9.2 Descriptive statistics . . . . . . . . . . . . . . . . . . 210

9.3 Jackknife resamplings . . . . . . . . . . . . . . . . . . . . . . . 211

9.4 Binomial cut-off of distance . . . . . . . . . . . . . . . . . . 214

9.5 PRIO-GRID . . . . . . . . . . . . . . . . . . . . . . . . 215

9.6 Table presenting results from models investigating different leads and lags of elections . . . . . . . . . . . . . . . . . . . . . 218 
9.7 Democracy versus autocracy: Alternative data . . . . . . . . . . . . 220

9.8 Table presenting results from models investigating different electoral formulas. . . . . . . . . . . . . . . . . . . . . 223

9.9 Table presenting results from placebo tests. . . . . . . . . . . . . . 224

Bibliography 


\section{List of Tables}

2.1 Benchmark and Selected Robustness Tests . . . . . . . . . . . . . . . 67

2.2 Alternative tests . . . . . . . . . . . . . . . . . . 69

2.3 Taking averages across longer time intervals . . . . . . . . . . . . . 72

2.4 Including the lagged dependent variable as regressor . . . . . . . . . . . . 73

3.1 Effectiveness of postal services . . . . . . . . . . . . 86

3.2 Effectiveness of postal services . . . . . . . . . . . . . . . 91

4.1 Main results: Regime type and the number and meters of Skyscrapers . . 107

4.2 Skyscraper excessiveness: CEM-matching at the building-level . . . . . . 110

4.3 Investigating the mechanisms . . . . . . . . . . . . . . 114

5.1 Elections and investment allocation . . . . . . . . . . . . . 134

6.1 Variable Description . . . . . . . . . . . . . . . . . 146

6.2 Descriptive Statistics . . . . . . . . . . . . . . . . . . . . . . . 149

6.3 Varying Depreciation Rates . . . . . . . . . . . . . . . . . . . 150

6.4 Including the lagged dependent variable as regressor. Robustness test on Polyarchy Stock with 5 percent depreciation rate. . . . . . . . . . . 156

6.5 Including multiple lags of the dependent variable as regressors (5-year panels) 156

6.6 Robustness test on benchmark models, using different democracy measures 157

6.7 Robustness test on benchmark models, using stock autocracy instead of stock democracy . . . . . . . . . . . . . . . . . . . . 158

6.8 Robustness test of benchmark models, excluding countries with socialist legal origin . . . . . . . . . . . . . . . . . . . . . . . . 158

6.9 Robustness test of benchmark models, excluding all observations with the value 0 on iron and steel production . . . . . . . . . . . . . 159

7.1 Descriptive statistics . . . . . . . . . . . . . . . . . . 161

7.2 Effectiveness of postal services . . . . . . . . . . . . . . . . . . . . . . . . . . 165

7.3 Effectiveness of postal services . . . . . . . . . . . . . . . 167

7.4 Effectiveness of postal services - Alternative measures . . . . . . . . . . 168

7.5 Effectiveness of postal services . . . . . . . . . . . . . . 169

8.1 Descriptive statistics for main variables . . . . . . . . . . . . . . 173

8.2 Polyarchy and mediators: Correlation . . . . . . . . . . . . . . . 175

8.3 Polyarchy and mediators: Within unit correlation . . . . . . . . . . . 175

8.4 Polyarchy and mediators: Share of correlation that is within-unit . . . . 175 
8.5 Regime type and the number and meters of Skyscrapers: Cutoff at 125 meter . . . . . . . . . . . . . . . . . . 177

8.6 Regime type and the number of tall $(150 \mathrm{~m}-300 \mathrm{~m})$ and supertall $(350 \mathrm{~m}+)$ skyscrapers . . . . . . . . . . . . . . . . . . . . . . 178

8.7 Regime type and the number and meters of Skyscrapers - include towers 179

8.8 Regime type and the number and meters of Skyscrapers - exclude demolished buildings . . . . . . . . . . . . . . . . . . . . . . . . . . 180

8.9 Skyscrapers inside and outside the capital city . . . . . . . . . . . . . 181

8.10 Regime type and ln number of new skyscrapers - dropping controls . . . 183

8.11 Regime type and the ln number of Skyscrapers with extra controls . . . . 184

8.12 Alternative democracy measures . . . . . . . . . . . . . . . . 185

8.13 Autocratic regime type and the number and meters of Skyscrapers . . . . 186

8.14 Boom cycles and the number and meters of Skyscrapers . . . . . . . . . . 187

8.15 Regime type and the number and meters of Skyscraper - 4 years lag . . . 189

8.16 Regime type and the number and meters of Skyscrapers post 1945 . . . . 190

8.17 Regime type and the number and meters of Skyscrapers post 1960 . . . . 191

8.18 Regime type and the number and meters of Skyscrapers post 1980 . . . . 192

8.19 First stage of zero-inflated model . . . . . . . . . . . . . . . . . . 193

8.20 Property rights . . . . . . . . . . . . . . . . . . . . 197

8.21 Regime type and excessiveness of skyscrapers _ . . . . . . . . . . . 198

8.22 Robustness test of skyscraper excessiveness: CEM-matching at the buildinglevel, with no post-matching controls . . . . . . . . . . . . 198

8.23 Robustness test of skyscraper excessiveness: CEM-matching at the buildinglevel, with continuous Polyarchy . . . . . . . . . . . . . 199

8.24 Robustness test of skyscraper excessiveness: CEM-matching at the buildinglevel and GDP . . . . . . . . . . . . . . . . . . 200

8.25 Robustness test of skyscraper excessiveness: CEM-matching on height to top occupied floor and GDP per capita . . . . . . . . . . . . . 201

8.26 Skyscraper excessiveness: Split-sample by capital and non-capital buildings 203

8.27 Robustness test of skyscraper excessiveness: Entropy Balancing . . . . . 204

8.28 Robustness test of skyscraper excessiveness: Entropy Balancing, using Boix, Miller, Rosato regime measure . . . . . . . . . . . . 205

8.29 CEM-matching at the building-level: Alternative proxies of the excessiveness of skyscrapers . . . . . . . . . . . . . . . . 206

8.30 Interaction models: Regime type and urbanization . . . . . . . . . . . 207

8.31 Interaction models: Regime type and ln GDP per capita . . . . . . . . 208

9.1 Descriptive statistics: Numeric variables . . . . . . . . . . . . . . . . . . 210

9.2 Descriptive statistics: Categorical variables . . . . . . . . . . . . . . 210

9.3 Descriptive statistics: GRID-data . . . . . . . . . . . . . . . . . 210

9.4 Effect of elections on the number of investment projects in geographical grid-cells . . . . . . . . . . . . . . . . . . . . . 217 
9.5 Elections and investment allocation: investigating timing . . . . . . . . 219

9.6 Elections and investment allocation: comparing democracies and autocracies 222

9.7 Elections and investment allocation: comparing electoral formulas . . . . 223

9.8 Placebo table of elections and investment allocation . . . . . . . . . . . . 224 



\section{List of Figures}

1.1 Countries in which regularly scheduled elections are on course. . . . . . . 32

1.2 Polyarchy across the globe in $2018 \ldots \ldots$. . . . . . . . . . . . . . . . . . . . . .

1.3 Causal model of the central theoretical framework. . . . . . . . . . . . 39

3.1 Boxplot of transparency and response rates . . . . . . . . . . . . . . . . 82

3.2 Map of letter response rates around the world . . . . . . . . . . . . 83

3.3 Estimated effect of binomial Polyarchy (Panels A and B) and BMR (Panels C and D) on the quality of postal services. . . . . . . . . . . . . 89

4.1 Skyscraper height and frequency throughout the 20th century . . . . . . 104

4.2 The ten buildings in the world with the highest number of vanity meters. 105

4.3 Interaction between Polyarchy and urbanization, marginal effects. . . . . 112

5.1 Project sizes as amount of 2011 USD involved. Take notice of labels as the range within each section differs. . . . . . . . . . . . . . . . . 128

5.2 Chinese Official Finance in Africa (black circles) and African HOS's birthplace (crosses). . . . . . . . . . . . . . . . . .

5.3 The estimated effect and corresponding 95\% confidence interval of parliamentary and presidential elections on the distance between HOS's birthplace and investment location, split by regime type. . . . . . . . . . .

5.4 The estimated effect and corresponding 95\% confidence interval of parliamentary and presidential elections on the distance between HOS's birthplace and investment location. . . . . . . . . . . . . . .

5.5 The estimated effects and corresponding 95\% confidence intervals of parliamentary and presidential elections from two different placebo models. .

5.6 Estimated effect of presidential, majoritarian parliamentary, and mixed and proportional parliamentary elections on the distance between HOS' birthplace and investment location. . . . . . . . . . . . . . . . . .

6.1 Regression coefficients, with $95 \%$ percent confidence intervals, for varying lags. . . . . . . . . . . . . . . . . . .

6.2 Varying Samples: Distribution of democracy stock coefficient when omitting countries (top) and entire regions (bottom) for Ln railway freight . .

6.3 Varying Samples: Distribution of democracy stock coefficient when omitting countries (top) and entire regions (bottom) for Ln energy consumption 153

6.4 Varying Samples: Distribution of democracy stock coefficient when omitting countries (top) and entire regions (bottom) for Ln iron and steel production . . . . . . . . . . . . . . . . . . 
6.5 Varying Samples: Distribution of democracy stock coefficient when omitting countries (top) and entire regions (bottom) for manufacturing value

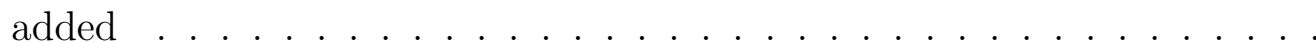

7.1 Scatterplot and local regression line of Ln domestic parcels items (imputed) +1 and the percent letters returned in the experiment . . . . . . . . .

7.2 Boxplot comparison of percent responded letters between countries AmazonGlobal does and does not export to . . . . . . . . . . . .

7.3 Boxplot of Polyarchy among countries that returned at least 1 letter, compared to those that returned $0 \ldots \ldots \ldots \ldots$

7.4 Distribution of the coefficient for Polyarchy after jackknife estimation of

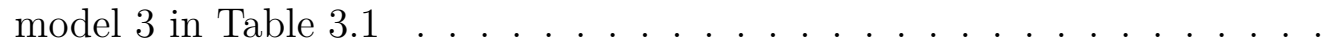

7.5 Distribution of the coefficient for Polyarchy after exclusion of individual regions when estimating the model 3 in Table $3.1 \ldots$. . . . . . . . . 164

8.1 Mean construction time of building projects during the 20th century . . . 174

8.2 Box plots of dependent variable, $\ln (1+$ new skyscrapers in year $t)$, in autocracies and in democracies. . . . . . . . . . . . . . . . . . . 194

8.3 Cook's D from model 1 in table 4.1 . . . . . . . . . . . . . . . . 195

8.4 Jackknifing results for Model 1 in Table 4.1, consecutively removing each of the observations with a high Cook's D (defined more than four times the mean Cook's D in the sample) in figure 8.3. . . . . . . . . . . . 196

8.5 Marginal effects: Interaction between Polyarchy and ln GDP per capita. . 208

9.1 Leave-one-leader-out from Model 3 in Table 5.1. Shows the distribution of the coefficients for presidential and parliamentary elections across the different subsamples. . . . . . . . . . . . . . . . .

9.2 Leave-one-country-out from Model 3 in Table 5.1. Shows the distribution of the coefficients for presidential and parliamentary elections across the different subsamples. . . . . . . . . . . . . . . . .

9.3 Leave-one-observation-out from Model 3 in Table 5.1. Shows the distribution of the coefficients for presidential and parliamentary elections across the different subsamples. . . . . . . . . . . . . . . . .

9.4 Investigating different cut-off points for home area. . . . . . . . . . . . . 214

9.5 Marginal effects of elections on the number of investment projects in the grid given distance the distance from the grid-centroid to the birthplace of the HOS. . . . . . . . . . . . . . . . . . .

9.6 Marginal effects of elections given whether it is the cell where the HOS was born. . . . . . . . . . . . . . . . . . .

9.7 The estimated effect and corresponding $95 \%$ confidence interval of parliamentary and presidential elections on the distance between HOS' birthplace and investment location, split by median value on polyarchy. . . . . 
9.8 The estimated effect and corresponding 95\% confidence interval of parliamentary and presidential elections on the distance between HOS' birthplace and investment location, split by DD measure on democracy and autocracy. . . . . . . . . . . . . . . . . . . 221 



\section{Political institutions and public expenditures}

\subsection{Introduction}

National governments budgeted more than 50 trillion US dollars in 2017 (CIA 2017). How governments prioritize how to spend this money is central for the development of their countries. A wide range of scholars, policymakers, and philanthropists believe that political institutions matter for how leaders are incentivized to spend public resources and what policies they pursue, more generally - and thereby promote or hinder economic development. The distinction between democracies and autocracies lies at the center of this debate. Democracy, the argument goes, makes leaders accountable to the population at large, and this motivates them to invest in public goods. These provisions of public goods, for various reasons, promote growth (Acemoglu and Robinson 2006; Acemoglu and Robinson 2012; Bueno de Mesquita et al. 2003; North 1990). However, these cited theoretical works seem to fail to deliver on some central predictions. For example, these theories imply than democratization should reduce inequalities in a society, but the empirical support for this prediction remains disputed (see for example Ansell and Samuels 2014; Dorsch and Maarek 2019; Scheve and Stasavage 2017). Consequently, the dynamics between political institutions and economic outcomes are still heavily debated (Acemoglu et al. 2019; Dellepiane-Avellaneda 2010; Doucouliagos and Ulubaşoğlu 2008; Gerring, Thacker, and Alfaro 2012; Hariri 2015; Krieckhaus 2004; Lake and Baum 2001; Przeworski et al. 2000; Przeworski and Limongi 1993; Ross 2006; Sirowy and Inkeles 1990).

This dissertation contributes to this debate, by developing theories and empirical tests that connect the general theories cited above with discussion on more specific assets that leaders may or may not pursue. I ask how do political institutions affect leaders' motivation and capacity to pursue different public expenditures, with implications for the type of assets they pursue, the quality of those assets, and the distribution of benefits from those assets?

This general research question is addressed by investigating three underlying hypotheses. First, I hypothesize that compared to democratic leaders, autocratic leaders will prioritize spending on more particularistic assets. These are assets such as certain physical capital investments (e.g., heavy infrastructure), but also regulations that favor particular economic sectors at the expense of others. Second, compared to autocratic leaders, democratic leaders foster the quality of public goods and services. Third, the procedures for leader selection affect how leaders allocate the distribution of benefits. Specifically, autocratic leaders tend to favor the rich with their public expenditures, while elections 
in both autocratic and democratic regimes make leaders allocate expenditures towards electorally important (narrow) geographical areas.

This dissertation builds on insights from, for instance, the selectorate theory by Bueno de Mesquita et al. (2003) and democratization theory by Acemoglu and Robinson (2006). It also provides independent support for the general hypothesis that political institutions, through leaders' motivation and capacity, affect public expenditure. Chapters $2-4$ concern how variation in regime type creates incentives for leaders to pursue different types of assets. Chapter 2, "Regimes and industrialization," shows that autocratic leaders have relatively stronger incentives to pursue industrialization. The chapter introduces two important aspects of autocratic regimes that recur throughout the dissertation. First, their base of support is generally narrower, making these leaders more motivated to seek investments that can be targeted at specific groups. Industrialization has without doubt been a huge benefit to the majority of the population, and expenditure that benefits a majority of the people is usually associated with democracies (Acemoglu and Robinson 2012 , p. 213-244, 274-300). But many policy tools that are perceived to be effective in generating industrialization - tax incentives, low-interest loans, subsidies, etc. - bestow benefits to specific social groups. Second, the capacity to apply coercion and therefore override opposition is stronger among autocratic than among democratic leaders. Industrialization often entails many losers in the short run, for example, due to vested interests in old modes of production, displacement, or reduced working conditions. The capacity of autocratic leaders to apply coercion helps them overcome opposition from such groups.

In addition to analyzing what type of assets leaders pursue, chapters 3, "Democracy and public services: Evidence from the postal services," and 4 "Leaders, private interests, and socially wasteful projects: Skyscrapers in democracies and autocracies," also show that there are differences in the quality of investments pursued by leaders in different regimes. An important point in these two chapters is that even when democracies and autocracies have made a certain investment, we should expect qualitative differences between those investments, which are not easily observable in their mere quantities. In chapter 3, I argue that democracies should provide better public services. To get around the problem that autocratic leaders tend to hide data that reflects badly upon their performance (Hollyer, Rosendorff, and Vreeland 2011; Martinez 2018), I use the example of postal service to show that postal services in democracies outperform postal services in autocracies. There is, to my knowledge, no other study that attempts to establish the causal link between regime type and postal services. In chapter 4, my co-author and I argue that autocratic leaders pursue more socially wasteful investment projects, showing that they build more and more wasteful skyscrapers. Just as with many policies associated with industrialization, the particularistic distribution of benefits from such construction projects is attractive to autocratic leaders.

In chapter 5, "Presidents, parliaments, and allocation of public investments during elections," I use geolocated investments in Africa to investigate how elections and legislatures affect leaders' motivation and capacity to target specific groups. The argument is two-fold. First, I argue that elections, even in autocracies, give political leaders moti- 
vation to allocate investments towards important voter-groups. This re-allocation need not be economically optimal or have redistributive consequences, but it follows incentives produced by the electoral systems, which have profound implications for the distribution of multi-million dollar investment projects across Africa. I then argue that since both the parliamentarians and the president want to allocate investments to their constituencies, they mutually constrain each other from geographically concentrating public expenditures. As such, the chapter investigates in detail some of the specific accountability mechanisms that constrain and motivate political leaders.

\section{Contributions}

While the research questions that I raise have already been addressed in existing literature, this dissertation brings three important contributions. First, I develop new theoretical insights, building upon the ample literature on institutionalism. These developments are, for the most part, related to important nuances of the general arguments proposed in the literature at large. For example, in chapter 4, we start out with the argument that autocracies outpace democracies on investments in physical capital (Przeworski et al. 2000; Tavares and Wacziarg 2001). We combine this with the observation that several autocratic countries have made substantial capital investments in socially inefficient projects (Robinson and Torvik 2005). We propose a series of arguments for why autocratic politics provide these leaders greater motivation and capacity to pursue what might be economically inefficient projects - be it vanity, providing cronies with opportunities for reaping bribes or excessive profits, or signaling the regime's capabilities to (foreign and domestic) competitors. We put this argument to the test, comparing aspects of skyscrapers built in autocracies and democracies, and finding robust evidence that skyscrapers built in autocratic countries are more wasteful compared to those built in democracies. Theoretical arguments about institutions and political leaders' public expenditures need to be fine-tuned according to the asset in question, as there can be very different incentives for different goods and services, and hence the effect of regime type is also different. By understanding the more specific dynamics between institutions, leaders, and public expenditures, we can, in turn, make more precise predictions about general developments such as economic growth or inequality.

The second contribution of this dissertation is to provide new, independent tests of institutional arguments. There is an abundance of theories in political science, but "the tools for understanding them are scarce and rather crude" (King, Keohane, and Verba 1994, p. 16). It is important that we continue to test our theories. Chapters $2-5$ therefore provide independent, empirical tests of central theories in political economy. In none of these tests do I replicate previous findings but rather develop new observable implications from the existing theories towards new types of economic outcomes. For example, in chapter 3 , I test the effect of regime type on public services by investigating a new measure of postal service quality. The causal effect of regime type on public services is a central debate within the literature on political institutions and economic outcomes 
(see for example Lake and Baum 2001; Ross 2006; Gerring, Thacker, and Alfaro 2012), and there is, to my knowledge, no other study that tests the theoretical arguments against data on postal service quality.

This brings me to the third important contribution of this dissertation, which is the collection of new data. Testing theories against data gathered from a variety of sources is important for our empirical tests, and "[t]he more evidence we can find in varied contexts, the more powerful our explanation becomes, and the more confidence we and others should have in our conclusions" (King, Keohane, and Verba 1994, p. 30). Together with co-authors but also in solo-authored chapters, I have gathered unique data. For example, in chapter 4, we have systematized data from the Council on Tall Buildings and Urban Habitats (CTBUH 2016) on all human (land-based) structures taller than 150 meters, including different features of the buildings. In chapter 5 , I have geolocated the birthplaces of all African presidents since 2000. Not least, together with the Historical Varieties of Democracy team (Knutsen et al. 2019b), I have collected data on a wide range of political institutions for the period 1789-1920, which is used in chapter 2.

I believe we have much to gain by diversifying the type of investments we study. A large portion of the literature seems to draw inferences about the causal effects of political institutions on economic outcomes based on relatively few economic measures: infant mortality rates, GDP per capita, and education (for a selection, see Doucouliagos and Ulubaşoğlu 2008; Carbone 2009; Gerring, Thacker, and Alfaro 2012; Hariri 2015; Kadt and Wittels 2019; Knutsen et al. 2019a; Nelson 2007). While there is much to learn from this literature, we must be cautious of generalizations based on a few areas. There are therefore theoretical reasons to diversify the economic outcomes we study. In this dissertation, I draw attention to measures as different as the height of individual buildings in chapter 4 , in order to analyze differences in construction projects between regime types, to countries' response rates to individual postal letters in chapter 3, to analyze the quality of public services. However, the concentration around a few economic outcomes is made problematic by several recent contributions highlighting potentially serious measurement issues. In short, these studies note that autocracies provide less public data on measures such as those recorded by the World Bank, and it is difficult to determine whether it is the worst-performing or best-performing autocracies we observe in the data (Hollyer, Rosendorff, and Vreeland 2011; Ross 2006). Furthermore, the data that are provided also seem to have been tampered with by the governments themselves in order to make their countries look more successful (Martinez 2018). These issues pertain to all data that are self-reported by governments. By diversifying the types of investments we study, and especially by including measures of assets that are not self-reported by governments, we can better evaluate the seriousness of these issues.

The remainder of this chapter is structured as follows. In section 1.2, I provide a review of the central literature on political institutions and economic policies. I concentrate on a few select theories that operate in the center of what is a very large compendium of literature, in order to focus the discussion. I then highlight what I regard as some of the shortcomings of the current literature and where my contribution enters. In section 
1.3, I flesh out the key concepts of this dissertation, namely democracy and autocracy and public expenditure. In section 1.4, I detail the theoretical framework and causal model that underlie this dissertation as a whole. In section 1.5, I explain my general methodological approach to inference, and in section 1.6 I summarize the rest of the chapters. Finally, conclusions and implications are proposed in section 1.7.

\subsection{Political institutions and public expenditures: The case for a more nuanced approach}

Social scientists have identified some central collective action problems - situations in which there is a conflict of interest between what is collectively rational and what is rational for the individual - that hinder the ability of humans to provide public goods. These are problems such as coordination and commitment (Fearon 1998; Hardin 1968; Kuran 1991; Olson 1971; Sandler 1992; Shepsle and Boncheck 1996), problems of agency (Macho-Stadler and Pérez-Castrillo 1997; Przeworski, Stokes, and Manin 1999; Staton and Vanberg 2008; Moe 1990), and problems relating to preference aggregation (Condorcet 2014; Riker 1980; Riker 1982; Romer and Rosenthal 1978). To date, these social dilemmas are among the fundamental building-blocks in the social sciences. Perhaps the most famous example is the tragedy of the commons, where some shared resourcepool, such as pasture, is depleted because it is in the self-interest of everyone to consume from the pool (Hardin 1968). While it is in the collective interest of everyone to restrict consumption, each individual can maximize his or her utility by reneging on this self-restriction while everyone else complies with the collective interest. But as everyone realizes that everyone else has a personal incentive not to restrict their consumption, each individual is at risk of being left in a situation where they restrict their own consumption but the resource is still depleted. This risk is not worth it, and therefore, no one will comply with self-restriction. Among the most common human responses to these situations is some form of centralized authority - a political institution - with the power to create and monitor regulations, such as property rights, and to sanction trespassers. But as centralized authorities are created, they have wider implications for the distribution of power, and in turn, distribution of economic (and other) resources. Research within rationalchoice institutionalism tries to understand this human technology (political institutions) and how it affects our behavior. ${ }^{1}$

The distinction between regime types, especially between democracy and dictatorship, has been central to this debate (Acemoglu, Johnson, and Robinson 2001; Lake and Baum 2001; North and Weingast 1989; Przeworski et al. 2000; Przeworski and Limongi 1993; Sen 1999; Tavares and Wacziarg 2001). Due to the amount of this literature, a broad summary would never do justice to the many contributions. I instead focus on two theoretical models that hold a central position in the contemporary debate. The first is

\footnotetext{
${ }^{1}$ It is termed "rational-choice" because humans are assumed to behave in a (perfectly or boundedly) rational manner.
} 
the selectorate theory by Bueno de Mesquita et al. (1999, 2003, 2004). The second is the democratization theory model by Acemoglu and Robinson (2006, 2012), here abbreviated as the AR-model. Insights from these two theories are also fundamental to my theoretical model.

\section{Selectorate theory}

The central premise of selectorate theory is that leaders aim to stay in power, and that there is always an abundant supply of challengers. This assumption underlies most of the literature within rational institutionalism (but for some exceptions, see Olson 1993; Wintrobe 1998). This central incentive for leaders to stay in power suggests that the institutions governing the selection of leaders can explain regularities in a wide variety of policies pursued (Bueno de Mesquita et al. 2003, p. 15-16).

The central actors of the theory are the members of the winning coalition, selectorate, residents, and the leader. All leaders must answer to some group in order to hold onto power. This group is the winning coalition. For example, at the time of this writing, there is an ongoing conflict in Venezuela between the opposition, whose front figure is Juan Guaidó from the political party Voluntad Popular, and the executive government of President Nicolás Maduro. Central to this conflict are the military forces, which constitute an important actor within Maduro's winning coalition. Consequently, for Maduro to survive this conflict, he must accommodate these military generals to keep them from defecting from his winning coalition and allying with the challenger.

The selectorate is the group of people from which the winning coalition is drawn. Each member of the selectorate could be a member of many different winning coalitions. To return to the example of Venezuela, the supporters of the opposition are ready to form a winning coalition under Juan Guaidó. They are struggling to find a constellation powerful enough to change the existing winning coalition led by Maduro. They attempt to sway supporters of President Maduro, including the military forces, to defect from his regime and join the opposition. Similarly, in a democratic system, the selectorate are all eligible voters and the winning coalition is the one that actually voted for the current incumbents. Government turnover happens because voters change their vote and thus create new constellations powerful enough to enter executive government. In both systems, a leader who seeks to survive in office must take care of the potential alternative constellations that the members of the selectorate could form in order to produce a new and more powerful winning coalition.

The residents are everyone in the polity. They are divided between those who are a part of the selectorate and those who are not a part of the selectorate. Residents who are not a part of the selectorate are deprived of political influence. As Bueno de Mesquita et al. (2003, p. 40) put it, they are "the cannon fodder of revolutions and war." In revolutions, the aim is often to exchange who, among the residents, gets to be part of the selectorate.

As noted, a leader must make sure that the members of the winning coalition do not 
defect to a potential challenger. The main tool leaders have to maintain their alliance is to collect taxes and use the revenues to concede goods to the members of the winning coalition. The leader can concede two types of goods: public or private. Public goods are commonly defined as being both nonexcludable and nonrival (Sandler 1992, p. 5). A good is excludable if the provider of the good can, without additional costs, limit access to it. A good is nonrival if its benefits can be consumed without reducing those available benefits. Thus, a public good can be accessed by all members of society, and any one's consumption does not reduce anyone else's available consumption of the same good. Typical examples of pure public goods are nuclear deterrent and pollution control. A private good is the opposite of a public good: it is excludable and rival. Typical examples are food and clothes.

In selectorate theory, both public and private goods are assumed to have a fixed cost, but public goods are more expensive than private goods. Public goods are enjoyed by all, while private goods are targeted to individuals. With a small winning coalition, the leader can buy off all the members with private goods. But as the winning coalition increases, it becomes increasingly expensive to pay the members off with private goods, and at some tipping point, it becomes cost-effective to buy support through public goods.

The theoretical framework outlined in section 1.4 and chapters $2-5$ build upon this central insight. Because autocrats more often want to target specific social groups with goods, they will also have a greater interest in spending revenues on more particularistic assets. In chapter 2 , we highlight the common strategies for industrialization that entail particularistic subsidies and investments and that give autocrats a greater motivation than democratic leaders to pursue industrialization. In chapter 3, I argue that democratic leaders have greater motivation to provide quality public services since they benefit a large portion of the population. In chapter 4, we argue that autocrats are more likely than democratic leaders to pursue wasteful construction projects because these can be targeted towards wealthy elites. Lastly, chapter 5 argues that elections in both autocracies and democracies create an incentive to target investments towards important electoral groups. Thus, this argument about the size of the winning coalition is crucial to this dissertation.

In practice, many assets do not fit neatly into the pure description of a public or private good. A number of assets are better understood as "club goods." These assets are (relatively) non-rivalrous but excludable, and it is therefore relevant how different assets lend themselves to different types of exclusion. For example, in the investigation of skyscrapers in chapter 4 , some of these expensive high-rises are likely to be unavailable to low- and middle-income sections of the population, effectively making them club goods. This nuance is also central to chapter 5, where I analyze the use of investments prior to elections. Such investments are only possible if the important electoral groups can be targeted and that responsibility for the investment can be attributed to the leader. In the majoritarian first-past-the-post electoral system, each constituency has one member in parliament (MP). Any irrelevant voter is therefore excluded by geography from the MP's constituency, and any public money attracted to the district can likely be attributed to the MP's efforts in parliament. In a proportional system, however, there will be several 
MPs from each constituency, from different political parties. This makes it both more difficult for the MP to target his or her voters in the constituency, and for the voters to attribute responsibility to the correct politician. Consequently, I show that it is less common to use investments for electoral purposes in systems with a proportional formula.

In selectorate theory, all actors are equal. The model is void of preferences or ideology, other than those demanded by the actors' cost-benefit analyses (Bueno de Mesquita et al. 2003, p. 74-75). This does not imply that selectorate theory is incompatible with a theory in which actors have preferences, for example, comparing winning coalitions consisting of military personnel versus a winning coalition of business elites. But the model is made for a level of abstraction where goods are either public or private and all that matters is the cost-benefit calculation.

\section{The Acemoglu-Robinson model}

In contrast, social groups with different preferences are central to the AR-model (Acemoglu and Robinson 2006), which rests on three fundamental assumptions (Acemoglu and Robinson 2006, p. xii). First, individuals' political preferences are given by their economic incentives. Second, individuals are part of groups that share economic incentives (and thus political preferences), and these groups are in conflict over how the political institutions should be designed. They are concerned with the formation of institutions because, in the end, these determine political outcomes and thus policy outcomes. Third, political institutions solve different commitment problems because they affect the distribution of future political power.

There are two actors at the core of the AR-model: a poor majority that favors democracy, and a rich minority that favors autocracy. In a logic that follows Meltzer and Richard (1981), rising inequality will increase the poor's demand for redistribution, since they have more to gain, and increase the elite's fear of redistribution, since they have more to lose. Since the poor have political power under a democracy, they will use this power to seize wealth from the rich with redistributive policies. Inequality therefore has a conflicting effect on democratization under autocracy. In autocratic societies with low inequality, the citizens have little to gain from political representation and consequently make few demands. In autocratic societies with high inequality, however, they have much to gain from democratization, and therefore make great demands and threaten revolution. The elites, however, have a lot to lose from democratization in this situation, and they will use repression to resist attempts at democratization. Acemoglu and Robinson (2006, p. 36-37) therefore expect an inverted U-shape in the relationship between inequality and democratization, where regime change is more likely to happen when inequality is high enough to make citizens dissatisfied with the status quo, but elites are not too averse to democratization as to favor repression.

These empirical predictions are very similar to those of the selectorate theory. The mechanism, however, is fundamentally different: In selectorate theory, public goods provision is the result of a calculation by the leader, where public goods are a cost-efficient 
to buy support. According to Acemoglu and Robinson, investments follows instead the political interests of the median "voter," which, under democracy, is the poor, and they prefer public goods that redistribute wealth. However, the AR-model never theorizes explicitly what type of assets different rulers pursue. The preferences of different groups are always expressed as levels of taxation and lump-sum transfers to social groups. This does not explain why a democratic leader would prioritize, for example, cash-transfers to each individual within social groups or instead prioritize improvements in public services. But the combined insights of selectorate theory and the AR-model allow for a world where a) different societal groups have different preferences, and b) the size of these groups matters for how rulers will attempt to accommodate them.

The different preferences of societal groups are central to this dissertation. In chapter 2, we highlight that industrialization favors the privileged formal sector of the economy. We contend that industrial policies are likely to reinforce existing inequalities (at least in the short-term), rewarding groups (i.e., the highly-skilled, well-educated, and urbandwelling) that are already relatively well-off. In chapter 3, I hold that the median voter under democracy has greater interest in high-quality public services than the median voter under autocracy. In chapter 4 , we argue that wasteful construction projects are not in the interest of the median voter in an electorate and constitute a luxury that only a rich elite would be willing to prioritize. This dissertation is also different from Acemoglu and Robinson's framework in that it does not attempt to analyze a society's overall economic distribution. Instead, I attempt to grapple with how leaders build alliances using different endowments. In formulating the preferences of different groups, I have relied much on the insights from the AR-model and the large amount of literature that surrounds this central contribution. Not least, the allocation of different endowments has implications for the overall distribution that concerns Acemoglu and Robinson.

\section{Caveats of the theories}

A problem for both of these theories, is that the median-voter model from Meltzer and Richard (1981) and the notion that democracy entails more equal distribution have repeatedly been called into question (Aidt, Daunton, and Dutta 2010; Aidt, Dutta, and Loukoianova 2006; Aidt and Jensen 2014; Haggard and Kaufman 2012; Harms and Zink 2003; Jackman 1974; Kenworthy and McCall 2008; Lott and Kenny 1999; Putterman 1997; Rodrigìuez 1999; Scheve and Stasavage 2009; Scheve and Stasavage 2017; Ross 2006; Gerring, Thacker, and Alfaro 2012). For example, Ansell and Samuels (2014) argue that democracy is often introduced when newly successful economic groups attempt to defend themselves from arbitrary expropriation by the old elites. The poor, according to the authors, are fragmented, disorganized, and have few resources. The important actors are the different groupings of wealthy elites and their political preferences. ${ }^{2}$ Building

\footnotetext{
${ }^{2}$ In defense of Acemoglu and Robinson (2006), they do extend their theory to include the middle class, which acts as an important mediator in the conflict between rich and poor. Since the middle class has preferences that are relatively more equal to the rich compared to the poor, a large middle class can
} 
on such insights, this dissertation will often move beyond the dynamic of "poor" versus "rich" and try to formulate how different groups are interested in different types of assets. This is evident in chapter 5, where emphasis is on how political leaders use local club goods targeted towards their constituencies. In this chapter, the distribution of assets instead concerns a "horizontal" geographical allocation.

There already exist alternative theories on different social groups' preference for specific assets. For example, Hollenbach (2019), following Galor and Moav (2006), argue that the urban business-elites during industrialization in Europe had an interest in human capital. Specifically, these urban business elites wanted education to create a skilled workforce and healthcare to get a stable, healthy workforce. By using public expenditure to pay for these services, the rural landowners would contribute to these expenses and in effect ease the costs of the urban elites. This is an important point to chapter 3, where I analyze the causal relationship between regime type and the quality of postal services. If autocratic elites are relatively more interested in public education and health services compared with other types of services, it is important that we diversify the types of services we study when trying to establish the link between regime type and public service provision.

Another popular theory was formulated by Lake and Baum (2001). According to them, states act like "firms that produce public services in exchange for revenue" (Lake and Baum 2001, p. 593). While states have many characteristics of a monopoly, their managers (e.g., politicians) face competition. A central feature of democracy, they claim, is that such regimes, through elections, ensure a more competitive environment for these political leaders. Without competition, rulers will restrict the supply of services, creating excess demand and making citizens "bid up the nominal tax price by offering bribes $[\ldots]$ or otherwise curry favor with those who have access to scarce resources" (Lake and Baum 2001, p. 593). Thus, democratic leaders should provide better public services than autocratic leaders. While both the theories of Hollenbach (2019) and Lake and Baum (2001) provide highly valuable insights, their scope of conditions are restricted either in terms of geography and time (a specific period in European history) or type of asset (public services). ${ }^{3}$

\subsubsection{Shortcomings of the existing literature}

In spite of well-developed theories and decades of empirical testing, there seems to be very little consensus on the economic effects of different institutional designs (Doucou-

reduce the elites' fear of democratization. They also point out that since the middle class has relatively more human and material resources compared to the poor, they are also more likely to initiate and lead potential (revolutionary) mobilization.

${ }^{3}$ I have not included theories outside of (and sometimes in conflict with) institutionalism, such as those that highlight culture as a dominating confounder, shaping both institutions and economic outputs (see for example Mokyr 2017). A large part of this literature is complementary to rational institutionalism, where political institutions and cultural characteristics have interacting effects on economic outcomes. Some of these theories are more in conflict with rational institutionalism, but since this theoretical impasse will not be solved in this dissertation, I have left them out for the sake of brevity. 
liagos and Ulubaşoğlu 2008; Carbone 2009; Gerring, Thacker, and Alfaro 2012; Hariri 2015; Kadt and Wittels 2019; Knutsen 2012; Knutsen et al. 2019a; Nelson 2007). In this literature, there are a few recurring variables: infant mortality rates, GDP per capita, and education, measured often as population literacy or primary/secondary school enrollment rates. Because these outcomes are affected by so many societal processes, they are believed to measure "the quality of the whole society" (Rosling, Rosling, and Rönnlund 2018). High infant mortality, for example, is assumed to be concentrated around the poorest families in a society, and thus a reduction in the infant mortality rate is generally interpreted as a result of improvements in the welfare of this segment of society (Ross 2006 , p. 861). It is the absence of a clear pattern in these variables that seems to drive the scholarly disagreement.

For example, Lake and Baum (2001) argue and empirically show that democracies are better at managing public services and consequently can improve the welfare of the poor, showing, among other things, that citizens in democracies enjoy lower levels of infant mortality. Ross (2006), however, claims that the extra money spent on health and education in democracies does not manifest into improved outcomes like lower infant mortality rates, because the money only reaches the middle- and upper-income families, which, in turn, simply shifts from private to public services. The differences in empirical results, Ross (2006) maintains, are due both to a measurement error in infant mortality rates, and because the best performing non-democracies are excluded from previous analyses (such as Lake and Baum 2001). Following up on this debate, Gerring, Thacker, and Alfaro (2012) propose that the effect of democracy on outcomes such as infant mortality rate does not manifest in the short term. Instead, they contend, one must account for the whole history of a country and the relative democraticness it has enjoyed over the long run.

Studies on educational quality show a similarly complex picture. Enrollment and spending is believed to be higher among democracies (see for example Ansell 2008; Lake and Baum 2001). But there is no evidence that democracies improve the quality of education (Dahlum and Knutsen 2017). Harding and Stasavage (2014) argue that democratic leaders will focus on policies that they believe voters will reward them for. They will therefore focus on visible policies such as free education and higher spending. This might increase enrollment but does not improve the quality of the education delivered. Quality is much more difficult to evaluate for both politicians and voters, and therefore is difficult to attribute to government policies, especially in developing countries with low bureaucratic capacity. Furthermore, free education alone does not inform us of how leaders invest in the necessary educational infrastructure. Ross's (2006) argument about democratic leaders simply prioritizing middle- and upper-income families is therefore still relevant.

Others have even maintained that paying for workers' education and health care might be in the long-term interest of autocratic business elites who are interested in a skilled and stable workforce (Galor and Moav 2006; Hollenbach 2019). If so, autocracies might be relatively more concerned with these two specific public services, which enhance the 
elites' consumption by increasing the productivity of their workforce, compared to, for example, postal services, which are not relevant to their consumption and might even enable the mobilization of the disenfranchised through better communication. This calls for caution in how far we generalize based on relatively few measures.

Perhaps the most hotly debated outcome is GDP per capita (Acemoglu et al. 2019; Kadt and Wittels 2019; Dorsch and Maarek 2019; Knutsen et al. 2019a; Hariri 2015). Because growth depends on a variety of economic factors, such as human capital, physical capital accumulation, inequality, and stability, the debate on regime type and growth tends to encapsulate all the others (Tavares and Wacziarg 2001). Therefore, the conclusions in this literature rest heavily on the conclusions reached on these other, mediating outcomes. In general, there seems to be a growing consensus that democracies improve human capital and stability, but the effect on physical capital accumulation and, as noted above, inequality, is still uncertain (Doucouliagos and Ulubaşoğlu 2008).

A way forward, I believe, is to further develop our understanding of the nuances in different investments. For example, investigations into regime type and physical capital accumulation usually focus on measures of investment rate as a percent of GDP (Tavares and Wacziarg 2001), but investing in a railroad, factory, or extravagant skyscraper has a very different effect on the economy. Furthermore, I reject the notion that what democracies do for their citizens, especially the poor, is adequately captured by single variables such as infant mortality rate. Even under equal levels of infant mortality rate, it is my belief that it matters for our quality of life whether our government prioritizes proper postal services or spends public money on extravagant infrastructure.

I address the above shortcomings in chapters $2-5$. Chapter 2 sheds light on physical capital accumulation by investigating the link between regime type and industrialization. Chapter 3 improves on our knowledge about regime type and public services by investigating the quality of postal services - a type of service that is (to my knowledge) absent in the literature. Chapter 4 shows how leaders can use public expenditures to pursue private interests by investigating the link between regime type and wasteful infrastructure projects. This chapter brings new information to the link between regime type and physical capital accumulation by showing that skyscrapers are more frequently built under autocracy. Furthermore, it contributes to this link by showing that, conditional on a skyscraper actually being built, there are systematic differences in the economic potential of skyscrapers in democracies and autocracies. Lastly, chapter 5 demonstrates how elections in Africa have profound effects on the geographical allocation of government spending, with implications for what parts of a country are likely to develop.

\section{Data quality}

We cannot rule out, however, that the lack of clear empirical patterns has nothing to do with the inadequacy of our theories but is instead due to systematic error in the reporting of data. It has become increasingly clear that autocratic governments both report less data and are more likely to fake the data they report. It is not easy to predict the direction 
of the bias (in the relationship between regime type and economic development outcomes) stemming from such measurement errors. First, autocracies in general fake their data, presenting themselves better than they actually are (Martinez 2018). Second, autocracies have clear incentives not to report statistics that reflect badly upon their performance. Thus, the remaining samples will be the best-performing autocracies (Hollyer, Rosendorff, and Vreeland 2011; Hollyer, Rosendorff, and Vreeland 2014). Third, the opposite might also be true. Since autocracies are not domestically compelled to report data, they do so only when forced to by international agencies. These are typically low-performing autocracies in need of assistance by the World Bank, International Monetary Fund, or United Nations Development Programme. If so, the observable samples of autocracies are the worst-performing ones (Ross 2006). This is especially problematic in the literature on regimes and economic outcomes since all three of these measurement errors systematically correlate with the treatment variable (regime) and outcome (economic performance), and therefore produce a systematic bias in the estimated relationships. Since they imply biases in conflicting directions, the final direction is impossible to determine if we cannot somehow overcome the measurement error.

These different potential errors come in addition to worries about the reliability of essential statistics from low- and middle-income countries. Due to the general lack of statistical capacity in many of these countries, measures of income and growth are based on only a few sources, and large portions of the economy are excluded from different economic aggregates. For the same reason, population statistics are also unreliable from many of these countries. Population censuses have the additional problem of being potentially controversial. For example, the Kenyan census of 2010 was used to decide how to distribute Sh14 billion (US\$180 million) from the government's Constituencies Development Fund, giving different groups incentives to exaggerate their population size (Jerven 2013 , p. 73). In other instances, when censuses are used in tax collection, individuals have incentives to hide from official records. Finally, these issues have been documented to systematically vary over time and space (Jerven 2013). Population statistics are essential to measures such as literacy or infant mortality rate, but it is not easy to determine how much such measurement error biases our estimated relationships between political institutions and different economic outcomes.

These different measurement errors have potentially significant implications for the existing literature. This is another reason to turn attention towards a broader set of variables and use different data sources as a strategy to gain leverage on the posited hypotheses (King, Keohane, and Verba 1994, p. 30). Comparisons of countries are a major source of information when we want to understand the effects of national institutions. Measures that are both comparable across contexts and that are not self-reported by the governments themselves, are valuable resources for this literature.

A second contribution of this dissertation is the use of diverse data and data that have not been generated by the governments themselves. The following four chapters will concentrate on a handful of dependent variables, ranging from country-level measures of infrastructure and consumption, to specific attributes of individual buildings. None of the 
measures is similar across chapters, and they all measure specific assets that are influenced by political decisions. Some of them are also exceptional in their comparability across countries. In chapter 4 , for example, we compare the height of skyscrapers. There is little room for measurement error and its interpretation is not dependent upon contextual factors. In chapter 3, I compare how well different postal services across the world performed on the exact same task, a task that included all countries that had declared they were able to do so. Collected by (Chong et al. 2014), it is a simple count of how many letters (out of 1,590) are returned to a sender in the United States. It is not subject to manipulation by governments nor does it need any assumptions about "best strategies," such as the correct amount of staff or post offices, or the use of private operators. It provides a unique comparison of postal services across the globe. Together with my coauthors, I have collected and/or assembled the data sets for all the chapters. Chapters 2,4 , and 5 include entirely new data collected by my co-authors and me.

\subsection{Key concepts}

There are two central and recurring concepts in this dissertation: regime type and public investments. In this section I define and discuss these two concepts.

\subsubsection{Democracy versus autocracy}

Regime type is measured as the difference between democracy and dictatorship. In this section, I discuss my guiding definition of democracy and how this is measured in the dissertation.

I use the definition of democracy formulated by Beetham (1992, p. 40):

Democracy I take to be a mode of decision-making about collectively binding rules and policies over which the people exercise control, and the most democratic arrangement to be that where all members of the collectivity enjoy effective equal rights to take part in such decision-making directly - one, that is to say, which realizes to the greatest conceivable degree the principles of popular control and equality in its exercise.

I highlight three important aspects of this definition. First, democracy is a scalar phenomenon. Political systems can only be more or less democratic not either/or. As such, political systems can be mapped spatially in a unidimensional system, with the democratic ideal at one end and autocracy at the other. Second, in the ideal democracy, there is both popular control over policies and political equality between citizens. Third, democracy is not the many formal procedures we associate with democracy. Many of these are, at our current technological level, the solutions that bring us as close to the democratic ideal as we are currently able to achieve, but they are not integral to democracy. 
Nevertheless, it is through the observation of specific institutional solutions that we ultimately code regimes. In this endeavor, this dissertation relies on Dahl's (1971; 1989; 1998) concept of Polyarchy, which is regarded as a more realistic implementation of the democratic ideals considering our existing technology and known forms of organization. Dahl's conception of democracy and polyarchy fits with Beetham's definition above.

First, a democracy consists of leaders who are selected through regularly held, contested elections. While elections once were the hallmark of democracy, it is clear that a mere election is far from sufficient for a functioning democracy (Schedler 2009). As illustrated in figure 1.1, only nine countries today do not regularly hold elections (Coppedge et al. 2018). ${ }^{4}$ Of these, one lacks independence and three are having a civil war. With important exceptions, such as China, most people in the world have experienced political elections during their lifetime. For genuine contestation, according to Dahl (1998, p. 85), elections must be both free and fair, and there must be associational autonomy. A free and fair election should have an election administration that is autonomous and capable of conducting well-run elections, but also the absence of irregular interference, such as vote buying, registration issues, ballot fraud, electoral violence, or government-induced intimidation. Associational autonomy, or freedom of organization, implies that voters must be able to coordinate preferences by organizing, develop political programs, and compete for political power without interference (Teorell et al. 2018, p. 79-80).

However, all of the above can be achieved if, say, political power is selected by a few wealthy elites while the majority lack influence. Furthermore, there can be genuinely contested elections even though information is restricted in a way that hinders part of the populace from expressing themselves or acquiring necessary information. Dahl (1971) therefore considers contestation to be only one of two dimensions, where the other is inclusiveness. Inclusiveness refers to the part of Beetham's definition that "all members of the collectivity enjoy effective equal rights to take part in such decision-making directly" (Beetham 1992, p. 40). Regimes with more inclusive suffrage, greater freedoms of expression, and wider access to information should be considered more democratic. Government censorship, harassment of journalists, or other political threats towards an independent media is therefore incompatible with democracy.

Throughout the dissertation, the central measure of democracy will be the Polyarchyindex (v2x_polyarchy) from Varieties of Democracy (V-Dem) (Teorell et al. 2018), constructed specifically in order to capture Dahl's 1998 conception of polyarchy. The measure is composed of five indices: "elected officials," "free and fair elections," "freedom of association," "freedom of expression," and "suffrage."

Polyarchy's first dimension, contestation, is represented first by whether the major political actors (head of state, head of government, and parliament) are popularly elected or are selected by bodies that are popularly elected. Second, to make sure that these elections were not determined by electoral fraud or other irregularities, countries with freer and fairer elections are coded as more democratic. Third, to ensure competitiveness

\footnotetext{
${ }^{4}$ China, Eritrea, Libya, Palestine, Qatar, Saudi Arabia, South Sudan, Syria, and Yemen.
} 


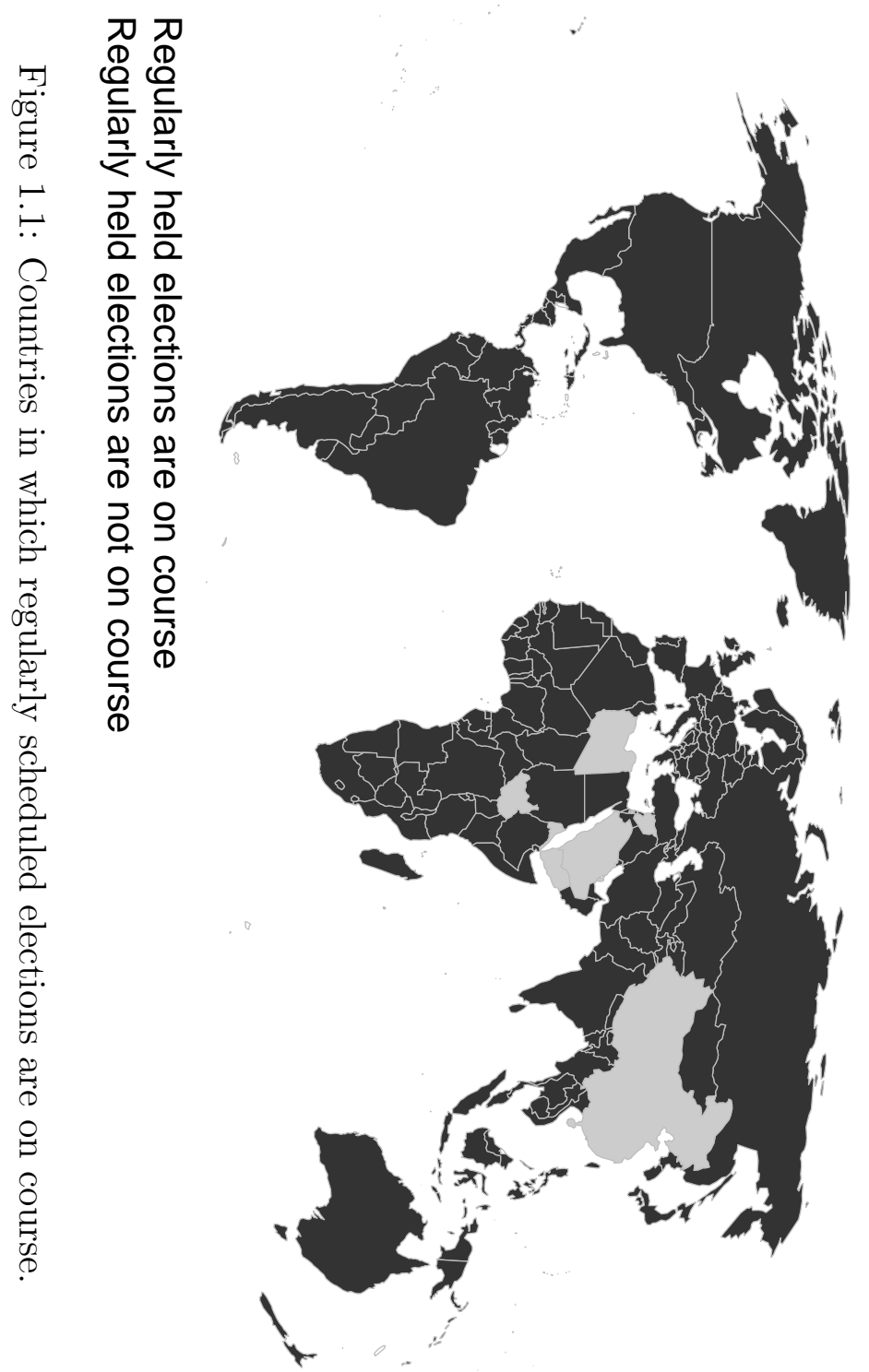


in the sense that anyone can join the race, countries are coded as more democratic when having greater freedom of association.

Polyarchy's second dimension, inclusiveness, is measured first by the extension of suffrage, and second, by freedom of expression. That is, the more people that can participate in elections and the easier they can express their opinions and be informed about others' opinions, the more democratic a country is coded.

The different components that go into the measurement of polyarchy are aggregated to a unidimensional scale using a combination of additive and multiplicative terms. This is important because the use these two of mathematical expressions assumes two different conceptions of the role of the individual components. With addition, the assumption is that the components are interchangeable. A score of, say, 0.3 can be the result of a score of 0.3 on, for example, either associational autonomy or clean elections. With multiplicative terms, however, the components are assumed to be necessary conditions, and a low score on one component will suppress the score of the overall Polyarchy-index. In this setup, associational autonomy is meaningless without clean elections and vice versa. Polyarchy uses an average of the additive and multiplicative approach in order to balance these two conceptions. ${ }^{5}$ Figure 1.2 illustrates how the countries in the world scored on this index in 2018.

One prominent criticism of my approach is that the measurement of democracy relies on subjective judgments. When evaluating whether an election was free and fair or to what degree people had access to information, coders are vulnerable to cognitive biases and may consider aspects outside of the definition, such as citizens' usage of (as opposed to access to) freedom of expression. Or even worse, if experts consider for example economic equality as part of political inclusiveness, then we cannot later analyze the relationship between regime type and economic equality (which, as noted in section 1.2 , is a much debated causal relationship). If we cannot escape our subjective biases and correctly measure "free and fair" or inclusiveness in any meaningful way, then we cannot make inferences about their effects. The concept might be correct but simply immeasurable, so we should instead focus on research questions we can actually answer.

For this reason, this dissertation relies on the measurement provided by V-Dem. Currently, V-Dem is the most rigorous attempt at overcoming the many problems associated with measuring these evaluative aspects of political institutions. Each indicator in each country is coded by a minimum of five experts, $60 \%$ of which are nationals to the country in question. To ensure comparability across countries, some experts code multiple coun-

\footnotetext{
${ }^{5}$ Specifically, they use the formula Polyarchy $=.5 \cdot$ Elected Officials $\cdot$ Clean Elections $\cdot$ Associational Autonomy $\cdot$ Suffrage $\cdot$ Freedom of Expression $+.0625 \cdot$ Elected Officials $+.125 \cdot$ Clean Elections +.125 - Associational Autonomy $+.0625 \cdot$ Suffrage $+.125 \cdot$ Freedom of Expression. In the additive part of the formula, components are multiplied by 0.0625 or 0.125 in order to find a balance between "the two components that can achieve high scores based on the fulfillment of formal-institutional criteria (Elected Officials and Suffrage)" and "the other components that enjoy a stronger independent standing in terms of respect for democratic rights (Clean Elections, Associational Autonomy, and Freedom of Expression and Alternative Sources of Information)" (Teorell et al. 2018, p. 82-83). For more details, see the original article.
} 


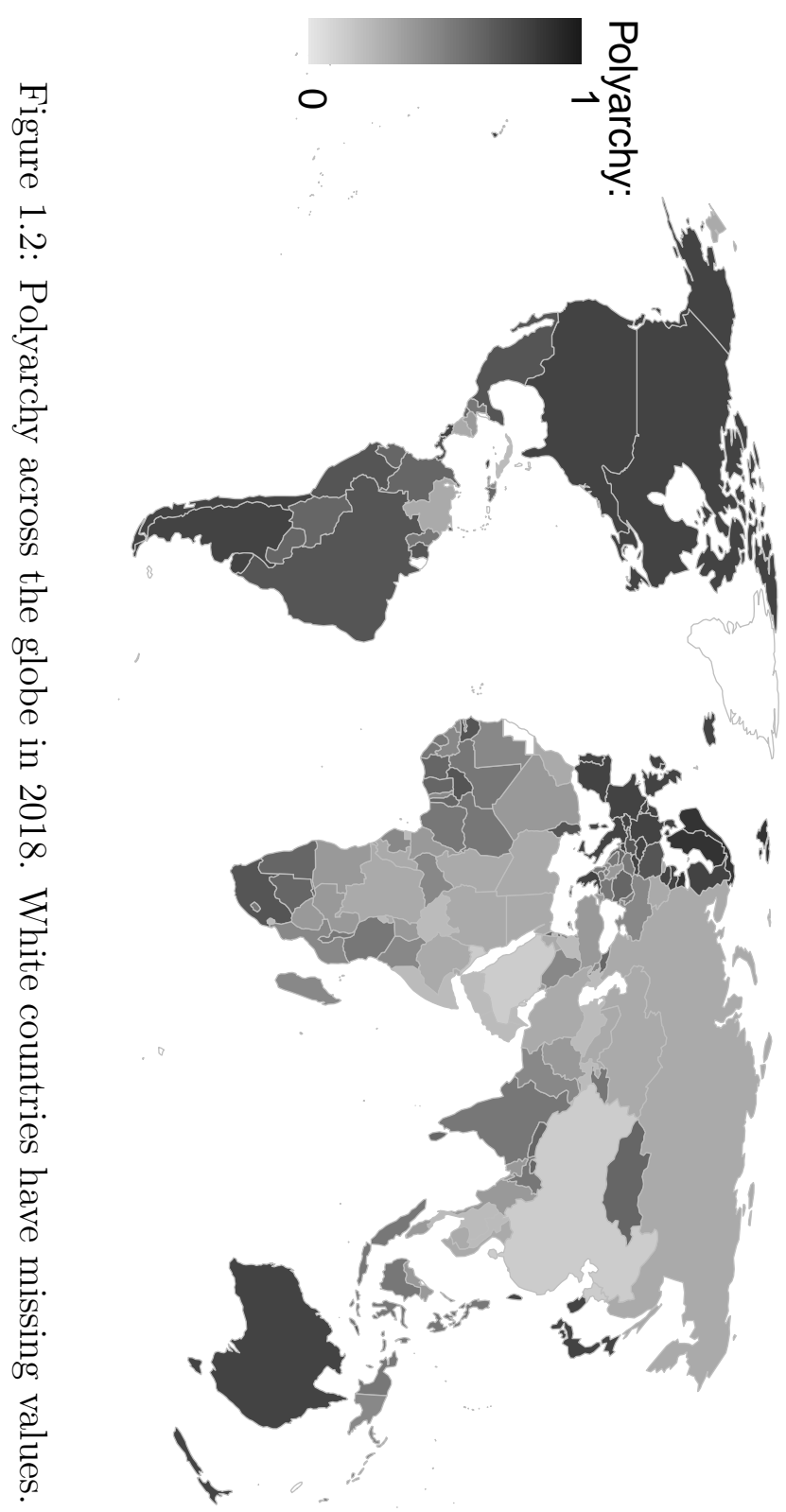


tries over time and all experts are confronted with "anchoring vignettes" - hypothetical scenarios that are equal to all experts and which can be used to gauge whether some experts are more lenient or restrictive on certain indicators. This, together with background variables on the experts and their own evaluations of their own certainty, are used in the V-Dem measurement model, which estimates the countries' final scores (Coppedge et al. 2019). For an elaborate comparison between V-Dem and other measures of democracy, see Boese (2019).

Another popular strand of measures opts for a "minimalist" approach to democracy, where regime type can be measured with "clean" observations that can easily be observed and thus easily replicated (Cheibub, Gandhi, and Vreeland 2010, p 71). Among these, the "BMR"-measure from Boix, Miller, and Rosato (2013) is most closely related to my definition of democracy. This measure also relies on Dahl's notion of contestation and participation. In the empirical investigations, I therefore use this measure in several robustness tests to evaluate how sensitive the results are to the coding of democracy. A broader discussion on the merits of different approaches to conceptualizing and measuring democracy is outside of the scope of this introductory chapter, but see Munck and Verkuilen (2002) for an excellent treatment of the topic.

\subsubsection{Public expenditures}

Another ambiguous concept is "public expenditures." I divide the discussion into two parts by first defining the meaning of "expenditures" and then the meaning of "public." I rely heavily on the work by international organizations that track such statistics across countries, specifically the "System of National Accounting" (UN et al. 2009), but I highlight some of the intrinsic difficulties and how they relate to the analysis in this dissertation.

\section{Expenditures, consumption, and investment}

Expenditures is defined as all fiscal expenses of some entity, in this case, the government. Expenditures can be divided into two broad categories: consumption and investments. Consumption is all activities that use up any good or service, divided into intermediate and final consumption. Intermediate consumption is the consumption of goods and services that is used up in the process of production. For example, in the investigating industrialization in chapter 2, part of the analysis looks at patterns in countries' regime type and energy consumption. We note that over $50 \%$ of world energy consumption takes place in the industrial sector, and it should be considered an intermediate consumption. Final consumption, on the other hand, is any good and service consumed to satisfy individual or collective needs and wants (UN et al. 2009, p. 8). For example, when Krobo Edusei, a member of Kwame Nkrumah's government in Ghana, used his position to purchase several expensive properties and luxury cars (Meredith 2011, p. 173), this counts as activity that consumes government revenues without being used for any productive purposes. 
Investment is the other subcategory of expenditure. For this dissertation, the most relevant type of investment is fixed capital formations. These are expenditures spent on acquiring new fixed assets, and fixed assets are anything that is repeatedly used in production, such as machinery and infrastructure. There are many details in the exact measurement of this. Financial assets are, for example, excluded from the definition of fixed capital formation. But for this dissertation, the essential part of the definition is that governments invest in assets that contribute to the continuous production of some goods.

It is often difficult to pinpoint whether a certain expenditure is an investment or a consumption. For example, when investigating investments in skyscrapers in chapter 4, we highlight how such structures can be used for both production and consumption. By increasing land available to the service sector, skyscrapers can, among other things, constitute valuable capital formations. However, we cannot exclude that some of these structures are used for continuous final consumption by political elites. They are still capital formations in the sense that they can repeatedly be used for lavish consumption, but at the expense of more productive uses of the same space. Thus, some skyscrapers lend themselves to be used for intermediate consumption in the production of services, while others are more rigged for final consumption. All skyscrapers should be considered capital formations. ${ }^{6}$

Many of the outcomes I investigate are not exclusively affected by fiscal government expenditures, but also government regulations. This includes postal services, construction of skyscrapers, manufacturing, energy consumption, railroads, and iron and steel production. In these cases, I am unable to identify the sole effect of government expenditures on the different outcomes. While the details of this will be addressed in the individual chapters, I generally expect leaders' incentives towards certain regulations to strongly correlate with incentives towards fiscal expenditures. For example, consider investments in skyscrapers. On average, such structures will be more valuable to the wealthy elite, and leaders who wish to build alliances with such elites can choose to make investments in skyscrapers. However, they can also establish a regulatory environment more favorable to elites who wish to make such investments. In contrast, many urban settlers might oppose large structures in their view, and demand that the government protect their property from being devalued by neighboring constructions. This will give democratic leaders a certain motivation to regulate tall infrastructure. Autocratic leaders, wanting to build alliances with wealthy developers, might be more inclined to disregard such considerations and instead grant wide opportunities for property development. More generally, it is difficult to find examples relevant to this dissertation where leaders' incentives towards investing in certain assets are opposite from their incentives to regulate investment in those same assets.

The provision of one asset can also be an indirect result of leaders' motivations and capacities to pursue other assets. Take for example postal services. While I argue that

\footnotetext{
${ }^{6}$ At least those that are used. The Ryugyong Hotel in North Korea remains dormant today even though construction started in 1987.
} 
democratic leaders have greater incentives to invest in such services, let us, for the sake of the example, assume that democratic and autocratic leaders have equal levels of motivation and capacity to improve postal services. However, autocrats might have a greater incentive to monitor their citizens, including their communication. As a result, postal services can possibly become less reliable and effective due to surveillance put in place in the system. The mechanism that links democracies to postal services then is not the motivation and capacities towards investing in postal services per se. Instead, postal services are affected by autocrats' investments in a domestic security apparatus.

In these cases, my primary concern is not the relative importance of the different mechanisms (investments in postal services versus surveillance efforts) but the provision of the specific asset (postal services) across different political systems. However, in many cases, I do attempt to approach this issue of which mechanism is most important. For example, by investigating how the effect of democracy changes when controlling for censorship of the media (which I assume correlates with surveillance of the postal system, lacking data on the latter), I gain leverage on the relative importance of this mechanism. In chapter 4 , we use a similar approach to gain leverage on the relative importance of a free media to inform the public of expenditures (and estimated profits) associated with the construction of skyscrapers.

\section{Public versus private}

Expenditures are public when they are made by a national, regional, or local government. This dissertation mainly addresses actions of the executive branch of government at the national level. For example, in chapter 5, I am specifically interested in decisions about investment allocations made by the head of state and how this is affected by vertical (elections) and horizontal (the parliament) accountability mechanisms. In some chapters, I cannot rule out that responsibility has been delegated to lower branches of government. For example, there could be instances where investments in postal services are delegated from the national to the regional or local levels of government. Such delegation is ultimately affected by national leaders' motivations and capacities to provide postal services, using different strategies at their disposal. In many cases, these are accountability-mechanisms deliberately introduced into the system, such as federal systems, to function as checks-and-balances.

A more problematic situation is if the national government lacks the capacity to implement policies. State capacity is defined as the "ability to implement official goals, especially over the actual or potential opposition of powerful social groups" (Skocpol 1985 , p. 9). The lack of state capacity is only a problem to the inferences made in this dissertation if it systematically varies with the institutional arrangements that I investigate, such as the democraticness of a country and the specific outcomes. I address this with different methodological tools, such as including state capacity as a controland matching variable in the statistical models.

Another aspect worth considering is how governments arrange the division of labor 
between the public and private sphere. Assets such as railways and postal services can be provided by private contractors. In practice, however, both railways and postal services have for the large part been established by government investments. Even where such services have been privatized, governments make extensive use of favorable lending schemes, regulations, or subsidies that effectively constitute public expenditures. Ultimately, the decision to use the private market instead of public companies is also affected by leaders' motivations and capacities, just as a re-delegation between central and local units, in line with the theoretical argument. Thus, in chapter 4, where we investigate investments into skyscrapers, we argue that autocratic elites, for different reasons, are more inclined to be involved in such projects. By investigating a subsample of the buildings, we find that political actors are much more likely to be involved in such projects in autocracies.

Finally, while the division between public and private is clear in theory, much private activity nevertheless involves political actors. For example, any firm operating in China is required by law to establish a party organization (Martina 2017). Similarly, the "Panama Papers," the exposure of more than 11 million documents from the law-firm Mossack Fonesca, revealed that President Joseph Kabila of the Democratic Republic of the Congo, together with his relatives, built a network of companies active in the country's private sector during his presidency (International Consortium of Investigative Journalists (ICIJ) 2016). By giving government contracts to these companies, he could convert public revenues into private wealth. In chapter 4 , we scrutinize a (stratified) random sample of 100 skyscrapers - 50 each in below- and above-median polyarchy observations. Among the 50 skyscrapers in relatively democratic countries, we were able to retrieve relevant and credible information for 46 of them (92\%), whereas the corresponding number was $32(64 \%)$ for autocracies. For the skyscrapers where we found information on ownership or financing, we identified state- or regime-affiliated ownership or financing for $50 \%$ of autocratic skyscrapers and $28 \%$ of democratic ones.

\subsection{Theoretical framework}

The causal path between political institutions and public expenditure is mediated by the agents that operate within these political institutions. In this section, I clarify the role of institutions, and how they shape the motivations and capacities of the political leadership. It is through motivations and capacities that political leaders adopt preferences for certain types of investments at the expense of others, as summarized in figure 1.3.

Motivations and capacities are closely related concepts, and we can easily imagine that we lose motivation if we lack the capacity or are made more capable by strong motivations. In this section, I will attempt to distinguish these two. Before delving into motivation and capacity, however, I start by outlining the central features of institutions that make them have this causal effect. 


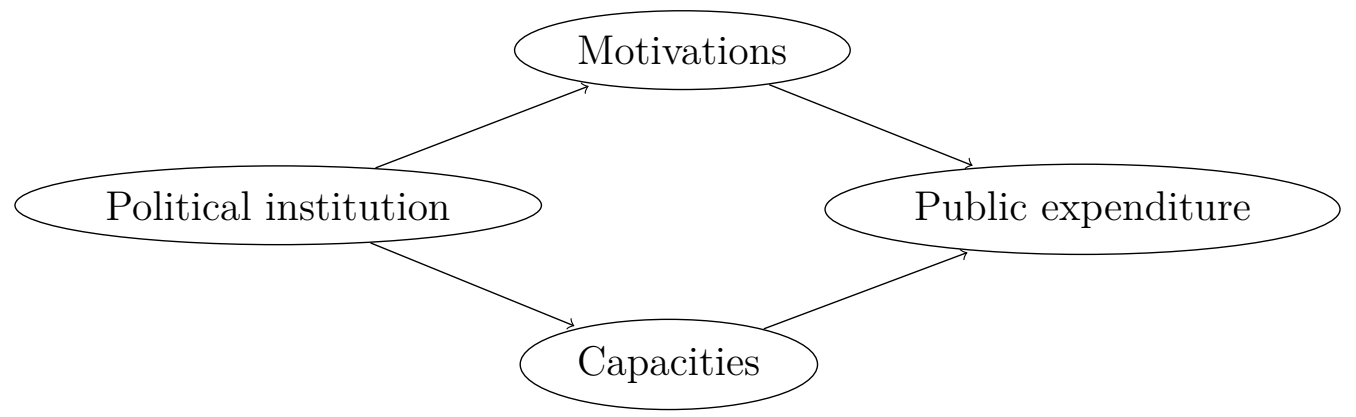

Figure 1.3: Causal model of the central theoretical framework.

\subsubsection{Political institutions}

In line with the literature at large, I assume that institutions form the rules of the game. Agents within these institutions are assumed to be (perfectly or boundedly) rational in their response to these rules. As such, institutions are assumed to be exogenously given and shape the motivations and capacities of the agents that act within them. This is what is usually labeled the "institutions-as-rules" view and follows the tradition of North (1990, p. 3): Institutions "are the humanly devised constraints that shape human interaction." By distributing power in different ways, such as leader-selection procedures, agenda control, committees, etc., institutions induce a social equilibrium, which, under different institutions, would have been different.

This last claim is worthy of some elaboration. It begs the question of why certain institutions emerge. It is common to think of certain "critical junctures," points in history when institutions were constructed and thereafter changed the course of history. The individuals who set up these institutions do so because they believe that, under this set of institutions, their private benefits will exceed their costs (North and Thomas 1973, p. 6). For example, in the theory by Ansell and Samuels (2014), the new urban business elites in the 19th and 20th centuries allied with the labor force against the rural landlord in order to protect themselves from expropriation, introducing and extending suffrage to the working class. The powerful business elites, the authors argue, believed that the cost of sharing political power was worth it in order to protect their businesses.

But if the structure of the game - the power relation between rural landowners, urban business elites, and the labor force - really decided the institutions, would this structure also have ensured the property rights of the business elites even without the extended suffrage? In other words, what would have happened if, absent of the extended suffrage, rural landlords attempted to expropriate the new businesses? If the outcome of such a struggle would be the same with and without the new institutions, the institutions were simply formalizations of a deeper social equilibrium, without any causal effect of their own (Przeworski 2004, p. 166).

This view is labeled as the "institutions-as-equilibria"-approach. ${ }^{7}$ In this view, any

\footnotetext{
${ }^{7}$ There are several labels for these two approaches. Some might prefer "institutional equilibrium" versus "equilibrium institutions," or "formal" versus "informal" institutions.
} 
self-enforcing equilibria by rational agents maximizing their preferences can be considered an institution (Clavert 1995; Greif and Kingston 2011; Greif and Laitin 2004).

These two approaches are not necessarily contradictory. Social equilibria can induce certain institutions, and these institutions, in turn, can have causal effects (Greif and Kingston 2011, p. 15). I follow this mainstream position.

I formulate the theory as if institutions affect the behavior of leaders, and in different ways, restrict potential moral hazard. Moral hazard is the possibility that the politician's preferences diverge from those of his or her winning coalition and may sometimes wish to make actions contradictory to their interests (Ferejohn 1986, p. 5). This implies that the same leader behaves differently under one set of institutions than what he or she would have done under another set of institutions. However, it is possible that different institutions do not change leaders' behavior but instead change who becomes leader altogether. That is, maybe institutions mainly work through the adverse selection of leaders, and therefore we observe different behavior (Besley 2006; Fearon 1999). If only adverse selection is at play, constraints can be neglected in institutional design: All that matters is to find mechanisms that ensure the selection of individuals with preferable motivations.

However, selecting "good" leaders, those with the same preferences as the winning coalition, effectively means not selecting, and thus sanctioning, "bad" types (Fearon 1999, p. 56-57). If "bad" types, as a result, pretend to be "good" types, then we are back in a world where moral hazard-mechanisms are operating. Thus, a pure selectionmechanism must assume that "bad" types make no attempt to stay in power. This seems to require assumptions that are less likely than if the moral hazard-mechanisms are operating. Since these are not mutually exclusive, it seems overwhelmingly plausible that both are operating.

\subsubsection{Motivation}

I assume that all leaders want to stay in power. Power allows leaders to achieve their goals, whatever they may be. Political institutions affect the rules for how these leaders can fulfill their motivation to stay in power. Politicians are in turn motivated to take other actions than they otherwise would, because these actions are perceived to increase their probability of staying in power.

To exemplify, let us accept the premise that under dictatorship, "political battle lines emerge as often among those in power as they do between an elite and the masses" (Svolik 2012, p. 24). A central way of staying in power in such a system is to deal with these intra-elite challengers. To co-opt potential challengers among these elites, autocrats might make investments in infrastructure and give the contracts to these challengers, as a way of converting public resources into private rents. While all politicians have a certain motivation for investing in infrastructure, such as a wish to stimulate general economic growth, the rules of the game give autocrats additional motivation that they would not 
have had under other institutional arrangements, thereby increasing the probability that they will prioritize such investments above other expenditures.

Leaders' motivations are central in both selectorate theory and in Acemoglu and Robinson's theory. The leader is motivated to invest in public goods when their winning coalition is large, according to Bueno de Mesquita et al. (2003), because this makes public goods more cost effective. Leaders under democracy are more motivated to invest in redistribution, according to Acemoglu and Robinson (2006), because the median voter is poorer under such a system compared to the median "voter" under autocracy. The motivation of political leaders is also a central aspect to all chapters. For example, in chapter 5, I argue that national elections give presidents and parliamentarians in both autocratic and democratic regimes an increased motivation to favor groups in society that will help them win the election. In chapter 2 , we argue that autocratic leaders are more motivated than democratic leaders to pursue particularistic expenditures because these lend themselves more easily to be targeted towards their more narrow winning coalitions.

\subsubsection{Capacities}

The capacity of leaders to pursue different strategies is linked to the different accountability mechanisms that constrain them. Accountability consists of two dimensions: Leaders are monitored by different actors, and some of these actors can impose sanctions should they observe something they disapprove of (Schedler 1999). ${ }^{8}$ Under full accountability, the leader is constrained in doing any action that is not preferable to those who hold him or her accountable. As such, the fortunes of the leader are linked to the preferences of whoever holds him or her accountable. As a useful categorization of different institutional constraints, I differentiate between horizontal and vertical accountability (Ferejohn 1986; Lührman, Marquardt, and Mechkova 2017).

Horizontal accountability refers to the monitoring and sanctioning of actors within the political system - checks and balances. Parliaments, independent judiciaries, and political parties are prime examples of formal horizontal accountability. These are empowered by the system to both monitor and sanction the executive leadership.

For example, in chapter 5, I argue that during elections, a president has a strong motivation to allocate public investments in a manner that helps him or her win the support of groups important for re-election. In the same way, parliamentarians have strong motivations to make public investments that ensure their re-election. Should the two elections co-occur, they mutually constrain each other's ability to allocate investments according to their preferences, because both have the ability to impose sanctions on the other. Their motivations remain unaltered, but their capacity to pursue them is limited by the matched motivation of other actors in the system.

\footnotetext{
${ }^{8}$ These two dimensions of accountability are sometimes labeled as "answerability" and "enforcement." I use monitoring and sanctioning as this is the terminology used for similar mechanisms in closely related phenomenon in political science (such as a patron-client relationship).
} 
Vertical accountability refers to the ability of the population at large to monitor and sanction their leaders - linking leaders' fortunes to the preferences of their electorates (Ferejohn 1986). Regularly held elections are the prime example of an institution that empowers vertical accountability. In chapter 4, we explain that history is filled with examples of political leaders who used their resources to invest in projects that cost more than the revenue they were expected to bring in, and that it seems unlikely the projects would ever have been prioritized if their respective regimes had had stronger vertical accountability mechanisms. For example, the Shwedagon Pagoda was rebuilt by Binnya U to 20 meters in the 14th century. Burmese heads of state have later added 80 more meters and golden plating around the structure, put a crown on top with 5,448 diamonds and 2,317 rubies, and a final bud on the top in 15 grams 76 carat diamond (Wikipedia n.d.). In 2009, the Burmese military regime completed a replica of the Shwedagon Pagoda in their ("artificial," recently erected) capitol Naypyidaw, but this structure is hollow on the inside. To take another example, President Félix Houphouët-Boigny built the "Basilica of Our Lady of Peace" in Yamoussoukro, Cote d'Ivoire, replicating St. Peter's Basilica in Rome (but with an extra 30 meters). This cathedral is estimated to have doubled the national debt (Mark 2015) in a country where about 20 percent of inhabitants are Catholic (CIA 2017). We believe such projects are unlikely to be in the interest of a majority of the citizens, and even though leaders may have private motivations to pursue them, stronger vertical accountability mechanisms will restrain them from doing so.

Horizontal and vertical accountability are empowered by independent media and freedom of speech more generally. Since monitoring is central for the ability of the different actors to hold each other accountable, more transparency improves the operation of accountability. The importance of an independent media is addressed directly in chapter 4, where we argue that autocratic leaders, compared to democratic leaders, more often invest in wasteful projects. Autocratic governments are systematically less transparent than democracies (Hollyer, Rosendorff, and Vreeland 2014), and we show evidence that access to information is perhaps the most important mediating channel for this causal relationship. As highlighted in section 1.2, the lack of transparency among autocracies might also cause severe measurement errors in statistics reported by governments.

A leader's capacity is also affected by a range of other factors, such as their available natural and economic resources or international alliances. Some of these factors are relevant confounders to the causal relationship illustrated in figure 1.3 and will be dealt with accordingly in the analyses.

\subsection{Reaching conclusions: Philosophy of science}

Making claims about what is true in the world requires compliance with certain principles in the philosophy of science. In this section, I discuss these principles. Since this dissertation attempts to explain causal relationships, I start by discussing the potential outcomes framework that I adhere to. I then justify the use of quantitative evidence, 
and some of the concerns that are important when trying to interpret causality from statistical relationships.

\subsubsection{Causal inference}

In this dissertation, I follow the potential outcomes framework for causal explanations (see Rubin 2005). The core of this framework is that each unit in the population of interest has, at a specific point in time, a potential outcome under each treatment state. In a setting with binomial treatment, each unit has two potential outcomes: one under receiving the treatment, and one under not receiving the treatment (often referred to as the control setting). However, only one state can be realized at a specific point in time, and thus we can never observe all potential outcomes (Morgan and Winship 2015, p. 4). A country cannot simultaneously be democratic and autocratic, and we will therefore never know how a specific leader behaves under different sets of institutions at the same point in time.

Formally, this situation is usually stated as each individual $i$ having potential outcomes $y_{i}^{1}$ and $y_{i}^{0}$, where superscript 1 indicates the treatment state, and 0 the control state. The causal effect of the treatment is defined as the contrast between these two, usually the difference $\left(y_{i}^{1}-y_{i}^{0}\right)$. This difference can never be observed, since both $y_{i}^{1}$ and $y_{i}^{0}$ can never be realized at the same time (Morgan and Winship 2015, p. 4).

To approximate this true causal effect, we must always introduce some assumptions. Most importantly, all of my empirical investigations assume that the units in question are identical in all relevant aspects, except for their treatment status, and can serve as counterfactuals for each other. If two units, $i$ and $j$, are identical in all relevant aspects, this estimated causal effect $\left(y_{i}^{1}-y_{j}^{0}\right)$ will equal the true causal effect $\left(y_{i}^{1}-y_{i}^{0}\right)$. However, in all empirical investigations in this dissertation, this will be a very strong and highly unlikely assumption. For example, in chapter 3, I compare the quality of postal services across countries. It is unreasonable to assume that, for example, Greece and Turkey are equal in all other respects other than their democraticness. The most common approach to alleviate this problem is to control for all aspects that correlate with both a country's level of democracy and the economic outcome in question, so that the units are equal conditional on the covariates controlled for. For example, economic development is a recurring control variable across all the empirical investigations. This is because economic development is important for what type of investments rulers can make, and it correlates strongly with electoral democracy (Knutsen et al. 2019a). This makes it an important confounder for the relationship between regime type and public expenditure.

To gain further leverage on the different hypotheses, I also use a series of robustness checks to exclude alternative explanations that are not included in the different benchmark models. For example, when comparing postal services in chapter 3, it is possible that a positive relationship between democracy and postal service quality is driven by European countries that industrialized at a time when postal systems were the main mode of long-distance communication, and that contemporary postal systems are sim- 
ply results of a path-dependency from this historical period. However, the association is robust to excluding any region or country of the world. This, in combination with the different control variables as well as matching, should reduce our belief that this historical path-dependency explains the empirical observation. Across the chapter, I probe different patterns in the empirical evidence in order to exclude all alternative explanations that I a) can think of and b) have the practical opportunity to investigate.

Still, there is usually a range of possible alternative explanations that I am unable to exclude (or think of) with available resources. Furthermore, while robustness tests reduce the probability that an alternative explanation is true, they are seldom decisive. Thus, there will always remain some uncertainty about whether we are actually observing causality.

I reiterate here that this dissertation tests a series of hypotheses derived from the general theoretical framework against very different sources of data. While we can imagine that there are some common, unknown confounders that can explain, for example, why some countries have good educational systems and good postal systems, it is far less intuitive that there exists some unknown confounder other than the ones I identify that makes countries' skyscrapers more extravagant and wasteful, reduces the quality of their postal services, and increases their energy consumption. When observable implications from the theory are confirmed across such a wide range of data sources, this should increase our belief in the theory (King, Keohane, and Verba 1994, p. 30).

\subsubsection{Statistical inference}

A large-N, statistical approach is best suited for my analyses for two reasons. Since we can only observe the realized outcome, and not all the potential outcomes, a large $\mathrm{N}$ allows us to compare different units that exist under the different treatment states. Since it is difficult to identify two units that are equal in all relevant aspects, a sufficiently large $\mathrm{N}$ makes it easier to find groups of units that are equal on average. Thus, while individual treatment effects might occur, the average treatment effect in a large sample is more likely to approximate the true average causal effect.

In using statistical inference, I follow the frequentist approach. This implies that probability is defined in terms of how often an event occurs in very large samples. The common approach is to test a hypothesized empirical pattern against a null hypothesis of no such pattern. For causal inference, the test is usually that some variable $\mathrm{X}$ affects some outcome Y, tested against the null hypothesis that there is no such relationship between $\mathrm{X}$ and $\mathrm{Y}$. To decide whether the null hypothesis should be rejected or not, a $p$-value is calculated, indicating the plausibility to observe this specific empirical pattern if the null hypothesis is true. In this setting, probability is defined in terms of frequencies and how often we would observe the null hypothesis if we repeated the sampling procedure and estimation an infinite number of times (the so-called sampling distribution) (McElreath 2015, p. 11). Following convention, this dissertation will assume that the null hypothesis can be rejected if it is expected to occur in $5 \%$ or less of the sampling distribution 
(conventionally named statistically significant).

In studies of political regimes, such a resampling is absurd: The population of regimes, or a large portion of them, will already be part of the sample, and some broader population to resample from is simply "a product of the statistician's imagination" (Fisher 1955, p. 71). Furthermore, the level of statistical significance, the $5 \%$ threshold, is arbitrary. There is no solid philosophical argument for this specific threshold.

My choice of a frequentist approach is mainly in order to adhere to scholarly convention. While the $5 \%$ threshold is arbitrary, there is so far no other alternative that unites researchers. However, it is also my strong preference to not only focus on whether or not an effect is likely to exist, based on this arbitrary decision-rule, but also to pay attention to the uncertainty of the estimate more generally, its stability across alternative specifications, and most importantly, the importance (e.g., size) of the estimated effect. Throughout the chapters, I aim to highlight all of these aspects.

\subsection{The structure of the dissertation}

This dissertation consists of this introductory chapter and four article-length chapters, each analyzing the relationship between political institutions and economic outcomes. All of the chapters have previously been presented at conferences, workshops, or seminars. All chapters are connected by the theoretical framework in section 1.4 and the causal model illustrated in figure 1.3. They all share the same methodological approach, using quantitative designs with various regression- and matching-models to reach inference. The sum of the chapters amounts to new insights into how public expenditures are used for political goals, and the literature on institutions and economic outcomes more broadly.

Each chapter has an independent contribution to how political institutions shape public investments. They address distinct aspects of different investments, and how this matters to their political incentives. Accordingly, they all investigate different dependent variables, and no chapters share the same data set. However, on the independent side, they all use the country-definitions and institutional variables from the V-Dem dataset (Coppedge et al. 2018), with polyarchy (v2x_polyarchy) as the authoritative measure on democracy.

In the following, I summarize each chapter and highlight its contribution to the overall structure.

\subsubsection{Regimes and industrialization}

Chapter 2 addresses how political institutions affect the different motivations and capacities for leaders to pursue policies for industrialization. Specifically, my co-authors and I argue that autocrats enjoy a significant advantage over democrats in both motivation and capacity to pursue such policies. Recent contributions indicate that democracy first and foremost improves human capital, and that this is the central link between democracy and economic growth (Doucouliagos and Ulubaşoğlu 2008). Although we do not make 
any claims about the economic effects of industrialization, we provide the flip-side of this argument, namely that heavy industry, infrastructure, and manufacturing is an area where autocrats might enjoy a significant advantage over democrats. Using four different measures of industrialization over approximately 150 years, we provide what is (to our knowledge) the first systematic and comprehensive large- $\mathrm{N}$ test of this argument.

We identify three reasons why autocrats might have greater motivation and/or capacity to pursue industrialization. First, following the line of argument in selectorate theory, autocrats have greater motivations than democrats because the policies associated with industrialization lend themselves more to particularistic targeting of supporters. These are policies such as tax incentives, low-interest loans, direct investments or subventions, expropriation of land, alterations in regulatory burdens, export subsidies, import tariffs, and repression of labor and civic organizations. Since the winning coalition tends to be smaller in autocracies, more particularistic investments will generally be more attractive for their political survival.

Second, autocrats are also more motivated because they govern in more hostile security environments. Autocratic leaders will more often have unresolved border disputes (Gibler 2007), their tenure is much more sensitive to conflict (including inter-state war) (Chiozza and Goemans 2004), and they have greater threats from internal dissent (Przeworski 1991). Industrialization is critical to security, both when considering external and internal threats (Chambers and Waitoolkiat 2017; Fravel 2019; Koistinen 1980; Robison 1988; Skidmore 1990; Smith 2015; Wavro 2003; Yamamura 1977).

Finally, autocracies enjoy greater capacity to pursue industrialization. Industrialization makes radical changes in the established economy, with a range of unpopular short-term consequences, such as displacement of historical settlement patterns, introduction of dangerous workplaces, destruction of inefficient modes of production, etc. The "creative destruction" of industrialization creates losers among those who benefited from the established systems, and these losers are likely to oppose many of the policies for industrialization (Schumpeter 1942). Autocrats have access to coercive policy tools that are simply not viable for anyone trying to win democratic elections, such as brute force and expropriation.

Over several specifications, we regress four measures of industrialization, namely railway freight, energy consumption, iron and steel production, and manufacturing value added, against polyarchy. We find a consistent negative association. ${ }^{9}$ This is robust to having fixed effects on country and year (e.g., only using change within countries to estimate the association, and controlling for any year-specific shocks), it is robust to include several different confounders into the model, such as differences in income from natural resources and economic growth, and it is robust to different time-specifications, such as using 5- and 10-year averages as units instead of yearly panels. We contrast these outcomes with public expenditures that increase consumption, namely real wage of the labor force and public expenditure as a percent of GDP and find a positive relationship

\footnotetext{
${ }^{9}$ Because industrialization is such a slow process, we have opted for a stock-version of polyarchy, which accounts for the history of a country's democraticness. We test several specifications of this stock.
} 
between democracy and these outcomes. Thus, we find systematic evidence that autocracies have higher physical investment accumulation, while democracies tend to prioritize consumption.

\subsubsection{Democracy and public services: Evidence from postal ser- vices}

In chapter 3, I turn attention to public services. Public services are closer to the ideal type of a pure public good and should be an area where the prediction that democracies improve public goods is more likely to be true. But as indicated previously, the literature disagrees over whether services really are improved by the increased spending under democracy (Dahlum and Knutsen 2017; Harding and Stasavage 2014; Lake and Baum 2001; Ross 2006).

In line with the central theories, I argue that democratically elected leaders are motivated to improve universal postal services in order to win votes. This is compounded by the monitoring and sanctioning of a parliament and free media. Autocrats, on the other hand, have greater incentives to prioritize spending towards a more narrow and wealthy winning coalition, which has less interest in an effective public postal service. Furthermore, autocrats might even have incentives to restrict citizens' communication both with each other and with the outside world, by underproviding necessary resources or engaging in costly surveillance of the items sent (Hachigian 2002; Holkeboer and Vreeland 2013; King, Pan, and Roberts 2013; King, Pan, and Roberts 2017; Knutsen 2015; Kuran 1989). Even if democratic leaders were interested in control of citizens' communications, and parcels risk security screening also in democracies, horizontal and vertical accountability mechanisms would seriously inhibit their capacity to enact widespread surveillance.

I use novel data from Chong et al. (2014) to test this argument. From December 2010 to January 2011, the authors sent out 10 letters to the five largest cities in 159 countries around the world. All of these letters stated that it was a matter of urgency, but if the letter was undeliverable, it should be returned to sender. The address on each letter had a correct ZIP-code to the relevant city, but a non-existent street name. All of the 159 countries have signed the "Universal Postal Union Letter Post Regulations Final Protocol" of 2009, which regulates that any incorrectly addressed mail shall be returned to the sender at the expense of the country in which the letter originated from, in this case, the United States. Thus, the task that the employees in the receiving country need to do first is to recognize that the letter is undeliverable, and second, return it.

The fact that this measure is not self-reported by the governments themselves, is a formidable advantage. Furthermore, measuring the quality of services across countries is very difficult. Think, for example, of the inherent difficulties in comparing the quality of public health service, given the wide, systematic variety of physical illnesses that doctors deal with in different countries. My measure of postal services, however, exposes the respective postal offices to the exact same task, with a clear measurement done by the same individuals for all data points. To my knowledge, there exists no other systematic 
test on regimes and postal systems. Compared to services such as health and education, postal services are usually less salient in public debates, which makes this a less likely case for the posited relationship between regime type and public services.

Democratic countries returned, on average, between 20-40\% more of the letters. This result is robust to a series of controls and matching-estimations, including economic development and state capacity. It is not exclusive to certain regions of the world and cannot be explained by historical events (such as colonial history) or geographical factors (such as tropical climate). The combined evidence strongly suggests that, compared to autocratic leaders, democratic leaders have greater motivation to prioritize public services.

\subsubsection{Leaders, private interests, and socially wasteful projects: Skyscrapers in democracies and autocracies}

Chapter 4 uses novel data on different features of skyscrapers to test a central implication of institutional theory, namely leaders' ability to pursue private rents. Previous studies of this phenomenon have often opted for measures of corruption, reporting mixed findings (see e.g., Rock 2009). However, most of these studies rely on corruption perceptions, which may be artificially deflated in autocracies without a free press and low transparency to report cases of bribery, theft, and excessive rent-seeking, thus generating biased estimates (see Knutsen 2010). By focusing on skyscrapers, we can get a comparable measure of investment projects that often imply a substantial drag on public resources.

We focus not only on the number of skyscrapers but also their design and placement. This chapter explains that the quantity of infrastructure, such as the measures we employ in chapter 2 , is only part of the story. Seemingly equal investment objects can be constructed in different ways, making them more or less economically wasteful.

We derive several arguments for why there will be constructed more and more-wasteful skyscrapers in autocratic countries. The first set of arguments relates to leaders' motivations. First, and in line with the selectorate model, construction contracts can be targeted in a particularistic manner, transferring government resources to political allies. Second, extravagant skyscrapers can be enjoyed by a wealthy elite, while being practically unavailable to poorer parts of the society. Thus, they achieve a socioeconomic exclusion. Third, if skyscrapers can be used as a psychological tool to project power, autocratic leaders might have an increased motivation to pursue them. For instance, if the lack of free and fair elections and a free press increases the need for alternative ways to signal affluence and power to the opposition and potential supporters alike to avoid a coup or revolutionary threats, autocratic leaders may prefer to expend more resources on building more and more-expensive skyscrapers than democratic leaders. As noted by Svolik (2012, p. 80), "the dictator's outward appearance of invincibility is as important as his actual power."

But autocrats also have greater capabilities to allow skyscrapers. Democracy may mitigate the building of expensive skyscrapers due to vertical accountability mechanisms. 
Well-informed voters could penalize politicians expending scarce resources on wasteful projects, thus disciplining politicians seeking re-election. This mechanism is attenuated access to information, such as an independent media. Furthermore, the typically stronger horizontal constraints on democratic leaders could mitigate skyscraper building. These relate, for instance, to requirements of passing spending bills through the legislature. While democratically elected prime ministers might also prefer spending on prestigious and costly construction projects for private reasons, legislators accountable to voters in their districts could be less eager to do so (particularly when the projects are located outside their districts).

Over a series of tests, we find that autocratic leaders build more skyscrapers than democratic leaders. Furthermore, we employ measures of "vanity height," defined as the distance between the highest occupiable floor and the architectural top of the structure. These distances capture spires or empty spaces. For example, the Makkah Royal Clock Tower in Saudi Arabia is topped with a 107-meters-tall gold-covered spire - just 10 meters shorter than Norway's tallest building. By matching buildings by their different characteristics, such as function and height, we find that conditional on a skyscraper being built, buildings constructed in autocracies have more of these vanity meters. We also find that skyscrapers are more likely to be built in democracies the greater their economic development and the greater the urbanization of the country, while there is no such systematic association for when skyscrapers are built in autocracies. We argue that this is further proof that autocratic leaders build skyscrapers for other reasons than their potential economic profit. We also try to disentangle the different causal mechanisms that we propose and find suggestive evidence that the most important causal link between regime type and the number of skyscrapers, is the relative transparency of information in democratic regimes compared to autocratic ones.

\subsubsection{Presidents, parliaments, and the allocation of public in- vestments during elections}

In the final chapter, I use geolocated investments in Africa to investigate how institutions, specifically elections and legislatures, affect leaders' motivation and capacity to target specific groups. The argument is two-fold. First, I argue that elections, even in autocracies, give political leaders motivation to allocate investments towards important voter-groups. This re-allocation need not be economically optimal or have redistributive consequences, but follows incentives produced by the electoral systems. While the other chapters assume that elections discipline leaders' investments, this paper explicitly tests some of the observable implications of this assumption.

This also contributes to a debate on the role of elections in non-democratic and developing democracies. There are several theories on why non-democratic leaders might prefer elections, especially related to how these can be used to co-opt opposition and increase the stability of the regimes (see for example Gandhi and Lust-Okar 2009; Gandhi and Przeworski 2006; Gandhi and Przeworski 2007; Knutsen, Nygård, and Wig 2017). 
However, I argue that as a necessary consequence, these leaders must accommodate certain social groups that are important both for popular support and in order to conduct electoral fraud.

The second part of the argument is that since both the parliamentarians and the president face the threat of electoral loss, the actors within these two institutions are incapable of perfectly allocating investments according to their will in cases where presidential and parliamentary elections co-occur. If the leader needs support from some of the parliamentarians, he or she must oblige their demand for some of the investments. This contributes to another debate on the role of parliaments in non-democratic and developing democracies. Just as with elections, there are reasons to believe that non-democratic leaders are interested in legislatures because these can help stabilize their rule. For example, parliaments formalize the bargaining-process and can help elites achieve more efficient outcomes, through alleviating commitment problems and reducing uncertainty (Fearon 2011). However, scholars do not agree on whether parliamentarians in such regimes are duly empowered to constrain their non-democratic leader (see for example Jensen, Malesky, and Weymouth 2014).

I test these hypotheses by investigating the geographical allocation of investments prior to election-years. This requires an assumption about where the president and parliamentarians want to allocate investments. To do this, I lend insights from principal-agent models and historical accounts of African electoral behavior (De Luca et al. 2018; Kasara 2007; Stokes et al. 2014; Meredith 2011). These predict that African leaders have an electoral interest in their home regions where they can mobilize help from a trustworthy network of agents.

Empirically, I find that the distance between the birthplace of the president and the average investment is reduced by almost $60 \%$ prior to election years. However, if presidential and parliamentary elections co-occur, there is no significant change in the distance. These conspicuous changes in geographical allocation are isolated to the year prior to election years. It is not confined to certain leaders or countries, and there is no difference between democratic and autocratic regimes. However, the effects are confined to majoritarian parliamentary elections. Since it is much more difficult for voters to attribute responsibility to the correct politicians in proportional systems, where there are several parliamentarians from different parties from each constituency, pork-barrel is a less effective strategy for winning support. Thus, I find strong evidence that political leaders are (relatively) motivated and constrained by the accountability mechanisms that political institutions introduce.

\section{Relation between the papers}

The chapters are united in that they all, in different ways, inform the general research question that political institutions affect leaders' motivation and capacity to pursue different public expenditures. In formulating the specific hypotheses, I draw on insights from selectorate theory to formulate how the size of the winning coalition affects the 
use of particularistic versus more universal assets. This recurs across all chapters. The preferences of different societal groups are also important to chapters $2-4$, and in this endeavor, I rely to a great extent on Acemoglu and Robinson (2006). For example, a possible mechanism explaining differences in the construction of skyscrapers across regimes in chapter 4 is that political power is more strongly skewed towards economic elites in autocracies, and they may prefer building fancy skyscrapers rather than prioritizing, for example, public services for the wider population. The same argument is proposed in chapter 3 when investigating the relationship between regime type and public services.

Constraints by vertical and horizontal accountability mechanisms are relevant to all chapters. For example, in chapter 4, my co-author and I directly address how leaders facing large winning coalitions are constrained from spending public revenue on wasteful projects, compared to leaders facing smaller, richer winning coalitions. In chapter 5 , I study the effect of two central institutions constraining presidential power: elections and legislatures. This directly addresses implications of vertical and horizontal accountability mechanisms. By comparing majoritarian and proportional electoral formulas, the chapter also illustrates how different vertical accountability mechanisms have different effects on the capability of political leaders to use public expenditures - in this case, the use of pork barrel investments.

Motivation is also central to all chapters. On a general level, I theorize how the size of the winning coalition motivates leaders to invest in particularistic versus more universal assets. This mechanism is present in all chapters. However, I also describe motivations that are more unique to the different assets. For example, in chapter 4, we contend that if the lack of free and fair elections and a free press increases the need for alternative ways to project and signal affluence and power to opposition and potential supporters alike in order to avoid a coup or revolutionary threat, autocratic leaders may be motivated to expend more resources on building more and more-expensive skyscrapers than democratic leaders, everything else being equal. In chapter 5, I argue that elections give leaders temporary motivations to allocating investments towards electorally important areas.

While the chapters are united in their use of the general theoretical framework, they are unique in the specific hypotheses they test and the data they use. In chapter 2, we use four rather general country-level measures from 200 years of history across the globe to make inferences about the relationship between regime type and industrialization. In contrast, in the most detailed analyses of chapter 3, I draw inferences from 1,590 letters sent to 159 countries in 2010-2011. In chapter 4, we analyze variation in different features of buildings around the globe to draw inferences about whether leaders in different regime types differ in how much they invest in wasteful projects. In chapter 5 , the main source of information is the geographical distance between the leader's birthplace and the location of the investment. The data-generating process behind these variables is very different. The fact that implications of the theoretical framework are confirmed across such a broad set of data patterns should increase our belief in the theory. 


\subsection{Implications}

Governments control vast resources that directly and indirectly affect the infrastructure around us. To understand how they allocate these resources has been and still is a major goal for political science and has broader implications for anyone concerned with development. In line with existing theory, I have argued that institutions shape political leaders' motivations and capacities in prioritizing public expenditure, and that this is manifested in the type, quality, and distribution of benefits from public investments. Based on the insights from chapters $2-5$, I here propose some implications for both research and policy.

A main contribution of chapters 2,3 , and 4 is to demonstrate how institutions affect whether leaders are more or less likely to pursue different types of assets. In broad strokes, chapters 2 and 4 can be contrasted to chapter 3. The former two chapters show autocratic leaders' relative emphasis on assets that can be targeted towards more wealthy and smaller social groups, compared to democratic leaders. The latter chapter illustrates democratic leaders' attraction to more universal assets that can benefit larger, poor- and middle-income groups. Together, these three chapters contribute to the much broader literature on the causal pathways between regime type and economic growth. They support the argument that autocratic leaders prioritize physical capital accumulation and savings, while democratic leaders prioritize human capital and consumption (Huntington 1968; Przeworski and Limongi 1993; Tavares and Wacziarg 2001). However, since chapter 4 demonstrates how autocratic leaders routinely invest in wasteful projects, my dissertation cannot confirm that investments in physical capital accumulation among autocracies imply that this contributes to greater economic growth among such regimes. To the contrary, a possible implication is that the economic output from investments in infrastructure and manufacturing among autocracies is lower than similar investments in democracies, because they are made with different motivations in mind. This should be an interesting avenue for future research.

This leads us to a second contribution from chapters 3 and 4. Both chapters study investments that have been made, in, respectively, postal services (including international coordination of postal items) and skyscrapers. They then investigate qualitative aspects of these assets. In chapter 3 , the observation is that even though almost all countries have invested in a postal service of some sort, and even though comparisons are made only based on the efforts of the postal services in the five largest cities within each country, postal services within democracies deliver significantly better service. Thus, there are some unobserved investments made in postal services in these countries that improve their quality. In chapter 4, it is illustrated that conditional on a skyscraper being built, these buildings have been made more extravagant in autocracies than in democracies. Taken together, the chapters provide evidence that democratic institutions improve the quality of the investments leaders make.

A contribution made particularly in chapter 5 but also implied in chapters 2, 3, and 4 is how institutions influence leaders to distribute public expenditure a) geographically 
(in chapter 5) and b) socio-economically (in chapters 2-4). The observation that elections, at least in the context of African countries, induce leaders to prioritize personal networks with public revenue can have long-term effects on the development of (different geographical areas of) countries. A possible implication that remains unaddressed in this dissertation, is that democratic leaders might initiate universal services such as postal services, as observed in chapter 3, but that the distribution of these services is constrained by politicians' prioritization of certain important constituencies. This should also be an interesting avenue for future research. For example, one possible implication from chapter 5 is that parliamentarians in majoritarian systems are more likely to spend time on constituency service. We should therefore observe that democracies with majoritarian electoral formulas, compared to democracies using proportional electoral formulas, have greater variation in the quality of the public services between constituencies.

Given the complexity in how public expenditures are spent on different assets, we should be cautious concerning how much we generalize from a few variables. Take, for example, infant mortality rate, argued to measure "the quality of the whole society" (Rosling, Rosling, and Rönnlund 2018). Nepal and Cambodia have a similar infant mortality rate (36.3 and 36.7, respectively, in 2010) and a quite similar GDP per capita PPP (1986 and 2253, respectively, in 2010). Yet, using data from chapter 3, the postal services of Cambodia are among the worst in the world, while in Nepal they perform on par with the best half. Infant mortality rate is important in its own right, and I believe we are doing ourselves a disservice by claiming too much about what we can infer about society from one (or a few) variables.

On the more general level, I encourage three recent developments in the literature. First is the increased emphasis on causal inference. While natural experiments are highly infrequent in the literature concerned with national institutions, the ongoing developments in statistical methods should be used to revisit past hypotheses (see e.g., Acemoglu et al. 2019). Second, we should increase our efforts to collect new and more varied data, preferably data that are not generated by governments themselves. By investigating a wide range of economic outcomes, we gain greater leverage for our hypotheses, and we can develop a more nuanced and complex causal framework for political economy (see e.g., Burnett and Kogan 2017; Williams 2017). Finally, with better methods for causal inference and more varied data, we should strive to develop our understanding of more detailed dynamics in the relation between various political institutions and economic outcomes. 



\title{
2 Regimes and Industrialization
}

John Gerring¹, Haakon Gjerløw, and Carl Henrik Knutsen²

\begin{abstract}
:
A large literature addresses the impact of regimes on domestic policies and outcomes, e.g., education, health, inequality, redistribution, public spending, wages, infrastructure, volatility, productivity, and economic growth. This study focuses on another vital outcome - industrialization - that no previous study has systematically explored. We argue that autocratic leaders are more likely to adopt an economic model of development centered on heavy industry because of three factors that distinguish democratic and autocratic regimes: different social bases, different security concerns, and different policy tools. Accordingly, autocracies have stronger incentives and better capabilities to pursue a rapid and comprehensive course of industrialization. We test this hypothesis using different measures of industrialization in a dataset spanning 200 years and most countries of the world. After a comprehensive series of tests, we conclude that industrialization stands out as one of the few areas where autocracies may enjoy a significant advantage over democracies.
\end{abstract}

Publication status:

Submitted

\footnotetext{
${ }^{1}$ Professor at the Department of Government, University of Texas at Austin

${ }^{2}$ Professor at the Department of Political Science, University of Oslo
} 


\section{$2.1 \quad$ Introduction}

A large literature addresses the impact of regimes on domestic policies and policy outcomes. This includes education (Brown and Hunter 2004; Stasavage 2005), health and mortality (Gerring et al. 2016), inequality, redistribution and various types of public spending (Boix 2003; Lee 2005; Mulligan, Gil, and Sala-i-Martin 2004; Lindert 2004; Ansell and Samuels 2014), wages (Rodrik 1999; Przeworski et al. 2000), infrastructure (Brown and Mobarak 2009; Burgess et al. 2015; Min 2015; Saiz 2006), volatility in economic performance (Mobarak 2005; Rodrik 2008), productivity and technological change (Faust 2007; Knutsen 2015) and economic growth (Acemoglu et al. 2019; Gerring et al. 2005).

In this study, we focus on another vital outcome - industrialization. This refers to the development of manufacturing, especially heavy industry, and certain types of infrastructure that support industry and manufacturing such as transport and energy. A large, historical literature documents the industrialization experiences of different countries and regions, and several case studies have focused on the role of particular industrialization policies and various, broader import-substitution or export-promoting strategies conducive to industrialization. Yet, few studies focus in a concerted fashion on the relationship between regime type and industrialization. To our knowledge, the present study is the first to examine this relationship with a global panel of countries.

While acknowledging that a host of factors influence industrialization -and that there is a good deal of heterogeneity in the industrial policies pursued by autocracies and democracies - we propose that autocratic leaders are more likely than democratic leaders to adopt an economic model of development centered on heavy industry. This, we argue, follows from three factors that distinguish democratic and autocratic regimes: different social bases, different security concerns, and different policy tools. Together, these mechanisms suggest that autocracies have stronger incentives and better capabilities to pursue industry-centered modernization.

To test this hypothesis we draw on data from a global sample of countries extending back to the early nineteenth century and employing measures that tap into various aspects of industrialization. The relationship between regime type and industrialization is tested with country- and year-fixed effects, varying lag structures, different panel units, the inclusion of multiple lags of the dependent variable as regressors, varying measures of democracy, varying measures of industrialization, several alternative outcome measures, and controls for potential confounders such as income, population, features of the bureaucracy and the state's overall role as an owner in the economy. Industrialization stands out as one of the few areas where autocracies may enjoy a significant advantage over democracies.

The paper is structured as follows. First, we briefly review extant work pertaining to institutions and industrialization, followed by our theoretical argument for why autocratic regimes may have a stronger incentive and greater capacity to pursue industrial policies. Next, we introduce the data and main tests, centered on four measures 
of industrialization: railway freight, energy consumption, iron and steel production, and manufacturing value added. Before concluding, we discuss tests on alternative outcomes as well as robustness tests of our main results.

\subsection{Industrialization and Politics}

Economic historians and sociologists have identified multiple factors that may have contributed to early industrialization in England (Goldstone 2009). This includes the existence of crucial raw materials such as coal (Pomeranz 2000), a cultural orientation favorable to progress and science (Landes 1998), a distinctive demographic profile (Hajnal 1965), trade and conquest during the age of imperialism (Pomeranz and Topik 2014), and political fragmentation (Jones 1981). In these stories, the state is peripheral, or as epiphenomenal.

Other accounts - especially those focusing on later periods of industrialization - grant a central role to the state as a handmaiden - or opponent - of industrialization. Prominent examples of the former include Prussia (Gerschenkron 1962), South Korea (Amsden 1989), the Soviet Union (Davies, Harrison, and Wheatcroft 1994), and China (Naughton and Tsai 2015). Governments may provide tax incentives, low-interest loans, direct investment or subvention, expropriation of land for industrial development, reductions in regulatory burdens (e.g., environmental, workplace, or consumer protection legislation and legal obstacles to industry), export subsidies, export processing zones, import tariffs, and/or repression of labor organization (which, in turn, reduces production costs). Governments may also build requisite infrastructure such as ports and railways or take direct ownership of production facilities in key sectors such as steel works or electricity plants.

There is no limit, in principle, to the policy instruments governments may employ to foster industrial development. (For present purposes, all such policies are "industrial policies.") In the nineteenth century, the Japanese state constructed proto-factories in order to diffuse relevant knowledge to private firms (Tipton 2008, p. 53-54). During the Great Leap Forward, the Chinese government requisitioned pots and pans from citizens to produce steel out of scrap metals in "backyard furnaces" (Chan 2001). Emphasis may be placed on expanding industrial exports, as was common in East Asia (Wade 2003), protecting domestic industries against international competition, as in the importsubstitution models pursued by several Latin American countries (see, e.g. Gereffi and Wyman 1990), or forcibly transforming the economy from agriculture to manufacturing, as occurred under Stalin in the USSR (Davies, Harrison, and Wheatcroft 1994; Shearer 1996).

With the exception of protectionism, attempts at rapid industrialization usually involve large-scale investments in various types of infrastructure and coordinated investments across several sectors (Murphy, Shleifer, and Vishny 1989; Rosenstein-Rodan 1943), tasks that are difficult to achieve without some sort of government intervention. Of course, virtually everything the government does has some impact on the propensity of a country 
to industrialize. However, some governments pursue this goal more directly and aggressively than others, as previous examples illustrate. One factor that may help explain varying policy responses is the character of the political regime.

Industrialization has been a hallmark of economic growth in East Asia, and the success of that growth model is often attributed to industrial policies undertaken - or at least initiated - under authoritarian auspices (Amsden 1989; Cummings 1984; Deyo 1987; Evans 1995; Gereffi and Wyman 1990; Kohli 2004; Wade 2003; Woo-Cumings 1999). Although writers do not usually identify regime type as a primary cause of those policies, it seems plausible to suppose that regime features might have played a role. Stylized contrasts between China and India support that conclusion (Bardhan 2012).

Likewise, authoritarian rule may also have been a driving factor behind industrialization in other regions such as Latin America (O'Donnell 1988). However, in discussing linkages between regime type and industrial strategy, Haggard (1990) highlights the complexity and likely heterogeneity of such a relationship. While a link between authoritarianism and industrial strategy is "plausible in the East Asian NICs," Haggard (1990, p. 255) declares that "the association between industrial strategy and authoritarian rule in Latin America appears to be weak."

A different literature focuses explicitly on regime characteristics and includes several large-sample tests, suggesting that autocracies are likely to emphasize savings and investment, a key component in industrialization, while democracies privilege consumption (Schweinitz 1959; Huntington 1968; Przeworski and Limongi 1993; Przeworski et al. 2000). The assumption is that autocratic regimes that do not rely on popular support can enact a variety of unpopular policies that push up aggregate savings rates without losing power, while under democratic rule myopic voters will vote against an incumbent that reduces consumption at the expense of increased private and public investments focused on long-term benefits. Indeed, autocracies have higher average savings rates and, while not entirely robust across studies, compared to democracies their growth is fueled to a larger extent by investments in physical capital (Przeworski et al. 2000; Tavares and Wacziarg 2001).

\subsection{Theory}

The literature reviewed above suggests that autocracies may be more likely to adopt an industry-centered model of development than democracies. ${ }^{3}$ However, a theory for why this might be so has not been fully articulated.

We argue that autocratic leaders are more likely than democratic leaders to adopt an

\footnotetext{
${ }^{3} \mathrm{~A}$ democratic regime, for present purposes, is one where important policymaking positions are filled through regularly scheduled competitive elections before a broad electorate (Dahl 1971). An autocratic regime is one where electoral institutions are absent or monopolized by a single party, or where the franchise is extremely limited. For heuristic purposes, we refer to democracies and autocracies as crisp types in the ensuing discussion, even though these differences are often matters of degree (and will be operationalized accordingly in the empirical section of this paper).
} 
economic model of development centered on heavy industry. This follows from three factors that distinguish democratic and autocratic regimes: different social bases, different security concerns, and different policy tools. Together, these mechanisms suggest that autocracies have stronger incentives and better capabilities to pursue a rapid and comprehensive course of industrialization. Following this discussion, we introduce a number of important clarifications and caveats to the theory.

\section{Social Bases}

Work on regimes indicates that the constituency base of autocracies is narrower and more privileged than the constituency base of democracies (Ansell and Samuels 2014; Bueno de Mesquita et al. 2003). To the extent that incumbents try to please their constituency base in order to retain power, it follows that democratic leaders are more likely to be attracted to broad policies with many beneficiaries. This may include widely distributed pork that benefits large sections of their voting base or public goods that benefit everyone (Boix 2003; Brown and Hunter 2004; Gerring et al. 2005; Przeworski et al. 2000). Autocratic leaders, by contrast, must channel resources towards paying off those whose support, or acquiescence, is crucial for the regime's survival such as the military, leaders of industry, leading families or clans, and other elites (Bueno de Mesquita et al. 2003; Svolik 2012).

Industrial policies, which are inherently particularistic, are well-suited for this purpose. Consider the following policy mechanisms: tax incentives, low-interest loans, direct investments or subventions, expropriations of land, alterations in regulatory burdens, export subsidies, import tariffs, and repression of labor and civic organizations. Each bestows benefits upon specific industries - sometimes, specific corporations and their owners - while distributing costs across a much larger group of citizens and taxpayers.

Industrialization also favors a privileged sector of the economy - namely, the formal sector. As such, industrial policies are likely to reinforce existing inequalities (at least in the short-term), rewarding groups - i.e., the highly-skilled, well-educated, and urbandwelling - that are already relatively well off. In other instances, industrial policies may be targeted towards particular families or ethnic groups that the leader demands support from, as demonstrated by numerous case histories from post-colonial Africa (Meredith 2011). It follows that industrialization suits the constituency profile of autocratic leaders more than it suits the constituency profile of democratic leaders.

\section{Security}

Autocratic leaders are generally more concerned with security issues than democratic leaders. To begin with, democracies are more likely to have resolved border disputes with neighboring states (although the direction of causality is not clear Gibler 2007). Second, the tenures of autocratic leaders are much more sensitive to the outcome of various types of conflict, including inter-state war, than the tenures of democratic leaders (Chiozza and Goemans 2004). Losing a war means an increased likelihood of being ousted for autocrats and winning a war means increased chances of staying in power, 
whereas these relationships are less clear for democratic incumbents. Third, autocratic leaders are more threatened by internal dissent as they have no institutional mechanism for resolving conflicts over political power in a peaceful manner (Przeworski 1991). For all these reasons, autocratic leaders have a direct interest in channeling resources towards developing strong security capacities.

This, in turn, should incline them toward policies that help build industrial capacity.

Industrialization is critical to security, both when considering external and internal threats to the state and regime. Transport infrastructure - i.e., roads, railroads, bridges, harbors, and airports - serves to bind the nation together, integrating disparate groups and regions that may exhibit fissiparous tendencies. It also allows governments to deploy troops, materiel, and bureaucratic officials throughout the land, overcoming rough terrain. Railroads have been identified by military historians as a key factor in transporting troops and supplies. For example, Prussia constructed double-track railroad lines running to strategic points at the border, ensuring that they could assemble an army corps three to seven times faster than France during the Franco-Prussian war (Wavro 2003, p. 74).

Manufacturing capacity is also closely linked to military capacity. The production of iron and steel, and downstream products such as vehicles and guns, is a primary case in point. The ability to produce these products domestically - obviating potential disruptions in supply and mitigating conditions that might be imposed by a cautious supplier is regarded as a primary military objective. Sometimes, the goal of industrialization is explicitly linked to a country's self-defense. In Meiji Japan, building a strong, modern army that could fend of external security threats was, in the words of one historian, "the principal motivation behind creating and expanding the arsenals and other publicly-financed shipyards and modern factories which acted as highly effective centers for the absorption and dissemination of Western technologies and skills" (Yamamura 1977, p. 113).

Although Japan may be an extreme case, any country with a robust defense establishment is likely to foster a "military-industrial complex" of some sort (Koistinen 1980). In countries such as China the military plays a direct role in manufacturing (Fravel 2019). Elsewhere, the military is a key procurer of industrial products, thus directing the development of new technology and new industrial processes and products. And where the government is controlled by a military junta, or the military lurks as a power behind the throne, policy emphasis is often placed on the development of industry (Chambers and Waitoolkiat 2017; Robison 1988; Skidmore 1990; Smith 2015). All of this seems to point to the existence of a tight connection between security needs and industrialization within autocratic regimes.

\section{Policy Tools}

Having identified the varying incentives facing autocratic and democratic leaders we turn to the question of policy tools. Here, too, we find important differences. Perhaps the most consequential difference is that autocratic leaders have greater leeway to apply coercion, and thus to override opposition by force (see, e.g., Davenport 2007). This is 
important in the present context because industrialization policies and policy outcomes are rarely Pareto optimal. Generally, there are losers, at least in the short run. Indeed, for those who bear the brunt of industrialization the experience is violent and dislocating, both physically and psychologically. Industrialization is commonly associated with the displacement people from their ancestral homes, a steep (at least relative) decline in agricultural or informal sectors, rising unemployment in those sectors, dangerous workplaces, and environmental degradation. These developments are apt to engender opposition from political parties, consumers, agricultural organizations, trade associations, labor unions, neighborhood associations, and other affected groups (Aldrich 2008; Galtung 1996; McDowell 1996; Schumpeter 1942; Smelser 1959 [2011]; Thompson 1966).

Whether governments are able to overcome this opposition will affect the pace at which industrialization occurs. Following our argument about the social bases of regime types, autocratic leaders should be less sensitive to political opposition from the grassroots than democratically elected leaders. While autocrats may fear certain segments of the elite, opposition to industrialization is more likely to arise at the popular level - from people whose lives, homes, neighborhoods, or livelihoods are threatened by economic change. These constituents matter more to democratic leaders than to autocratic leaders. Moreover, autocratic leaders have the tools to win the contest by the application of brute force, i.e., by detaining, deporting, or assassinating opposition leaders, crushing demonstrations, and preventing the dissemination of critical reportage.

These same coercive tools can be used to implement aggressive and transformative industrial policies. Autocratic leaders may infringe upon property rights or upon wellestablished traditional rights so as to allow factories or vital infrastructure (e.g., dams, railroads, airports, energy plants) to be erected in areas where people previously lived and worked (Nielsen 2010; Sargeson 2013). They may remove price subsidies, import duties, and other regulatory supports for declining sectors, as well as statutorily fixed prices for commodities (e.g., energy or grain).

These actions are contentious, and may violate existing statutory law, constitutional law, or legal precedent, provoking opposition from the judiciary. However, rule of law, the independence of the judiciary, and the protection of private property rights are typically much weaker in autocracies than in democracies (Ansell and Samuels 2014; Helmke and Rosenbluth 2009), which strengthens the hand of autocratic rulers.

The cumulative effect of coercive policies should reduce costs for industry and thus hasten the process of industrialization. It is quicker and cheaper to seize land for a new factory or road than to wade through a lengthy process of procurement through legal channels from thousands of small owners, each of whom may set a different price, and to fight numerous legal and political fights that may arise from community groups and environmental groups that oppose the move. Note also that if opposition persists, courts are unsympathetic, or the support of elected officials is tenuous, police power may be essential to overcoming gridlock.

Finally, it is important to note the recursive nature of policy choice and policy implementation. If industrial policies are more difficult to implement in a democracy - due 
to legal processes of deliberation and norms of consent - it raises their cost, understood both as a pure economic cost and a political cost for politicians who might embrace those policies. If so, it follows that industrial policies are, everything else equal, less likely to be adopted by democratic leaders than autocratic ones.

\subsubsection{Clarifications and Caveats}

Before concluding, we want to make four important clarifications/caveats about the theory.

First, our argument is limited in ambition. It does not imply that other proposed causes of industrialization - including natural resources, cultural features, and particular industrial policies - are irrelevant. Indeed, they may be quite potent, but they are nonetheless orthogonal to our theory. It follows that there are many deviant cases, i.e., cases that do not fit the general relationship between regime type and industrialization that we have argued for, e.g., Sub-Saharan African autocracies that have not industrialized or democracies like England that have undergone extensive industrialization. Our goal is not to develop a comprehensive theory capable of explaining all the variation in industrialization across the modern era. Rather, we aim to explain some share of the variation by pointing to one general factor - namely regime type - that may be applicable across geographical and temporal contexts.

Second, the relationship between regimes and industrialization may be subject to temporal scope-conditions. One might argue, for example, that states played a less prominent role in early industrialization, e.g., in 18th and early-19th century England and Belgium. If so, we would expect that the posited relationship theory would apply weakly - if at all - in this era. As it happens, only one of our outcome measures of industrialization extends back to the early-19th century, and the sample at this point in time is small. None of our measures extends to the 18th century. So, this potential time-constraint is not directly testable.

Third, there may be important moderators in the relationship between regime-type and industrialization. For example, among democracies one might plausibly expect variation due to differences in electoral systems, as proportional representation systems often yield policies that are favorable to producer interests (Chang et al. 2010). Without losing sight of these sorts of complexities, we believe it is important to establish whether there is an aggregate "regime" effect, one that is applicable - with error - across the world in the modern era. We leave to future research the task of investigating nuances in this general relationship.

Finally, the expectation that autocracies experience stronger industrial development does not imply that autocracies also experience stronger GDP per capita growth. Many channels connect regime type to economic development, and democracies seem to enjoy advantages in other areas such as human capital or productivity growth (see studies cited at the outset), which may offset any disadvantages they experience in industrialization. Moreover, industrialization by itself does not always inaugurate long-term growth. In- 
deed, some notable examples of state-led industrialization including Mao's Great Leap Forward and import-substitution policies in Latin America may have had deleterious effects on long-term growth, and many industrial policies are expensive boondoggles (Keefer and Knack 2007). Our focus is therefore on that set of policies and policy outcomes identified with industrialization, which we regard as an interesting and important outcome in its own right.

\subsection{Data and model specification}

To operationalize industrialization we enlist four measures that tap into different aspects of this diffuse concept: railway freight, energy consumption, iron and steel production, and manufacturing value added. This mitigates possible measurement error while maximizing historical coverage, as some dimensions are measurable across a longer historical time-period than others. It also allows us to assess the robustness of findings across various aspects of industrialization that may not always move in tandem. Detailed descriptions of all variables, their sources, and definitions are available in Appendix Table 6.1 and summary statistics in Table 6.2.

Our first measure focuses on railways. Alongside the steam engine, the railway was perhaps the most visible embodiment of the industrial revolution. The first system to compete effectively with inland transportation by rivers and canals was the StocktonDarlington Railway in the UK, inaugurated in 1825. This revolutionary means of transporting goods and people soon spread to other countries in Europe and abroad, serving as a spur to industrialization everywhere (Tang 2014). The vast increase in inland transportationcapacity allowed for a general increase in production and consumption by reducing transaction costs associated with transporting goods and materials. Even today, trains remain a highly efficient mode of transporting heavy goods and a central medium of industrialization (Adler, Pels, and Nash 2010; Behrens and Pels 2012; Román, Espino, and Martín 2007). As an indicator of industrialization, we want to know how much freight railways carried, not merely the distance that they cover. Accordingly, we focus on railway freight that is transported within a country, excluding livestock and passenger baggage. This is measured by the ton-kilometer and transformed by the natural logarithm. ${ }^{4}$

As a second measure of industrialization we use primary energy consumption, measured as thousands of coal-ton equivalents (once again we transform by the natural logarithm), gathered from the Correlates of War (COW) dataset (Sarkees and Wayman

\footnotetext{
${ }^{4}$ More precisely, we transform this and other variables discussed below by taking $\ln (\mathrm{X}+1)$, thus ensuring that our dependent variables are always positive. This transformation helps us deal with the strongly right-skewed nature of these variables. This also follows the plausible assumption that an increase in, e.g., rail transport from 0 to 1000 ton-kilometers is a more substantial change than going from 100000 to 101000 ton-kilometers. Regarding this specific dependent variable, we note that freight for servicing of railroads is typically excluded but may be included for some countries. Yet, we also note that as long as such definitional characteristics are constant for a country over time, they should be addressed by our inclusion of country fixed effects in the regression analysis, and thus hopefully not affect results.
} 
2010). Energy usage is directly connected to activities associated with industrialization. For example, the development of railroads and factories will increase primary energy consumption. Worldwide, industry accounts for roughly $50 \%$ of the world's energy consumption, a figure that has been fairly constant for as long as such statistics have been produced (BP 2018, p. 14). Thus, energy consumption offers a good proxy for industrialization.

A third measure captures a key industrial output, which, like energy, is simultaneously a central input for production processes in various industries. This is the production of iron and steel, measured as a state's production of pig iron (1816-1899) and steel (1900-2012), drawn from COW (Sarkees and Wayman 2010), and transformed by the natural logarithm. ${ }^{5}$ Of course, the production of iron and steel is ultimately dependent on an abundance of minerals (primarily iron ore, but also coal), which is unequally distributed between nations. Consequently, this measure has many zero-observations, where we cannot effectively differentiate between the lack of natural resources and the lack of necessary investments. However, if we are willing to assume that deposits of iron ore and coal are randomly assigned across countries, or at least not an independent cause in regime outcomes, this will increase the standard errors but not bias the estimated coefficients. (We thus also conduct robustness tests omitting all zero-observations.)

Our fourth and final measure captures the share of total production that emanates from the manufacturing sector. More specifically, it measures manufacturing value added, or the net output of this sector after adding up all outputs and subtracting intermediate inputs, as percent of a country's total GDP, drawn from the World Development Indicators (WDI) of the World Bank. This is our most comprehensive measure of manufacturing, though it extends back only to 1960.

To measure democracy we draw on the Polyarchy index (Teorell et al. 2018) from the Varieties of Democracy (V-Dem) project (Coppedge et al. 2018). This index includes components measuring whether or not the executive is (directly or indirectly) elected, the freeness and fairness of elections, freedom of association, freedom of speech, and the extent of voting rights. With the recent historical extension of V-Dem (Knutsen et al. 2019b), we are able to extend this finely grained measure of democracy back to the French Revolution for most sovereign (and some semi-sovereign) countries.

Insofar as regime type affects industrialization, it is likely to do so through both short- and long-term channels. Government policies such as tariffs may affect business decisions in the near term, impacting the level of industrialization a few years later. Other policies, such as the construction of a nuclear plant, may take years to bring to fruition, with secondary effects on the economy that extend through the next half-century as the plant generates electrical power. Thus, we consider a country's level of industrialization in year $\mathrm{t}$ as the product of its regime history, extending back a century or more with some

\footnotetext{
${ }^{5}$ We note that the inclusion of year-fixed effects in the regressions below, should, in theory, mitigate issues with the time-period specific aspect of the operationalization driving our results. In any case, we also note that iron and steel production is the dependent variable where we find the least robust results for regime type.
} 
(difficult to specify) level of depreciation (so that more recent years are accorded greater weight). To do so, we construct a stock version of Polyarchy with a slow depreciation rate of $1 \%$ annually in our benchmark model. While we prefer a slow depreciation rate that gives historical experiences relatively strong weight for theoretical reasons, the specific discount factor will inevitably be arbitrary. Yet, in opting for $1 \%$ as the benchmark, we follow the study by Gerring et al. (2005) on democracy and growth, and we also experiment with other depreciation rates $(5 \%$ and $10 \%)$ in later robustness tests. We also run models using only the current level of Polyarchy (lagged) in order to shed light on short-term effects.

Our benchmark specification treats country-years as units of analysis, analyzed in an ordinary least squares (OLS) model with country- and year-fixed effects. Right-side variables are lagged five years behind the outcome in an attempt to reduce problems of simultaneity. Standard errors are clustered by country in order to mitigate concerns about panel-level serial correlation. ${ }^{6}$

The inclusion of the country-fixed effects is vital for our purposes. Holding countryspecific factors constant allows us to side-step key questions about whether certain countries (such as the UK) were inherently better positioned to experience an industrial transformation than other countries (such as China) by reason of static features such as geography, culture, or historical developments that occurred prior to 1800 (Landes 1998; Pomeranz 2000; Clark 2007). Control for time-invariant factors at the countrylevel means that, for instance, differential endowments of resources such as coal or iron that are deemed critical for certain types of industrialization (e.g., Pomeranz 2000), and which may also influence prospects for democratization (e.g., Ross 2012), are accounted for. (We also measure energy resource wealth separately in order to account for the discovery and development of these latent resources.)

Year fixed-effects should account for major global shocks - for example in the form of industrial innovations or construction technologies - that may influence the costs and payoffs of investing in industrial infrastructure (and which may correlate with regime type).

In addition, we control for income and population levels, both of which may systematically influence the propensity to industrialize as well as the regime type in a country. In robustness tests we control for additional possible confounders, such as urbanization, but we keep our benchmark specification sparse in order to mitigate post-treatment bias (an expansion of the manufacturing sector likely affects migration to the cities, and hence urbanization). A full description of the data, and data sources, is provided in Appendix Table 6.1.

\footnotetext{
${ }^{6}$ We remark that for all outcome variables that are transformed by the natural logarithm, the estimated effect of a one unit increase in the democracy stock measure is a change in the outcome of $(e \beta-1) \times 100 \%$, where $\beta$ is the regression coefficient for democracy stock.
} 


\subsection{Results}

Models 1-4 in Table 2.1 represent the benchmark specification for our four outcomes. Model 1 employs railway freight measure as dependent variable, and includes 5,476 country-year observations from 92 countries, with time series extending from 1852-1993. The two time-varying controls, Ln GDP per capita and Ln Population (both taken from Fariss et al. 2017, see Appendix Table 6.1), have the expected sign, as richer and more populous countries predict more goods being transported by railway. Concerning our main hypothesis that autocracy is positively related to industrialization, we find that the democracy stock measure, based on Polyarchy and with a $1 \%$ depreciation rate, has the expected sign. The coefficient is also precisely estimated with a t-value of -2.50 .

In order to gauge the substantive size of the estimated effect, consider two otherwise similar countries, $A$ and $B$, that start out with 0 in democratic stock, reflecting histories of harsh autocratic rule. At year $t$, country $A$ experiences a democratic transition, increasing the Polyarchy score to 0.8 (about the score of United Kingdom in the 1950s or presentday Taiwan), and maintains that score until year $t+10$ (leading to a Polyarchy stock of 8.37). These divergent histories would, according to the point estimates of Model 1, lead to Country $B$, which maintained its autocratic regime, having about 49 percent more railway freight than Country $A$ in year $t+15 .^{7}$ While we underscore that this point estimate is associated with a lot of uncertainty, the best guess from our benchmark specification thus suggests that regime type matters quite a lot for this indicator of industrialization.

Results are even stronger, both in terms of coefficient size and absolute t-value, for the energy consumption measure in Model 2. This result draws on a total of 13291 countryyear observations from 175 countries, with time series running from 1816 to 2012, and provides further support for the notion that autocratic regimes are associated with more rapid industrialization.

Iron and steel production, the outcome in Model 3, is also negatively related to democracy stock, following our expectations, although the coefficient on democracy stock is here is only close to statistically significant at the 10 percent level with a t-value of -1.63 . We discuss possible methodological issues behind the weak result below, pertaining to many 0-observations and measurement errors, and report alternative tests that mitigate these issues in the appendix (e.g., Appendix Table 6.9). Yet, even in the benchmark the point estimate is substantial: When comparing the two hypothetical countries A and B from above - where A undergoes a democratization from 0 to 0.8 on Polyarchy in year $\mathrm{t}$ whereas B remains autocratic - Model 3 predicts that country B will have an iron and steel production volume that exceeds that of country A by 24 percent in year $t+15$.

Results are much clearer when broadening our focus from iron and steel production to manufacturing production, more generally. The point estimate in Model 4 predicts that, for the hypothetical comparison between the democratizing country A and the

\footnotetext{
${ }^{7}$ The prediction pertains to $t+15$ rather than $t+10$, since the outcome is measured five years after the covariates.
} 


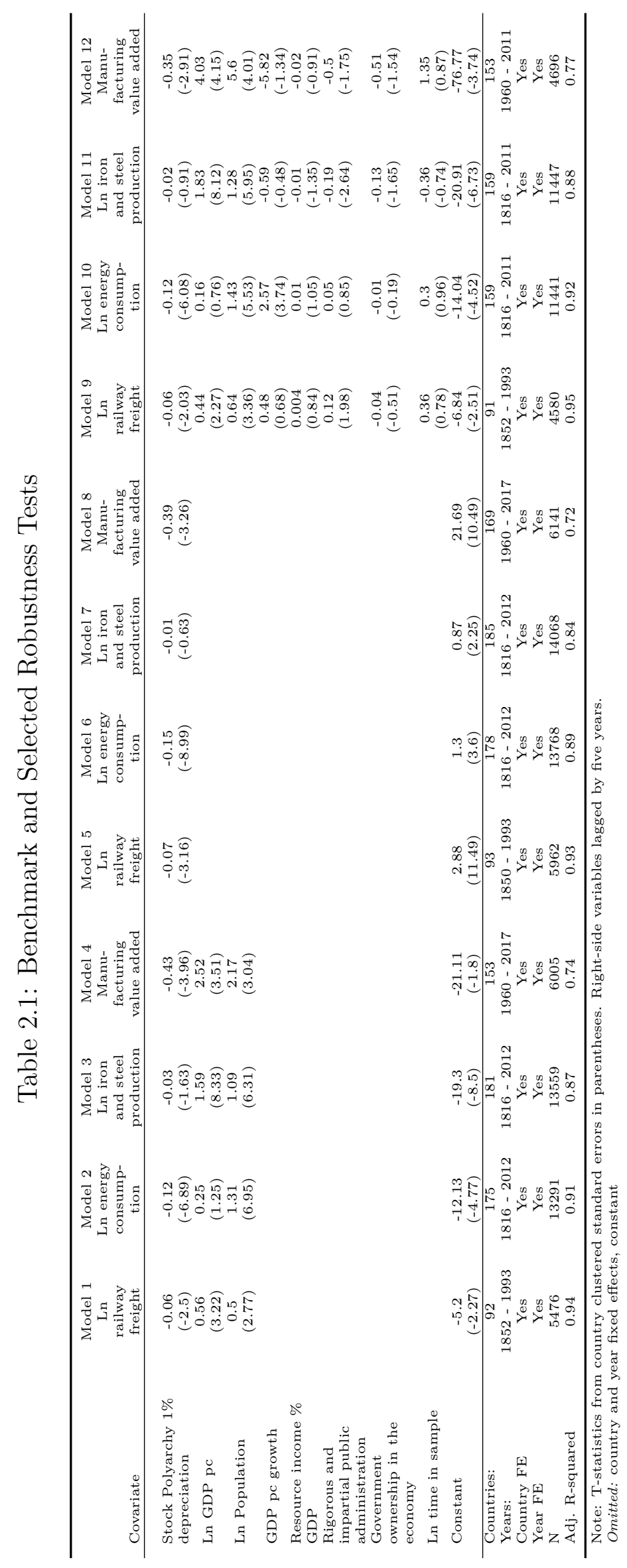


autocratic country B, B would have about 3 percent more of its total GDP coming from manufacturing production in year $t+15$. The coefficient on manufacturing value added as share of GDP is highly significant $(\mathrm{t}=-3.96)$.

We ran a large number of alternative specifications to check the sensitivity of our results. We highlight from the outset that the benchmark is fairly representative in the sense that, while consistently negative, the results for iron and steel production are associated with much uncertainty, and regime type is not robust for this outcome. When we - for reasons outlined below - later employ a set-up with 5- and 10-year averages, however, regime type is clearly related to iron and steel production. We turn now to discussing our alternative specifications in more detail, and start by assessing potential issues of post-treatment- or omitted variable bias.

Models 5-8 in Table 2.1 represent one such specification. Here, we drop the controls for both income and population. While this risks introducing omitted variable bias, the rationale is that both factors are possibly endogenous to regime type (Przeworski et al. 2000). Controlling for these variables could thus introduce post-treatment bias for the regime coefficient. Yet, results are fairly similar in this very parsimonious specification that controls only for country- and year-fixed effects.

The specification used for Models 9-12, Table 2.1, in contrast, privilege mitigating omitted variable bias by adding measures of other plausible confounders to the benchmark. More specifically, we include measures of economic growth (GDP p.c. growth rate from t-1 to t) and natural resource dependence (oil, natural gas and mineral income as share of GDP). Next we want to ensure that the relationship between regime type and industrialization is not merely a spurious finding reflecting systematic differences in state capacity or the state's overall role in the economy. Thus, we control for indicators of bureaucratic quality (the extent to which the public administration is impartial and rule-following) and government ownership in the economy. Finally, we condition on the number of years a country has been included in the sample. This variable is added mainly to account for a potential trend in industrialization being related to low democracy stock scores, by construction, appearing early in a country's history. The democracy stock coefficient is stable in size and remains statistically significant at least at the $5 \%$ level for railway freight, energy consumption, and manufacturing as share of GDP. The sign of the democracy stock coefficient remains negative also for iron and steel production in Model 6, but the coefficient is attenuated and insignificant at any conventional level when adding the above-described controls $(t=-0.91)$.

Thus, the result that autocracy is systematically related to industrialization is not entirely robust across all our outcome measures. Yet, the overall pattern is fairly consistent and in line with our theoretical expectations. This pattern is perhaps even more notable when contrasting the findings on our measures capturing different aspects of industrialization with findings from similar specifications on other outcome variables. We turn now to such alternative tests, reported in Table 2.2, where we either anticipate no relationship or a positive relationship with democracy, before we later return to additional specification tests on our measures of industrialization. 
First, and in line with the expectations that democracies prioritize human capital (thus giving more productive workers, likely to earn higher wages) and that autocracies may also suppress wages (e.g., through suppressing unions and freedom of association more generally) in order to attract industrial activity, we find that democracies pay higher wages (see also, e.g., Rodrik 1999). The Polyarchy stock measure is positive, and highly significant with a t-value of 7.4 .

Our theoretical argument focused on how autocratic and democratic regimes would prioritize differently when it comes to setting public policy, with autocratic regimes allocating more funding and attention towards activities and investments that might help boost industrialization. In this regard, we note that Model 2 suggests that the abovereported relationship between autocracy and industrialization is not simply a reflection of higher levels of public spending in general. In fact, we find that democracies have higher public spending as share of GDP, and this relationship is also highly significant (t-value of 6.4). Thus, insofar as the diverging industrialization experiences of autocratic and democratic regimes are driven by systematic differences in the policies pursued, they reflect the prioritization of public spending on industrial infrastructure and projects in autocracies over other forms of spending such as social welfare- or education spending (see, e.g., Lindert 2004). ${ }^{8}$

Table 2.2: Alternative tests

\begin{tabular}{|c|c|c|c|}
\hline Covariates & $\begin{array}{l}\text { Model } 1 \\
\text { Laborer real wage }\end{array}$ & $\begin{array}{c}\text { Model } 2 \\
\text { Public expenditure as \% of GDP }\end{array}$ & $\begin{array}{c}\text { Model } 3 \\
\text { Agriculture as \% workforce }\end{array}$ \\
\hline Stock Polyarchy & 1.98 & 0.76 & 0.2 \\
\hline $1 \%$ depreciation & $(7.45)$ & $(6.41)$ & $(1.5)$ \\
\hline \multirow{2}{*}{ Ln GDP pc } & 6.36 & 0.43 & -6.48 \\
\hline & $(1.24)$ & $(0.29)$ & $(-5.66)$ \\
\hline \multirow{2}{*}{ Ln population } & -6.45 & -3.91 & -8.2 \\
\hline & $(-1.53)$ & $(-2.04)$ & $(-4.23)$ \\
\hline \multirow[t]{2}{*}{ Constant } & 20.61 & 36.66 & 208.62 \\
\hline & $(0.34)$ & $(1.6)$ & $(11.38)$ \\
\hline Countries: & 117 & 155 & 154 \\
\hline Years: & $1820-2008$ & $1880-2011$ & $1815-2006$ \\
\hline Country FE & Yes & Yes & Yes \\
\hline Year FE & Yes & Yes & Yes \\
\hline $\mathrm{N}$ & 3609 & 6740 & 10107 \\
\hline Adj. R-squared & 0.77 & 0.78 & 0.92 \\
\hline
\end{tabular}

Note: T-statistics from country clustered standard errors in parentheses.

Right-side variables lagged by five years.

Omitted: country and year fixed effects, constant

Finally, we test a measure with extensive coverage (1815-2006) that could be construed as an 'anti-industrialization' measure, namely share of the workforce that works in agriculture. However, we immediately note that this is not a perfect inverse relationship between how extensive agriculture in a society is and how small the manufacturing sector is. Notably, the service sector is, often by far, the largest employer in many contemporary

\footnotetext{
${ }^{8}$ We cannot rule out, however, that differences in industrial output reflect that the development of industrial infrastructure is less costly in an autocracy, for example through lower wages, and thus labor costs. If so, it would be in line with the 'coercion'-mechanism outlined in the theory section.
} 
societies, so a small agricultural sector can co-exist with a small manufacturing sector. Still, on average, we would expect countries with larger agricultural sectors to have smaller manufacturing sectors. Indeed, we find that our Polyarchy stock measure is positively correlated with employment in agriculture, as expected. However, the coefficient falls short of conventional levels of statistical significance.

We return now to our four core dependent variables tapping into different aspects of industrialization and discuss the robustness of these findings to different specification choices. We start out with our specification of the democracy stock variable. As we discussed, the choice of a 1 percent depreciation rate was done in order to privilege long-term effects of regime type. However, the choice of exact rate is inherently arbitrary, and we therefore assess the extent to which this choice drives results. We also want to test specifications that strike a different balance between capturing and weighting historical/long-term effects versus short-term effects, by privileging the latter more strongly.

The relevant results are reported in Appendix Table 6.3, where Models 1-4 replicate the benchmark for the four different measures of industrialization, but with a $5 \%$ depreciation rate. Models 5-8 prioritize recent regime features even more by using a 10\% depreciation rate for calculating the Polyarchy stock measure. In all these specifications, Polyarchy stock is negatively signed. The t-values are comparatively weaker when iron and steel production is the dependent variable $(-1.23$ for $5 \%$ depreciation rate and -1.01 for $10 \%$ depreciation rate), whereas results are significant at least at the $10 \%$ level for all three other measures. The most robust results are those for energy consumption, with t-values of -4.35 (5\% stock) and -3.64 (10\% stock). Finally, Models 9-12, Table 6.3 presents the specification with a simple level measure of democracy (Polyarchy score measured 5 years before the outcome variables), thereby capturing only shorter-term effects. Once again, the signs of the relationships are consistently in the expected direction, and the negative Polyarchy level coefficients are significant at the $10 \%$ level for railway freight $(\mathrm{t}=-1.94)$ and at the $1 \%$ level for energy consumption $(\mathrm{t}=-3.31$ ( and manufacturing as share of GDP $(\mathrm{t}=-6.82)$. The $\mathrm{t}$-value for Polyarchy in Model 11 on Iron and steel production is -0.89 , falling short of conventional levels of significance.

While the above-discussed specifications assessed sensitivity to assumptions about the weighting of historical vs more contemporary effects of regime type, we also deal with the issue of ambiguous expectations on timing by trying out different lag-specifications. In the benchmark, the outcomes are measured five years after the covariates. In Appendix Figure 6.1, we show that the results - both in terms of coefficient sizes and t-values - are very stable to varying the time lag, measuring the outcomes between $t+1$ and $t+9$.

Regarding the choice of democracy measure and construction of democracy stock, we find that results from the benchmark are equivalent to the benchmark models if we invert the Polyarchy measure and construct an equivalent "autocracy stock" measure. We also tested alternative operationalizations of democracy (see Table 6.6). When we employ Lexical Index of Democracy from Skaaning, Gerring, and Bartusevičius (2015) rather than Polyarchy to construct democracy stock, it falls short of statistical significance 
for iron and steel production and manufacturing value added. But, when we use the dichotomous electoral democracy measure from Boix, Miller, and Rosato (2013), we once again find clear results for railway freight, energy consumption, and manufacturing value added.

Results are also quite stable to altering the sample, and omitting particular countries and regions that one might expect could drive the overall relationship. For example, the benchmark specification shows that democracy stock is negative with t-values of, respectively, $-2.5,-7.1,-1.5$ and -3.5 for railway freight, energy consumption, iron and steel production, and manufacturing value added once we omit all countries coded by La Porta et al. (1999) to have a Socialist legal origin (Table 6.8). This alleviates concerns that the correlations between autocracy and measures of industrialization simply reflected the rapid industrialization experiences of Communist countries such as the Soviet Union and China. More generally, the results are not simply due to countries in one particular geographic region - such as East Asia - achieving industrialization under less democratic regimes. With one exception (removing Europe for the iron and steel regression), the estimated coefficient for democracy stock is always negative, for all four outcome measures, no matter which region of the world we exclude from the benchmark. Additional results, presented in Appendix Figures 6.2-6.5 alongside the results for specifications omitting entire regions, show that the results are also stable to omitting any single country from the regressions.

We opted to test our expectations on four quite different measures, tapping into various key aspects of industrialization. The least robust result is for the measure on Ln iron and steel consumption, although we remind that the result is always negative and substantial in size and sometimes statistically significant at conventional levels. One plausible reason for the lack of robustness pertains to measurement errors in this variable, which extends back to $1816 .^{9}$ Data for any single year may be over-reported or under-reported. If this measure error is unsystematic, we should not expect any bias in the democracy stock coefficient. But the standard errors should be overestimated, thus making it more likely that we conduct Type II errors (i.e., falsely rejecting a relationship for a given level of significance). One way to mitigate such measurement error is to average across broader time periods, as over-reporting of production in one year carries less weight and may even be cancelled out by under-reporting in another year.

Thus, we ran regression specifications with 5 or 10 -year periods as the relevant time unit, averaging across our variables for each period and lagging the covariates one period before the outcomes. While such specifications may overlook relevant information stemming from (real) short-term changes to regime type and the outcomes, another ben-

\footnotetext{
${ }^{9}$ Another potential explanation is that Ln iron and steel production is far from normally distributed, and that there may be violations to the assumptions of the OLS model. More specifically, a large number of observations are clustered at the value 0 , reflecting that many countries, at least over long time intervals, did not produce any iron or steel (or produced insufficient quantities of iron and steel to register on our variable). When omitting all the zero observations, and re-running our benchmark on the observations with positive values on the iron and steel variable, reported in Table 6.9, democracy stock remains negative and the relationship turns clearer with a t-value of -4.9.
} 
efit (often highlighted by economists who favor such specifications) is that using longer panels further reduces autocorrelation issues, thus giving more accurate hypothesis tests. Non-modeled changes in outcomes are larger from one decade to the next than from one year to the next

The 5- and 10-year panel results are reported in Table 2.3. The point estimates are remarkably similar to in the benchmark specifications presented in Table 2.1. Interestingly, democracy stock is statistically significant at least at the $5 \%$ level for all four outcome variables, both when using the 5-year panels and when using the 10-year panels.

Table 2.3: Taking averages across longer time intervals

\begin{tabular}{|c|c|c|c|c|c|c|c|c|}
\hline Covariate & $\begin{array}{l}\text { Model } 1 \\
\text { Ln } \\
\text { railway } \\
\text { freight } \\
\end{array}$ & $\begin{array}{l}\text { Model } 2 \\
\text { Ln energy } \\
\text { consump- } \\
\text { tion } \\
\end{array}$ & $\begin{array}{l}\text { Model } 3 \\
\text { Ln iron } \\
\text { and steel } \\
\text { production } \\
\end{array}$ & $\begin{array}{c}\text { Model } 4 \\
\text { Manu- } \\
\text { facturing } \\
\text { value added }\end{array}$ & $\begin{array}{l}\text { Model } 5 \\
\text { Ln } \\
\text { railway } \\
\text { freight } \\
\end{array}$ & $\begin{array}{l}\text { Model } 6 \\
\text { Ln energy } \\
\text { consump- } \\
\text { tion } \\
\end{array}$ & $\begin{array}{c}\text { Model } 7 \\
\text { Ln iron } \\
\text { and steel } \\
\text { production } \\
\end{array}$ & $\begin{array}{c}\text { Model } 8 \\
\text { Manu- } \\
\text { facturing } \\
\text { value added }\end{array}$ \\
\hline $\begin{array}{l}\text { Stock Polyarchy } 1 \% \\
\text { depreciation }\end{array}$ & $\begin{array}{l}-0.06 \\
(-2.62)\end{array}$ & $\begin{array}{l}-0.12 \\
(-7.03)\end{array}$ & $\begin{array}{l}-0.04 \\
(-2.19)\end{array}$ & $\begin{array}{l}-0.32 \\
(-3.14)\end{array}$ & $\begin{array}{l}-0.06 \\
(-2.59)\end{array}$ & $\begin{array}{l}-0.12 \\
(-6.62)\end{array}$ & $\begin{array}{l}-0.05 \\
(-2.46)\end{array}$ & $\begin{array}{l}-0.28 \\
(-2.58)\end{array}$ \\
\hline Ln GDP pc & $\begin{array}{l}0.58 \\
(3.03)\end{array}$ & $\begin{array}{l}0.37 \\
(1.75)\end{array}$ & $\begin{array}{l}1.66 \\
(7.88)\end{array}$ & $\begin{array}{l}2.74 \\
(3.1)\end{array}$ & $\begin{array}{c}0.5 \\
(2.62)\end{array}$ & $\begin{array}{c}0.28 \\
(1.28)\end{array}$ & $\begin{array}{l}1.69 \\
(8.27)\end{array}$ & $\begin{array}{l}2.97 \\
(2.97)\end{array}$ \\
\hline Ln population & $\begin{array}{c}4.92 \\
(2.42)\end{array}$ & $\begin{array}{l}11.81 \\
(7.67)\end{array}$ & $\begin{array}{c}7.26 \\
(4.26)\end{array}$ & $\begin{array}{l}25.19 \\
(2.89)\end{array}$ & $\begin{array}{c}3.42 \\
(1.78)\end{array}$ & $\begin{array}{l}10.08 \\
(6.47)\end{array}$ & $\begin{array}{l}7.77 \\
(4.64)\end{array}$ & $\begin{array}{l}26.53 \\
(2.63)\end{array}$ \\
\hline Constant & $\begin{array}{l}-11.38 \\
(-2.26) \\
\end{array}$ & $\begin{array}{r}-26.83 \\
(-6.47) \\
\end{array}$ & $\begin{array}{l}-25.57 \\
(-5.73) \\
\end{array}$ & $\begin{array}{c}-60.4 \\
(-2.38) \\
\end{array}$ & $\begin{array}{c}-6.86 \\
(-1.46) \\
\end{array}$ & $\begin{array}{l}-22.39 \\
(-5.42) \\
\end{array}$ & $\begin{array}{l}-26.87 \\
(-6.08) \\
\end{array}$ & $\begin{array}{c}-64.58 \\
(-2.3) \\
\end{array}$ \\
\hline Countries: & 92 & 175 & 181 & 165 & 92 & 175 & 181 & 165 \\
\hline Years: & $1853 \quad 1989$ & $1818 \quad 2009$ & $1818 \quad 2009$ & $1963 \quad 2014$ & $1858 \quad 1989$ & $1818 \quad 2009$ & $1818 \quad 2009$ & $1968 \quad 2009$ \\
\hline Averages: & 5-year & 5-year & 5-year & 5-year & 10-year & 10-year & 10-year & 10-year \\
\hline Country FE & Yes & Yes & Yes & Yes & Yes & Yes & Yes & Yes \\
\hline Year FE & Yes & Yes & Yes & Yes & Yes & Yes & Yes & Yes \\
\hline $\mathrm{N}$ & 1180 & 2779 & 2836 & 1304 & 647 & 1494 & 1524 & 682 \\
\hline Adj. R-squared & 0.94 & 0.91 & 0.87 & 0.73 & 0.94 & 0.9 & 0.87 & 0.72 \\
\hline
\end{tabular}

Finally, in Table 2.4, we replicate the set-up in Table 2.3, but include the lagged dependent variable as regressor in each specification. By doing so, we want to further mitigate concerns about omitted confounders correlating with any flexible, country-specific trend in both our main independent and dependent variables. As such, these models estimate the effect of a change in Polyarchy stock at $t$ on the change in our industrialization measures from $t$ to either $t+5$ or $t+10$.

Once again, the coefficients are consistently negative across all our four measures of industrialization, for both the 5-year and 10-year specifications. Results are not robust for the railway measure when including the lagged dependent variable, however, as the standard errors are larger than the coefficient estimates. In contrast, results are very clear for the three other measures, with t-values ranging between -3.4 and -5.8 for energy consumption, iron and steel production, and manufacturing as share of GDP.

The results are virtually identical when we substitute the $1 \%$ depreciation rate version of Polyarchy stock with a 5\% depreciation rate (see Appendix Table 6.4). Thus, even when weighting historical regime characteristics less strongly, we find that autocracy is systematically related to larger subsequent increases in energy consumption, iron and steel production and manufacturing as share of income. Finally, since there may be more complex dynamics in the outcome variable, and past realizations of industrialization may affect regime type, we also tested specifications with multiple lags of the dependent variable as regressor (Appendix Table 6.5). This control strategy should further mitigate 
Table 2.4: Including the lagged dependent variable as regressor

\begin{tabular}{|c|c|c|c|c|c|c|c|c|}
\hline Covariate & $\begin{array}{l}\text { Model } 1 \\
\text { Ln } \\
\text { railway } \\
\text { freight } \\
\end{array}$ & $\begin{array}{c}\text { Model } 2 \\
\text { Ln energy } \\
\text { consump- } \\
\text { tion } \\
\end{array}$ & $\begin{array}{l}\text { Model } 3 \\
\text { Ln iron } \\
\text { and steel } \\
\text { production } \\
\end{array}$ & $\begin{array}{c}\text { Model } 4 \\
\text { Manu- } \\
\text { facturing } \\
\text { value added }\end{array}$ & $\begin{array}{l}\text { Model } 5 \\
\text { Ln } \\
\text { railway } \\
\text { freight } \\
\end{array}$ & $\begin{array}{c}\text { Model } 6 \\
\text { Ln energy } \\
\text { consump- } \\
\text { tion } \\
\end{array}$ & $\begin{array}{c}\text { Model } 7 \\
\text { Ln iron } \\
\text { and steel } \\
\text { production } \\
\end{array}$ & $\begin{array}{c}\text { Model } 8 \\
\text { Manu- } \\
\text { facturing } \\
\text { value added }\end{array}$ \\
\hline $\begin{array}{l}\text { Stock Polyarchy } 1 \% \\
\text { depreciation }\end{array}$ & $\begin{array}{c}-0.01 \\
(-1.33)\end{array}$ & $\begin{array}{c}-0.02 \\
(-5.46)\end{array}$ & $\begin{array}{l}-0.01 \\
(-2.86)\end{array}$ & $\begin{array}{l}-0.13 \\
(-2.9)\end{array}$ & $\begin{array}{l}-0.01 \\
(-0.94)\end{array}$ & $\begin{array}{l}-0.04 \\
(-5.11)\end{array}$ & $\begin{array}{l}-0.03 \\
(-2.83)\end{array}$ & $\begin{array}{l}-0.25 \\
(-2.92)\end{array}$ \\
\hline Ln GDP pc & $\begin{array}{c}0.13 \\
(1.91)\end{array}$ & $\begin{array}{c}-0.02 \\
(-0.41)\end{array}$ & $\begin{array}{l}0.28 \\
(4.35)\end{array}$ & $\begin{array}{l}1.11 \\
(2.6)\end{array}$ & $\begin{array}{c}0.15 \\
(1.28)\end{array}$ & $\begin{array}{l}-0.06 \\
(-0.54)\end{array}$ & $\begin{array}{c}0.5 \\
(4.22)\end{array}$ & $\begin{array}{l}1.67 \\
(2.29)\end{array}$ \\
\hline Ln population & $\begin{array}{c}0.21 \\
(0.33)\end{array}$ & $\begin{array}{c}1.97 \\
(4.69)\end{array}$ & $\begin{array}{c}2.51 \\
(5.41)\end{array}$ & $\begin{array}{c}8.75 \\
(2)\end{array}$ & $\begin{array}{l}-0.38 \\
(-0.35)\end{array}$ & $\begin{array}{c}3 \\
(3.78)\end{array}$ & $\begin{array}{l}4.22 \\
(5.13)\end{array}$ & $\begin{array}{l}14.08 \\
(1.55)\end{array}$ \\
\hline Lagged D.V. & $\begin{array}{c}0.82 \\
(26.51)\end{array}$ & $\begin{array}{c}0.81 \\
(44.16)\end{array}$ & $\begin{array}{c}0.86 \\
(63.19)\end{array}$ & $\begin{array}{c}0.64 \\
(15.71)\end{array}$ & $\begin{array}{c}0.7 \\
(12.88)\end{array}$ & $\begin{array}{l}0.66 \\
(18.3)\end{array}$ & $\begin{array}{c}0.74 \\
(29.35)\end{array}$ & $\begin{array}{l}0.45 \\
(7.86)\end{array}$ \\
\hline Constant & $\begin{array}{l}0.65 \\
(0.4)\end{array}$ & $\begin{array}{c}-3.73 \\
(-3.31)\end{array}$ & $\begin{array}{c}-7.09 \\
(-5.87)\end{array}$ & $\begin{array}{l}-21.02 \\
(-1.71)\end{array}$ & $\begin{array}{c}2.37 \\
(0.85)\end{array}$ & $\begin{array}{c}-5.25 \\
(-2.54)\end{array}$ & $\begin{array}{l}-12.05 \\
(-5.53)\end{array}$ & $\begin{array}{l}-32.84 \\
(-1.41)\end{array}$ \\
\hline $\begin{array}{l}\text { Countries: } \\
\text { Years: } \\
\text { Averages: }\end{array}$ & $\begin{array}{c}91 \\
1858 \quad 1989 \\
5 \text {-year }\end{array}$ & $\begin{array}{c}175 \\
1823 \quad 2009 \\
5 \text {-year }\end{array}$ & $\begin{array}{c}181 \\
1823 \quad 2009 \\
5 \text {-year }\end{array}$ & $\begin{array}{c}165 \\
1968 \quad 2014 \\
5 \text {-year }\end{array}$ & $\begin{array}{c}1 \\
1868 \quad 1989 \\
10-\text { year }\end{array}$ & $\begin{array}{c}175 \\
1828 \quad 2009 \\
10-\text { year }\end{array}$ & $\begin{array}{c}181 \\
1828 \quad 2009 \\
10 \text {-year }\end{array}$ & $\begin{array}{c}161 \\
1978 \quad 2009 \\
10-\text { year }\end{array}$ \\
\hline Country FE & Yes & Yes & Yes & Yes & Yes & Yes & Yes & Yes \\
\hline Year FE & Yes & Yes & Yes & Yes & Yes & Yes & Yes & Yes \\
\hline $\mathrm{N}$ & 1096 & 2638 & 2694 & 1143 & 575 & 1364 & 1393 & 538 \\
\hline Adj. R-squared & 0.99 & 0.98 & 0.97 & 0.89 & 0.98 & 0.96 & 0.94 & 0.84 \\
\hline
\end{tabular}

risks of omitted variable bias as well as concerns of autocorrelation (see Acemoglu et al. 2019). Our main result turns out robust also to this estimation strategy.

\subsection{Conclusion}

We have proposed that countries that are governed by autocratic regimes are more likely to experience a substantial industrialization of their economies than democratically governed countries. The argument leading to this expectation rests on the differences in incentives facing autocratic and democratic leaders - leading autocratic leaders to prioritize policies that aid industrialization more heavily - as well as a difference in the capacity to enact measures that lead to industrialization. More specifically, we pointed to three likely mechanisms pertaining to the added importance of security issues and particularism in autocracies as generating incentives for industrialization, and, as regards capabilities, the more coercive nature of autocratic politics as conducive to transforming the economy towards more industrial production.

We leveraged four (quite different) measures of industrialization, with some time series running back to the early 19th century (when only Britain could be considered an industrialized economy). We also tested different measures of democracy, but mainly relied on a stock measure of (electoral) democracy that accounts for the likely drawn-out effect of regime type on industrialization. When doing so, we find support for the hypothesis that autocracy is conducive to industrialization. While our results are not entirely robust across specifications and outcome measures, the weight of the evidence supports the relationship anticipated from our argument suggesting that autocratic regimes may serve as handmaidens of industrialization. 



\title{
3 Democracy and public services: Evidence from postal services
}

\begin{abstract}
:
The causal relationship between political regime type and public services has been subject to decades of scholarly debate and numerous empirical investigations. Different theories make different predictions on how institutions will lead political elites to make different economic priorities. Many of the empirical proofs rely on data that are self-reported by governments. But these data are known to suffer from measurement error that is especially problematic when answering questions about regimes and leaders' incentives. Using novel data on the quality of postal services, which do not suffer from any of these validity-issues, I show that postal services in democracies deliver significantly better services, responding to somewhere between 20 and 40 percentage points more letters. The effect is not driven by any single country or region, is not driven by different bureaucratic capacity or economic development, and cannot be explained by countries' historical legacies.
\end{abstract}

Publication status:

Submitted 


\subsection{Introduction}

A broad range of scholars have debated whether to expect democracies to provide better public services than autocracies (Besley 2006; Bueno de Mesquita et al. 2003; Donaghy 2011; Lake and Baum 2001; Przeworski and Limongi 1993; Ross 2006). The central argument is that accountability mechanisms in democracies will align the preferences of political leaders with the preferences of the public. But the empirical results have been mixed, and several counter-arguments, such as clientelism and short time-horizons in democracies, have been presented (Dahlum and Knutsen 2017; De Luca et al. 2018; Doucouliagos and Ulubaşoğlu 2008; Fukuyama 2015; Gerring, Thacker, and Alfaro 2012). Investigations of this relationship have largely been conducted using macroeconomic data such as gross domestic product (GDP), infant mortality rate, education, and illiteracy. The use of such measures is defended by the (highly valid) argument that democratic institutions will have a generally positive effect on the quality of life, although the exact routes differ depending on local contexts.

There are two potential problems with such tests. First, there is increasing evidence that these macroeconomic measures suffer from low validity (Jerven 2013), with measurement issues that systematically vary with regime type. For example, as shown by Hollyer, Rosendorff, and Vreeland (2014), autocratic governments are systematically reporting less data, and/or more censored data, and Martinez (2018) documents a systematically larger elasticity of official GDP- figures to nighttime lights in autocracies. As long as such concerns remain, we cannot know whether mixed results are signals of bad hypotheses, or wrong measurement. Second, the macroeconomic approach hides important nuances in the different incentives that face political leaders, and what we should expect of their investments. For example, investments can differ in their potential to be particularized to specific individuals and groups. Political leaders whose survival depends on the support of smaller, particular groups of society are more likely to pursue these types of public goods, instead of goods that are more difficult to particularize (Knutsen and Rasmussen 2017; McCubbins and Rosenbluth 1995). Or it can be more or less easy for centralized governments to capitalize votes based on public investments, depending on how easy it is for the electorate to identify central leadership and responsibility, which will make certain investments more sought after by democratic leaders (Harding and Stasavage 2014). It should be a goal for the literature to understand how governments prioritize different kinds of investments, and again how these investments relate to the overall development of the state.

In this article, I aim to do a rigorous test of the general argument on the case of the quality of the postal services. This has two central benefits. First, it contributes to the cumulative knowledge on how leaders invest in different public services. To my knowledge, no other study has investigated the link between regime type and postal services. Postal services in particular have been of major importance to the modern economy, most recently exemplified by the advent of online retail and the general growth in parcel deliveries worldwide. Historically, postal services have been of major importance 
to the general economy (Rogowski 2016; Rogowski et al. 2018). Second, the data are especially well-suited for cross-country comparisons, without any of the validity concerns often associated with global data. Specifically, I use the data produced by Chong et al. (2014). They sent ten fake letters to 159 countries, two letters to each of the five largest cities. By international regulation, the respective postal services were required to recognize that the letters were undeliverable and return them to the sender, at the expense of the United States. These response rates are not subject to any of the issues concerning self-reported data, and they provide information on how countries perform on the exact same task.

I find clear support for the argument that democracies improve public services. On average, democracies have 40 percentage points better response rates. This is robust to different specifications with different controls, robust to investigating both country aggregates and individual letters, and robust to leave-one-out jackknife estimate. To get further leverage on causal identification, I calculate the matching frontier and show that the results are robust to minimizing both Mahalanobis distance and discrete imbalance $\left(L_{1}\right)$ across a wide range of sample sizes (King, Lucas, and Nielsen 2016).

The findings are not explained by alternative hypotheses. For example, this is not driven by differences in state capacity, level of development, or city-level nightlight intensity. Nor are the results an artifact of deep historical causes. Climate, colonial history, European descendants, genetic composition, and other factors that could explain why some countries are democratic, rich, and well-developed are important also for postal services (Spolaore and Wacziarg 2013). Yet even when accounting for this, electoral democracy has a strong effect on the quality of postal services.

\subsection{Literature review}

There is abundant literature on the link between democracy and the provision of public goods. The debate originates from the simple and intuitive idea that public participation in government will make the latter more accountable to the former. This is expected to, in different ways, affect outcomes that are relevant for the well-being of a population, such as civil liberties, equality, innovation, and public services. In different contributions, this has been reformulated to general, sophisticated theories on government behavior.

Much of the literature suggests a positive relationship between democracy and public services. In the well-known theories of Acemoglu and Robinson (2006), democracy is the result of a power struggle between societal groups, one in which the poor have won considerably more political power than under other regimes. While the argument is formulated in more abstract terms of fiscal (re)distribution, the argument implies that the poor will in general favor public services that the rich, in general, do not wish to pay for. To Acemoglu and Robinson (2012, p. 73-87), the implications are massive, and can explain the greater portion of nations' success and failure across the globe.

Bueno de Mesquita et al. (2003) present the idea through "winning coalitions": Any 
political leader must satisfy a winning coalition in order to remain in power, drawn from a pool of potential supporters known as the "selectorate." Normally, political leaders will give particularistic goods to their winning coalition. But with larger winning coalitions, universal public services become a cost-efficient way to buy their alliance. Since democratic leaders often need the support of a majority of the potential voters, winning coalitions tend to be larger in democracies than in autocracies. Thus, democratic institutions secure the provision of public goods.

The theory by Lake and Baum (2001, p. 590) more directly address the governing of public services. They hold that states are assumed to act like "firms that produce public services in exchange for revenue." While states have many characteristics of a monopoly, their managers (e.g., politicians) face competition. Political leadership can be displaced more or less easily, which, they argue, depends on the barriers to exit for potential competitors and the cost of political participation for citizens. The higher the barriers to exit and cost of political participation, the more monopolistic-like this market will be, and the state will provide fewer and worse public services while earning greater rents. When politicians restrict the supply of services, creating an excess demand, citizens will "bid up the nominal tax price by offering bribes [...] and otherwise curry favor with those who have access to scarce resources" (Lake and Baum 2001, p. 593). This also helps to explain why autocrats invest in public services at all, namely that it provides an organizational hierarchy through which rents can be accrued. Democracies, they claim, are characterized by lower barriers to exit and lower costs to participate. Thus, leaders in democratic regimes should, compared to leaders of autocratic regimes, provide better public services. Across different measures of health and education, they find a positive relationship between democracy and human development (Lake and Baum 2001).

In sum, there are at least two reasons for why we should expect a positive relationship between democracy and better postal services. First, due to the relative size of winning coalitions in democracies, they are generally more motivated to use public services as a tool to build their alliances. Nondemocratic leaders, in comparison, are motivated to spend government revenue on relatively particularistic assets, since these leaders are often accountable to comparatively narrower winning coalitions.

Second, autocratic leaders might be less capable of prioritizing postal services. To the extent that autocratic elites are populated by more wealthy individuals, these elites might be less willing to accept the increase in taxes necessary to finance postal services. Thus, even if a nondemocratic leader should be motivated to prioritize effective postal services, fear of repercussions from wealthy elites could potentially constrain the leader. In comparison, relatively stronger vertical accountability mechanisms in democracies link the fortunes of the leader to the preferences of the public (Ferejohn 1986). Contested, multi-party elections provide dissatisfied citizens the opportunity to remove incumbents. Furthermore, stronger horizontal accountability mechanisms in democracies provide constraints on the executive. For example, legislators accountable to voters in different districts might oppose legislation that reduces their access to postal services.

The combination of vertical and horizontal accountability mechanisms also makes the 
opposition, who is intent on winning the next election, motivated to identify and call out shortcomings in the provision of postal services. Since democracies also tend to have greater access to information through an independent media, the under provision of postal services in democracies is more likely to be identified, and thus addressed. This leads to the first hypothesis: There is a positive relationship between democracy and the quality of postal services.

However, the empirical investigations of democracy and public services have not been robust in favor of democracy (see for example Ansell 2008; Gerring, Thacker, and Alfaro 2012; Ross 2006; Shandra et al. 2004; Stasavage 2005). However, I argue that there are two reasons for why we should be cautious in how much we generalize based on these studies.

Measurement problems are a real hindrance to broad investigations of this, because of three problems related to data that are self-reported by governments. First, autocracies in general seem to fake their data, presenting themselves as better than they actually are (Martinez 2018). Second, autocracies have clear incentives not to report statistics that reflect badly upon their performance. Thus, the remaining sample will be the bestperforming autocracies (Hollyer, Rosendorff, and Vreeland 2011; Hollyer, Rosendorff, and Vreeland 2014). Finally, the opposite might also be true. Since autocracies are not domestically compelled to report data, they only do so when forced to by international agencies. These are typically low-performing autocracies in need of assistance by the World Bank, The International Monetary Fund, or United Nations Development Programme. If so, the observable sample of autocracies are the worst-performing ones (Ross 2006). These issues are especially problematic in the literature on regimes and economic outcomes, since all three types of measurement errors systematically correlate with the treatment variable (regime) and outcome (economic performance) and therefore produce a systematic bias in the estimated relationships. Since they imply biases in conflicting directions, the final direction is impossible to determine if we cannot somehow overcome the measurement error.

These different potential errors come in addition to worries about the reliability of essential statistics from low- and middle-income countries. Due to a general lack of statistical capacity in many of these countries, measures of income and growth are based on only a few sources, and large shares of the economy are excluded from different economic aggregates (Jerven 2013, p. 2-4). For the same reason, population statistics are also unreliable from many of these countries. But population censuses have the additional problem of being potentially controversial. For example, the Kenyan census of 2010 was used to decide how to distribute Sh14 billion (US\$180 million) from the government's Constituencies Development Fund, giving different groups incentives to exaggerate their population size (Jerven 2013, p. 73). In other instances, for example when censuses are used to determine tax collection, individuals instead have incentives to hide from official records. Finally, these issues have been documented to systematically vary over time and space (Jerven 2013; Manning 2010). Population statistics are essential to other measures such as literacy or infant mortality rate, but it is not easy to determine how much such 
an error in measurement biases our estimated relationships between regime type and different economic outcomes.

The central point is not to discredit all empirical work done in this field. For example, if the issue is simply that each country has a constant error equal to $\alpha$, then regressions using country fixed effects should be able to filter out a potential bias. But we do expect the error to change systematically if there is a change in a country's political regime. We simply do not know if our fixed effects solve the problem. If the underlying data are fundamentally flawed, then no amount of rigorous statistical tests can fix that.

The second reason we should be cautious in making conclusions about public services in general based on existing studies, is because many of them rely on measures of health and education. It is possible that autocratic or democratic leaders are more or less interested in certain public services and not others. For example, Hollenbach (2019), following Galor and Moav (2006), argue that elites who own capital that relies on human capital, such as industrial elites, are interested in public education and health services because this will increase their return on capital. They argue that in such situations, autocracies will outperform democracies in the provision of such services. Thus, autocratic countries might have relatively stronger motivations to pursue services in health and education, which have been so central to much of the literature. If so, these measures are less representative if we are concerned with the general provision of public services. Indeed, this insight implies that we should diversify the various services we investigate in order to get a better picture of how they relate to different regime types.

This might play in favor of a positive relationship between democracy and postal services. Several authors argue that autocratic leaders have incentives to restrict communication technologies because diffusion of information can empower the political opposition and threaten the regime (Hachigian 2002; Holkeboer and Vreeland 2013; Knutsen 2015). While security concerns could also motivate democratic leaders to allow extensive surveillance measures, we should expect autocratic leaders to be relatively more capable of pursuing such policies. Again, these relate to the relative strength of vertical and horizontal accountability mechanisms among democracies. If citizens, on average, dislike extensive surveillance measures, they can remove incumbents who restricts their freedom of communication. Horizontal constraints, such as passing laws through parliament, create more veto-points against legislation that expands surveillance or censorship efforts.

But there are good theoretical arguments for why we should not observe a positive relationship between democracy and public services. Democratic elites, concerned with electoral cycles, might be more concerned with visible, short-term projects from which they can attract votes. Thus, building new schools, large roads, or, in this setting, post offices might be more valuable for a politician seeking votes compared to long-term, and less salient, investments in the quality of services (Dahlum and Knutsen 2017; Min 2015). Furthermore, many suspect democratic leaders of being vulnerable to favoritism of different kinds, prioritizing public expenditure towards narrow electoral constituencies or co-ethnic areas (De Luca et al. 2018; Fukuyama 2015; Kramon and Posner 2013; Rogowski 
2016). ${ }^{1}$ If politics in democracies are dominated by such short-term behavior, it is less likely that there will be any difference in the quality of postal services between democracies and autocracies. Postal service quality is generally not as salient as services such as public health or education, making this a strict test of the relationship between democracy and public services. This leads to the second hypothesis: There is no systematic relationship between democracy and postal service quality.

\subsubsection{My contribution}

The data on postal services from Chong et al. (2014) do not suffer from these issues. From December 2010 to January 2011, the authors sent out 10 letters to the five largest cities in 159 countries around the world. All of these letters stated that it was a matter of urgency, but if the letter was undeliverable, it should be returned to the sender. The address on each letter had a correct ZIP code to the relevant city but a nonexistent street name. All of the 159 countries have signed the "Universal Postal Union Letter Post Regulations Final Protocol" of 2009, which regulates that any incorrectly addressed mail shall be returned to the sender at the expense of the country in which the letter originated from, in this case, the United States. Letters should be returned within a month of entering the country. Thus, the task that the employees in the receiving country need to do first is to recognize that the letter is undeliverable, and second, return it.

Furthermore, all of the letters were framed as business opportunities. The sender, Professor Rafael La Porta, is a Professor of Finance at the Tuck School of Business. The fake letter-receivers have fake workplace names such as "Smart Computer Services" or "Smart Company Supply Services." As pointed out by the authors, returning letters that concern business cooperation with the United States is potentially one of the most productive activities that postal services can do, especially in developing countries (Chong et al. 2014, p. 282). This aspect of the data highlights the economic benefit of completing the task at hand and the cost associated with having a postal service that is unable to complete its tasks or is ridden by censorship or theft.

The data have several preferable characteristics compared to other measures in the literature. First, the data do not suffer from any of the mentioned transparency issues associated with self-reported data. The data were compiled by professors in the United States, in a secret experiment with a clear inclusion criterion.

Figure 3.1 is a boxplot of the transparency index from Hollyer, Rosendorff, and Vreeland (2014) among groups of countries with different response rates. This simple description illustrates a part of the problem: Better-performing countries tend to be more transparent than worse-performing countries. Since these data are not self-reported, they do not suffer from this problem.

Second, the measure is comparable. All postal services were subject to the same task, the same number of times. All countries have declared that they should be able

\footnotetext{
${ }^{1}$ However, Tajima, Samphantharak, and Ostwald (2018) finds that ethnic segregation can increase the overall public goods provision.
} 


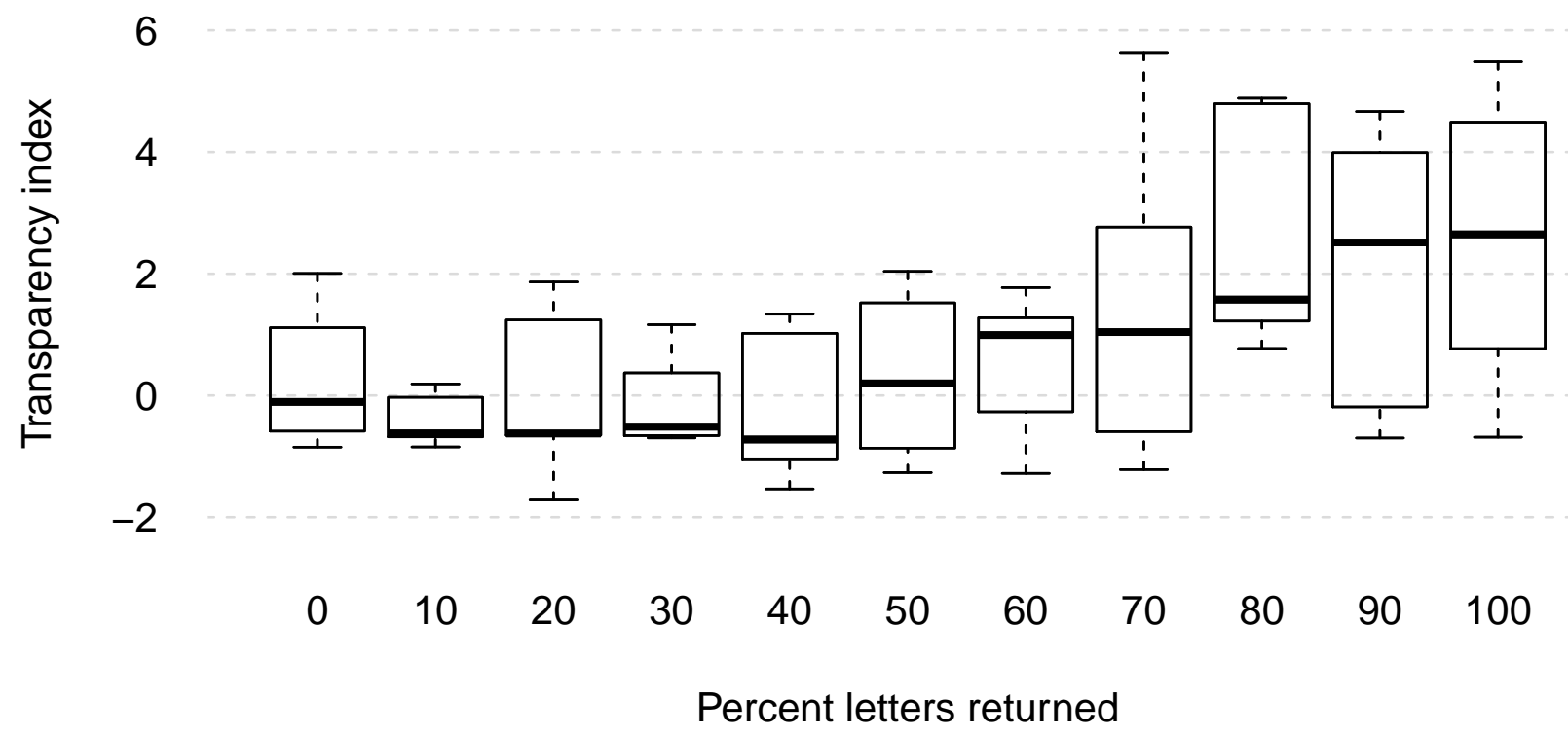

Figure 3.1: Boxplot of transparency and response rates

to complete this task. Third, the measure does not need any assumptions about "best strategies," such as the correct amount of staff or post offices, or the use of private operators. It simply measures the number of delivered letters, whatever strategy governments use to achieve it.

\subsection{Postal services}

Postal services perform a vital job in modern economies. The importance of a national and international transportation- and communication system is difficult to overestimate. Even after the advent of the internet and electronic communication, the world sends more than an estimated 380 billion letters every year (UPU 2011, p. 4). In many countries, it is the main mode of communication between the bureaucracy and the citizens. For the economy, a well-functioning postal service plays an essential role in offering logistical solutions to private actors, most recently exemplified by the growth of internet retail. The quality of the postal services correlates with volumes in parcel delivery more broadly, and countries with better postal services are more likely to be able to order products from Amazon (see figures 7.1 and 7.2 in the appendix). Contemporary quality of the postal service is not just an artifact of the timing of industrialization: Many emerging markets today experience increases in the use of postal services (UPU 2011, p. 8). To this day, investments made in the postal services have positive benefits to the economy (Rogowski et al. 2018). 
The postal services have, for all practical purposes, been built by governments. For most of history, most postal services have been governed as postal monopolies, starting with the British ban on private services by Queen Elizabeth in 1591 (Priest 1975, p. 3334). Today, all members of the Universal Postal Union have an operator designated to fulfill the obligations in the convention. The decision to allow private operators is ultimately made by governments, but even under more liberal market regimes, government actions have unavoidable consequences for postal systems. Governments handle collective action problems such as street names, addresses, and postal codes. They participate in international coordination systems such as the Global Monitoring System and International Postal System (UPU 2011). They even have indirect influence on postal systems through the maintenance of vital infrastructure such as roads.

\subsection{Data and design}

My main dependent variable is the percentage of letters returned to the United States from each country in the experiment by Chong et al. (2014). On average, $60 \%$ of the 1,590 letters were returned, $35 \%$ within 90 days, and $4 \%$ within one month. The authors stopped to systematically check their mail in February 2012, giving countries a little more than one year to return the letters. Figure 3.2 illustrates the percentage of returned letters around the world. Further details are available in the original article.

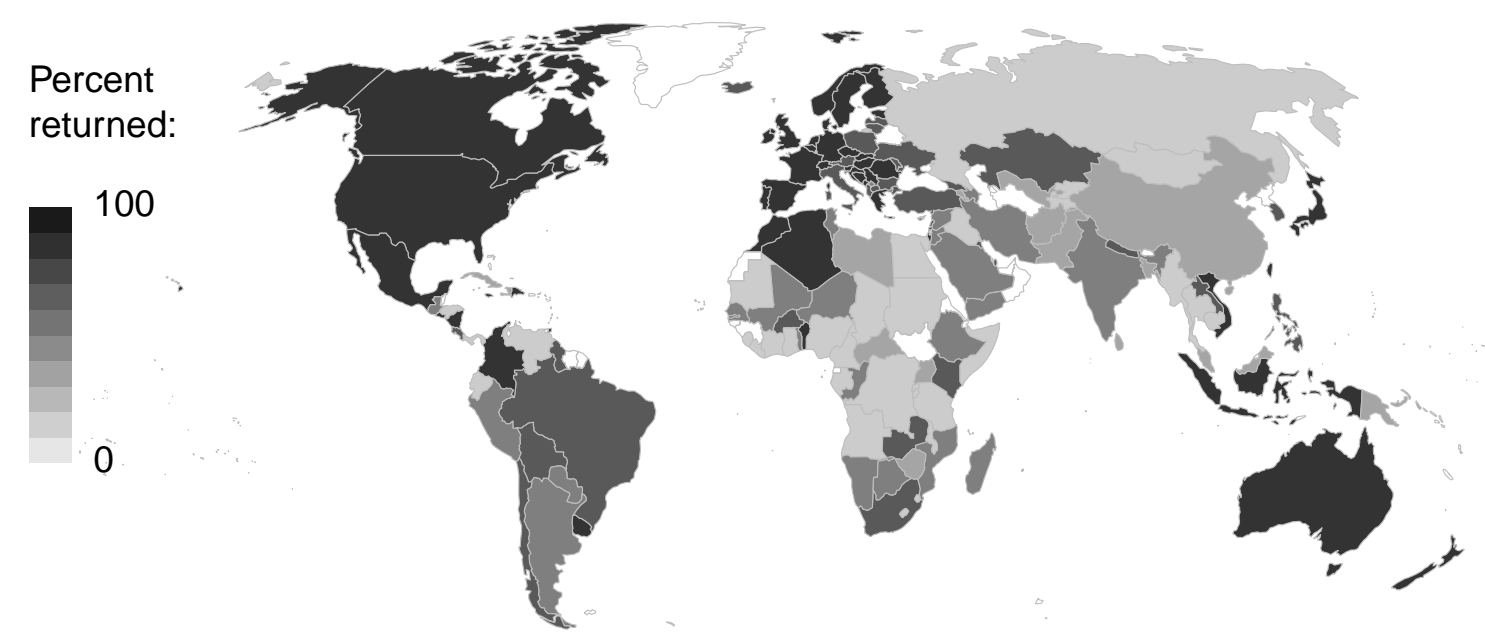

Figure 3.2: Map of letter response rates around the world. Countries in white have missing values.

The main drawback of these data is the lack of time-series, which inhibits the potential for causal identification. Specifically, it makes it more difficult to establish that postal services were improved after the introduction of democracy.

It is possible that the results are driven by countries that industrialized in the heyday of postal services, such as many of the countries in the Western world. It could be that 
these countries tend to be more democratic today and that postal services are better in this part of the world due to a path dependency from investments made during a more autocratic past. Such a mechanism implies that postal service quality is a very constant phenomenon that governments have few opportunities, or little will to change. While I find this unlikely, I also show that the results are robust to leaving out any country or region of the world and are not explained by historical forces such as European descendancy, climate, or colonization (Spolaore and Wacziarg 2013). To further improve identification, I also compute the matching frontier, minimizing imbalance according to Mahalanobis distance and $L_{1}$ across several sample sizes (King, Lucas, and Nielsen 2016).

\subsubsection{Democracy}

The main variable measuring democracy is the electoral democracy index from the Varieties of Democracy (V-Dem) Project (Coppedge et al. 2017; Pemstein et al. 2015; Teorell et al. 2018), which combines measures on elected officials, electoral fraud, suffrage, freedom of association, and freedom of expression. It builds on the Polyarchy concept from Dahl (1971), which considers the extent of competitiveness of elite selection and how broad popular participation is in this selection process. This is exactly what the theories identify as the important aspects of democracy.

$\mathrm{V}$-Dem is undoubtedly the most rigorous effort to alleviate any concern about measurement issues related to regime type (Pemstein et al. 2015). Nevertheless, I also show that the analyses are robust to using the binomial measure of democracy from Boix, Miller, and Rosato (2013) (BMR).

\subsubsection{Confounders}

A central confounder is state capacity. There is abundant literature on the difficult relationship between democracy and state capacity for economic outcomes (for a few recent examples, see Fukuyama 2015; Knutsen 2013; Persson and Povitkina 2017; Rothstein and Teorell 2008). Government efficiency was also the original intention of the authors who collected the postal data, as they study the government productive function and "do not focus on broader political and economic forces shaping the government production function, such as democracy or accountability" (Chong et al. 2014, p. 278).

My main variable for the state capacity is V-Dem's measure on rigorous and impartial public administration. I also do robustness tests using expert survey data from the Quality of Government Institute (Dahlström et al. 2015). To relieve any further suspicion of this confounder, I also control for state ownership in the economy. Since this could introduce post-treatment bias in the estimates for democracy, as political institutions are likely to produce different incentives for involvement in the economy and governance of the bureaucracy, I also present analyses that excludes these. I also highlight that the reported results are also robust to leaving out any region of the world. 
Measures of GDP PPP per capita, population, and country size in square kilometers are collected from The World Bank (2010). There is a correlation between democracy and GDP per capita, and a strong economy is likely to affect the quality of public services (Przeworski et al. 2000). It has also been argued that larger populations make it harder to sustain consolidated democracies (Dahl and Tufte 1973). The same logic applies to country size, and it could be more difficult to manage postal services in larger countries. While there is reason to believe that there are problems with the measurement of these variables, this is less problematic as long as they are used as control variables.

Regional categorizations are from the Quality of Government dataset (Teroell et al. 2017), and each country's spatial distance from the United States is collected from the CShapes dataset (Weidmann, Kuse, and Gleditsch 2010). Both of these capture several confounding aspects. It takes longer to transport a letter back to the United States if the spatial distance in greater. While it is not obvious that such distance affects whether or not a country is democratic, it is possible that some spatial-contingency effect is at play. Regional dummies capture similar spatial dependency in institutions, be it democratic institutions, public services, work-norms, or other aspects that tends to cluster spatially. For the same reason, I also do robustness tests where I include a dummy variable for whether the country has a Latin alphabet, gathered from Chong et al. (2014). Sharing language might increase the probability of spatial dependency in institutions, and it should be easier for workers to read letters from the United States if they share alphabet.

With these main variables, 151 countries remain from the original 159. The data are reduced because eight countries that were included in the experiment are not included in the V-Dem dataset. ${ }^{2}$ All covariates are measured in 2010, but the results are not sensitive to using longer lags. A full descriptive overview of all variables is available in table 7.1 in the appendix.

\subsection{Analysis}

The analysis is divided into three parts. First, I present models using the standard regression approach. Then I present models using various matching-methods. Finally, I present results aimed at testing alternative hypotheses related to historical trajectories.

\subsubsection{Regressions}

In table 3.1, I present the results from three different models, introducing covariates in a stepwise manner. First, I only include distance to the United States and the country size in $\mathrm{km}^{2}$. This avoids any post-treatment bias in the coefficient for democracy but is likely to suffer from omitted variable bias. Then I introduce the rest of the covariates, excluding regional fixed effects, which is introduced in model 3. These two models take better care of omitted variable bias but run the risk of introducing post-treatment bias.

\footnotetext{
${ }^{2}$ Bahrain, Belize, Brunei Darussalam, Hong Kong, Luxembourg, Malta, Tonga, United Arab Emirates.
} 
For example, it has elsewhere been argued that democracy affects government spending (Doucouliagos and Ulubaşoğlu 2008, p. 78), which is here introduced as a confounder of democracy. If democracies are better at public services, one could also imagine that GDP and population are mediators and not confounders.

In all specifications, Polyarchy has a strong and significant effect on whether or not countries return the letters. In the least optimistic results, it is expected that a democracy is likely to return 38 percentage points more letters than an autocracy, and 42 percentage points if we include regional dummies. In the most optimistic model, model 1 , the effect of democracy is almost 70 percentage points.

To illustrate, Bulgaria and Azerbaijan, two countries which are approximately equally large with approximately equally large economies, have respectively 0.69 and 0.21 on the Polyarchy scale. The model expects Bulgaria to return approximately two more letters than Azerbaijan due to this difference. Incidentally, the postal services in Azerbaijan returned five of the letters, and Bulgaria seven.

Table 3.1: Effectiveness of postal services

\begin{tabular}{|c|c|c|c|}
\hline & $(1)$ & $(2)$ & $(3)$ \\
\hline Polyarchy & $\begin{array}{c}69.4^{* * *} \\
(8.9)\end{array}$ & $\begin{array}{l}37.6^{*} \\
(15.4)\end{array}$ & $\begin{array}{l}43.5^{*} \\
(17.1)\end{array}$ \\
\hline Ln distance from USA & $\begin{array}{l}-2.6 \\
(1.6)\end{array}$ & $\begin{array}{l}-0.9 \\
(1.6)\end{array}$ & $\begin{array}{l}-1.1 \\
(1.8)\end{array}$ \\
\hline Ln country size $\mathrm{km}^{2}$ & $\begin{array}{c}-2.9^{*} \\
(1.2)\end{array}$ & $\begin{array}{c}-3.1^{*} \\
(1.5)\end{array}$ & $\begin{array}{l}-2.3 \\
(1.7)\end{array}$ \\
\hline State ownership in the economy & & $\begin{array}{c}2.8 \\
(2.9)\end{array}$ & $\begin{array}{c}2.5 \\
(3.0)\end{array}$ \\
\hline Ln GDP pc PPP & & $\begin{array}{c}9.9^{* * *} \\
(2.2)\end{array}$ & $\begin{array}{c}4.5 \\
(3.3)\end{array}$ \\
\hline Impartial government officials & & $\begin{array}{c}0.9 \\
(2.5)\end{array}$ & $\begin{array}{c}2.4 \\
(3.0)\end{array}$ \\
\hline Ln population & & $\begin{array}{c}1.9 \\
(1.9)\end{array}$ & $\begin{array}{c}0.8 \\
(2.3)\end{array}$ \\
\hline Constant & $\begin{array}{c}59.9^{* * *} \\
(2.2)\end{array}$ & $\begin{array}{c}60.4^{* * *} \\
(2.0)\end{array}$ & $\begin{array}{c}64.0^{* * * *} \\
(4.9)\end{array}$ \\
\hline Regional FE & No & No & Yes \\
\hline Observations & 151 & 151 & 151 \\
\hline $\mathrm{R}^{2}$ & 0.4 & 0.5 & 0.5 \\
\hline
\end{tabular}

Other covariates are also as expected. Overall, being close to the United States does not matter for whether letters are returned or not. It should be noted that the distribution on this variable is somewhat bimodal. The countries surrounding the United States form one cluster with low values, and the rest form a separate cluster with higher values. For 
the average country, the impact of distance is simply not strong enough to explain a great portion of the variation.

GDP per capita has a strong effect on the quality of the postal services, seen in model 2. For each increase in the natural logarithm of GDPpc PPP, a country is expected to return one more letter. However, this effect is halved and turns insignificant when the regional-dummies are included, since economy sizes are geographically clustered.

The size of the country only has a small impact on the response rates. If we compare the difference in response rate between the first quantile (approximately the size of Slovakia) and the third quantile (approximately the size of Afghanistan), the difference in size is expected to change the response rate by less than 10 percentage points.

These results are not sensitive to individual observations. For example, since all letters are sent from the United States, one might imagine that this extraordinary situation is driving the positive results of democracy. But as shown in figures 7.4 and 7.5 in appendix section 7.3, the results are equal if any single observation is removed from the sample or if whole regions are removed from the sample. The results do not change if I include a dummy variable for Latin alphabet, a dummy variable for whether the country had an ongoing conflict, or a variable for the average number of times the country voted equal to the United States in the United Nations General Assembly. These results are presented in table 7.2 in the appendix. Neither are the models sensitive to the exclusion of any of the variables included in model 3, shown in appendix table 7.3. As shown in table 7.4 in the appendix, the results also hold if I use the BMR measure for democracy (Boix, Miller, and Rosato 2013) and the professionalism measure as a measure of quality of government (Dahlström et al. 2015).

In theory, the OLS estimation is unfit for variables such as these, with a lower and upper bound. In addition, we only observe integer-numbers, which increases the standard errors in the model. In reality, this is a binomial process with an unobservable, latent probability for returning each letter. Nevertheless, the presented models do not show any serious diagnostic issues, and in-sample predictions are all within the real range of the dependent variable.

Yet, to investigate the suitability of the linear assumption, other model-specifications have been tested. In table 7.5 in the appendix, the unit is each individual letter and whether it was returned or not. Here I employ a logistic regression instead. This level of analysis also allows me to control for letter-specific situations, such as whether the letter was sent in December (and thus hit the Christmas rush) or whether the letter was sent to the capital city. While they have strong independent effects, neither of these covariates correlates systematically with regime type, and thus does not improve leverage on the causal identification. The effect of democracy remains strong.

\subsubsection{Matching}

In absence of random distribution of regime type across the globe, the covariates might be heavily imbalanced across democracies and autocracies (Iacus, King, and Porro 2012). 
This can bias the estimates. In this section, I aim to remove concerns about balance by calculating the matching frontier (King, Lucas, and Nielsen 2016).

There are several possible methods for balancing, but neither is optimal for this analysis. First, methods relying on propensity scores are problematic because they can potentially increase the imbalance (Iacus, King, and Porro 2012). An alternative is "coarsened exact matching" (CEM), which has a good track record for reducing imbalance. The process works by categorizing all covariates, and thereafter extracting bins of categories that contains observations from both treated- and control groups, and weighting them to reduce "discrete imbalance" or $L_{1}$ (King, Lucas, and Nielsen 2016, p. 13). Yet in many applications, such as this one, there is no obvious way to choose categories. Furthermore, observations in bins that do not contain observations from both treated and control groups are thrown away, which often, as in this application, drastically reduces the sample sizes (King, Lucas, and Nielsen 2016).

There are therefore several ambiguous decisions during the process of achieving balance. The matching frontier helps to overcome this. With an efficient formula, it finds the maximum possible balance across all possible sample sizes, according to the chosen measure (Mahalanobis distance or $L_{1}$ ) (King, Lucas, and Nielsen 2016). For each sample size, it thus re-estimates the model using whatever weighting scheme that maximizes balance and reports the effect of the treatment (e.g., democracy) on the outcome (letters returned).

The only remaining issue is that the treatment variable, Polyarchy, needs to be binary, an issue matching frontier shares with other approaches. Therefore, Polyarchy is dichotomized based on its mean value. Given that any cut-off would be somewhat arbitrary, I also present the analyses using the BMR binomial measure of democracy from Boix, Miller, and Rosato (2013). Otherwise, the model is similar to model 3 in table 3.1, with democracy matched on all other covariates in the model.

The results are illustrated in figure 3.3. There are four different specifications: using the binomial Polyarchy measure and minimizing Mahalanobis distance and $L_{1}$, and using the BMR measure and minimizing these two statistics.

Starting with panel A, which minimizes Mahalanobis, we see that countries with above the mean value on Polyarchy are expected to return almost 40 percentage points more letters than countries with a Polyarchy value below average. The estimate stays positive and significant even at very small sample sizes, but the uncertainty naturally becomes very large.

Looking at panel B, I am now minimizing the $L_{1}$ imbalance measure. The confidence interval of the binomial Polyarchy measure is very stable between approximately 25 and 45 for all sample sizes, down to about two-thirds of the data set. From there, the point estimate rapidly decreases in line with increasing confidence intervals.

In panel $\mathrm{C}$ and $\mathrm{D}$, I instead use BMR as a measure of democracy. In panel $\mathrm{C}$ where Mahalanobis is minimized, we see that democracies are expected to return somewhere between 35 and 45 percentage points more letters than autocracies. These numbers become gradually lower as the sample size decreases, but stays strongly positive and 

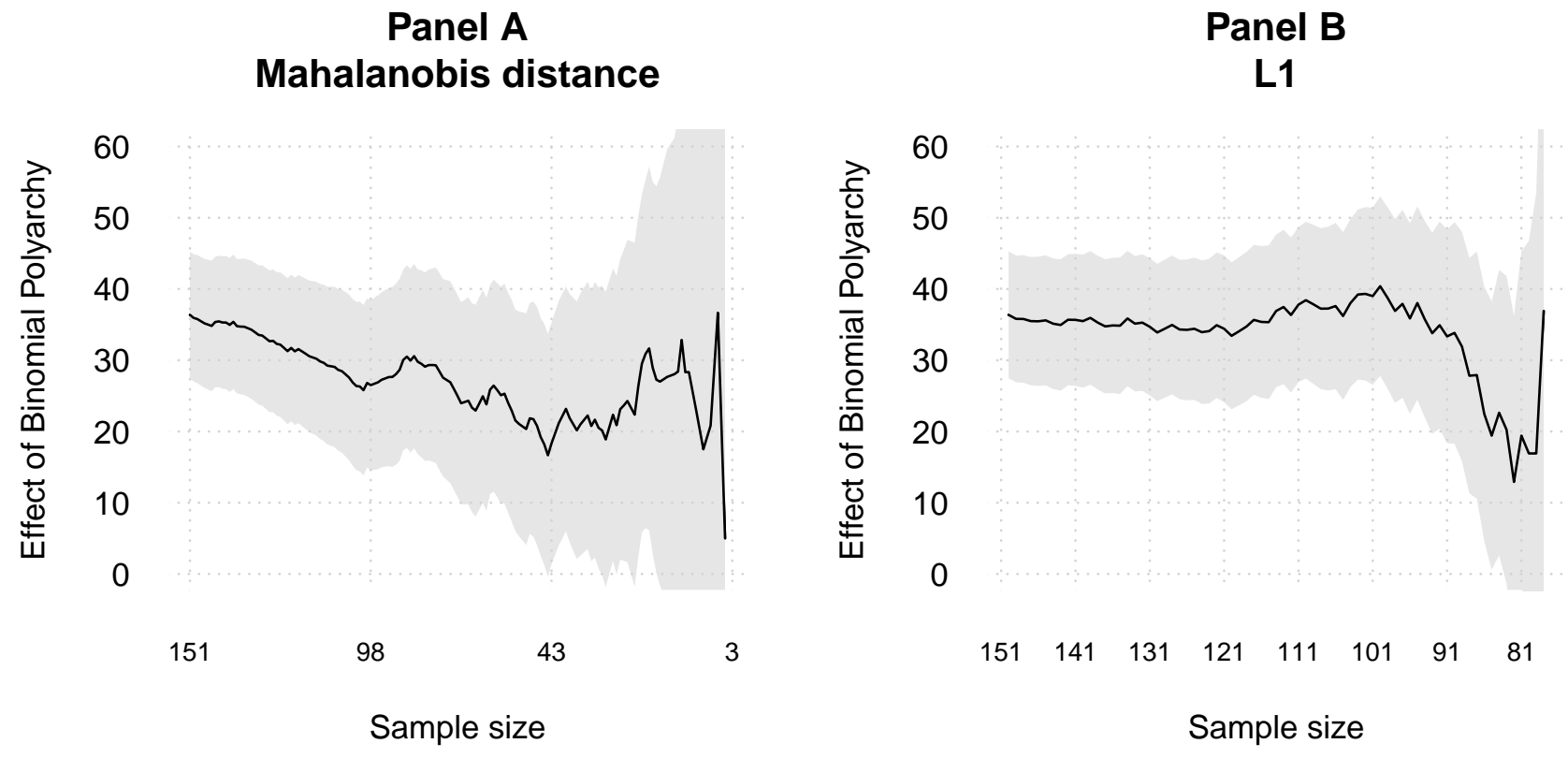

\section{Panel C Mahalanobis distance}

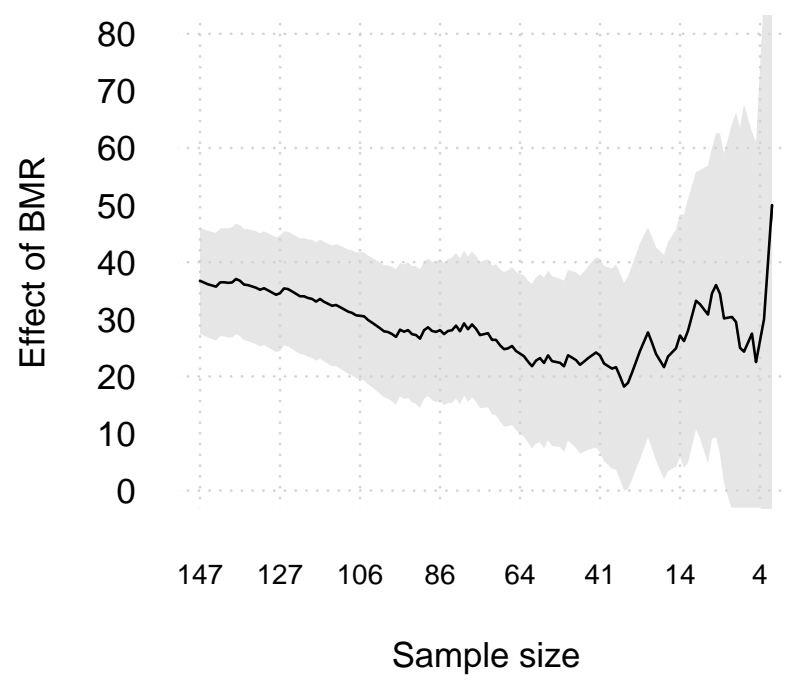

Figure 3.3: Estimated effect of Binomial Polyarchy (Panels A and B) and BMR (Panels $\mathrm{C}$ and $\mathrm{D}$ ) on the quality of postal services. The point-estimates along the $\mathrm{Y}$-axis are indicated as solid black lines; the gray band indicates the $95 \%$ confidence intervals. The $\mathrm{X}$-axis indicates the sample size in which imbalance is minimized according to the Mahalanobis distance (Panels A and C) or $L_{1}$ (Panels B and D) 
significant even at very small sample sizes. From sizes of about one-third and lower of the original sample, the confidence intervals become increasingly larger.

In panel $\mathrm{D}, L_{1}$ is minimized, and we see that the confidence interval for BMR stays very stable between approximately 25 and 45, and slightly increases as the sample size approaches approximately 100. Again, the algorithm stops after $40 \%$ of the observations are removed.

I highlight two things from these results. First, democracy has a very robust, positive effect on postal service quality over a large span of sample sizes when accounting for imbalance. Second, the estimated effect is quite consistent around about 35, even when changing to the BMR measure of democracy.

\subsubsection{Alternative historical explanations}

Measurement and model specifications aside, there are several competing explanations for why we observe a relationship between democracy and public services. In this section, I will test alternative hypotheses that are related to the long-term historical trajectories of countries that affect social and genetic inheritance with implications for economies today (Spolaore and Wacziarg 2013).

Geographical explanations for human development have been around for a long time (Bloom et al. 1998; Kamarck 1976; Myrdal 1968; Masters and McMillan 2001; Rappaport and Sachs 2003; Sachs 2001). There are different stories for why this is the case, but geography has a systematic effect on disease environment, access to natural resources, and transportation and communication between humans. Furthermore, there seems to be a general agreement that geography has had an important impact on the distribution of human resources, such as population patterns but also institutions and social capital.

If these theories are correct, democratic countries might have systematically appeared under more favorable geographical conditions. At the same time, the operation of public services, both through disease environment and indirectly through social capital and norms, might vary systematically with certain geographical factors.

To empirically investigate the impact of geographical origins, I introduce absolute latitude, percent land area with tropical climate, a landlocked-dummy, and an islanddummy to model 3 from table 3.1. The results are reported in model 1 in table 3.2. All these variables are gathered from Spolaore and Wacziarg (2013).

The only covariate with a substantial magnitude, and which is statistically significant by conventional standards, is the measure for tropical climate. As argued by Sachs (2001), tropical climate is associated with low agricultural productivity and a high burden of disease. If tropical climate reduces productivity through human health, it is likely that this also matters for public services. But more important for this analysis, the relationship between democracy and public services remains unaffected when controlling for these geographical factors.

Another possible mechanism of geography is the impact on human settlement, and specifically European settlement (Acemoglu, Johnson, and Robinson 2001; Easterly and 
Table 3.2: Effectiveness of postal services

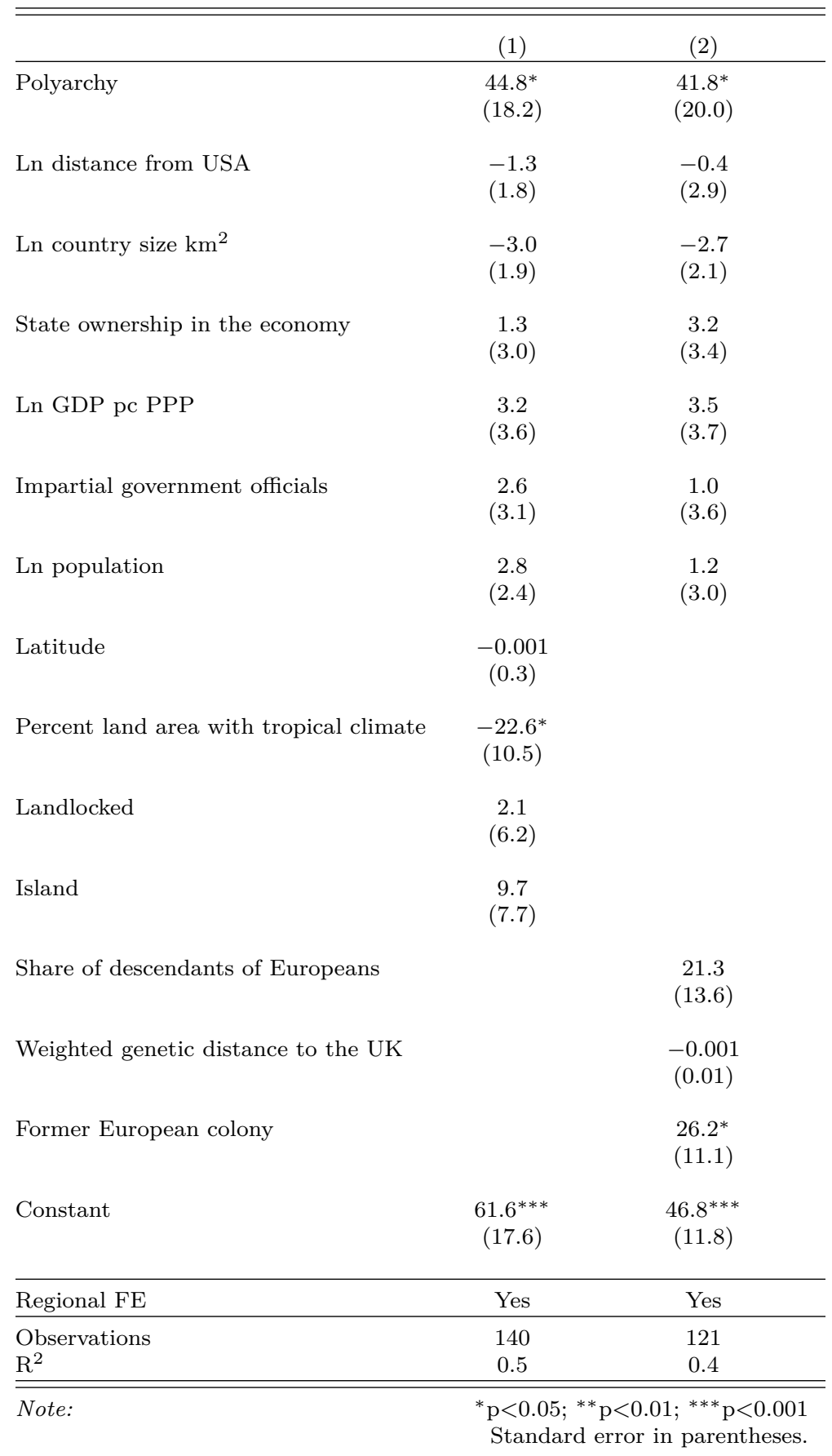

Levine 2016; Engerman et al. 2002). There are two different mechanisms for this hypothesis. Both assume that Europeans systematically settled under certain geographical conditions. In the first formulation of this, European settlers brought with them European institutions, such as rule of law, property rights, and parliaments, which ever since have affected the prosperity of areas where they settled (Acemoglu, Johnson, and Robinson 2001). The other story, however, is that settlers also, or most importantly, brought with them their own human capital (Easterly and Levine 2016; Glaeser et al. 
2004; Spolaore and Wacziarg 2013).

To investigate whether the results are driven by a European heritage, I include three covariates to model 3 from table 3.1: share of descendants from Europeans in 2000, a dummy for whether or not the country is a former European colony, and a variable of a country's weighted genetic distance to the UK. Weighted here means that it is the expected genetic distance between two randomly chosen individuals from the two countries (Spolaore and Wacziarg 2013, p. 342). In this model, I remove Western Europe, North America, Australia, and New Zealand. The results are reported in model 2 in table 3.2 .

Of these three variables, being a former colony is the only one with a conventionally significant effect. In no specification have I found any meaningful effect of the weighted genetic distance to the UK. Again, Polyarchy remains unaffected by these changes to the model.

\subsection{Conclusion}

A core value of democracy is the posited instrumental value such regimes have on human development (Sen 1999). Being able to properly formulate what to expect of democratic rule should be of great importance to our discipline. In this regard, the provision of public services has been, and still is, central in the literature on political regimes. While there are several good reasons to expect a positive relationship between democratic rule and public service provision, the empirical results have not been entirely robust.

I have pointed out potential issues with much of the current empirical tests. For different reasons, data that are self-reported by governments can be subject to different measurement errors that systematically correlate with regime type (Hollyer, Rosendorff, and Vreeland 2011; Martinez 2018; Ross 2006). It remains unclear whether the mixed results in the literature are due to wrong hypotheses or questionable data, and we need to develop tests that do not rely on data reported by governments.

In this paper, I have therefore used data on the quality of postal services from Chong et al. (2014). I have argued that the data, which are the percentage of letters returned to the United States, hold many advantages for cross-country comparisons that previous studies lacks. First and foremost, that data are not self-reported by governments. Second, the data allows for a global comparison of countries, arguably one of the most difficult samples for comparative analyses.

The empirical results show unambiguous support for the relationship between democracy and public services. Across a wide range of statistical models with different statistical controls and using different sub-samples of countries, a fully-fledged democracy is expected to have somewhere between 20 and 40 percentage points better response rate than a full dictatorship. This relationship does not seem to be explained by historical forces that have made some countries better off than others. 
A potentially major implications of these results, is that previous studies have underestimated the positive relationship between democracy and public services. For example, Ross (2006) argues that autocracies only report data when forced to by international agencies, and that these are typically low-performing autocracies in need of assistance by the World Bank, The International Monetary Fund, or United Nations Development Programme. If so, the observable sample of autocracies are the worst-performing ones. But if this were the dominating measurement problem, we should not observe a positive relationship between democracy and postal services in these data, which are not self-reported by governments. Similarly, Dahlum and Knutsen (2017) find no relationship between democracy and educational quality, but they do not exclude the possibility that autocratic countries only report results from their best-performing students. Such concerns seem to be supported by my results.

However, the study cannot conclude that different results are due to systematic measurement errors. It might also be that there are theoretical reasons for why autocracies are relatively more interested in services such as health and education but opposed to services that empower freedom of speech and diffusion of information, such as postal services. Future research must therefore look for data on different types of public services, and not at the least look for data that are not reported by the governments themselves. 



\title{
4 Leaders, private interests, and so- cially wasteful projects: Skyscrapers in democracies and autocracies
}

Haakon Gjerløw and Carl Henrik Knutsen ${ }^{1}$

\begin{abstract}
:
Political leaders often have private incentives to pursue socially wasteful projects, but not all leaders are able to pursue these interests. We argue that weaker accountability mechanisms allow autocratic leaders to more easily realize wasteful projects than democratic leaders. We focus on one particular project, skyscraper construction, where we obtain objective measures comparable across different contexts. We test different implications from our argument by drawing on a new dataset recording all buildings exceeding 150 meters, globally. We find that autocracies systematically build more new skyscrapers than democracies. Further, autocratic skyscrapers are more excessive than democratic ones, and - in contrast with democracies - autocracies pursue skyscraper projects to about the same extent in rural/poor and urban/rich societies. When investigating different mechanisms entailed in our argument, the link between regime type and skyscraper construction seems due in large part to stronger vertical accountability mechanisms and more open information environments in democracies.
\end{abstract}

Publication status:

Published in Political Research Quarterly

${ }^{1}$ Professor at The University of Oslo 


\subsection{Introduction}

Democracies outperform autocracies on several development and policy outcomes, including infant mortality rates (e.g., Gerring, Thacker, and Alfaro 2012), the number of children enrolled in school (e.g., Lake and Baum 2001), and even, in some contexts, quality of government (Charron and Lapuente 2010). Yet, several studies show that autocracies outpace democracies on investments in (physical) capital (e.g., Przeworski et al. 2000; Tavares and Wacziarg 2001). Some explanations for this pattern highlight more benevolent motives combined with the high capacity of autocratic regimes in undertaking large investment projects. The large literature on East Asian development states, for example, focuses on how autocratic regimes bent at increasing economic growth have the autonomy to drive up savings rates, invest in infrastructure, and subsidize capital for export-producing industrial firms (Leftwich 2000; Wade 2003; Young 1995)

Yet, on closer inspection many investment projects in autocracies do not seem to be very productivity-enhancing. As Robinson and Torvik (2005) note when discussing developing countries, several countries have made substantial capital investments, but many of them in socially inefficient projects. The seeming misallocation of investments on unproductive projects - which, when it comes to construction- and development projects, more generally, can make up a substantial share public funds (see Williams 2017, p. 706) - may be deliberate and reflect less sanguine motivations on the part of the leader. Political leaders often have personal reasons - be it vanity, providing cronies with opportunities for reaping bribes or excessive profits, or signalling the regime's capabilities to (foreign and domestic) competitors - to expend public resources on costly, but societally unproductive, investment projects. Regime type is thus potentially relevant, since a large theoretical literature has highlighted how institutional features associated with democracy might limit such wasteful spending through constraining the power of leaders or through incentivizing leaders to show self-restraint (e.g., Ferejohn 1986; Przeworski 2000; Lake and Baum 2001; Besley 2006).

Despite this, comprehensive and systematic empirical studies on whether autocratic leaders, in fact, are more likely than democratic leaders to pursue societally unproductive investment projects remain scarce. Addressing a somewhat related question, crossnational measures of corruption have been used to asses links with democracy, reporting mixed findings (see, e.g., Rock 2009). However most measures rely on corruption perceptions, which may be artificially deflated in autocracies without a free press and low transparency to report cases of bribery, theft, and excessive rent-seeking, thus generating biased estimates (see Knutsen 2010). Corruption perception measures are also related to several other problems, such as translation and measurement-equivalence issues, ideological biases and sensitivity to current corruption scandals. Hence, perception-based measures may yield different results than experience-based measures of bribery or other forms of corruption (Treisman 2007). Yet, objective measures of rent-seeking or corruption have often been possible to construct only for single countries, and even experienced-based indicators that cover multiple countries and tap into survey-respondents' experience with, 
e.g., police bribes (see the Afrobarometer survey) come with limited time series.

As an exception, recent studies on leaders, rents, and favoritism have employed a more objective measure, based on satellite data on nighttime light activity, to investigate how local economic activity increases in regions from which the chief executive originates (Hodler and Raschky 2014). Yet other studies, more directly related to ours, have investigated how (local) political leaders and elite coalitions manage to expend public resources on excessively costly sports stadiums or events (e.g., Delaney and Eckstein 2003). Interestingly, leaders - also democratically elected ones - may draw on the support of organized local constituencies in the form of fan bases, which have strong interests in constructing (even wasteful) stadiums. Despite these exceptions, the evidence base for a link between regime type and wasteful investment projects is relatively thin, presumably reflecting the lack of relevant measures of such projects that are amenable to systematic comparisons across space and time.

In order to help fill this gap, we conduct an empirical study of how autocratic and democratic countries differ on one type of investment project that leaders may have private reasons to pursue, namely skyscrapers. As we detail below, skyscrapers may be built by private entrepreneurs without much state involvement, by state-affiliated actors or private actors with full funding from the state, or via other ownership and financial arrangements. Private entrepreneurs may also construct skyscrapers with the more indirect involvement of political actors through subsidies, provision of complementary infrastructure, passing regulation that mitigates costs or hindrances to building large structures, etc. As Barr (2012) details by drawing on data from New York City, many skyscrapers - even those financed by private corporations - are economically inefficient. Yet, their costliness as well as the different incentives for political leaders to get involved, mean that political actors and public financing are often involved in their construction. This is corroborated by our investigation of 100 randomly drawn skyscrapers, although - as our theoretical argument anticipates - this exercise shows that there is more frequent political involvement in skyscraper construction in autocracies than in democracies. Thus, albeit to varying extents, skyscraper projects often constitute a substantial drag on public resources. We construct two datasets with extensive time series - one at the country-yearand one at the building-level - drawing from an impressive online archive including all buildings exceeding 150 meters, globally (CTBUH 2016).

The empirical analysis strongly suggests that when countries become more autocratic, they subsequently build more new skyscrapers. This result holds up to controlling for other relevant factors such as income and urbanization, and is not due to skyscrapers being more popular in particular countries (e.g., China or Kuwait) that happen to be autocratic; results are clear even when we control for country (and year) fixed effects. Subsequent analysis on the potential mechanisms suggest that this relationship partly stems from typically more open and critical media environments in democracies, contributing to increased vertical accountability. Other features associated with democracy, such as stronger legislative constraints on leaders, do not seem to play a role. Further, we test different proxy measures of the vanity of building projects. When conducting match- 
ing analysis at the building level, we find systematic evidence that autocratic skyscrapers are more wasteful than democratic ones. Finally, whereas autocratic regimes build (more) skyscrapers regardless of whether they preside over a rich or poor, or urban or rural, society, skyscraper construction in democracies closely follows income and urbanization. Also this latter finding corroborates the notion that skyscraper construction is more attuned to socio-economic cost-benefit calculations in democracies than in autocracies.

\subsection{Argument}

Why would leaders want to channel resources towards projects that cost more than the revenue they are expected to bring in? After all, these projects funnel scarce resources away from productive investments or services widely desired by citizens. One straightforward answer is that they enhance the (private) utility of political leaders, be it through increased personal consumption or, alternatively, through other non-pecuniary benefits such as personal glory or a strengthened hold on power. ${ }^{2}$ Expensive palaces such as the Versailles built under French King Louis XIV, for which some records indicate a pricetag of more than 2 billion 1994 US Dollars (Guiffrey 1901), yield obvious private gains for the leaders residing in them. A more recent example is the new 1150 room, 300,000m² Turkish presidential palace, initiated by President Erdogan. Yet, large, costly buildings - as well as other remarkable projects and events such as high-speed trains, enormous dams, and major sports events - can also serve a signalling purpose for leaders. Such expensive symbols may bring fame and help leaders shape the perceptions of their country's, and by extension their own, power and affluence. Projecting power through expensive construction projects can also be a strategy for leaders seeking to secure their own hold on power. As Svolik (2012, p. 80) notes, "the dictator's outward appearance of invincibility is as important as his actual power". Expensive construction projects can thus contribute to co-opt opposition members, or at least deter potential uprisings, by altering beliefs about the chances of successfully contesting the regime.

One type of building that fits such a power-projecting purpose is the skyscraper. Skyscrapers provide an easily recognizable symbol for a city, or even a country and its regime, and bring international attention and status (as did the palaces and churches of older days). Leaders may prefer building extravagant skyscrapers to physically display the country's - and by extension its leadership's - wealth or capabilities. They, for instance,

\footnotetext{
${ }^{2}$ We note that our argument is mainly intended to pertain to national leaders. Yet, we see no clear reason why the argument is irrelevant for comparing (more or less democratic) leaders at other levels of government, who may sometimes make decisions influencing skyscraper construction. Nonetheless, leaders, as other people, can be motivated by a number of things. Some leaders may be strongly motivated by religious convictions, and large and expensively decorated religious buildings constitute another type of historically prominent "white elephant project". One example comes from Cote d'Ivoire, where President Félix Houphouët-Boigny built the "Basilica of our Lady of Peace" in Yammasoukrou, which was to replicate the Peter's Basilica in Rome in terms of architectural style but with an extra 30 meters to its size. This cathedral is estimated to have doubled the country's national debt (Mark 2015), in a country where only about 20 percent of the population are Catholic.
} 
serve to remind the opposition that the resources of the country are under the control of the incumbent leadership. Large, extravagant skyscrapers are, of course, not the only means that leaders have to achieve such projection of power. Yet, large structures have been popular among political leaders throughout the centuries, with skyscrapers as one of the most common expressions of this in the 20th and 21st century. Arguably, skyscrapers are also more visible than many of their close alternatives, such as dams, spacecrafts, and bridges, and a nice feature of skyscrapers is that they can be placed about anywhere, depending on the preferences of the decision makers. Regarding the cost-effectiveness of skyscrapers, this depends on various factors, including how the building is constructed and the land value of the location. Building a given skyscraper may carry net economic gains in Manhattan, but not in Dubai or Kigali.

Yet, building very tall skyscrapers is, in general, very costly. To take one extreme example, the $1000 \mathrm{~m}$ high Jeddah Tower in Saudi Arabia is projected to cost about $\$ 1.2$ billion upon completion in 2019, equivalent to the total annual public expenditures for Rwanda in 2014. Thus, cost-inefficient skyscrapers are often built or part-financed by states, or by actors with access to public resources such as state-owned enterprises or nominally private firms with strong (family or other) ties to the leader. For instance, the estimated 400 million US Dollar Khan Shatyr Entertainment Centre in Astana, Kazakhstan and the estimated 306 million USD SOCAR Tower in Baku, Azerbaijan, were both fully government financed. Sometimes skyscrapers are even built without being used for any further revenue-generating purpose. The 330m high Ryugyong Hotel in Pyongyang, North Korea - on which construction started in 1987-remains unoccupied even today.

\subsubsection{Why democracies may build fewer and less expensive skyscrap- ers than autocracies: Potential mechanisms}

While all leaders may be tempted to pursue costly projects, such as skyscraper construction, for private reasons, we surmise that they will be less likely to pursue such projects in relatively democratic countries. In general, this is because leaders in autocracies may have stronger incentives to pursue skyscraper projects - even when they are "white elephants" that yield negative social surplus (Robinson and Torvik 2005) - than democratic leaders and because autocratic leaders have greater capacities to pursue such projects in practice. We highlight that in order for skyscrapers to be built, the actors undertaking the investment decision, be they political leaders, company leaders, or a conglomerate of political and business actors, must have both the motivation and the capacity to pursue the project. Hence, factors that increase either motivation or capacity should, given that the other factor is already present above some minimum level, increase the frequency of skyscraper construction. Similar considerations may apply also to other facets of skyscraper construction than merely the decision to build one extra such building, including decisions on the vanity and costliness of structures. Thus, we will review factors that influence the motivation or capacity to build more, or more expensive, skyscrapers. While we will address various factors, we mainly zoom in on three potential mechanisms 
that may link regime type to wasteful projects in general, and costly skyscraper projects in particular. The three mechanisms suggest that autocracies build more skyscrapers than democracies, and two of them also suggest that autocracies build more wasteful skyscrapers.

First, well-functioning vertical accountability mechanisms in democracies - linking the fortunes of leaders to the preferences of their electorates (e.g., Ferejohn 1986)-should mitigate the pursuit of wasteful projects in democracies. Specifically, contested multiparty elections provide dissatisfied citizens with a channel for removing incumbents that expend resources on costly and ineffective projects. Democratic leaders will thus more likely anticipate future personal costs from pursuing such projects. Yet, well-functioning vertical accountability mechanisms presume not only that principals (citizens) can freely select and remove their agents (leaders), but also that the principals are well-informed about the agents' actions (Besley 2006). Importantly, democracies typically provide a richer and more critical information environment than autocracies, which allows voters to be better informed about the costs and benefits of various policies. ${ }^{3}$ Opposition parties or independent media outlets, with the opportunities and incentives to spread information on costs of large-scale projects, will thus mitigate incentives to pursue wasteful projects. Monitoring disciplines spending (and other types of) behavior (e.g., Olken 2007), and forward-looking leaders should, under these conditions, rather channel public resources to presumably more popular items such as primary education or local roads (e.g., Harding 2015). Indeed, vertical accountability mechanisms may, in some (low state-capacity) settings, even deter potentially problematic investment decisions during election years, due to increased scrutiny and voter preferences to mitigate wasteful spending (Pierskalla and Sacks 2018). ${ }^{4}$

Second, well-functioning checks and balances in democracies-with institutions and actors outside the executive being able to affect policy making and even veto executive decisions - provide horizontal constraints on leaders. These relate, for instance, to requirements of passing spending bills through the legislature. While also democratically elected

\footnotetext{
${ }^{3}$ We note, however, that there exists an informational dilemma for autocratic leaders. Signaling incumbent strength, which we argue that skyscrapers can serve to do, is enhanced by increasing (the visibility of) costs of a project. However, this might also increase the demands by elite supporters, and others, for obtaining a larger share of the economy. The latter point, in isolation, suggests that for incumbents engaged in corruption, which we address as our third mechanism below, revealed costs should be low and there may be benefits to hiding information that could signal ample access to resources. Interestingly, in our sample of 100 skyscrapers, there was more information on contractors and investors for those built in democratic countries than those built in autocratic ones.

${ }^{4}$ Different theoretical models - formal and informal-address rent-seeking by leaders, highlighting the conditions under which they can select policies for private gain despite the social costs (see, e.g., Rowley, Tollison, and Tullock 1988). This "moral hazard" problem is exacerbated under weak or no institutionalized mechanisms of accountability and when information is asymmetric and opaque. But, these conditions also amplify issues of "adverse selection" (Besley 2006). Conversely, competitive elections and institutions ensuring transparent information to voters mitigate not only moral hazard but also adverse selection, by enabling voters to screen and select more honest leaders, or leaders with similar policy preferences as themselves. This bolsters the prediction that democracies, due to stronger vertical accountability mechanisms, observe fewer socially wasteful projects than autocracies.
} 
prime ministers might prefer spending on prestigious and costly construction projects for private reasons, legislators accountable to voters in their districts could be less eager to do so (particularly when the projects are located outside their districts). Hence, an empowered legislature could help mitigate wasteful projects in democracies (see North and Weingast 1989), and many democracies have additional "constraining institutions", such as independent judiciaries. In contrast, the relatively weaker institutional constraints placed on autocratic leaders should enable autocrats to pursue extravagant skyscraper projects with less interference.

We note that the two first mechanisms pertain to the capacity of leaders to pursue (many and/or wasteful) skyscraper projects in an unconstrained manner. In the discussion, we thus assumed that leaders are inherently motivated to pursue such projects. Following the discussion from the previous section, we can assume that there are various motivating factors, including vanity or the incentive to signal and project power, for leaders to erect or otherwise encourage skyscraper construction. To the extent that different institutional mechanisms contribute to selecting leaders of different types (Besley 2006), i.e. leaders with different motivations and personal priorities, this might contribute to explain why autocracies and democracies differ in terms of skyscraper construction. Yet, institutional features associated with the democracy-autocracy distinction may also affect the motivation by leaders to pursue such projects, even if the personal preferences of the leaders are similar. For instance, if the lack of free and fair elections and a free press increases the need to project and signal affluence and power to opposition and potential supporters alike in order to avoid a coup or revolutionary threat, autocratic leaders may prefer to expend more resources on building more/more expensive skyscrapers than democratic leaders, everything else equal. Another such mechanism that may increase the motivation of otherwise similar leaders to pursue costly skyscraper projects pertain to how leaders link up to quite different core constituencies under different regimes.

Thus, the final mechanism that we consider pertains to the possibility that autocracies could observe more skyscrapers due to particular links between political leaders and their core supporters under such regimes. All leaders rely on the support of some key constituencies, but in autocracies these constituencies tend to be less encompassing (Bueno de Mesquita et al. 2003) and often dominated by economic elites (e.g., Acemoglu and Robinson 2006). Large-scale construction projects is one helpful tool for autocrats wanting to please their rich and relatively few key supporters, as over-priced building contracts can be used to secretively transfer resources. Even absent such corruption, business elites may prefer public resources being spent on financing or subsidizing skyscrapersfor example through direct transfers, tax breaks, or the government providing cheap inputs - rather than financing, say, primary schools or clinics in rural areas. Indeed, political power concentration with economic elites may lead to more skyscrapers in autocracies even if these skyscrapers are fully financed by private actors. This is because economic elites may influence leaders into pursuing regulatory and other policies of relevance for the building of also privately financed skyscrapers. (One regulatory policy of obvious relevance pertains to maximum height limits on buildings in major cities, but 
also the implementation of zoning plans and provision of complementary infrastructure can affect opportunities for private actors to build skyscrapers.) Interestingly, from the leader's side, channeling resources to core constituencies via such construction projects, might even be more beneficial to the leader if the project is socially wasteful. The reason, as outlined by the theoretical argument in Robinson and Torvik (2005) on the political logic of "white elephant projects", relates to the fact that also other potential leaders could credibly commit to redistributing via socially efficient projects. In contrast, the implementation of a wasteful project redistributing to a particular constituency is often contingent on the particular leader holding power, thus creating a strong bond of mutual gains between the leader and constituents. As such, wasteful skyscraper projects may make political sense to autocrats wanting to channel resources to his/her few and wealthy supporters and thereby shore up support.

If at least one of these three mechanisms are operative, we should observe that fewer skyscraper projects are initiated in democracies than in autocracies. The two first mechanisms on vertical and horizontal accountability also predict that democrats should build less expensive skyscrapers. In contrast, if the dominating mechanism is the third one, suggesting that autocrats transfer funds to core supporters through such construction contracts, we should arguably not expect autocratic skyscrapers to be systematically more extravagant than democratic ones. Illicit transfers of resources via construction contracts to supporters do presumably not require that the buildings are made more wasteful.

The three mechanisms above were presented in a stylized fashion, and there are plausible counter-arguments, or at least caveats, to all of them:

Regarding vertical accountability, also autocrats may be restricted in their actions by the broader public, if not through free and fair elections then through anticipated reactions such as protests, riots and revolts (Acemoglu and Robinson 2006). Further, vertical accountability mechanisms operate with varying degrees of strength also in democracies. Notably, even when freedom of speech and media are formally ensured, the true costs of construction projects can be hidden from the public. This is particularly pertinent in democracies where independent/opposition newspapers or broadcast media are negligible. Regarding horizontal accountability, dictators are seldom all-powerful, as their decision-making powers are restricted by, e.g., regime parties and multi-party legislatures (Gandhi 2008b; Svolik 2012; Wright 2008). Conversely, some democratic leaders operate within (majoritarian) systems that have relatively few institutional veto players. Regarding links with key supporters, also democratic leaders, more than occasionally, engage in corrupt activities (e.g., Rock 2009), and economic elites may carry disproportionately large political influence also in democracies (Przeworski 2010).

These caveats imply that the links between regime type and number and wastefulness of skyscrapers remain empirical questions. They also imply that we could observe systematic correlations between measures of media and the information environment, horizontal checks on leaders, corruption, and concentration of power with economic elites, on the one hand, and measures pertaining to skyscraper projects, on the other, even when 
controlling for democracy.

\subsection{Data}

In order to investigate the various empirical implications from our argument, we collected data on skyscrapers from the Council for Tall Buildings and Urban Habitats' (CTBUH 2016) Skyscraper Center. This online database includes all known human constructions of 150 meters or taller, plus numerous lower buildings. With varying coverage, buildings are accompanied with information on their function, construction materials, number of floors, etc. We developed an automated data-scraping routine (see Appendix A.1) to convert this information into one country-year- and one building-level dataset. Since coverage is incomplete for buildings lower than 150 meters, and the selection criteria are unclear, we restrict our operationalization of skyscrapers to buildings $\geq 150$ meters where we (in principle) have full coverage. There are 7853 structures that are 150 meters or taller in our dataset, and after removing planned and incomplete buildings there are 5048 structures. Further, our baseline excludes industrial structures (e.g., factories with very tall chimneys) and telecommunications masts (including these structures only marginally affects results). This leaves us with 4704 relevant skyscrapers.

Figure 4.1 plots meters and completion year for these relevant structures. Construction technologies have improved since the early 20th century, and skyscrapers are built more frequently in recent decades. Further, the very tallest buildings have become taller, and three current buildings exceed 600m. These "mega-structures" are located in Mecca (Saudi Arabia), Shanghai (China), and Dubai (United Arab Emirates). The global trend in the number of very tall buildings points to the importance of accounting for time-period effects in our regressions.

Next, we leverage information on the years when construction began and ended in order to inform the time-lag used for our covariates. Some building projects took several decades, but for almost the entire time-period the typical skyscraper took 3-4 years to construct (see Appendix Figure 8.1). Thus, we lag all independent variables with 3 years. This should also mitigate reverse causality issues; new skyscrapers built, e.g., in 1998 should not strongly affect level of democracy in 1995.

We construct three types of dependent variables. The first pertains to number of new skyscrapers in a country in a year. The right-skewed nature of this variable means that we mainly employ the natural logarithm of (new skyscrapers+1). Second, we employ the (log-transformed) number of skyscraper-meters $(+1)$ built in a year, capturing that some countries may not only build more, but also taller skyscrapers. Third, we employ measures of "vanity height", defined as distance between the highest occupiable floor and the architectural top of the structure (see Figure 2). These distances capture spires or empty spaces. The 828 meter tall Burj Khalifa in Dubai, for example, carries 244 meters of vanity height, $29 \%$ of total height. We thus aim to capture height that has a symbolic functionwhich could still be in leaders' private interest - but no clear economic function except, 


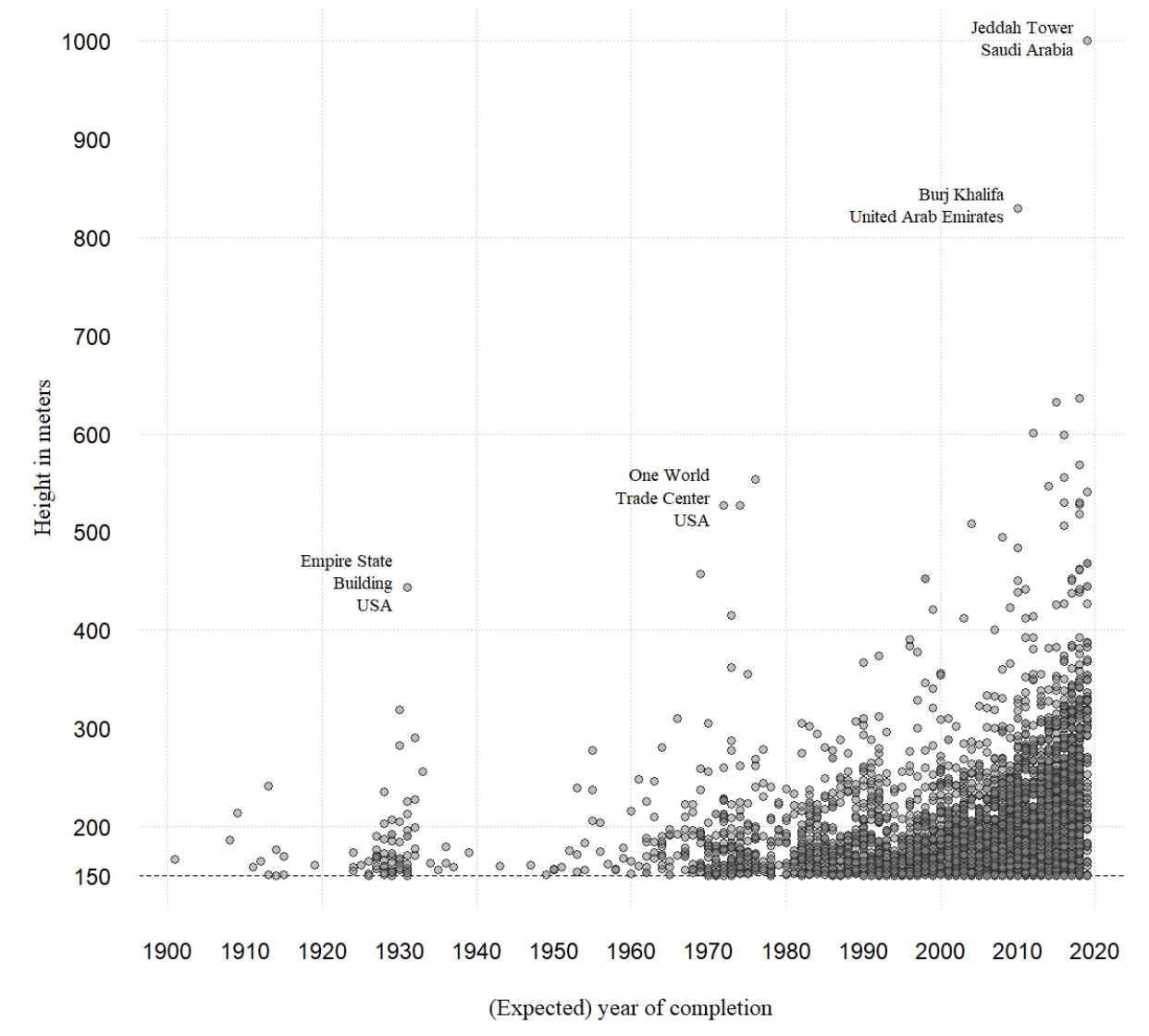

Figure 4.1: Skyscraper height and frequency throughout the 20th century

perhaps, attracting some extra tourists. We try out different specifications, including $\ln$ (vanity meters +1 ), number of vanity meters, and vanity meters/total building height, both for the entire building mass of skyscrapers that year and only for "signal buildings" such as the tallest skyscraper constructed that year.

To measure democracy, we mainly use Polyarchy (Teorell et al. 2018), the main measure of electoral democracy from the V-Dem dataset (Coppedge et al. 2016; Pemstein et al. 2018). Polyarchy includes indicators on whether or not the chief executive is (directly or indirectly) elected, "cleanness" of elections, freedoms of association and speech, and suffrage extension. A weighted combination of additive and multiplicative aggregation is used to capture the partial substitutability between these indicators, and the measure ranges from $0-1$.

Our benchmark is a simple Ordinary Least Squares (OLS) regression controlling for factors that may plausibly affect skyscraper construction and correlate with regime type. First, we control for log GDP per capita from Bolt and van Zanden (2014) (via Coppedge et al. 2016). Higher income levels could make some skyscraper projects economically beneficial, despite the costs of erecting them, and income correlates strongly with electoral 


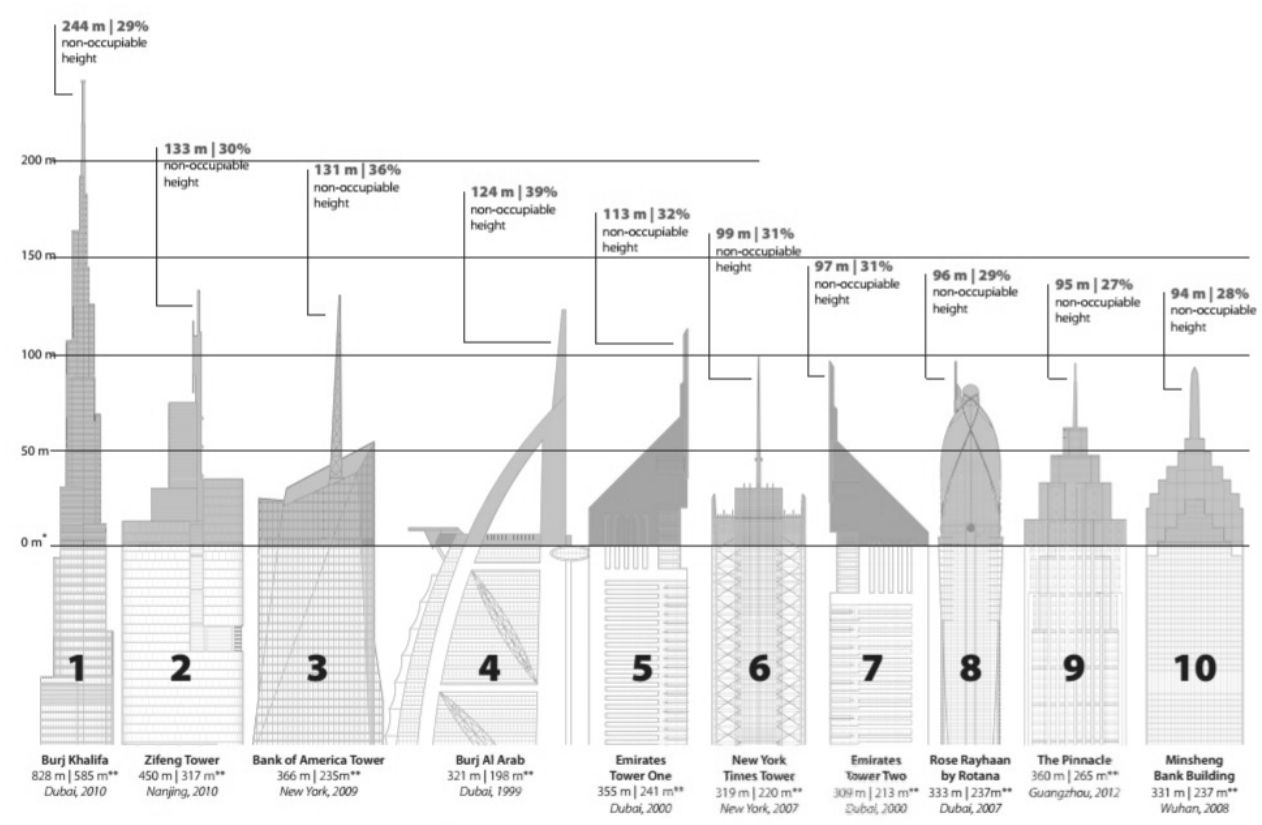

Figure 4.2: The ten buildings in the world with the highest number of vanity meters. Notes: Vanity meters are represented by the colored (top) part of the buildings. Please note that the scale differs on the non-vanity (bottom) part of the buildings. Source: The illustration is taken from CTBUH (2013).

democracy (Knutsen et al. 2019a). Further, we control for log population size (also from Bolt and van Zanden 2014) and urbanization (from WDI, via Coppedge et al. 2016); larger and more urban countries should contain more high-rise buildings simply due to scale and pressures for area-intensive housing. We also control for income per capita from fuels and minerals (from Haber and Menaldo 2011), which are sources of revenue that leaders can more easily monopolize and use for pet projects, including skyscrapers. The benchmark includes country- and year-fixed effects to account for, respectively, relevant countryspecific factors (e.g., related to geography or some cultural affinity for tall structures) and time-varying, global factors (e.g., related to building technology and architectural trends).

\subsection{Empirical Analysis}

In this section, we start out by analyzing the empirical implication that more autocratic regimes build more skyscrapers. We next turn to the implication that more autocratic regimes build more wasteful skyscrapers, first by comparing the characteristics of buildings and second by considering the socio-economic context within which skyscrapers are built. Finally, returning to the first empirical implication on number of skyscrapers, we present tests that speak to the three plausible, but distinct, mechanisms that we surmised may link regime type to skyscraper construction. 


\subsubsection{Tests on numbers of skyscrapers and skyscraper meters}

Model 1, Table 4.1 is our benchmark OLS specification, using $\ln ($ new skyscrapers +1 ) as dependent variable. This specification finds evidence in line with the first empirical implication from our argument: more autocratic regimes are systematically associated with more, new skyscraper projects. Polyarchy is negatively signed and precisely estimated $(p<0.01)$ in Model 1. According to the point estimate, going from maximum (1) to minimum (0) on Polyarchy is predicted to add about one extra new skyscraper three years later. This result holds up across different specifications. For instance, results are fairly similar when we omit country-fixed effects and allow for cross-country comparisons in Model 2, or when we use the raw count of new skyscrapers in Model 3 rather than the log-transformed version used in Model 1.

We also tested a Zero-Inflated Negative Binomial model, where the first stage separates observations without new skyscrapers from those building at least one, thus dealing with the many 0-observations. The second stage considers observations that build $\geq 1$ skyscraper, modelled as a count process. While democracies are not systematically more (or less) likely to be in the 0-skyscraper group, the second stage (Model 4) shows that - among observations building skyscrapers - autocracies systematically build more of them. Model 5, a Random Effects Tobit model with 0 as lower-bound censoring value, also predicts that autocracies build more skyscrapers. Returning to the benchmark OLS specification, Model 6 employs $\log$ (skyscraper meters +1 ) as its dependent variable, and Polyarchy remains negative, although only significant at $10 \%$. Once employing skyscraper meters (untransformed) as dependent variable in Model 7, Polyarchy is highly significant, predicting that going from high-quality democracy (Polyarchy $=1$ ) to dictatorship $(0)$ increases skyscraper meters built in year $t+3$ by almost 150 meters.

We conducted various robustness tests of the specifications in Table 4.1, and these results are presented in Appendices A.3-A.7. To briefly summarize some of the key patterns, the main results on regime type are stable to adding plausible confounders, such as civil war, economic growth in the prior 5-/10-year period, change in urbanization, and the building stock (total number of existing buildings) in $t-1$. Given extant research on the drivers of skyscraper construction, by Barr (2012), we know that growth volatility, rather than average growth rates, may be a key driver of skyscraper building. While investors have preferences to build taller than their competitiors, they must also consider the costs and potential for building "too tall". Barr (2012) argues that the opportunity costs are lowest during booms, and that investments in skyscrapers will therefore follow boom-cycles. Further, several studies find that autocracies much more volatile growth records than democracies (see, e.g., Rodrik 2008). Even if growth volatility is causally driven by being an autocratic regime, and controlling for growth volatility may thus introduce posttreatment bias, we still run models controlling for it, as this represents a very different mechanism to the one posited above. More specifically, we construct running measures of the standard deviation in annual growth rate over the last tenyear period, and include this as a regressor in the benchmark. The results, reported 


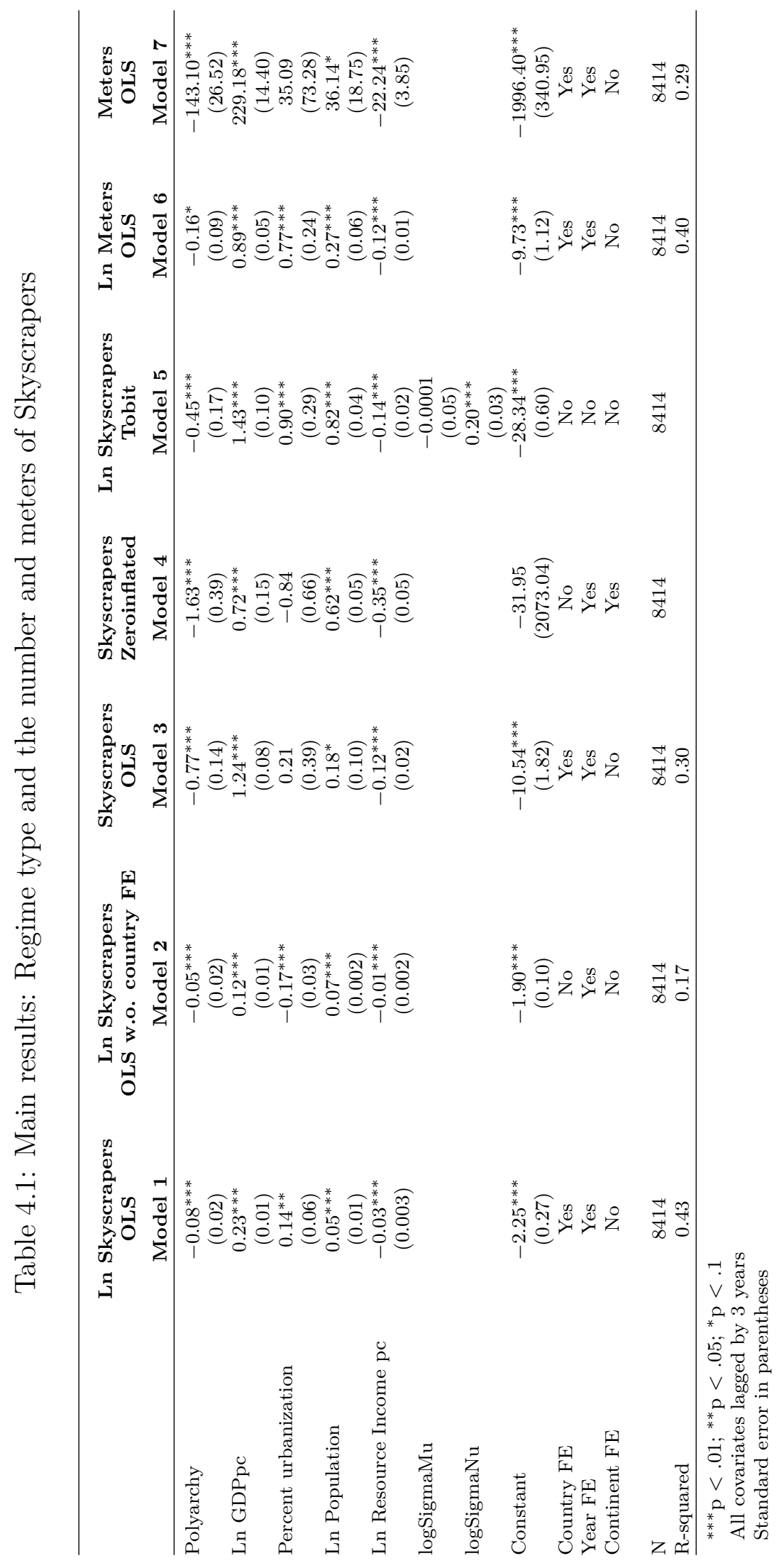


in Appendix Table 8.14, shows that this is not what explains the differences between democracies and autocracies, as the effect of Polyarchy remains mostly unchanged in these models.

The main results are also robust to using other democracy measures than Polyarchy. Further, results are robust to making different operationalization decisions on the dependent variables, such as excluding demolished buildings or counting telecommunication masts as skyscrapers, and to re-running our models on, e.g., post-1945, post-1960, and post-1980 samples. We also re-estimated our benchmark with a jackknife-routine, omitting the 370 most influential observations (Cook's D > 4) seriatim. The point-estimates for Polyarchy are very stable.

One key issue remains: Our argument rests on the premise that state actors, regulatory policies and/or public resources may often influence decisions to build skyscrapers, and that the active use of such sources of political influence, and thus the extent to which "politically induced skyscrapers" occur, will vary according to regime type. We find it plausible to assume that in both democracies and autocracies there may be some purely private skyscrapers, some publicly financed skyscrapers, and some skyscrapers with mixed private-public sources of financing and influences on construction processes. Yet, given the argument on how autocratic leaders may have stronger motivations and fewer constraints associated with skyscraper construction, we expect that the share of skyscraper brought about by public financing or via other political support mechanisms will be higher in autocracies than in democracies. In other words, the results reported above would not reflect our argument well if they are primarily driven by systematic differences between democratic and autocratic countries in the preferences and capabilities of private businesses and real-estate developers (when these differences are unrelated to political decisions). We see no clear theoretical reason for why such business incentives and capabilities to build skyscrapers should be systematically higher in autocracies than in democracies, especially when conditioning on income, urbanization, natural resource income, and country- and year-fixed effects. Still, we wanted to check that our results are not driven simply by state-controlled economies building more (or less) skyscrapers, and that state ownership and control over the economy, more generally, happens to differ between democracies and autocracies. ${ }^{5}$ However, our results are stable when controlling for the indicator on state ownership and control of the economy from V-Dem (Appendix Table A.7). ${ }^{6}$

To more directly investigate our key assumption on political involvement, we scru-

\footnotetext{
${ }^{5}$ The power of regional administrations could also differ systematically between autocracies and democracies, while this is more likely an effect than cause of differences in regime type. Nonetheless, if regional governments control a larger share of resources, heads of state will have reduced capability to support costly projects. But, regional leaders in autocratic systems may have similar incentives as national leaders. Non-accountable regional strongmen could, for instance, allocate available funds to skyscrapers in the regional capital to signal prestige or reward local supporters. Thus, it is hard to predict the overall effect of, say, a federal structure on skyscraper construction.

${ }^{6}$ The reason we excluded this variable from our benchmark is that this coding could be post-treatment to V-Dem country experts observing that leaders build skyscrapers with state resources.
} 
tinized a (stratified) random sample of 100 skyscrapers - 50 each in below- and abovemedian Polyarchy observations. Indeed, scrutinizing and establishing ties between political elites and contractors is far from easy (for a careful case study on contractors in road building in India and ties to politicians,see Lehne, Shapiro, and Eynde 2018), and is often made even more difficult by the incentives of the involved actors to hide any connection, especially in the case of outright corruption or patrimonial relationships. While comparable measures on the exact amount of state subsidies for skyscrapers do not exist, CTBUH provides information, for some observations, on firms involved in the construction process, and for many additional projects such information is available from other online sources. ${ }^{7}$ We thus investigated whether skyscrapers are fully or partly public funded, whether involved firms are state-owned, and whether involved firms are otherwise linked to the political regime (e.g., owned by a close relative of the leader or by a party member). We employed a conservative routine, only coding state involvement if this was explicitly identified in credible sources.

Among the 50 skyscrapers in relatively democratic countries, we were able to retrieve relevant and credible information for 46 of them (92\%), whereas the corresponding number is $32(64 \%)$ for autocracies. We note that this difference in easily available information across regimes dovetails nicely with extant research on regime type and transparency (Hollyer, Rosendorff, and Vreeland 2011). For the skyscrapers where we found information on ownership or financing, we identified state- or regime-affiliated ownership or financing for $50 \%$ of autocratic skyscrapers and $28 \%$ of democratic ones. Given our conservative coding rules for identifying and registering state involvement, our informed guess - also based, e.g., on the majority of autocratic skyscrapers with missing information being located in China, where state financing presumably dominates - is that our numbers almost certainly underestimate the extent of state involvement, especially in autocracies. In sum, although there are various financing arrangements and degrees off political involvement in different construction projects in both democracies and autocracies, this exercise provides strong support for the expectation that skyscrapers are more often the result of political actors and public financing in autocracies than in democracies. Thus, the findings are consistent with the notion that politics plays a key role in explaining the observed higher propensity of autocracies to build skyscrapers.

\subsubsection{Which types of skyscrapers do autocrats build and in what contexts do autocrats build skyscrapers?}

So far we have focused on the hypothesis that autocracies build more skyscrapers than democracies. But, despite our attempts to identify and account for alternative explanations, we certainly cannot exclude the possibility that other differences (than the theorized ones) between regimes drive our results. In order to further assess our argument - on how

\footnotetext{
${ }^{7}$ Yet, the lack of easily available and transparent information for many buildings, and especially the ownership status of involved companies, makes this time-consuming to code. This explains why we investigate only a sample.
} 
autocratic leaders more freely can pursue projects that yield personal benefits such as glory, recognition or projection of power, but that are socio-economically costly - we thus turn to testing our second set of observational implications. These implications pertain to autocratic skyscraper projects being more wasteful than democratic ones. First, we test the expectation that otherwise comparable buildings are more excessive in autocracies than in democracies. Conditional on skyscrapers being constructed, autocrats should be freer to spend more resources on buildings being tall and elegant, and care less about their economic costs. While we unfortunately do not have high-quality, comparable data on building costs and revenue streams generated, we do have proxies that should provide fairly strong signals on the vanity of skyscraper projects. Second, certain contextual factors should make building skyscrapers socio-economically beneficial — or, at least, less wasteful - and our argument suggests that democratic leaders need to be more attentive to such concerns. Urbanization is one important contextual factor for which we test this implication: Skyscrapers should make more socio-economic sense in highly urbanizedthan in rural societies.

Concerning the first set of tests, we employ the vanity measures discussed in the data section. To reiterate, these measures leverage information on distance in meters between the top of the skyscraper and the highest occupied floor, proxying for the part of the building with no economic activity. (If autocrats also build skyscrapers where lower floors are left unoccupied to boost total height, our analysis will underestimate the relationship between autocracy and skyscraper vanity.) Using different versions of this measure (e.g., logged vs non-logged vanity meters, percent vanity meters for all buildings or only for the tallest new building in a year), we find negative relationships with Polyarchy in our benchmark country-year specification. These results are reported in Appendix A.8.

Table 4.2: Skyscraper excessiveness: CEM-matching at the building-level

\begin{tabular}{lccc}
\hline & $\begin{array}{c}\text { Percent } \\
\text { Model 1 }\end{array}$ & $\begin{array}{c}\text { Ln meters } \\
\text { Model 2 }\end{array}$ & $\begin{array}{c}\text { Absolute meters } \\
\text { Model 3 }\end{array}$ \\
\hline Polyarchy (above median) & $-1.44^{* *}$ & $-0.13^{* *}$ & -2.73 \\
& $(0.57)$ & $(0.06)$ & $(1.72)$ \\
Ln height to top occupied floor & -2.86 & $0.62^{* * *}$ & $30.19^{* * *}$ \\
& $(1.78)$ & $(0.17)$ & $(5.35)$ \\
Part of building-complex & $-6.63^{* * *}$ & $-0.65^{* * *}$ & $-21.68^{* * *}$ \\
Building function: Office & $(1.77)$ & $(0.17)$ & $(5.32)$ \\
& -1.83 & -0.26 & -8.41 \\
Building function: Residential & $(2.96)$ & $(0.29)$ & $(8.89)$ \\
& -1.02 & -0.002 & -6.33 \\
Constant & $(2.26)$ & $(0.22)$ & $(6.76)$ \\
& $31.63^{* * *}$ & 0.27 & $-113.60^{* * *}$ \\
Decade FE & $(10.23)$ & $(1.00)$ & $(30.69)$ \\
Matched subclass FE & Yes & Yes & Yes \\
N & Yes & Yes & Yes \\
R-squared & 592 & 592 & 592 \\
***p $<.01 ;{ }^{* *} \mathrm{p}<.05 ;{ }^{*} \mathrm{p}<.1$ & & 0.20 & 0.21 \\
Standard error in parentheses & & & \\
\end{tabular}

Next, we constructed a dataset with buildings as units, and conducted Coarsened Ex- 
act Matching (CEM) (Iacus, King, and Porro 2012) comparing otherwise similar buildings in relatively autocratic and democratic countries. Since CEM demands categorical variables, we divide Polyarchy by its median sample-value. We match buildings on meters to the highest occupied floor (divided by sample-median), decade completed, being part of a building complex, and office and/or residential functions. We subsequently control for all matching variables plus decade- and matching-subclass fixed effects in an OLS regression when estimating the association with Polyarchy. Models 1, 2, and 3 in Table 4.2 employ, respectively, vanity meters as percentage share of skyscraper meters, $\ln$ (vanity meters +1 ), and absolute vanity meters as dependent variables. Polyarchy is consistently negative, though insignificant in Model 3. We tested additional specifications (see Appendices A.8-A.10), for example dropping controls post-matching, matching on extra country-level covariates, and employing Entropy Balancing (Hainmueller 2011). Polyarchy is fairly, though not entirely, robust. Using similar specifications as in Table 4.2 , we also find that autocratic skyscrapers have more meters per floors and meters per ground floor area, further corroborating the notion that autocratic skyscrapers are, on average, more wasteful than democratic ones.

We also conducted tests trying to account for various alternative explanations. First, the correlation between regime type and skyscraper height, or vanity, may be driven by what goes on in the capital, or alternatively another major urban centre, in autocratic countries. Ades and Glaeser (1995) detail how political factors may drive large urban agglomerations, and that the largest cities in autocracies are, on average, 50 percent larger than comparable cities in democracies. High property prices and resulting pressure on building tall buildings in autocratic capitals may thus explain the regime difference. However, we coded whether or not a building was located inside or outside the capital, and ran split-sample tests on a capital and an outside-the-capital sub-sample. The pattern does not suggest that our results reflect differences in skyscraper construction in autocratic and democratic capitals, rather to the contrary. Conditional on a skyscraper being built, democracies are more likely to locate the skyscraper in the capital. Further, when we repeat our baseline model on capital/non-capital sub-samples (see Table 8.9), the predicted regime patterns are much stronger outside the capital. ${ }^{8}$

Finally, certain contextual factors should make building skyscrapers socio-economically beneficial - or, at least, less wasteful - and democratic leaders are expectedly more attentive to such concerns. The discussion so far has mainly focused on how skyscrapers are often a waste of resources - although to differing degrees, following our discussion of vanity meters. Yet some skyscraper projects are associated with economic benefits that outweigh costs, especially in metropolitan areas with limited space and high property prices such as Manhattan or downtown Tokyo. Since extensive, comparative data on property prices where skyscrapers are built are unavailable, we use cruder proxies to in-

\footnotetext{
${ }^{8}$ We note that this is in line with the result discussed directly below on autocracies being less sensitive to urbanization than democracies when it comes to constructing skyscrapers. However, we also note that most results, even in the non-capital sub-sample, fail to achieve conventional levels of statistical significance.
} 

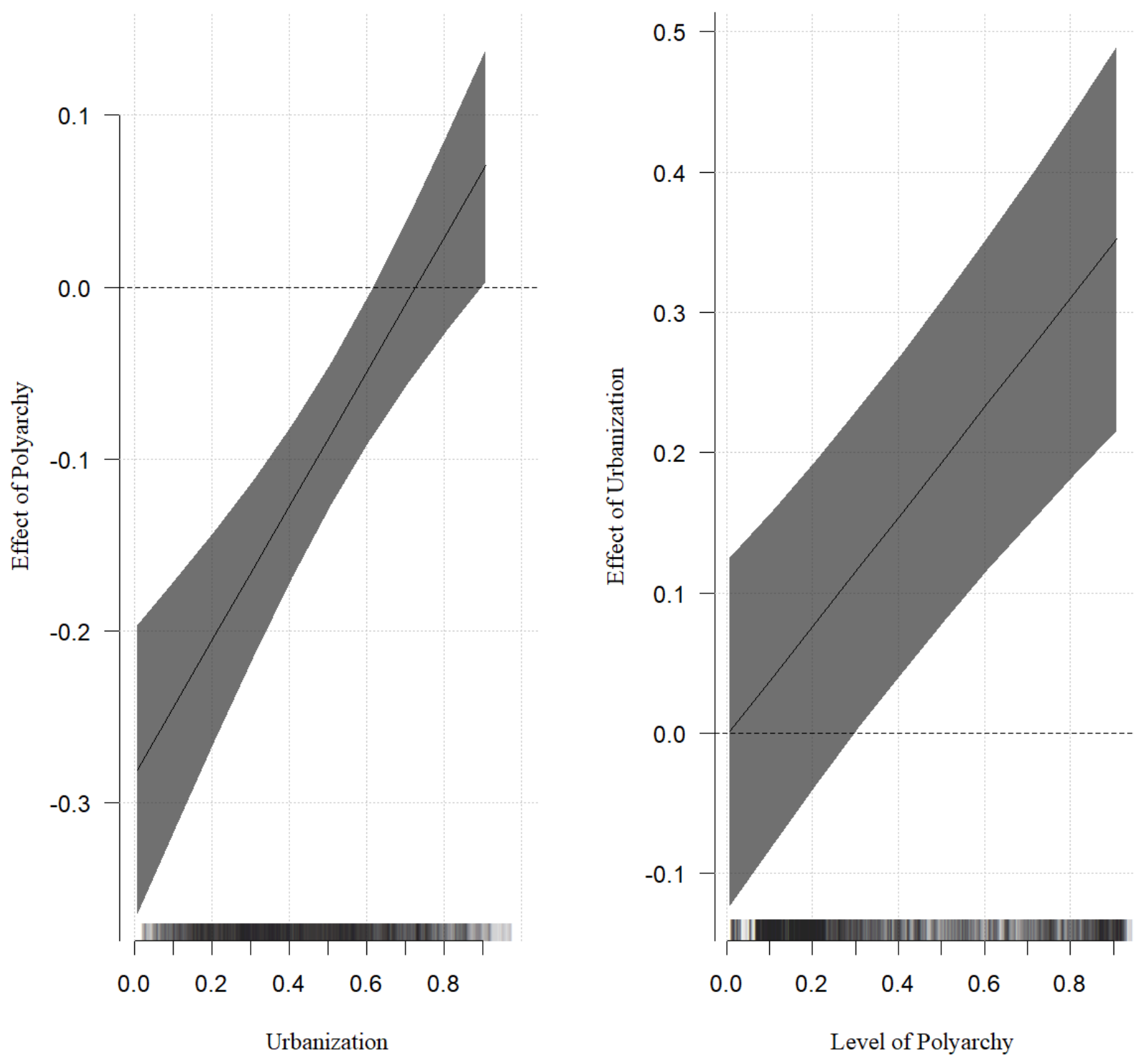

Figure 4.3: Interaction between Polyarchy and urbanization, marginal effects.

Notes: Point estimates and 95\% confidence intervals are based on Model 1 of Appendix Table A.21, with $\ln$ (skyscrapers +1 ) as dependent variable. Observation densities are indicated by transparent lines for each observation along X-axes.

vestigate whether autocracies are less responsive to such economic calculations. Notably, skyscrapers are, on average, likely to be more cost-efficient in urbanized societies, with higher demands for offices, hotel rooms, and housing in geographically limited spaces. We thus extend our benchmark (Model 1, Table 4.1) by including a multiplicative interaction term between Polyarchy and urbanization. 
Figure 4.3 illustrates the results. The leftmost diagram shows that autocracy is associated with more skyscrapers being built not only in very rural societies, but also in fairly urban ones (up until where about two-thirds of the population live in cities). For the most urbanized societies, however, there is no clear relationship between regime type and skyscrapers. The rightmost diagram shows that whereas urbanization is associated with more skyscrapers in "mixed" and democratic regimes, there is no systematic relationship in more autocratic regimes. In stark contrast with fairly democratic regimes, harsh dictatorships seem equally eager to build skyscrapers independent of whether they preside over rural or urban societies. When interacting Polyarchy with GDP per capita instead of urbanization (Appendix A.11), we find similar patterns. This provides further indications that autocracies tend to experience more wasteful construction projects than democracies.

\subsubsection{Investigating mechanisms}

Finally, we try to come closer to an empirically informed answer on why it is that regime type matters for skyscraper construction. More specifically, we assess which (if any) of our proposed mechanisms that generate the link between regime type and skyscrapers. To quickly recapitulate the discussion from the theory section, we proposed, first, that democracy may mitigate the building of expensive skyscrapers due to vertical accountability mechanisms. Well-informed voters could penalize politicians expending scarce resources on wasteful project, thus disciplining politicians seeking re-election. Second, the typically stronger horizontal constraints on democratic leaders could mitigate skyscraper building. Third, skyscraper projects may be used (more often) by autocratic leaders to please a few core (elite) supporters, for example by funnelling resources to them through providing artificially inflated contracts.

Disentangling these mechanisms and coming up with definite answers to which one is relatively more important is, admittedly, very hard. Yet, we can provide suggestive evidence. While features such as institutional checks on the leader and control of corruption are generally more prevalent in democracies, regimes display different combinations of institutional features. There are corrupt (Indonesia) and non-corrupt (Denmark) democracies, and autocracies with relatively weak (Zaire under Mobutu) and relatively strong (Mexico under the PRI) institutional checks on leaders. The V-Dem dataset (Coppedge et al. 2016) allows us to capture such nuances, and track fine-grained institutional developments for countries across our entire time period. As in the previous section our baseline measure of democracy is Polyarchy. But, we employ other, and more specific, VDem indicators pertaining to the different mechanisms in a simple set-up, adding these variables seriatim to our benchmark. If Polyarchy drops markedly in size and significance once controlling for an indicator, and the indicator is systematically linked to the dependent variable, this provides suggestive evidence that the associated mechanism is operative. ${ }^{9}$

\footnotetext{
${ }^{9}$ We write "suggestive evidence" since such mediation tests rest on strong assumptions, and results
} 


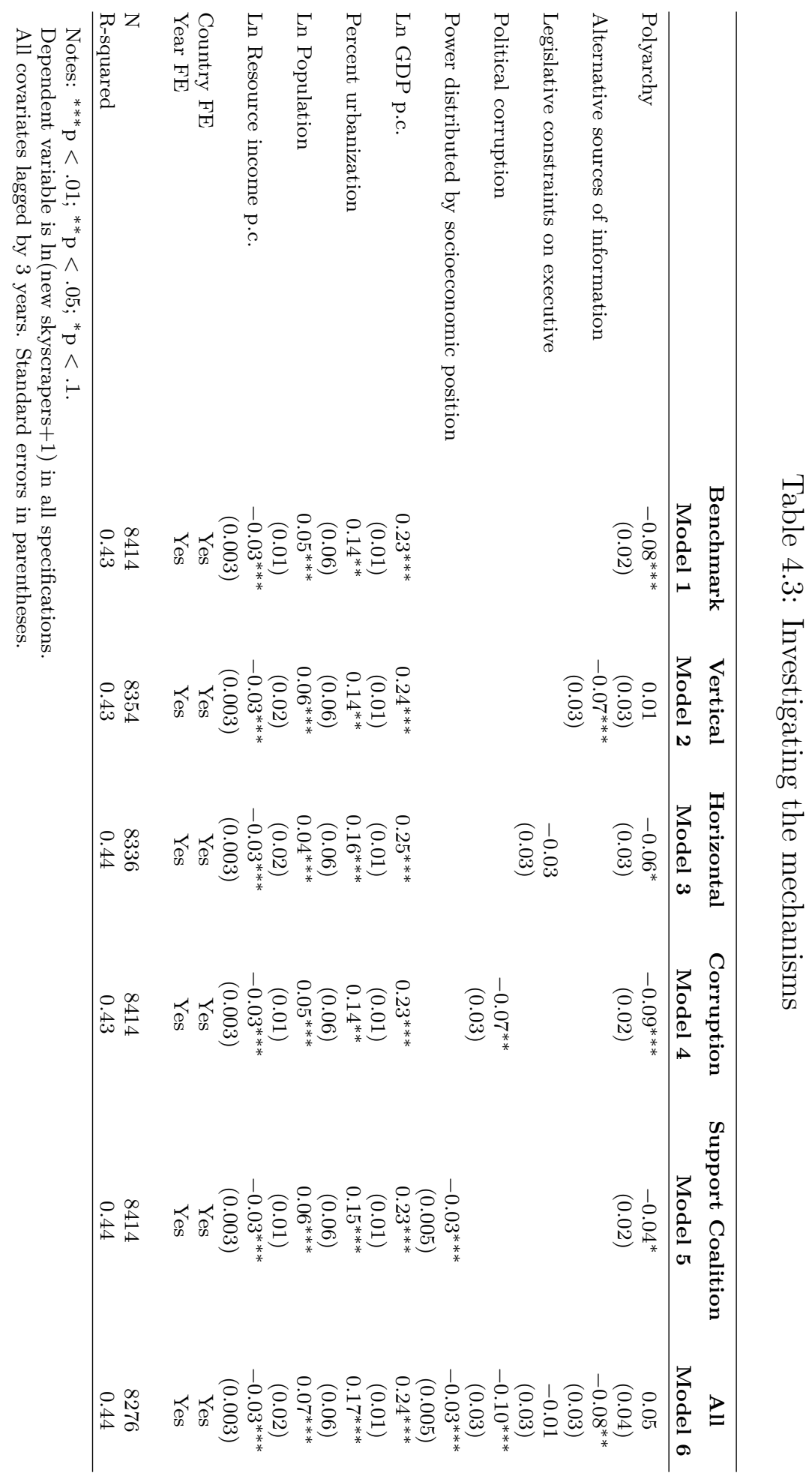


Model 1, Table 4.3 replicates the benchmark on $\ln$ (number of new skyscrapers +1 ) (Model 1, Table 4.1). The Polyarchy coefficient is -0.08 and highly significant. Model 2 includes our favored proxy of the vertical accountability mechanism-reflecting that informed voters are a requisite for disciplining politicians - namely V-Dem's "Alternative Sources of Information Index" (ASI). ASI captures the extent to which the media is "(a) un-biased in their coverage (or lack of coverage) of the opposition, (b) allowed to be critical of the regime, and (c) representative of a wide array of political perspectives" (Coppedge et al. 2016). ASI correlates fairly strongly (.87), though not perfectly, with Polyarchy overall, and the within-unit correlation is .82. Polyarchy actually flips sign, to 0.01 , but is statistically insignificant once controlling for this index in Model 2, Table 4.3. Once accounting for differences in the information environment, democracies do not build more skyscrapers than autocracies. Further, ASI is negative and significant at the 1 percent level. This suggests that informed citizens are critical for disciplining politicians, and this could, to a large extent, account for why democracies build fewer skyscrapers than autocracies.

We do not find similar support for the other potential mechanisms. Model 3 includes our favored proxy for the horizontal accountability mechanism, namely V-Dem's Legislative Constraints on the Executive Index (LCI). Overall, the bivariate correlation with Polyarchy is .81, but the within-unit correlation is .72. In Model 3, Table 4.3, Polyarchy, which remains weakly significant, only changes from -0.08 to -0.06 when controlling for LCI. Further, LCI is not clearly separable from zero.

One might speculate that the institutions theorized to constrain executives from pursuing wasteful projects could fail to work, in practice, if they are populated by actors who themselves find such projects attractive. Our third mechanism points to situations where leaders pursue skyscraper projects exactly because they benefit key supporters. One is environments that allow for embezzlement and bribes, as large building projects provide great opportunities for self-enrichment for those involved. If so, the association between autocracy and skyscrapers may be "explained" by autocracies being more corrupt. We discussed above how perception-related measures of corruption may be problematic, and PCI relies on several expert perception-based measures of more specific notions of bribery and embezzlement. Ideally, we should have complemented this analysis with one using more objective measures of corruption, which might have given different results (Treisman 2007), but no such measure with comparable country- and time-series coverage exists. Nonetheless, the bivariate correlation between Polyarchy and V-Dem's Political Corruption Index (PCI) is .47, and their within-unit correlation is .10. However, Polyarchy actually increases slightly in size once accounting for PCI in Model 4, and more corrupt countries are - in contrast with expectations - predicted to build fewer skyscrapers. We also tested whether autocracies build more skyscrapers because political power is more strongly skewed towards economic elites, who may prefer building fancy skyscrap-

can be quite sensitive. This is particularly relevant here, since our argument suggests multiple plausible mechanisms, and omitting relevant mediators may induce bias if the included and omitted mediators correlate. 
ers rather than prioritizing, e.g., schools or clinics for the wider population. Polyarchy correlates .62 with V-Dem's indicator on political power distribution by socioeconomic position (PPSP), and the within-unit correlation is .55. Model 5 predicts that the more concentrated political power is with economic elites, the more new skyscrapers are built. Polyarchy drops when controlling for PPSP, but remains sizeable (-0.04) and significant at the 10 percent level. The Polyarchy coefficient from Model 5 also lies well within the 95 percent confidence interval of Polyarchy from the baseline. Hence, the evidence on this mechanism driving the net relationship is not clear.

Model 6 controls for all four proxies simultaneously, and results are stable for all the mediators. As in Model 2, Polyarchy flips sign (0.05) but is statistically insignificant. In sum, we find suggestive evidence for the notion that democracies build fewer skyscrapers due to vertical accountability mechanisms; well-informed voters may discipline democratic leaders interested in re-election from engaging in such projects. To a lesser extent, we also find some indications that autocracies build more skyscrapers due to stronger concentration of power with economic elites. In contrast, there is little evidence that democracies build fewer skyscrapers because leaders are checked more strongly by powerful legislatures.

We also conducted a number of other tests that either speak indirectly to the mechanisms discussed above or tap into alternative mechanisms that may link regime type and skyscraper construction. Specifically, we first test an alternative mechanism pertaining to differences in property rights protection. Democracies, in general, provide stronger protection of property rights than autocracies (Knutsen 2011). Further, a strict property rights regime may deter the construction of skyscrapers. Lax environmental and zoning requirements, as well as the possibility to acquire property and demolish old infrastructure - even occupied houses in urban areas attractive for skyscraper construction - are important practical requisites for the construction of skyscrapers. Insofar as democracies protect the rights of existing property owners, and display other regulatory standards that hinder skyscraper construction in practice, this may be a key reason behind the correlations discussed above. ${ }^{10}$ However, protection of property rights also affects the private sectors' willingness to invest, and is likely to increase private investments in skyscrapers when this is profitable. To test this alternative mechanism, we add the property rights protection index from V-Dem, covering the entire time series and original sample, to the benchmark model. The results are reported in Appendix Table 8.20. We find that protection of property rights increase the expected number of skyscrapers, but that the regime effect is retained, and in fact becomes even stronger, once controlling for property rights.

Finally, we investigate whether different types of autocracies differ systematically

\footnotetext{
${ }^{10}$ Several specific policy measures, such as schemes for land taxation or particular environmental or building standards might also affect skyscraper construction. Yet, controlling for such measures would be problematic if the aim is to obtain unbiased estimates of the net effect of regime type on skyscraper construction, rather than investigate mechanisms - these policy measures are likely posttreatment to regime type. Nonetheless, studying policy differences between regimes as potential mechanisms would require comparable data across countries and time on the policy in question, and such data are sparse.
} 
in terms of skyscraper construction. To this end, we draw on data from Anckar and Fredriksson (2018), who have recently extended the coding from Geddes, Wright, and Frantz (2014) backward in time. This allows us to investigate whether there are differences between party-based autocracies, monarchies, personalist regimes, military regimes, and other autocracies in terms of how many skyscrapers they build and the vanity of these skyscrapers. The results, presented in Appendix Table 8.13, suggest that monarchies and party-based autocracies, but also to some extent personalist regimes, display the largest and clearest differences with democracies on different outcome variables. There is less evidence that military regimes and "other" types of dictatorships differ systematically from democracies.

\subsection{Conclusion}

We have argued that the weaker accountability mechanisms in autocracies enable leaders to spend more freely on costly and ineffective projects that these leaders prefer for personal reasons. Historically, grand castles and churches were typical examples of such projects. A more recent example is the skyscraper. Being remarkable buildings that stand out in the landscape, skyscrapers are often viewed as symbols of the power, glory, and greatness of countries and their leaders. But, building skyscrapers is also costly, and fully funding or subsidizing such projects will often detract resources from more mundane investments in local roads, schools or health clinics throughout the country. While many skyscrapers are privately funded, our investigations into a random sample of skyscrapers worldwide suggest that state-owned enterprises, various political initiatives and public funding arrangements are prevalent in skyscraper construction in democracies and, especially, in autocracies. Hence, while leaders and elites may adore them, local populations may prefer to limit the construction of large skyscrapers, especially in poor countries where resources are scarce.

Several of our posited mechanisms are valid for public investments more generally. While incentives related to the extravagant nature of skyscrapers, such as power projection or personal preferences of political leaders, are more specific for "white elephant" projects, other mechanisms, such as fewer regulatory constraints and greater opportunity to invest in physical infrastructure that favors some important constituency, should be relevant for investment in physical infrastructure more generally. How important these different motivations and constraints truly are, could thus be further elaborated on by employing designs such as those used in this paper to different types of infrastructure and other investment projects.

Our empirical analysis shows that autocracies build more new skyscrapers (and meters of skyscrapers) than democracies. Further analysis suggests that autocratic regimes tend to build more excessive such buildings, and, in contrast with democracies, build skyscrapers regardless of whether the country is urbanized or not. This further corroborates the notion that autocratic leaders are freer to pursue projects that generate "private rents", 
broadly conceived, at the expense of wider society. Going forward, systematic empirical studies on other types of construction projects and different proxies for rents, for instance assessing the private residencies of leaders, would allow us to better gauge whether our findings on skyscraper projects are generalizable. This would, however, require the systematic collection of new data. 


\title{
5 Presidents, parliaments and the allocation of public investments during elections.
}

\author{
Haakon Gjerløw
}

\begin{abstract}
:
Theories on how autocrats co-opt their opposition rest on at least two central but contested assumptions: that legislators are sufficiently empowered to demand concessions from the president, and that even unfree elections are competitive enough to discipline political elites. In the case of public investments in both autocratic countries and developing democracies, I find support for both of these crucial assumptions. Using data on georeferenced investment projects across Africa, I find that these investments are more in line with the president's preferences prior to presidential elections, but more in line with legislators' preferences close to legislative elections. Taken together, the findings suggest that legislators in such systems do have the power to demand concessions from the president, and that even unfree elections can discipline political elites. This has important implications for the allocation of multi-million dollar investments.
\end{abstract}

Publication status:

Not submitted 


\subsection{Introduction}

Executives and legislators often have significant powers to allocate public expenditure. Different institutional settings dictate whether and how elites can use investments to manipulate support. A central question is whether such actors in autocratic systems can and will use their powers to allocate investment to try to win the support of critical parts of the electorate (Blaydes 2010; Gandhi 2008b; Gandhi and Lust-Okar 2009; Gehlbach, Sonin, and Svolik 2016; Jensen, Malesky, and Weymouth 2014; Miller 2015c; Wright 2008).

I present a two-fold argument in this paper. First, I argue that elections, even unfree, give political leaders motivation to allocate investments towards important electoralgroups. This need not be economically optimal or have redistributive consequences, but follows incentives produced by the electoral systems. There are several theories on why non-democratic leaders might prefer elections, especially related to how these can be used to co-opt opposition and increase the stability of the regimes (see for example Gandhi and Lust-Okar 2009; Gandhi and Przeworski 2006; Gandhi and Przeworski 2007; Knutsen, Nygård, and Wig 2017). However, I argue that as a necessary consequence, these leaders must accommodate certain social groups that are important both for popular support and in order to conduct electoral fraud.

The second part of the argument is that since both the parliamentarians and the president face the threat of electoral loss, the actors within these two institutions are both motivated to use public expenditure to their advantage. However, neither group is capable of perfectly allocating investments according to their will in cases where presidential and parliamentary elections co-occur. If the leader needs support from some of the parliamentarians, as part of the leader's strategy to co-opt their opposition, he or she must oblige these parliamentarians' demand for some of the investments. This contributes to another debate on the role of parliaments in non-democratic and developing democracies. Just as with elections, there are reasons to believe that non-democratic leaders are interested in legislatures because these can help stabilize their rule. For example, parliaments formalize the bargaining-process and can help elites achieve more efficient outcomes, through alleviating commitment problems and reducing uncertainty (Fearon 2011). However, scholars do not agree on whether parliamentarians in such regimes are duly empowered to constrain their non-democratic leader (see for example Jensen, Malesky, and Weymouth 2014).

I test these hypotheses by investigating the geographical allocation of multi-million dollar investment projects prior to election years across Africa in the period 2000-2011. The African political systems have long been characterized by a strong centralization of power around the presidency (van de Walle 2003). However, due to the lack of data on constituencies and electoral support (which, in any instance, could be uninformative due to electoral fraud) from most of the African countries in this period, I need to introduce assumptions about where the president and parliamentarians want to allocate investments. To do this, I lend insights from principal-agent models and historical accounts of 
African electoral behavior (De Luca et al. 2018; Kasara 2007; Stokes et al. 2014; Meredith 2011). These predict that African leaders have an electoral interest in their home regions where they can mobilize the help from a trustworthy network of agents.

In the empirical analyses, I show that the average distance between investment locations and the birthplace of the Head of State (HOS) is reduced by $57 \%$ prior to a presidential election, but that this effect vanishes if a parliamentary election is held in the same year. The results are robust to including leader and year fixed effects and stable across a series of jackknife estimations. Furthermore, the effects vary with the electoral formula of the parliamentary elections. In line with existing literature on investment allocation and elections in democracies (Fiva, Halse, and Smith 2018; Gordon and Simpson 2018), the patterns are limited to legislative elections with majoritarian electoral formulas, where individual members of parliament more easily can capitalize politically on such investments.

The results are not driven by alternative hypotheses, for example, that leaders might simply have general altruism towards the home-region irrespective of elections. Only in the year prior to elections is there an increase in spending towards the home area (this, of course, does not rule out that the leaders also have general altruism towards this area). In placebo tests, I find that if the leader was born outside of the country they rule or if fake elections are randomly allocated to various years, elections have no relationship with allocation towards their home region.

There is no systematic difference between democratic countries and autocratic countries. The fact that elections affect the allocation of public spending equally in autocratic and democratic systems is evidence in favor of two central assumptions in the literature on autocratic governance, namely that legislatures are sufficiently empowered to demand concessions from the president, and that politicians in such systems, at least to some degree, fear electoral loss in spite of elections being unfree and unfair (Gandhi 2008a; Jensen, Malesky, and Weymouth 2014; Lust-Okar 2006; Miller 2015c; Wright 2008).

\subsection{Legislatures, elections, and resource allocation}

To map out where I make my contribution, I give a brief summary of the role of legislatures and (presidential and legislative) elections in developing- or non-democratic systems, before presenting my hypotheses.

Legislatures can function as platforms where elites ${ }^{1}$ make compromises (Boix and Svolik 2013; Gandhi and Przeworski 2006; Gandhi 2008b). In both non-democratic countries and young, developing democracies, formalizing the bargaining-process can help elites achieve more efficient outcomes, through alleviating commitment problems and reducing

\footnotetext{
${ }^{1}$ In the following, I use the term "elite" to include both the president and MPs but also candidates attempting to get a seat in parliament. I use the term leader, president, and head of state (HOS) interchangeably. Candidates for parliament include individuals attempting to get a seat in parliament but which might not yet have won a seat.
} 
uncertainty (Fearon 2011). This has several important consequences for governance, such as stability and greater economic growth (Gandhi 2008a; Gehlbach and Keefer 2011).

A point of discussion is whether the existence of elected legislatures does anything to help policy congruence between voters and elites, beyond what is in the personal interest of the members of parliament (such as protection of property rights), when elections are far from free and fair (Blaydes 2010; Chauvet and Collier 2009; Jensen, Malesky, and Weymouth 2014; Little 2017; Lust-Okar 2006; Miller 2015c; Wright 2008). From the literature, we know that elections in autocratic systems, but also in developing democracies, can serve at least three purposes. First, elections can be used by the incumbent leader to split-and-conquer the opposition. By promising different private goods, such as political advancement, to electoral winners, leaders can effectively have opponents to their power compete against each other, increasing the collective action problem of these opponents in uniting against the ruling regime (Gandhi and Lust-Okar 2009). It is also possible that the concessions offered have a direct effect by reducing opponents' willingness to challenge the regime (Gandhi and Przeworski 2006; Gandhi and Przeworski 2007). Second, and related to this, elections provide information about regime support across the population, as well as the strength of the opposition, which leaders in turn can use to decide the correct level of concessions (or repression) (Cox 2009; Malesky and Schuler 2011; Miller 2015b; Levitsky and Way 2010; Little 2017; Wig and Rød 2014; Zaslavsky and Brym 1978). Third, elections can signal strength if the ruling elite is (or pretends to be) popular, thereby increasing the legitimacy of the regime both domestically and internationally (Beaulieu and Hyde 2009; Levitsky and Way 2010; Little 2015; Little 2017; Magaloni 2006; Simpser 2013). For a regime seeking survival, elections have a lot to offer (Knutsen, Nygård, and Wig 2017). At least the two latter mechanisms are also relevant for presidential elections. ${ }^{2}$

In the most pessimistic accounts, unfree elections have no effect on, and can possibly even be detrimental to, citizen welfare. The president can give personal goods to members of the opposition in exchange for their support, which stabilizes the governing regime, and at the same time makes the opposition accountable to this leader, and not the electorate (Chauvet and Collier 2009; Lust-Okar 2006; Woo and Conrad 2019). Others highlight that the theories on cooptation rests on the legislatures' ability to constrain non-democratic leaders, but that "there is very little evidence [...] demonstrating that legislatures are duly empowered" (Jensen, Malesky, and Weymouth 2014, p. 663).

More optimistic accounts have, however, argued that there is sufficient electoral pressure as well as uncertainty about the outcome, even under unfree electoral systems, that they do discipline elites to provide social welfare to the electorate (Miller 2015c; Miller 2015b). "It is tempting to make the faulty inference that because many autocratic elections are won by large margins, they cannot motivate regimes to provide public services. However, this is akin to arguing that because a champion boxer consistently wins his

\footnotetext{
${ }^{2}$ Although elections could pit challengers against each other also in presidential elections, it is less clear that the leader afterwards would offer any concessions to the losers, which is central to the splitand-conquer strategy.
} 
fights, he must not feel the need to train very hard" (Miller 2015c, p. 1534). Furthermore, Little (2017) argues that as long as elections reveal some information about the incumbent strength, elections make voters more able to adjust their support or opposition to the incumbent, and elites, gaining information about support, engage in less inefficient conflict about distribution of goods and repression.

\subsubsection{Theory}

In line with these optimistic accounts, I argue that the concessions offered to members of parliament by the president can benefit parts of the electorate, by affecting the allocation of investments. Because candidates for parliament are interested in winning elections, the leader can buy their support by using his or her vast resources to aid these candidates' campaign. The president has many tools at his or her disposal to help a candidate secure an election, and "pork" investment, that is, investments allocated to important constituencies prior to elections, is one such tool (Ferejohn 1974). There are already a number of studies investigating the effects of cash handouts or distribution of other private goods from politicians during electoral campaigns (see for example Guardado and Wantchékon 2018; Kramon 2016), and larger investments can be used in much the same way.

Identifying the important constituencies across Africa is difficult for two reasons. First, there is a general lack of both maps of constituencies and data on constituency level electoral results from several of the African countries (see for example Kollman et al. 2019). Second, since several of the elections included in this study are subject to (sometimes extensive) fraud, it is unclear how one should identify important electoral areas based on (previously) reported results. Therefore, this study instead focuses on a specific aspect of electoral behavior in Africa (and developing countries more generally), namely the politicians' incentives to mobilize their home regions. That voters in Africa tend to value local public goods has been documented in several quantitative studies, qualitative studies, and historical accounts of Africa (Baldwin 2013; Barkan 1995; Kramon 2013; Meredith 2011; Wantchékon 2003). Vote-buying prior to elections is a costly signal to the electorate that the candidate will promote their interests.

But using investments to buy votes suffers from two of informational problems, both of which can be solved by a network of trusted brokers (Stokes et al. 2014). First, investments are vulnerable to free-riding, since voters who benefit from an investment can still support a challenging candidate they prefer, without fear of repercussion. ${ }^{3}$ With a network of intermediate brokers, politicians can effectively monitor and sanction parts of the electorate that fail to vote "correctly" (Stokes et al. 2014, p. 18-20). Second, politicians lack information about the needs of the local populations and what types of investments are more likely to be appreciated by voters. ${ }^{4}$ They "serve as the technology

\footnotetext{
${ }^{3}$ The politician can still hope that the investment will change the preference of the median voter in the politician's favor.

${ }^{4}$ While elections are the focus of this study, the role of these networks is not exclusive to vote-buying.
} 
by which local goods and services are demanded and delivered" (Baldwin 2013, p. 795).

No matter which of these roles is more important, both of them depend on a trustworthy relationship between the politician and the broker. Brokers have incentives to exaggerate the need for investments from their patron, in order to acquire more resources. Trust is therefore of fundamental importance for such political networks, and politicians are more likely to find trustworthy individuals among close friends from their home regions (Stokes et al. 2014, p. 18-20). This helps us understand politicians' preferences, at least on an abstract level, in investments allocation.

Previous research has found that in developing countries, investments tend to be concentrated towards the birth- or ethnic area of the current incumbent (Burgess et al. 2015; De Luca et al. 2018; Dreher et al. 2016a; Franck and Rainer 2012; Hodler and Raschky 2014). In much of this literature, the prevailing explanation is some form of favoritism (Dreher et al. 2016a; Kramon and Posner 2013). I propose that at least part of this empirical pattern can be explained by clientelist networks. Presidents during presidential elections use investments to mobilize their intermediate brokers, and their network is likely to be larger closer to their home region (and more likely to be co-ethnics, in line with observational implications of ethnic favoritism). However, I propose that the pattern will be different during legislative elections. Since members of parliament have their own geographically located networks, I expect investments to be more diffuse during legislative elections. I outline three precise observable implications from this:

H1: Prior to presidential elections, investments will be concentrated towards the birthplace of the president.

H2A: Prior to parliamentary elections, investments will be located further from the birthplace of the president.

H2B: If presidential and parliamentary elections co-occur, there will be no change in the location of public investments.

These hypotheses play into a central assumption in theories of autocratic co-option. If parliamentarians are able to attract investments during parliamentary elections when these co-occur with presidential elections, this indicates that the president, who is motivated to prioritize his or her own important constituencies, is obliged to concede at least some public expenditures to these parliamentarians. Previous research from the African context have found that power is strongly centered around the presidency, and that the opposition in many countries remains weak (Rakner and van de Walle 2009; van de Walle 2003). A central question then is whether we should interpret this as the president conceding to demands versus the president co-opting parts of the (potential) opposition by offering them rewards for their support. I argue that these are flip-sides. The strategy of co-option rests on the leader sharing spoils with parts of the opposition. It is the

For example, Kasara (2007) finds that leaders in Africa tend to tax their home regions more. The lack of an impartial public bureaucracy makes tax collection into a similar informational problem, vulnerable to free-riding. Nor are these networks exclusive to politics. Rates on loans in poor areas are often very high, partly because moneylenders need to rely on informal networks to follow up their clients (Aleem 1990; Banerjee and Duflo 2011; Burgess and Pande 2005). 
lure of spoils that pits the opposition against each other (Gandhi and Lust-Okar 2009, p. 405). Furthermore, the most popular candidates are also likely to be more capable of mobilizing against the regime. By aiding these candidates, the leader can ensure that these candidates stay loyal to the regime. Thus, concessions are central to co-option.

These hypotheses deviate somewhat from other prominent theories on elite behavior during elections. First, to demarcate the difference from theories on ethnic favoritism, one could argue that such theories, if understood as an unconditional altruism towards co-ethnics, should expect less favoritism during elections, since the ability to favor one's own depends on electoral victory (Martin 2016; Müller and Strøm 1999). Anyone seeking to get their altruistic leader into power would potentially support a temporary deviation from favoritism during elections in order to secure votes, and then return to favoritism in-between elections. Instead, the hypotheses above coincide with a strategic type of favoritism, in which favoritism is a means to win office. However, such a strategic type of favoritism might as well be explained with more mainstream theories on electoral behavior, such as constituency service (Cain, Ferejohn, and Fiorina 1990).

The hypotheses also deviate from the classical median-voter theorem (Downs 1957). Since presidents need a majority of constituents across the whole country, a medianvoter strategy seems contradictory to a concentration around the leader's birthplace (although median-voter theory could predict a concentration around important swingconstituencies). The only situation in which these two theories would converge, is if the clientelist network of the president is also a voter group that constitutes an electoral majority, and it is possible that something akin to this is achieved with targeted repression (see for example Bhasin and Gandhi 2013). For legislative elections, the hypotheses above correspond to median-voter strategies.

But a politician can only capitalize votes with investments that are attributable to their actions (Harding and Stasavage 2014). If voters cannot identify the responsible politician, they cannot update their preferences accordingly. Therefore, for at least two reasons, such pork barrel tactics are generally easier to do in majoritarian electoral systems. First, majoritarian systems typically have one member in parliament from each constituency, which makes it likely that it was this member who secured investments through his or her activity in parliament. In PR-systems, however, there are several members from each constituency, often from different parties. In this situation, opposition candidates can also claim credit for any investment in their constituency, making such investments a more noisy signal to voters. Second, PR-systems tend to be more party centered, with larger constituencies, and voters in such systems are often more loyal to party labels. Personal networks, often geographically concentrated, are less important in such systems (Cain, Ferejohn, and Fiorina 1990; Fiva, Halse, and Smith 2018). I therefore propose a third hypothesis:

H3: Investments will be located further from the birthplace of the president prior to parliamentary elections with majoritarian formulas than parliamentary elections with proportional formulas.

A potential objection to these hypotheses is that leaders in autocratic systems, as 
opposed to democratic ones, do not need to "waste" large investments on voters, since they can help candidates to power with electoral fraud. But in addition to the fact that presidents in such systems do occasionally lose elections (Bunce and Wolchik 2010), there are two reason for why leaders with unfree and unfair elections might still use investments (in addition to other tools at their disposal). First, conducting electoral fraud also relies on a network of intermediates (Rundlett and Svolik 2016), which will expect resources in exchange for their services. Furthermore, these principal-agent relationships suffer from a conflict of interest: The agents will want to avoid helping a candidate who loses in fear of prosecution or other reprisals from whoever wins (Rundlett and Svolik 2016). In this twisted incentive structure, agents are more likely to participate in fraud if they already believe that their patron will win. Mobilizing voters by other means is therefore necessary in order to win by fraud.

Second, elections are especially prone to violent conflict. Because of the threat of violence and possibly coup, a leader must not only achieve a favorable result, he or she must also deal with the expectations of an election happening, prior to results (Cederman, Skrede, and Hug 2013; Davenport 1997; Fearon 2011; Hafner-Burton, Hyde, and Jablonski 2014; Knutsen, Nygård, and Wig 2017). Fraud on election day can by definition not douse such sentiment prior to elections, and a (more or less) obviously fraudulent election can possibly make it worse afterwards (Gehlbach and Simpser 2014). Investments can potentially be used as a tool to please violence-prone parts of the population. As will be shown in the analysis, differences in investment allocation only appears right before elections, not after. The expected pattern of allocation is similar in democracies and autocracies, indicating that fraud does not matter much to these incentives.

To summarize, I analyze the relationship between presidents and parliaments prior to elections in Africa. Based on assumptions about the role of local goods and the importance of clientelistic networks during elections, I propose that electoral competition creates incentives for presidents to concentrate investments towards their birthplace. If this is observed, this indicates that elections are sufficiently competitive in order to make presidents spend millions of dollars towards winning those elections. Parliamentarians on the other hand, are not motivated to invest in the president's birthplace. Instead, they are interested in allocating investments towards their important constituencies. If we observe that a concentration around the president's birthplace does not occur if presidential and parliamentary elections co-occur, I argue that this indicates that the parliamentarians are sufficiently empowered to demand certain concessions from the president.

\subsection{Empirical design}

To test these hypotheses, I investigate the geographical allocation of Chinese Official Finance (COF) in Africa. I use the distance between the birthplace of the HOS (the president) and the investment projects, and test whether this distance differs systematically prior to presidential and parliamentary elections. In the following, I describe the 
data, and argue why the allocation of COF makes a good test of these hypotheses.

\subsection{Chinese official finance (COF) to Africa}

Ideally, we would have data on the official budgets of African governments and draw inference from investments made there. However, such data do not exist, and they are difficult to collect from African countries. In their absence, the data from COF-projects collected by Strange et al. (2017) provide a comparable measure of public investments across countries.

Data on COF include three types of financial flows from China to African governments. First, they include "Official Development Assistance," the governing definition of aid among OECD countries. Second, they include "Other Official Flows." The difference from "Official Development Assistance" is that the "grant" part of these projects can be less than $25 \%$ of the value, and "Other Official Flows" are usually given for commercial or representational reasons. Third, the data include "Vague Official Flows," in which there is not enough information to assign the project to any of the other two (Strange et al. 2017). This difference between the three types of flows is irrelevant for the current study. The type of flow is not systematically associated with either election years or locations.

There are considerable resources involved in these Chinese projects. For the 618 projects in this analysis where coders were able to find the amount, $60 \%$ of them have a budget greater than 1 million 2011 US dollars. Among the smallest projects of less than 100,000 USD, we find titles such as "Donation of anti-malarial drugs," "Grant to President's efforts in supporting vulnerable children,", and "Construction of hospital." There are seven projects with a budget greater than USD 1 billion, six of which involve the construction of heavy infrastructure (railways, mines, electricity grid) and one project for agricultural development in Angola. An overview of the frequency of different budget sizes is provided in figure 5.1 .

The different determinants of COF locations in Africa are still unclear. Recent contributions indicate that the Chinese government has both commercial and political interests in their allocation of $\mathrm{COF}$, but also that domestic realities in the Chinese economy, such as steel exports, determines the amounts that are invested (Dreher et al. 2016a; Dreher et al. 2016b; Dreher and Fuchs 2016). Most COF are given after concessions by the recipient, but these are concessions from outside of the deal of the financed project. No one has found any indications that the institutional framework of the recipient country is important (Dreher and Fuchs 2016), and with the exception of Somaliland, which remains formally unrecognized by foreign States, and the colony Western Sahara, all countries in mainland Africa have received official finance, as illustrated in figure 5.2.

The important feature of COF is that the Chinese government follows a policy of non-intervention, effectively giving African leaders much power to allocate the projects as they see fit (Dreher et al. 2016a, p. 4). This aspect is crucial, since the hypotheses above relate to the motivation of leaders in Africa, and not the motivation of Chinese 


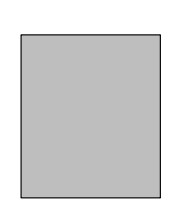

$<100,000$

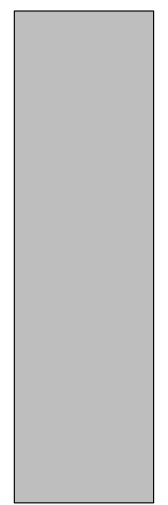

$1 M-9 M$

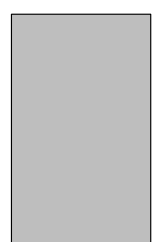

$10 \mathrm{M}-24 \mathrm{M}$

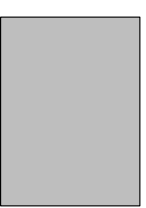

$25 \mathrm{M}-49 \mathrm{M}$

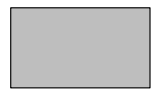

$50 \mathrm{M}-74 \mathrm{M}$

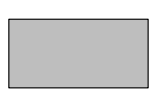

$75 M-1 B$

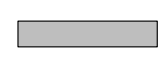

Figure 5.1: Project sizes as amount of 2011 USD involved. Take notice of labels as the range within each section differs.

donors. The non-intervention principle, which is stated by the Chinese government itself (State Council 2014), has been confirmed by several studies (Dreher et al. 2016a; Isaksson and Kotsadam 2018; Tull 2006). While the Chinese argue that this contributes to a local ownership of development policy, critics point out that this conveniently allows China to buy good friends abroad. As a final point, Chinese interests are also unlikely to be much different from the motivation of African elites. Since the elites in the recipient countries have given concession to China, it is likely that the Chinese have few objections to let these same elites use COF to secure the regime.

However, if African leaders do not make the decisions with these investments, contrary to prior research, and if Chinese interests are different from the interests of the African leaders, we should not observe the posited observational patterns. Since the results do follow the hypothesized preferences of the African leaders, there is reason to believe that prior research is correct in that African governments have discretionary power over these investments.

Use of these data holds many advantages over other common strategies. As highlighted by Kramon and Posner (2013), the geographical allocation of public investments seems to be dependent upon the type of investment one studies, such as education, healthcare, or electrical grids. The data on COF includes a wide variety of investment types, and can therefore allow us to make general inferences. It is of course also possible to investigate differences between types of investments.

Many similar studies use different macro-level measures such as infant mortality rates, and trace differences in these measures within countries to argue for some unequal distribution of investments (for a discussion, see Kramon and Posner 2013). Typically, studies 
like these investigate developing countries, in which the measurement error could be very high (Jerven 2013; Martinez 2018). The use of COF is likely to hold an unknown amount of under-reporting, but with reliable information on the projects that are included.

Another popular approach is to use nightlight intensity, as a proxy for economic activity (De Luca et al. 2018). This approach has the advantage of being both general, as economic activity can be produced from different types of investments. However, different types of investments are likely to have different effects on nightlight activity (and different effects on economic activity), and, to repeat myself, different types of investments seem to be distributed unequally (Kramon and Posner 2013). The combination of these two facts opens the possibility that politicians are budgeting the same amount of money to all areas within a country but are investing in different things, such as solar panels versus a hospital. Differences in nightlight could then be a result not of unequal investment, but of differences in how different investments manifest into nightlight. COF does not suffer from this, as it allows us to investigate the allocation of individual projects. Thus, while certainly not decisive, the data on COF provides a unique opportunity to analyze how African elites allocate public expenditure.

\subsubsection{Data}

The dependent variable is the distance between the project location and the birthplace of the HOS. The two main independent variables of interest are presidential election years, and parliamentary elections years.

The data on COF are from AidData (Strange et al. 2017). The data include several characteristics of the project, including the type of project (such as school, health, agriculture, emergency, etc.), what kind of location (the capital, rural village unit, etc.), and the amount of money involved (although coverage is not as good). The variable of interest here is the coordinates of the different projects, which has full coverage. I only include completed or implemented projects, and exclude projects that have only received some form of pledge or commitment.

HOS are identified by the Varieties of Democracy (V-Dem) dataset (Coppedge et al. 2017). The coordinates of the birthplaces of these different leaders are easily available online. In order to validate that I had found the correct location, I compared my coding to the coding by Dreher et al. (2016a).

Several African HOS were born outside of the country they are governing. For example, Francois Bozize Yangouvonda, HOS of the Central African Republic between 2003 and 2013, was born in Mouila in Gabon. All HOS born outside of their country are removed from the analyses. However, I utilize these instances in a placebo test.

Figure 5.2 shows the resulting distribution of projects (circles), HOS birthplaces (crosses), and HOS born outside of their country (Xs) across the continent of Africa in the period 2000-2011.

The goal of the main analysis is to identify the effect of elections on the distance between the circles and the crosses. The main dependent variable is obtained by calcu- 
lating the shortest path on an ellipsoid (the geodesic) in meters between the location of the project and birthplace location of the HOS. In all specifications, I use the natural logarithm of this variable, as the importance of placing a project $0 \mathrm{~km}$ or $100 \mathrm{~km}$ away from the HOS' birthplace, is much more important than the difference between $500 \mathrm{~km}$ and $600 \mathrm{~km}$. I also do robustness tests where I instead code a dummy variable for whether or not the project is located with $\mathrm{K} \mathrm{km}$ of the birthplace, where $\mathrm{K}$, in seriatim, takes each integer value from 3 to 200.

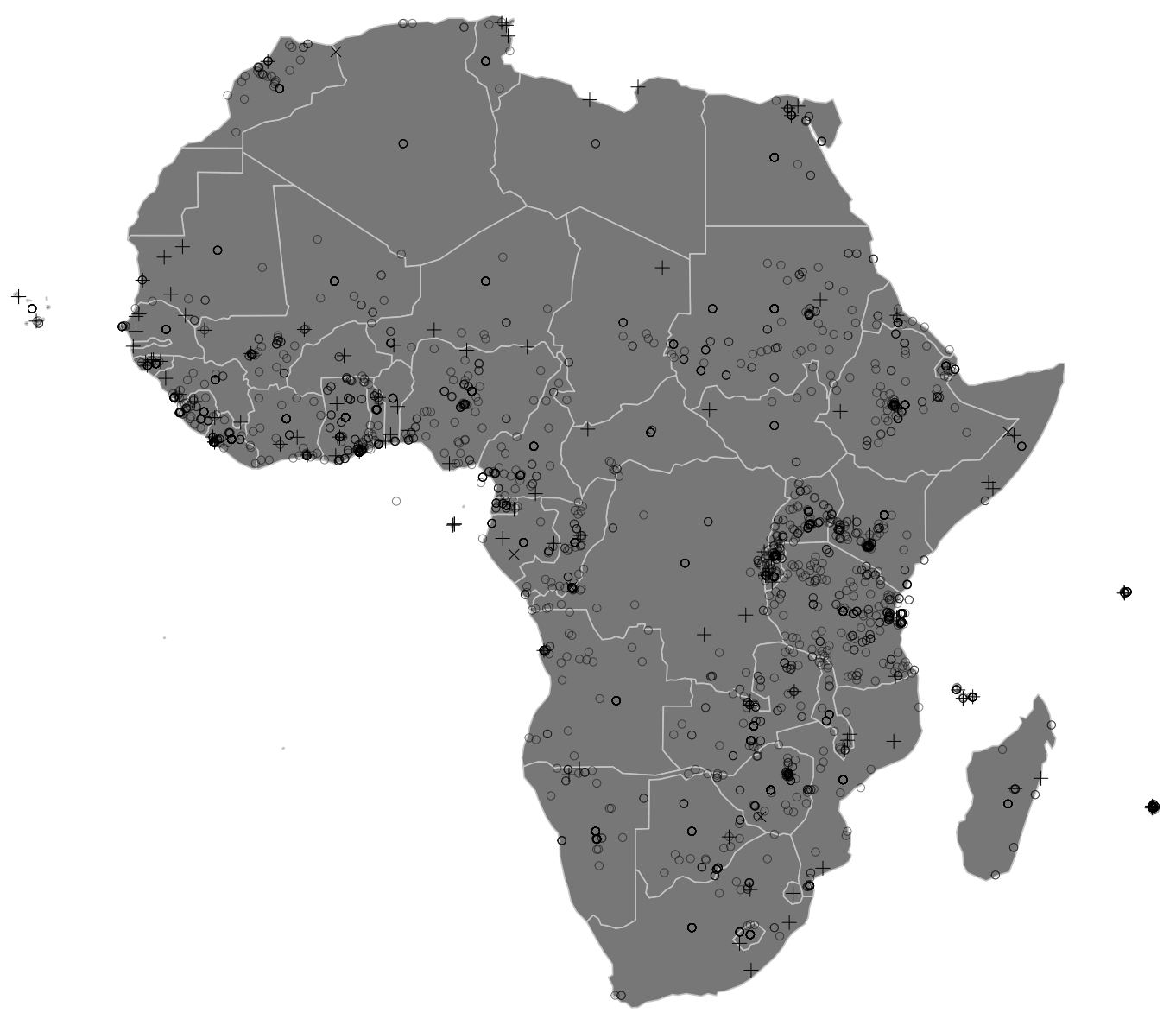

Figure 5.2: Chinese Official Finance in Africa (black circles) and African HOS's birthplace (crosses). Xs indicate birthplaces of HOS born outside of their country.

Information on presidential and parliamentary election years is obtained from the V-Dem data (Coppedge et al. 2017). In all specifications, these dummies indicate the pre-election year, not the election year. Investigations of election year leads and lags are provided in the analysis. 


\subsubsection{Confounders}

I include a variable on how long the HOS has been in office. Elections might happen disproportionately often in leaders' early years, when power is not yet consolidated. If a leader is able to consolidate power, or is in the process of doing so, he might cancel elections. At the same time, this consolidation of power affects the leader's ability to allocate investments to his preferences.

I control for the level of impartial bureaucracy. As highlighted by others, several African countries struggle with the inability to implement policy from the central government. This might therefore affect the ability to hold elections, but also where projects can be allocated. The variable is from V-Dem (Coppedge et al. 2017).

In split-sample tests, I show that the results are equal in autocratic and democratic sub-samples. In the main models using the full sample, I instead control for a scalar level of democracy, using the Polyarchy measure from V-Dem (Coppedge et al. 2017; Teorell et al. 2018).

I also include a measure on whether the HOS is selected by election, by selection of the parliament, or through other means. Other means includes coup (for example LaurentDesire Kabila in the Democratic Republic of the Congo (DRC)), appointed by a ruling party (Paul Kagame of Rwanda), hereditary succession (Mohammed VI of Morocco), or appointed by the military (Andry Rajoelina of Madagascar). The variables are collected from V-Dem (Coppedge et al. 2017).

I control for the number of conflict events in a given year. Elections sometimes spur electoral violence, and projects might be allocated to avoid such violence. This is constructed from the Uppsala Conflict Data Program (UCDP)/Peace Research Institute Oslo (PRIO) georeferenced event dataset (GED) (Croicu and Sundberg 2017; Sundberg and Melander 2013).

I also control for the natural logarithm of GDP per capita from the Maddison project (Bolt and van Zanden 2014) and the natural logarithm of the total population, both gathered from V-Dem (Coppedge et al. 2017).

Still, there are several possible confounders, such as systematic traits about the birthplace of presidents. All models therefore include fixed effects on year and either country or leader. The latter are arguably better, as they give the flexibility to estimate the average allocation of projects for each individual HOS, and remove any constant characteristic of their rule, such as characteristics of the birthplace of the leader or his or her personal traits.

In the appendix, I also show results from a dataset where each project and birthplace is assigned to its $3025 \mathrm{~km}^{2}$ grid-squares ${ }^{5}$ as defined by the PRIO-GRID dataset (Tollefsen et al. 2012). In this setup, the dependent variable is instead the number of projects allocated to each square in a given year. I then run two different models with these data. First, I interact presidential and parliamentary elections with whether this is the square

\footnotetext{
${ }^{5}$ Exact square-size depends on the distance from the equator.
} 
where the HOS was born. Second, I interact presidential and parliamentary elections with the distance between the centroid of the square and the birthplace of the HOS.

These models, however, are inferior to my main design, as they erroneously assume that each country is equally large, producing high heterogeneity in the results. For example, Gambia overlaps three cells, so the grid where the leader was born covers onethird of the country. In other countries, such as Algeria, Sudan, and DRC, there are hundreds of cells, making the birthplace-cell a much smaller proportion of the country as a whole.

Nevertheless, this setup allows for several other controls. First, it allows for cell fixed effects, which removes any concern that there is some constant confounder for the birthplace of the HOS and investment projects. Second, several other controls about the investment location can be included. I control for nightlight intensity, percentage of urban area in the cell, the size of the cell in $\mathrm{km}^{2}$, natural logarithm of $\mathrm{km}$ distance to the capital from the square centroid, and population density over the square's land area. These are from the PRIO-GRID dataset (Tollefsen et al. 2015). In addition, I control for the number of conflict events in the square, collected from the GED dataset (Croicu and Sundberg 2017; Sundberg and Melander 2013).

\subsection{Analysis}

In this section, I first present what I consider to be the benchmark model. The rest of the models are nuances and robustness tests to this benchmark. This includes a comparison of democracies and autocracies, highlighting that the effect is restricted to the year prior to elections, as well as placebo tests of the benchmark and differences between legislative elections with majoritarian and proportional formulas.

The first set of regressions is presented in table 5.1. The first model is stripped of all covariates except country and year fixed effects. The estimated effects of presidential elections and parliamentary elections are as expected. In pre-presidential election years, projects are significantly concentrated closer to the birthplace of the HOS, reducing the average distance by $36 \% .{ }^{6}$ Parliamentary elections have an opposite and almost identical large effect: One year prior to parliamentary elections, the average distance between project locations and the birthplace of the HOS increases by $32 \%$.

These estimates are almost unchanged when the covariates are included. Pre-presidential election years see an average reduction in distance of $36 \%$. The corresponding estimate for pre-parliamentary election years is an increase of $32 \%$.

To control for characteristics of the HOS birthplaces, as well as the personal capacities of the individual HOS, it is arguably better to estimate the model with leader fixed effects. This is what I present in model 3, which I consider the best specification. Here, the effects of elections are further strengthened. The average reduction in distance during

\footnotetext{
${ }^{6}$ Since I use the natural logarithm of the dependent variable, the expected percentage change can be found by the formula $(\exp (\beta)-1) * 100=(\exp (-0.444)-1) * 100=35.85$.
} 
presidential elections is now $40 \%$, and the average increase during parliamentary elections is $45 \%$ - quite substantial changes. These results are not driven by a few influential observations. As illustrated in section 9.3 in the appendix, the coefficients are stable across several jackknife estimations, namely leave-one-leader-out, leave-one-country-out, and leave-one-observation-out.

However, many of these elections co-occur. In model 4, I introduce an interaction between parliamentary and presidential elections, indicating that both elections will take place next year. This interaction runs the risk of overfitting on relatively few observations. Nevertheless, the results illuminate that parliamentary elections first and foremost cancels out the concentration caused by presidential elections, and very little decentralization occurs during parliamentary elections. If only presidential elections are to take place, projects are on average allocated $58 \%$ closer to the birthplace of the president. But when both elections will happen next year, the predicted change is $-4 \%$, and far from significant on conventional levels. This is close to the same prediction one would arrive at by adding up the effects of parliamentary and presidential election in models 1-3.

This is evidence in favor of the power of parliaments. While the average African president seems to concentrate investments during elections, they are unable to do so, or choose an alternative strategy, if this co-occurs with legislative elections, forcing the HOS to please the electoral interests of the legislators.

Most of the other covariates do not show any significant effect. These are the level of impartial bureaucracy, the level of democracy, the HOS's cumulative days in office, the number of conflict events, and the size of the population.

Notably, HOS's that are selected by the legislature are less likely to allocate projects close to their birthplace. This is also an indication that project allocation is partially the result of a bargaining process between the leader and the parliament. In contrast to leaders selected by the legislature, there is no general significant difference between leaders who have been elected to power and leaders who have not been elected to power.

Furthermore, while the economy seems to matter in model 2, it diminishes and turns statistically insignificant in the stricter models 3 and 4 .

So far, the dependent variable has been measured as distance in log meters. But one could argue that being located in the home area of the HOS is not really a question of degrees. Instead, projects are either in the area, or outside of it. That is to say, it is not that all projects are moved by $\beta$ closer to the birthplace of the HOS, but that a greater portion of the projects are being located within the home area.

However, the problem is to define the boundary of the "home area," be it a district, an administrative unit, a town, a city area, etc. In addition, the size of this boundary is likely to be different between birthplaces. To complicate further, administrative boundaries are often changed, especially in the context of elections, introducing endogeneity issues in estimation.

Lacking any clear data on what constitutes the correct boundary, any cut-off point will be somewhat arbitrary. I therefore run a series of regression models. First, I define the "home area" as anywhere within 3 kilometers, and construct a dummy variable of whether 
Table 5.1: Elections and investment allocation

\begin{tabular}{|c|c|c|c|c|}
\hline & \multicolumn{4}{|c|}{ Dependent variable: } \\
\hline & \multicolumn{4}{|c|}{ Ln meters to birthplace } \\
\hline & $(1)$ & $(2)$ & $(3)$ & $(4)$ \\
\hline Presidential election next year & $\begin{array}{c}-0.44^{* * *} \\
(0.11)\end{array}$ & $\begin{array}{c}-0.44^{* * *} \\
(0.11)\end{array}$ & $\begin{array}{c}-0.50^{* * *} \\
(0.12)\end{array}$ & $\begin{array}{c}-0.86^{* * *} \\
(0.18)\end{array}$ \\
\hline Parliamentary election next year & $\begin{array}{l}0.28^{*} \\
(0.11)\end{array}$ & $\begin{array}{l}0.28^{*} \\
(0.11)\end{array}$ & $\begin{array}{c}0.37^{* *} \\
(0.12)\end{array}$ & $\begin{array}{c}0.10 \\
(0.15)\end{array}$ \\
\hline Impartial bureaucracy & & $\begin{array}{l}-0.15 \\
(0.14)\end{array}$ & $\begin{array}{l}-0.35 \\
(0.20)\end{array}$ & $\begin{array}{l}-0.31 \\
(0.20)\end{array}$ \\
\hline Polyarchy & & $\begin{array}{c}0.13 \\
(0.85)\end{array}$ & $\begin{array}{l}-0.94 \\
(1.10)\end{array}$ & $\begin{array}{l}-1.17 \\
(1.10)\end{array}$ \\
\hline Ln days in office & & $\begin{array}{l}-0.02 \\
(0.04)\end{array}$ & $\begin{array}{l}-0.04 \\
(0.06)\end{array}$ & $\begin{array}{l}-0.04 \\
(0.06)\end{array}$ \\
\hline HOS selected by legislature & & $\begin{array}{c}0.24 \\
(0.30)\end{array}$ & $\begin{array}{l}0.83^{*} \\
(0.38)\end{array}$ & $\begin{array}{l}0.87^{*} \\
(0.38)\end{array}$ \\
\hline HOS elected & & $\begin{array}{c}0.03 \\
(0.24)\end{array}$ & $\begin{array}{c}0.37 \\
(0.33)\end{array}$ & $\begin{array}{c}0.43 \\
(0.33)\end{array}$ \\
\hline Ln number of conflict-events & & $\begin{array}{l}0.005 \\
(0.04)\end{array}$ & $\begin{array}{l}0.003 \\
(0.04)\end{array}$ & $\begin{array}{l}0.001 \\
(0.04)\end{array}$ \\
\hline Ln GDP per capita & & $\begin{array}{l}0.89^{*} \\
(0.45)\end{array}$ & $\begin{array}{c}0.23 \\
(0.55)\end{array}$ & $\begin{array}{c}0.26 \\
(0.55)\end{array}$ \\
\hline Ln population & & $\begin{array}{l}-2.14 \\
(1.66)\end{array}$ & $\begin{array}{c}0.19 \\
(2.02)\end{array}$ & $\begin{array}{c}0.59 \\
(2.02)\end{array}$ \\
\hline Pres. and Parl. election next year & & & & $\begin{array}{c}0.72^{* *} \\
(0.27)\end{array}$ \\
\hline Constant & $\begin{array}{c}12.20^{* * *} \\
(0.44)\end{array}$ & $\begin{array}{c}33.38 \\
(19.74)\end{array}$ & $\begin{array}{c}8.62 \\
(30.10)\end{array}$ & $\begin{array}{c}2.11 \\
(30.14)\end{array}$ \\
\hline Country FE & Yes & Yes & No & No \\
\hline Year FE & Yes & Yes & Yes & Yes \\
\hline Leader FE & No & No & Yes & Yes \\
\hline Observations & 1,593 & 1,593 & 1,593 & 1,593 \\
\hline $\mathrm{R}^{2}$ & 0.39 & 0.39 & 0.42 & 0.42 \\
\hline
\end{tabular}


or not each project was closer than this. I then run a logistic regression that is otherwise similar to model 3 in table 5.1, but with this binomial measure as the dependent variable instead. I repeat this process 198 times, increasing the definition of the "home area" by 1 kilometer for each repetition. However, I highlight that any such fixed boundary will be a very different portion of, for example, Rwanda (approx. 27,000 $\mathrm{km}^{2}$ ) than of its neighbor DRC (approximately 2.3 million $\mathrm{km}^{2}$ ). Thus, the effects at each specific cut-off can be heavily influenced by a few countries, and is less likely to represent some general average treatment effect.

The effect of presidential and parliamentary elections on projects being placed within these "home areas" is illustrated in figure 9.4. The results hold across these models. Both effects are stronger as long as the "home area" is defined as smaller than approximately $70 \mathrm{~km}$ radius, and it becomes much weaker after this. This supports the notion that it is not that projects in general are moved somewhat closer to the birthplace of the HOS but rather a portion of the projects is being allocated to this home area, and thus pulling the average distance down.

The results are again confirmed when using grid-cells as the unit of analysis, reported in appendix section 9.5. Squares closer to the birthplace of the president receive more projects prior to presidential elections, and the square where the HOS was born can expect 0.9 more projects the year prior to a presidential election. The effect of a parliamentary election is opposite, expecting somewhere between -0.03 and -0.02 fewer investments in areas closer than $50 \mathrm{~km}$ to the HOS birthplace. The square where the president was born can expect approximately -0.7 fewer investments prior to a legislative election.

\subsubsection{Democracy and autocracy}

It is possible that the estimates are heavily reliant upon the democratic countries in the sample, while elections do not have the same effect in more autocratic regimes. To investigate this, I re-estimate model 3 from table 5.1, but leave out the Polyarchy-control and instead split the sample between democracies and autocracies. In this setup, I use the binomial democracy definition from Boix, Miller, and Rosato (2013), but the reported results are similar when using Polyarchy from Teorell et al. (2018) split by the mean or the binomial Democracy-Dictatorship (DD) measure from Cheibub, Gandhi, and Vreeland (2010). These results are available in appendix section 9.7.

In both samples, the point estimates are very similar to the main results, indicating that the effect is not specific to any regime type. But the uncertainty is much greater for democratic regimes, and the coefficients are only significant at the $10 \%$-level. While it cannot be excluded, it would be too hasty to conclude that this type of pork barrel behavior is a specifically autocratic phenomenon. The sample size of democratic regimes is less than half the sample size of autocratic regimes, as the majority of countries in Africa are not considered democratic. The more likely conclusion is that there is no clear difference between regimes. 


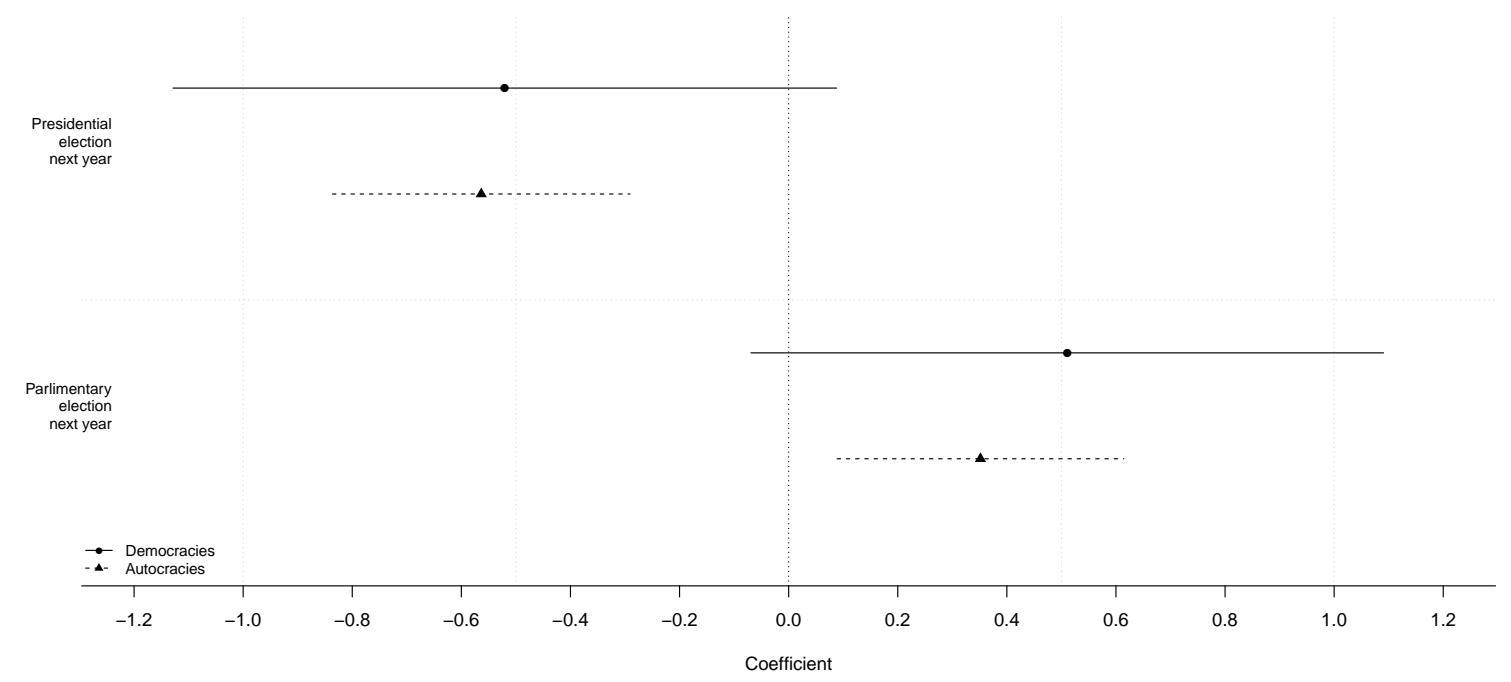

Figure 5.3: The estimated effect and corresponding 95\% confidence interval of parliamentary and presidential elections on the distance between HOS's birthplace and investment location, split by regime type. Except for excluding the control for Polyarchy, the model is similar to model 3 in table 5.1. Control variables are left out of the illustration.

\subsubsection{Timing}

My theoretical propositions are related to the expectations of elections, and I have imposed this on the models by estimating the effect of the year before an election. To investigate whether the effect actually follows this pattern, I have re-estimated model 3 from table 5.1, but included dummies for each year from two years before an election year, up to two years after an election year. Thus, the model includes five dummies for presidential elections and five dummies for parliamentary elections. These coefficients are illustrated in figure 5.4.

The only coefficient that is significant by conventional standards, and the only coefficient with any substantial size, is the effect of the year before an election year. The coefficients for the year the elections take place are also close to significant, but smaller in size. Due to the lack of exact starting dates for the projects, the model does not perfectly identify projects that happened before and after the election in the same year. Therefore, it is likely that some projects are initiated due to the expectation of the election that year.

\subsubsection{Placebo analyses}

As mentioned and illustrated in figure 5.2, several presidents were born outside of their country. As a placebo test, I investigate whether elections matter on the sample of projects that were initiated under these leaders' terms. A few caveats should be men- 

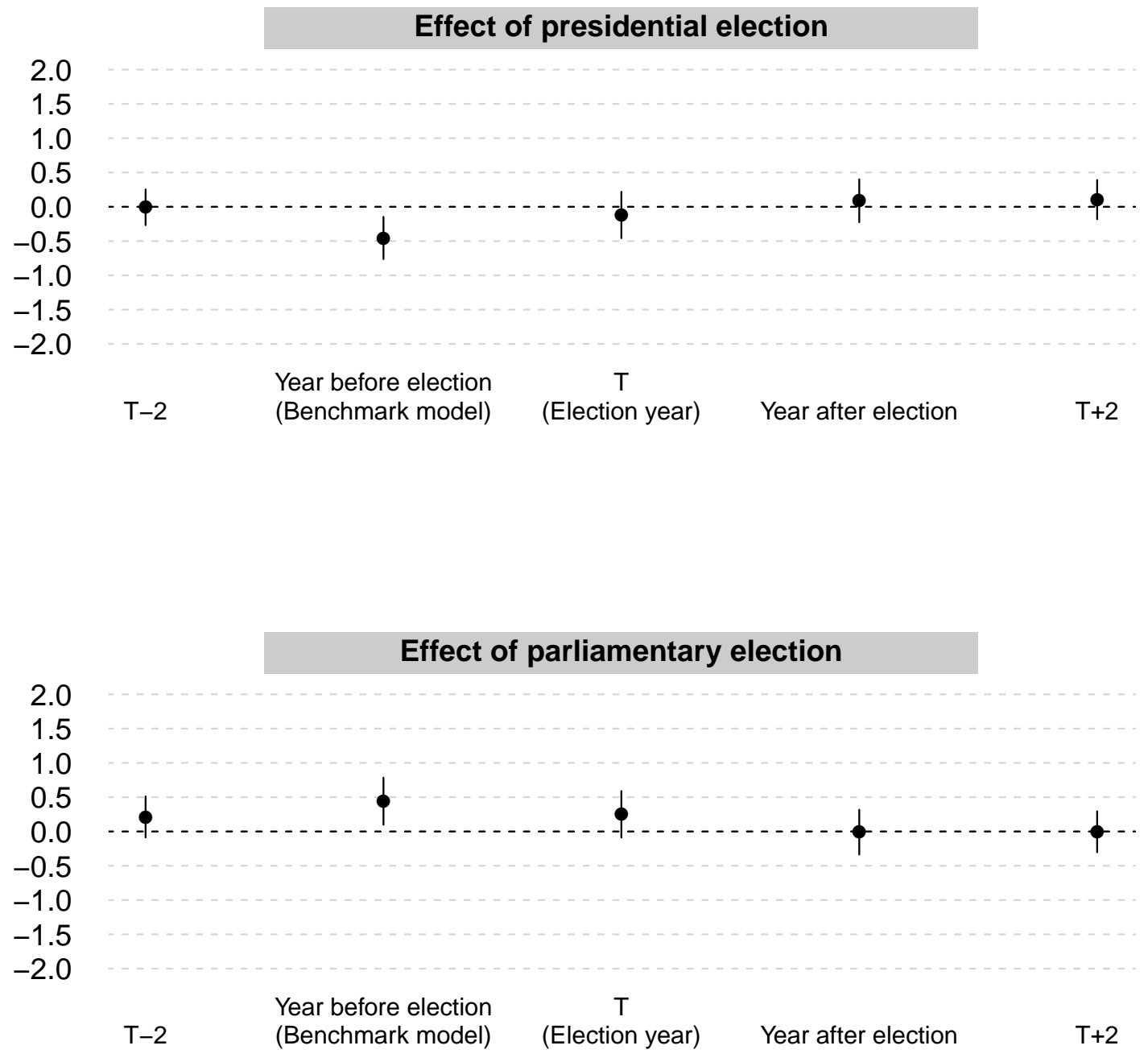

Figure 5.4: The estimated effect and corresponding 95\% confidence interval of parliamentary and presidential elections on the distance between HOS's birthplace and investment location. Other than including 5x2 different election-dummies instead of $1 \times 2$ electiondummies, the model is similar to model 3 in table 5.1. Control variables are left out of the illustration.

tioned. First, this sample only consists of 72 observations, which can produce both unreliable coefficients and standard errors. Several of the confounders lack variation, I therefore only use year and leader fixed effects in this model. Second, if the parents of these leaders found jobs just across the border or fled during conflict, etc., it would be possible that the cardinal point direction of the birth-country of the leader from the centroid of the country he or she rules over, correlates with the cardinal point direction 
of the leaders' co-ethnic area(s) within the country they rule over, creating a correlation that could be in line with the theoretical arguments presented above.

Therefore, I do an additional placebo test where I randomly allocate presidential and parliamentary elections with the same probability as they occur in the data. ${ }^{7}$ The results are illustrated in figure 5.5, and in neither model do elections have any effect on the allocation of investments.

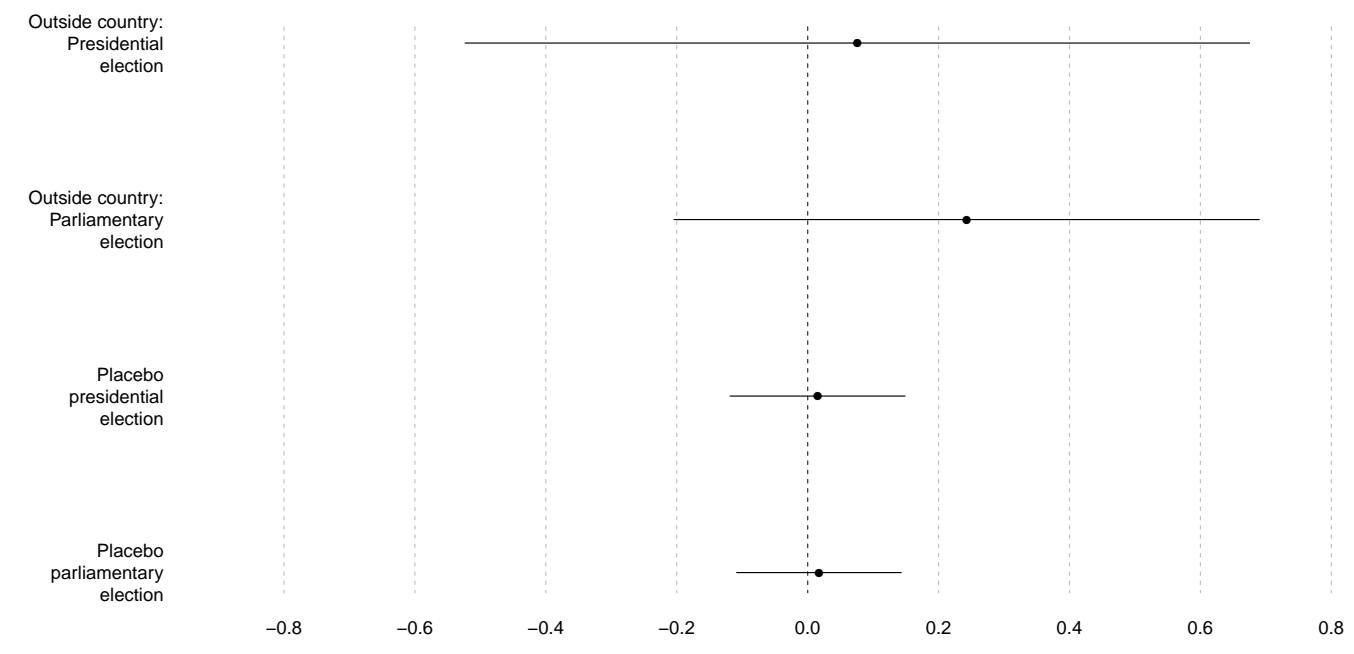

Figure 5.5: The estimated effects and corresponding 95\% confidence intervals of parliamentary and presidential elections from two different placebo models. The first model is a subset of leaders born outside of their country. The second model uses randomly drawn "elections." Both models include year and leader fixed effects.

\footnotetext{
${ }^{7}$ Changing this to a $50 \%$ probability of an election happening at each row does not alter these results.
} 


\subsubsection{Proportional versus majoritarian systems}

As argued above, vote-buying is easier to do in majoritarian systems. Therefore, if votebuying is the reason we observe these changes in investment allocation, they should only exist, or at least be stronger, under majoritarian electoral formulas. I investigate this by altering model 3 from table 5.1. Instead of a single dummy for parliamentary elections next year, I split this variable into a dummy for elections with majoritarian formulas, and elections with mixed or proportional formulas. The point-estimates and corresponding 95\% confidence intervals are illustrated in figure 5.6.

Electoral formulas have quite an impact on the general trend. Parliamentary elections with majoritarian formulas in majoritarian systems increase, on average, the distance to the birthplace of the HOS by $72 \%$. In comparison, parliamentary elections with proportional and mixed formulas show an increase of $18 \%$, but this is not statistically significant. This difference between majoritarian and proportional and mixed parliamentary elections is statistically significant.

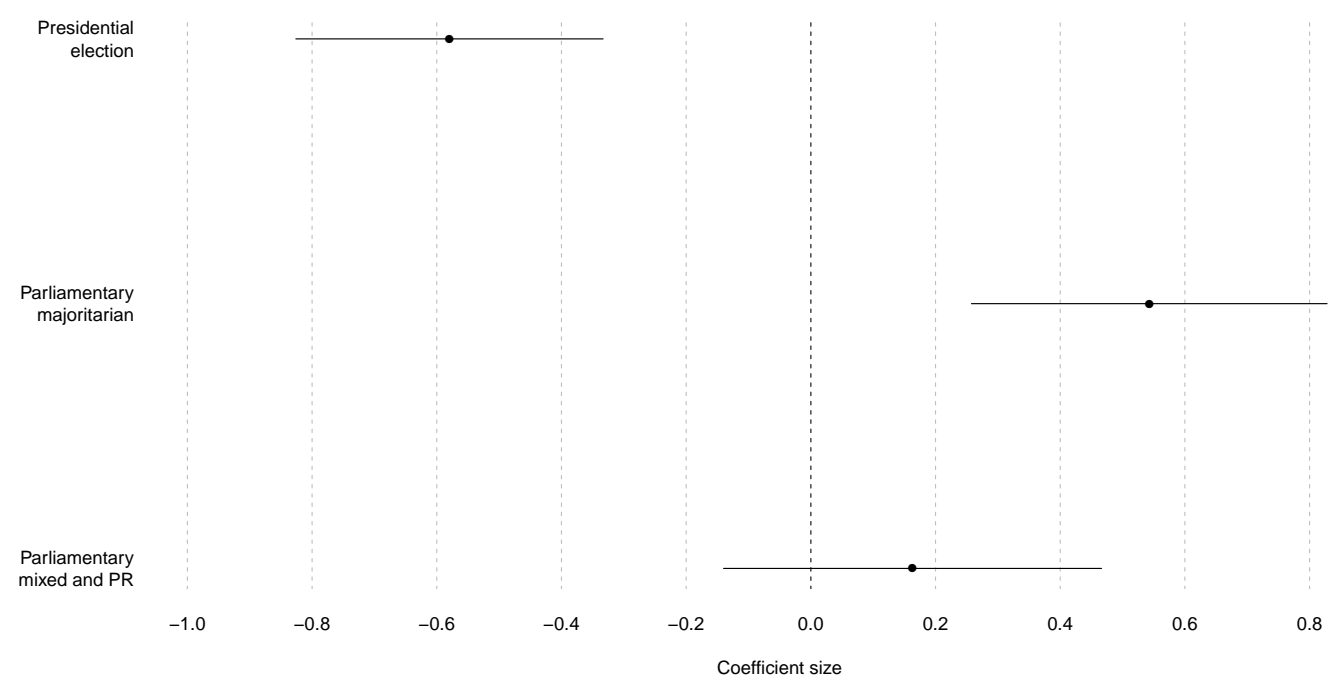

Figure 5.6: Estimated effect of presidential, majoritarian parliamentary, and mixed and proportional parliamentary elections on the distance between HOS' birthplace and investment location. Lines indicate $95 \%$ confidence interval. The model is similar to model 3 table 5.1. Control variables are left out of the illustration. 


\subsection{Conclusion}

In line with the abundant literature on political survival, I propose that even unfree elections affect the allocation of public investments. Theories on co-option in non-democratic systems assumes a certain level of real competition in elections in order to pit potential opponents against each other. As part of the ongoing bargaining process between political elites, I argue that members of parliament are able to get the president's aid in winning elections. The president, in turn, is willing to give such concessions as a strategy to buy the support of a potential opposition. As a result, public investments are used to buy the support of voters, with implications for the distribution of large, multi-million dollar investments.

I have found support for three hypothesis. First, as posited in the first hypothesis, investments are concentrated close to the birthplace of the president prior to presidential elections. Second, as stated in hypothesis 2B, if presidential elections co-occur with parliamentary elections, no change occurs in the allocation. This indicates that the parliament is empowered to avoid a concentration around the president's ideal point. Finally, as suggested in hypothesis 3, the effects of parliamentary elections are restricted to those using a majoritarian formula.

This conclusion has a number of important implications. First, the conclusion contributes to the political economy in development. Nominally democratic institutions can affect the allocation of investments even in otherwise non-democratic systems. However, different allocation does not necessarily imply more economically efficient results or more equal distribution of resources, neither do my results give any evidence that legislatures or elections will increase the amount of public spending on public goods (for studies of this, see Miller 2015c; Miller 2015b). Furthermore, targeted goods are far from the only tool in the box. To fully comprehend the dynamics of electoral autocracies, future research should aim to understand how and when these different tools are used.

Second, in the context of Africa, this conclusion gives nuance to the prevailing view that African presidents enjoy extensive political powers (Rakner and van de Walle 2009; van de Walle 2003). My results also documents this centrality of the presidency, but gives evidence that these presidents nevertheless need to respect at least part of their parliamentary opposition. This feature seems common to all the African states. The analysis has focused on the central dynamic between the president and the parliament, and due to the lack of data, I have been unable to address how the investments are allocated to different parliamentarians and their constituencies. Future research should aim to overcome this inability and conduct systematic studies of the within-parliament dynamics, not least to identify which and why certain parliamentarians are rewarded.

The results also fit well with evidence from outside of Africa, such as why geography is such an important aspect of public spending in the United States (Ansolabehere, Gerber, and Snyder 2002; Ferejohn 1974; Rogowski 2016), while Fiva, Halse, and Smith (2018) find no geographical benefits in the proportional system of Norway. My results support the argument that politicians elected under proportional formulas tend to spend 
less on targeted goods and more on broader investments (Funk and Gathmann 2013; Gagliarducci, Nannicini, and Naticchiono 2011).

Finally, the results imply that we should continue to encourage contested elections in non-democratic contexts. For all their flaws and shortcomings, they do seem, at least partly, to link the fortunes of political leaders to the preferences of their electorates the vertical accountability that we usually associate with truly democratic elections. We might hope that such repeated elections will eventually lead to full democratization (Lindberg 2009). Given that the analysis does not find any difference between democracies and non-democracies, the results seem to support that there is a net benefit of elections on vertical accountability, as proposed by Miller (2015b, p. 1553), even in the absence of the less tangible aspects of democracy, such as civil liberties. 

Appendices 



\section{Appendix for Chapter 2}

\subsection{Summary}

In this this online appendix, we first present a table (Table 6.1) displaying the variable definitions and sources for all variables employed in our analysis. The next table (Table 6.2) presents a series descriptive statistics for these variables.

The following series of tables and figures report various robustness tests that are briefly discussed, but not reported in detail, in the paper. These include a replication of the main results table for alternative depreciation rates on the Polyarchy stock measure, as well as regressions using the level of Polyarchy instead of stock (Table 6.3). We also present coefficient plots for results from regressions where we use alternative lag structures (Figure 6.1) to the one used in the benchmark specification (DV measured in $t+5)$. Next, we report results from our jackknifing exercises omitting either entire regions or countries from the benchmark regressions (Figures 6.2-6.5). As a robustness test of Table 4 in the paper, we report results when using a $5 \%$ depreciation rate for the 5- and 10-year panel specifications that also include a lagged dependent variable as regressor (Table 6.4). Further, we run tests on the 5-year panel specifications where we include several additional lags on the dependent variable as regressors, in order to further mitigate omitted variable bias and autocorrelation concerns (Table 6.5).

The following tables present results where we alter the core independent variable in the benchmark, either by using alternative democracy measures for calculating democracy stock (Table 6.6) or by calculating autocracy stock instead of democracy stock (Table 6.7). Finally, we report results when omitting particular observations that may be suspected to drive our results, namely (former) Communist countries (Table 6.8) and all observations with 0-scores on iron and steel production (Table 6.9). 


\subsection{Data descriptions}

Table 6.1: Variable Description

VARIABLE (ORIGINAL $\mid$ DESCRIPTION
NAME)
DEPENDENT VARIABLES USED

Railway freight (railtkm)

Source: The Cross-country Historical Adoption of Technology (CHAT) dataset (Comin and Hobijn 2009).

Definition: Ton-KM of freight carried on railways (excluding livestock and passenger baggage). Freight for servicing of railroads is typically excluded but may be included for some countries.

Notes: In all models, we add 1 to this variable and take the natural logarithm.

Energy consumption (pec)

Source: Correlates of War (COW) dataset (Sarkees and Wayman 2010)

Definition: Primary energy consumption (thousands of coal-ton equivalents). Primary Energy Consumption is a state's consumption of energy (metric ton coal equivalent) in each year for the period 1816-2012.

Notes: In all models, we add 1 to this variable and take the natural logarithm.

Iron and steel production (irst) Source: Correlates of War (COW) dataset (Sarkees and Wayman 2010)

Definition: Iron and steel production (thousands of tons). Iron and Steel production reflects a state's production of pig iron (1816-1899) and steel (1900-2012) in each year for the period 1816-2012.

Notes: In all models, we add 1 to this variable and take the natural logarithm.

Manufacturing value added

Source: World development indicators (WDI) (The World (NV.IND.MANF.ZS)

Bank 2010) 
Agriculture (agro)

Laborer real wage

(LabourersRealWage)
Definition: Manufacturing, value added (\% of GDP). Manufacturing refers to industries belonging to ISIC divisions 15-37. Value added is the net output of a sector after adding up all outputs and subtracting intermediate inputs. It is calculated without making deductions for depreciation of fabricated assets or depletion and degradation of natural resources. The origin of value added is determined by the International Standard Industrial Classification (ISIC), revision 3 .

Source: Miller (2015a)

Definition: Employment in agricultural sector, \% of total employment.

\section{Source: Clio Infra (www.clio-infra.eu)}

Definition: Building laborers' real wage by country. Measured as subsistence ratios, which indicate how many times the daily wage of a male unskilled construction laborer can buy the daily subsistence basket. Data is originally interpolated on the basis of real wages indices from the (older) literature

Notes: In all models, we add 1 to this variable and take the natural logarithm.

Public expenditure (Government expenditure (\% of GDP))

INDEPENDENT VARIABLES USED

Polyarchy Electoral democracy index (v2x_polyarchy)
Source: The Varieties of Democracy Dataset (V-Dem) (Coppedge et al. 2018) with Historical V-Dem extension (Knutsen et al. 2019b). Variable constructed by Teorell et al. (2018) 
GDP per capita

Population

Natural resources income

Rigorous and impartial public administration (v2clrspct)
Definition: The index is formed by taking the average of, on the one hand, the weighted average of the indices measuring freedom of association thick ( $\mathrm{v} 2 \mathrm{x}$ _frassoc_thick), clean elections (v2xel_frefair), freedom of expression (v2x_freexp_altinf), elected officials (v2x_elecoff), and suffrage (v2x_suffr) and, on the other, the five-way multiplicative interaction between those indices.

Notes: In all models, we add 1 to this variable and take the natural logarithm.

Source: Fariss et al. (2017)

Definition: GDP per capita (PPP-adjusted)

Notes: In all models, we use the natural logarithm of this variable. The Fariss et al. data provide estimates of income by drawing on information from different historic and contemporary sources and using a dynamic latent trait model. In addition to an expansive coverage across time and countries (i.e., few missing values), their procedure mitigates various measurement errors that affect other extant GDP measures. We use their estimates benchmarked in the long-time series data from the Maddison project (see Bolt et al. 2018).

Source: Fariss et al. (2017)

Definition: Population

Notes: In all models, we use the natural logarithm of this variable. The Fariss et al. data provide estimates of population by drawing on information from different historic and contemporary sources and using a dynamic latent trait model. We use their estimates benchmarked in the long-time series data from the Maddison project (see Bolt et al. 2018).

Source: Miller (2015a)

Definition: Natural resource income as \% of GDP

Source: The Varieties of Democracy Dataset (V-Dem) (Coppedge et al. 2018) with Historical V-Dem extension (Knutsen et al. 2019b).

Definition: Are public officials rigorous and impartial in the performance of their duties? 
State ownership of economy (v2clstown)

Time in sample
Source: The Varieties of Democracy Dataset (V-Dem) (Coppedge et al. 2018) with Historical V-Dem extension (Knutsen et al. 2019b).

Definition: Does the state own or directly control important sectors of the economy?

Source: Constructed by us.

Definition: Variable is constructed by subtracting the country's first year with a valid value on $v 2 x \_$polyarchy from the current year.

Note: In all models we use the natural logarithm of this variable.

Table 6.2: Descriptive Statistics

\begin{tabular}{llllllll}
\hline Variable name & Min & 1st & MedianMean & 3rd & Max & N \\
\hline Agriculture, \% of workforce & 0.00 & 26.20 & 53.60 & 50.77 & 75.00 & 96.90 & 10653 \\
GDP per capita growth & -0.27 & 0.01 & 0.02 & 0.03 & 0.05 & 0.71 & 20773 \\
Government ownership in the econ- & -4.15 & -0.96 & 0.25 & 0.05 & 1.15 & 3.31 & 25568 \\
omy & & & & & & & \\
Labourers real wage & 0.03 & 7.44 & 15.44 & 27.99 & 31.59 & 361.27 & 4305 \\
Ln energy consumption & 0.00 & 5.15 & 7.92 & 7.29 & 9.97 & 15.49 & 14080 \\
Ln GDP per capita & 4.65 & 6.82 & 7.42 & 7.61 & 8.26 & 11.36 & 20602 \\
Ln iron and steel production & 0.00 & 0.00 & 0.00 & 2.93 & 6.22 & 13.50 & 14494 \\
Ln Population (in thousands) & 3.33 & 7.42 & 8.44 & 8.47 & 9.52 & 14.04 & 20602 \\
Ln railway freight & 0.00 & 5.71 & 7.38 & 7.32 & 9.12 & 15.18 & 5983 \\
Manufacturing value added & 0.00 & 8.36 & 12.78 & 13.34 & 17.38 & 54.21 & 6161 \\
Natural resources income & 0.00 & 0.00 & 0.20 & 3.59 & 2.20 & 100.00 & 13342 \\
Polyarchy Stock, 1 \% depreciation & 0.01 & 1.46 & 5.10 & 9.57 & 12.43 & 67.05 & 24205 \\
Polyarchy Stock, 5 \% depreciation & 0.01 & 0.78 & 2.54 & 3.95 & 5.16 & 18.14 & 24205 \\
Polyarchy Stock, 10 \% depreciation & 0.01 & 0.49 & 1.51 & 2.28 & 3.03 & 9.18 & 24205 \\
Polyarchy & 0.01 & 0.06 & 0.17 & 0.26 & 0.37 & 0.95 & 24205 \\
Public expenditure as \% of GDP & 0.00 & 13.41 & 22.49 & 25.41 & 35.16 & 96.65 & 6987 \\
Rigorous and impartial public ad- & -3.63 & -1.15 & -0.15 & -0.03 & 0.86 & 4.62 & 25255 \\
ministration & & & & & & & \\
\hline
\end{tabular}




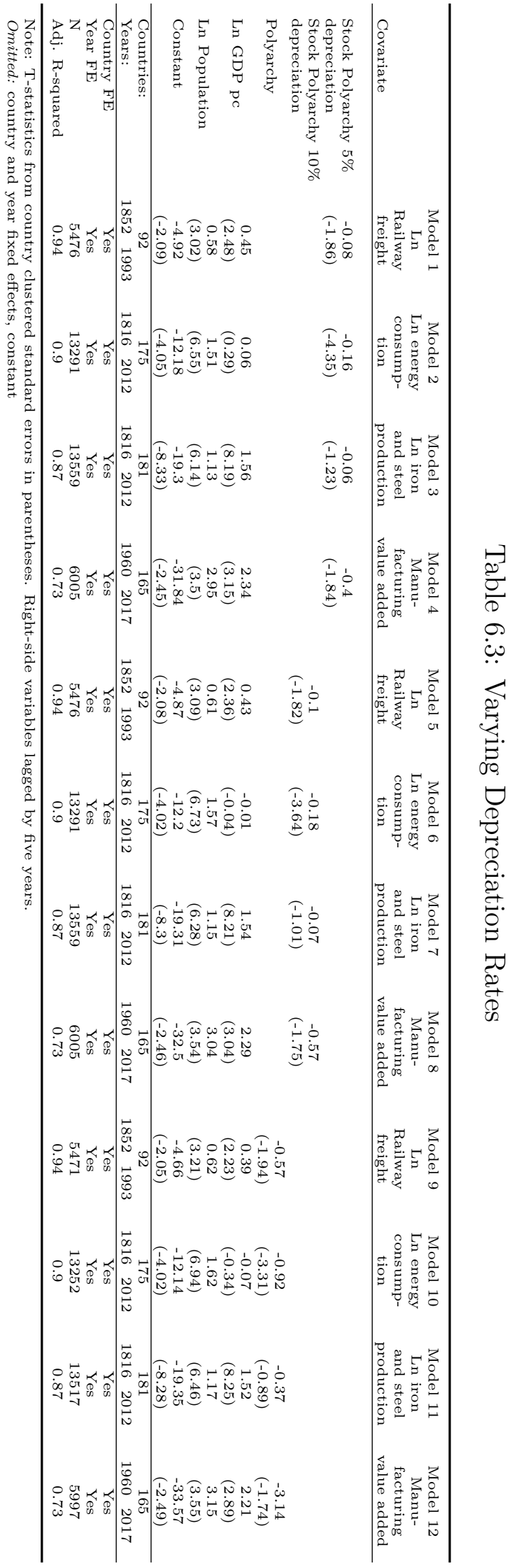



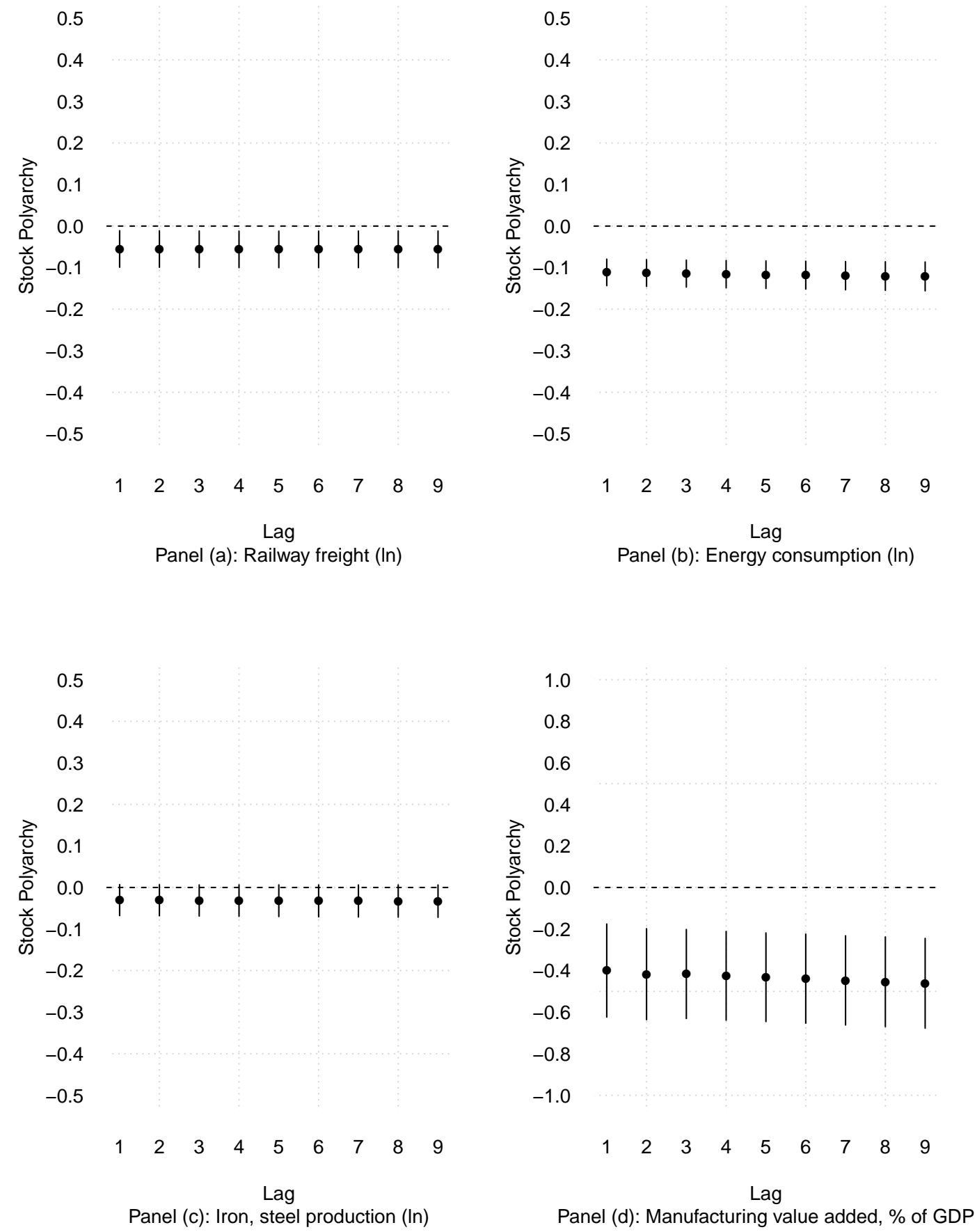

Figure 6.1: Regression coefficients, with 95\% percent confidence intervals, for varying lags. Note: Coefficients and standard errors for democracy stock (1\%) estimated from benchmark model (Models 1-4, Table 2.1) as lag varies from t-1 to t-9. 

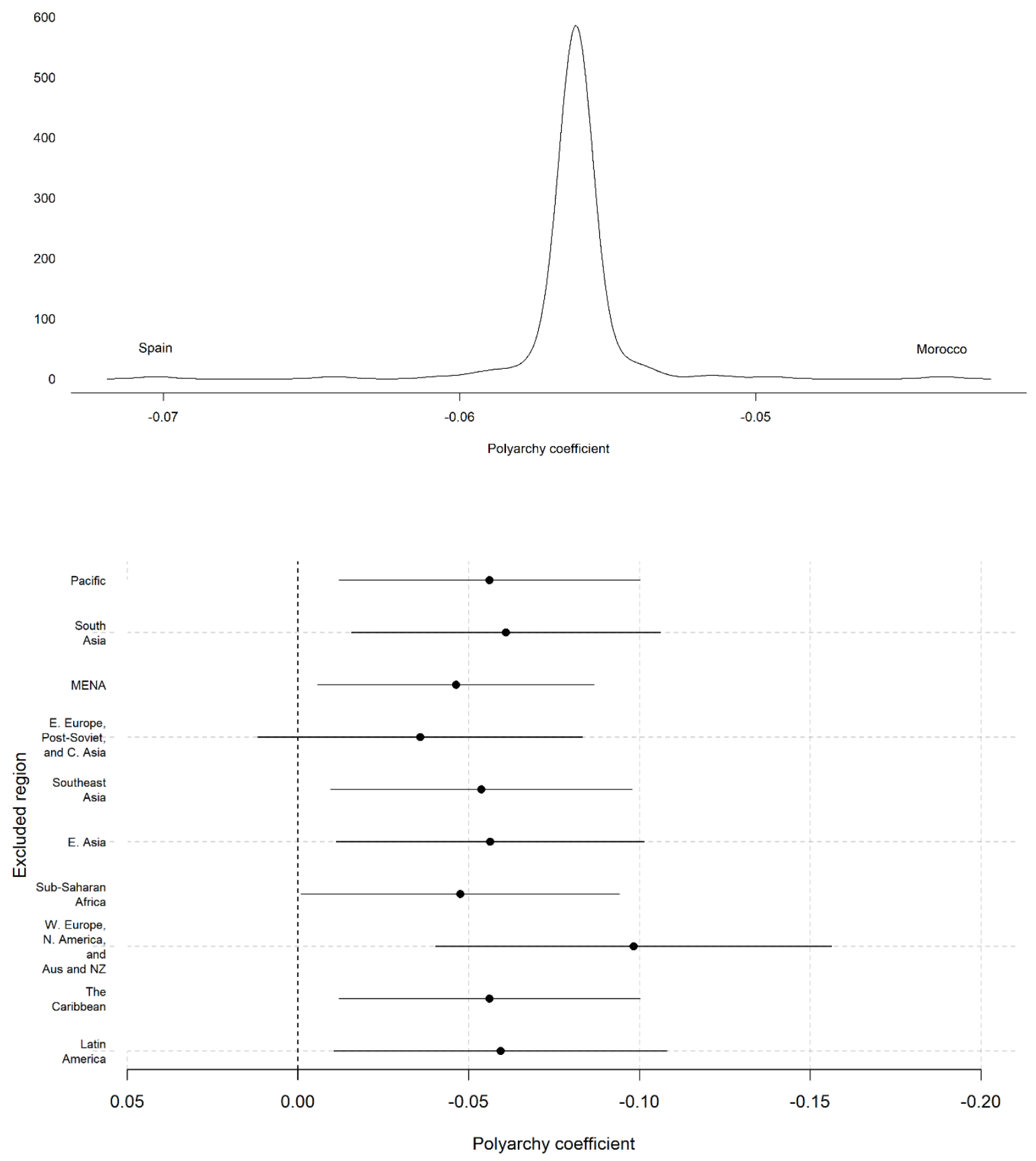

Figure 6.2: Varying Samples: Distribution of democracy stock coefficient when omitting countries (top) and entire regions (bottom) for Ln railway freight 

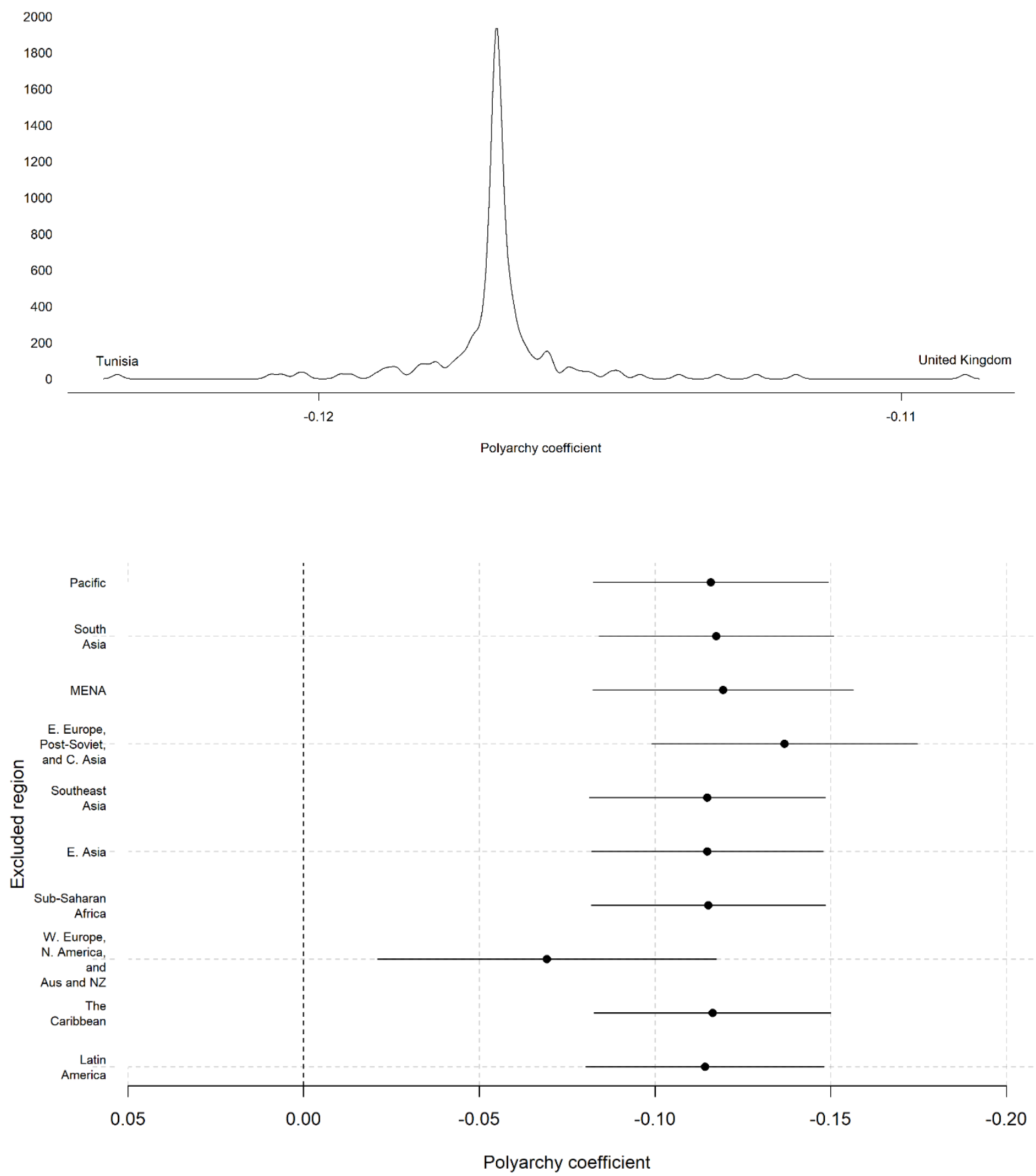

Figure 6.3: Varying Samples: Distribution of democracy stock coefficient when omitting countries (top) and entire regions (bottom) for Ln energy consumption 

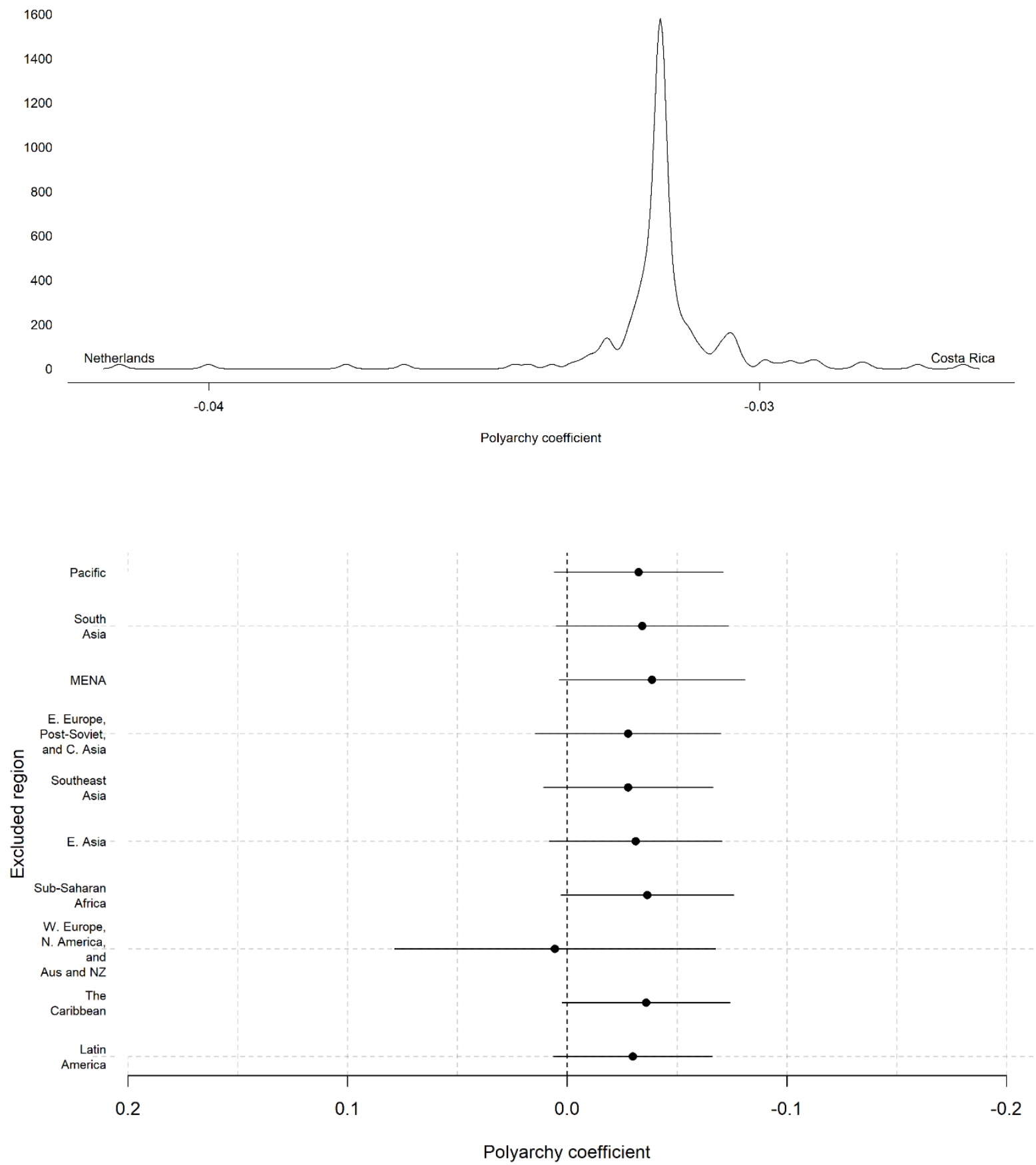

Figure 6.4: Varying Samples: Distribution of democracy stock coefficient when omitting countries (top) and entire regions (bottom) for Ln iron and steel production 

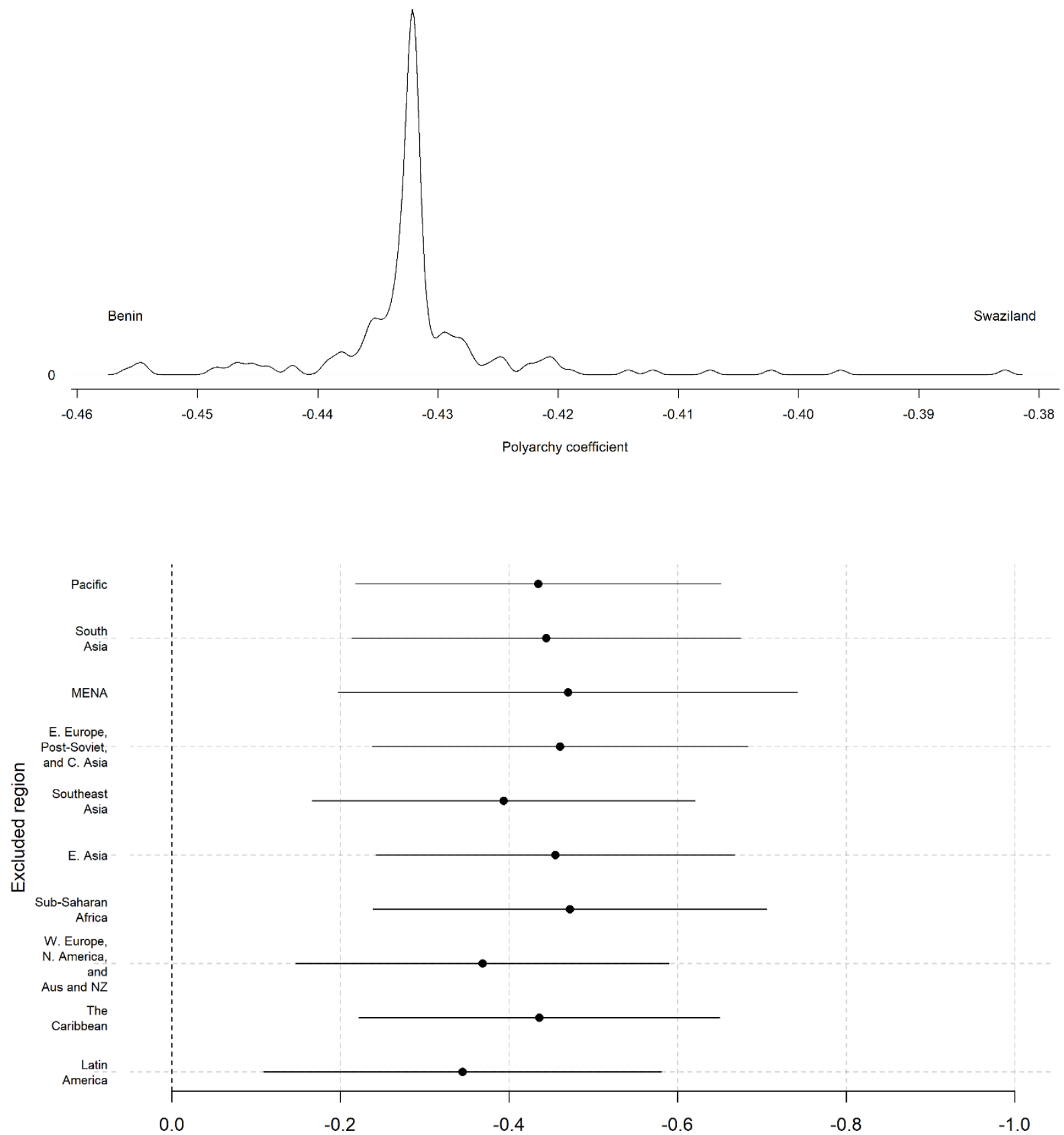

Figure 6.5: Varying Samples: Distribution of dem democracy stock coefficient when omitting countries (top) and entire regions (bottom) for manufacturing value added 


\subsection{Robustness tests of depreciation and lag}

\subsection{Different jackknife-estiamtions}

\subsection{Robustness tests of models with 5- and 10-year averages}

Table 6.4: Including the lagged dependent variable as regressor. Robustness test on Polyarchy Stock with 5 percent depreciation rate.

\begin{tabular}{|c|c|c|c|c|c|c|c|c|}
\hline Covariate & $\begin{array}{l}\text { Model } 1 \\
\text { Ln } \\
\text { Railway } \\
\text { freight } \\
\end{array}$ & $\begin{array}{c}\text { Model } 2 \\
\text { Ln energy } \\
\text { consump- } \\
\text { tion } \\
\end{array}$ & $\begin{array}{l}\text { Model } 3 \\
\text { Ln iron } \\
\text { and steel } \\
\text { production } \\
\end{array}$ & $\begin{array}{c}\text { Model } 4 \\
\text { Manu- } \\
\text { facturing } \\
\text { value added }\end{array}$ & $\begin{array}{c}\text { Model } 5 \\
\text { Ln } \\
\text { Railway } \\
\text { freight } \\
\end{array}$ & $\begin{array}{c}\text { Model } 6 \\
\text { Ln energy } \\
\text { consump- } \\
\text { tion } \\
\end{array}$ & $\begin{array}{c}\text { Model } 7 \\
\text { Ln iron } \\
\text { and steel } \\
\text { production } \\
\end{array}$ & $\begin{array}{c}\text { Model } 8 \\
\text { Manu- } \\
\text { facturing } \\
\text { value added }\end{array}$ \\
\hline $\begin{array}{l}\text { Stock Polyarchy } 1 \% \\
\text { depreciation }\end{array}$ & $\begin{array}{l}-0.01 \\
(-1.27)\end{array}$ & $\begin{array}{c}-0.03 \\
(-2.86)\end{array}$ & $\begin{array}{c}-0.02 \\
(-1.63)\end{array}$ & $\begin{array}{l}-0.09 \\
(-1.12)\end{array}$ & $\begin{array}{l}-0.01 \\
(-0.85)\end{array}$ & $\begin{array}{l}-0.05 \\
(-2.94)\end{array}$ & $\begin{array}{l}-0.03 \\
(-1.62)\end{array}$ & $\begin{array}{c}-0.22 \\
(-1.51)\end{array}$ \\
\hline Ln GDP pc & $\begin{array}{c}0.12 \\
(1.93)\end{array}$ & $\begin{array}{l}-0.06 \\
(-1.01)\end{array}$ & $\begin{array}{c}0.25 \\
(3.84)\end{array}$ & $\begin{array}{l}1.03 \\
(2.32)\end{array}$ & $\begin{array}{c}0.14 \\
(1.3)\end{array}$ & $\begin{array}{l}-0.12 \\
(-1.09)\end{array}$ & $\begin{array}{c}0.45 \\
(3.64)\end{array}$ & $\begin{array}{c}1.48 \\
(1.95)\end{array}$ \\
\hline Ln Population & $\begin{array}{c}0.22 \\
(0.34)\end{array}$ & $\begin{array}{c}1.92 \\
(4.26)\end{array}$ & $\begin{array}{c}2.69 \\
(5.45)\end{array}$ & $\begin{array}{l}11.09 \\
(2.4)\end{array}$ & $\begin{array}{l}-0.37 \\
(-0.33)\end{array}$ & $\begin{array}{c}2.86 \\
(3.39)\end{array}$ & $\begin{array}{c}4.51 \\
(5.13)\end{array}$ & $\begin{array}{c}18.2 \\
(1.85)\end{array}$ \\
\hline Lagged D.V. & $\begin{array}{c}0.82 \\
(27.7)\end{array}$ & $\begin{array}{c}0.83 \\
(42.74)\end{array}$ & $\begin{array}{c}0.86 \\
(63.71)\end{array}$ & $\begin{array}{c}0.65 \\
(16.41)\end{array}$ & $\begin{array}{c}0.7 \\
(13.56)\end{array}$ & $\begin{array}{c}0.69 \\
(18.11)\end{array}$ & $\begin{array}{c}0.74 \\
(29.39)\end{array}$ & $\begin{array}{c}0.46 \\
(8.36)\end{array}$ \\
\hline Constant & $\begin{array}{c}0.68 \\
(0.41) \\
\end{array}$ & $\begin{array}{l}-3.34 \\
(-2.8)\end{array}$ & $\begin{array}{c}-7.26 \\
(-5.73) \\
\end{array}$ & $\begin{array}{l}-27.38 \\
(-2.13) \\
\end{array}$ & $\begin{array}{c}2.42 \\
(0.87) \\
\end{array}$ & $\begin{array}{l}-4.46 \\
(-2.04) \\
\end{array}$ & $\begin{array}{l}-12.24 \\
(-5.33) \\
\end{array}$ & $\begin{array}{l}-43.69 \\
(-1.73) \\
\end{array}$ \\
\hline Countries: & 91 & 175 & 181 & 165 & 91 & 175 & 181 & 161 \\
\hline Years: & $1858-1989$ & $1823-2009$ & $1823-2009$ & $1968-2014$ & $1868-1989$ & $1828-2009$ & $1828-2009$ & $1978-2009$ \\
\hline Averages: & 5-year & 5-year & 5-year & 5-year & 10-year & 10-year & 10-year & 10-year \\
\hline Country FE & Yes & Yes & Yes & Yes & Yes & Yes & Yes & Yes \\
\hline Year FE & Yes & Yes & Yes & Yes & Yes & Yes & Yes & Yes \\
\hline $\mathrm{N}$ & 1096 & 2638 & 2694 & 1143 & 575 & 1364 & 1393 & 538 \\
\hline Adj. R-squared & 0.99 & 0.98 & 0.97 & 0.89 & 0.98 & 0.96 & 0.94 & 0.84 \\
\hline
\end{tabular}

Note: T-statistics from country clustered standard errors in parentheses.

All variables are averaged across the (5/10-year) time periods

Right-side variables lagged by five years. Omitted: country and year fixed effects, constant

Table 6.5: Including multiple lags of the dependent variable as regressors (5-year panels)

\begin{tabular}{|c|c|c|c|c|c|c|c|c|}
\hline Covariate & $\begin{array}{l}\text { Model } 1 \\
\text { Ln } \\
\text { Railway } \\
\text { freight } \\
\end{array}$ & $\begin{array}{c}\text { Model } 2 \\
\text { Ln energy } \\
\text { consump- } \\
\text { tion } \\
\end{array}$ & $\begin{array}{c}\text { Model } 3 \\
\text { Ln iron } \\
\text { and steel } \\
\text { production } \\
\end{array}$ & $\begin{array}{c}\text { Model } 4 \\
\text { Manu- } \\
\text { facturing } \\
\text { value added } \\
\end{array}$ & $\begin{array}{l}\text { Model } 5 \\
\text { Ln } \\
\text { Railway } \\
\text { freight } \\
\end{array}$ & $\begin{array}{c}\text { Model } 6 \\
\text { Ln energy } \\
\text { consump- } \\
\text { tion } \\
\end{array}$ & $\begin{array}{c}\text { Model } 7 \\
\text { Ln iron } \\
\text { and steel } \\
\text { production } \\
\end{array}$ & $\begin{array}{c}\text { Model } 8 \\
\text { Manu- } \\
\text { facturing } \\
\text { value added } \\
\end{array}$ \\
\hline $\begin{array}{l}\text { Stock Polyarchy } 1 \% \\
\text { depreciation }\end{array}$ & $\begin{array}{l}-0.004 \\
(-0.74)\end{array}$ & $\begin{array}{c}-0.023 \\
(-5.501)\end{array}$ & $\begin{array}{l}-0.014 \\
(-2.603)\end{array}$ & $\begin{array}{l}-0.169 \\
(-3.347)\end{array}$ & $\begin{array}{l}-0.003 \\
(-0.531)\end{array}$ & $\begin{array}{l}-0.016 \\
(-4.612)\end{array}$ & $\begin{array}{l}-0.012 \\
(-2.151)\end{array}$ & $\begin{array}{l}-0.152 \\
(-2.426)\end{array}$ \\
\hline Ln GDP pc & $\begin{array}{c}0.066 \\
(0.994)\end{array}$ & $\begin{array}{c}0.021 \\
(0.333)\end{array}$ & $\begin{array}{c}0.325 \\
(4.629)\end{array}$ & $\begin{array}{c}1.069 \\
(2.356)\end{array}$ & $\begin{array}{c}0.037 \\
(0.574)\end{array}$ & $\begin{array}{l}-0.032 \\
(-0.672)\end{array}$ & $\begin{array}{c}0.302 \\
(4.288)\end{array}$ & $\begin{array}{c}1.294 \\
(2.609)\end{array}$ \\
\hline Ln Population & $\begin{array}{c}0.113 \\
(0.168)\end{array}$ & $\begin{array}{c}2.739 \\
(5.206)\end{array}$ & $\begin{array}{c}2.524 \\
(5.164)\end{array}$ & $\begin{array}{l}8.042 \\
(1.389)\end{array}$ & $\begin{array}{c}0.126 \\
(0.191)\end{array}$ & $\begin{array}{c}2.249 \\
(4.622)\end{array}$ & $\begin{array}{l}3.002 \\
(5.43)\end{array}$ & $\begin{array}{l}16.957 \\
(2.711)\end{array}$ \\
\hline DV lagged 1 period & $\begin{array}{c}0.918 \\
(16.81)\end{array}$ & $\begin{array}{c}0.947 \\
(21.744)\end{array}$ & $\begin{array}{c}0.988 \\
(37.417)\end{array}$ & $\begin{array}{c}0.703 \\
(9.932)\end{array}$ & $\begin{array}{c}0.876 \\
(13.16)\end{array}$ & $\begin{array}{c}1.025 \\
(28.502)\end{array}$ & $\begin{array}{c}1.001 \\
(39.83)\end{array}$ & $\begin{array}{c}0.736 \\
(14.701)\end{array}$ \\
\hline DV lagged 2 periods & $\begin{array}{c}-0.121 \\
(-2.441)\end{array}$ & $\begin{array}{c}-0.172 \\
(-5.544)\end{array}$ & $\begin{array}{l}-0.165 \\
(-8.67)\end{array}$ & $\begin{array}{c}-0.093 \\
(-1.414)\end{array}$ & $\begin{array}{c}-0.098 \\
(-1.746)\end{array}$ & $\begin{array}{l}-0.166 \\
(-5.439)\end{array}$ & $\begin{array}{c}-0.221 \\
(-7.942)\end{array}$ & $\begin{array}{l}-0.165 \\
(-3.515)\end{array}$ \\
\hline DV lagged 3 periods & & & & & $\begin{array}{l}-0.011 \\
(-0.356)\end{array}$ & $\begin{array}{l}-0.029 \\
(-2.535)\end{array}$ & $\begin{array}{c}0.053 \\
(1.978)\end{array}$ & $\begin{array}{l}0.035 \\
(0.876)\end{array}$ \\
\hline Constant & $\begin{array}{l}1.124 \\
(0.67) \\
\end{array}$ & $\begin{array}{c}-5.441 \\
(-3.921) \\
\end{array}$ & $\begin{array}{c}-7.388 \\
(-5.787) \\
\end{array}$ & $\begin{array}{l}-17.642 \\
(-1.169) \\
\end{array}$ & $\begin{array}{l}1.463 \\
(0.95) \\
\end{array}$ & $\begin{array}{c}-4.316 \\
(-3.574) \\
\end{array}$ & $\begin{array}{c}-8.385 \\
(-5.833)\end{array}$ & $\begin{array}{l}-41.517 \\
(-2.517)\end{array}$ \\
\hline Countries: & 91 & 173 & 179 & 161 & 91 & 172 & 178 & 156 \\
\hline Years: & $1863-1989$ & $1828-2009$ & $1828-2009$ & $1973-2014$ & $1868-1989$ & $1833-2009$ & $1833-2009$ & $1978-2014$ \\
\hline Country FE & Yes & Yes & Yes & Yes & Yes & Yes & Yes & Yes \\
\hline Year FE & Yes & Yes & Yes & Yes & Yes & Yes & Yes & Yes \\
\hline $\mathrm{N}$ & 1007 & 2464 & 2515 & 972 & 916 & 2288 & 2333 & 806 \\
\hline Adj. R-squared & 0.987 & 0.98 & 0.967 & 0.895 & 0.988 & 0.985 & 0.967 & 0.905 \\
\hline
\end{tabular}

Note: T-statistics from country clustered standard erro
All variables are averaged across 5 -year time period

Right-side variables lagged by one time period. Omitted: country and year fixed effects, constant 


\subsection{Alternative samples}

Table 6.6: Robustness test on benchmark models, using different democracy measures

\begin{tabular}{|c|c|c|c|c|c|c|c|c|}
\hline Covariate & $\begin{array}{l}\text { Model } 1 \\
\text { Ln } \\
\text { Railway } \\
\text { freight }\end{array}$ & $\begin{array}{c}\text { Model } 2 \\
\text { Ln energy } \\
\text { consump- } \\
\text { tion } \\
\end{array}$ & $\begin{array}{c}\text { Model } 3 \\
\text { Ln iron } \\
\text { and steel } \\
\text { production }\end{array}$ & $\begin{array}{c}\text { Model } 4 \\
\text { Manu- } \\
\text { facturing } \\
\text { value added }\end{array}$ & $\begin{array}{l}\text { Model } 5 \\
\text { Ln } \\
\text { Railway } \\
\text { freight } \\
\end{array}$ & $\begin{array}{c}\text { Model } 6 \\
\text { Ln energy } \\
\text { consump- } \\
\text { tion } \\
\end{array}$ & $\begin{array}{c}\text { Model } 7 \\
\text { Ln iron } \\
\text { and steel } \\
\text { production }\end{array}$ & $\begin{array}{c}\text { Model } 8 \\
\text { Manu- } \\
\text { facturing } \\
\text { value added }\end{array}$ \\
\hline $\begin{array}{l}\text { Stock BMR } 1 \% \\
\text { depreciation }\end{array}$ & $\begin{array}{l}-0.037 \\
(-3.374)\end{array}$ & $\begin{array}{l}-0.063 \\
(-6.808)\end{array}$ & $\begin{array}{c}-0.011 \\
(-0.938)\end{array}$ & $\begin{array}{l}-0.141 \\
(-1.972)\end{array}$ & & & & \\
\hline $\begin{array}{l}\text { Stock Lexical } 1 \% \\
\text { depreciation }\end{array}$ & & & & & $\begin{array}{l}-0.004 \\
(-1.844)\end{array}$ & $\begin{array}{l}-0.013 \\
(-5.441)\end{array}$ & $\begin{array}{c}-0.001 \\
(-0.571)\end{array}$ & $\begin{array}{l}-0.014 \\
(-0.99)\end{array}$ \\
\hline Ln GDP pc & $\begin{array}{c}0.599 \\
(3.512)\end{array}$ & $\begin{array}{c}0.268 \\
(1.259)\end{array}$ & $\begin{array}{c}1.552 \\
(7.649)\end{array}$ & $\begin{array}{c}2.832 \\
(3.111)\end{array}$ & $\begin{array}{l}0.496 \\
(2.701)\end{array}$ & $\begin{array}{c}0.21 \\
(1.027)\end{array}$ & $\begin{array}{c}1.499 \\
(8.101)\end{array}$ & $\begin{array}{l}2.187 \\
(2.92)\end{array}$ \\
\hline Ln Population & $\begin{array}{c}0.524 \\
(3.608)\end{array}$ & $\begin{array}{l}1.523 \\
(7.342)\end{array}$ & $\begin{array}{c}1.088 \\
(5.844)\end{array}$ & $\begin{array}{c}3.561 \\
(3.141)\end{array}$ & $\begin{array}{c}0.522 \\
(3.803)\end{array}$ & $\begin{array}{c}1.558 \\
(7.435)\end{array}$ & $\begin{array}{c}1.15 \\
(6.298)\end{array}$ & $\begin{array}{c}2.872 \\
(2.948)\end{array}$ \\
\hline Constant & $\begin{array}{c}-6.148 \\
(-3.191) \\
\end{array}$ & $\begin{array}{l}-14.515 \\
(-5.164) \\
\end{array}$ & $\begin{array}{l}-19.169 \\
(-7.761) \\
\end{array}$ & $\begin{array}{l}-44.396 \\
(-2.736) \\
\end{array}$ & $\begin{array}{l}-4.013 \\
(-2.068) \\
\end{array}$ & $\begin{array}{c}-13.642 \\
(-4.84) \\
\end{array}$ & $\begin{array}{l}-19.037 \\
(-8.011) \\
\end{array}$ & $\begin{array}{l}-28.536 \\
(-1.994) \\
\end{array}$ \\
\hline Countries: & 92 & 164 & 171 & 151 & 92 & 176 & 185 & 165 \\
\hline Years: & $1851-1993$ & $1816-2007$ & $1816-2007$ & $1960-2007$ & $1851-1993$ & $1816-2012$ & $1816-2012$ & $1960-2016$ \\
\hline Country FE & Yes & Yes & Yes & Yes & Yes & Yes & Yes & Yes \\
\hline Year FE & Yes & Yes & Yes & Yes & Yes & Yes & Yes & Yes \\
\hline $\mathrm{N}$ & 4820 & 11981 & 12270 & 4236 & 4817 & 13431 & 13794 & 5810 \\
\hline Adj. R-squared & 0.953 & 0.91 & 0.873 & 0.763 & 0.954 & 0.907 & 0.872 & 0.739 \\
\hline
\end{tabular}

Note: T-statistics from country clustered standard errors in parentheses. Right-side variables lagged by five years.

Omitted: country and year fixed effects, constant 
Table 6.7: Robustness test on benchmark models, using stock autocracy instead of stock democracy

\begin{tabular}{lcccc}
\hline & $\begin{array}{c}\text { Model } 1 \\
\text { Ln } \\
\text { Railway } \\
\text { freight }\end{array}$ & $\begin{array}{c}\text { Model 2 } \\
\text { Ln energy } \\
\text { consump- } \\
\text { tion }\end{array}$ & $\begin{array}{c}\text { Model } 3 \\
\text { Ln iron } \\
\text { and steel } \\
\text { production }\end{array}$ & $\begin{array}{c}\text { Model } 4 \\
\text { Manu- } \\
\text { facturing } \\
\text { value added }\end{array}$ \\
\hline Stock Polyarchy Autocracy & 0.03 & 0.07 & 0.01 & 0.2 \\
1 \% depreciation & $(2.19)$ & $(5.79)$ & $(0.34)$ & $(2.66)$ \\
Ln GDP pc & 0.45 & 0.17 & 1.51 & 2.36 \\
Ln Population & $(2.49)$ & $(0.81)$ & $(7.91)$ & $(3.18)$ \\
Constant & 0.49 & 1.31 & 1.17 & 2.44 \\
& $(2.54)$ & $(6.39)$ & $(6.32)$ & $(3.28)$ \\
Countries: & -5.08 & -13 & -19.37 & -39.55 \\
Years: & $(-2.18)$ & $(-4.74)$ & $(-8.2)$ & $(-3.08)$ \\
\hline Country FE & 92 & 175 & 181 & 165 \\
Year FE & $1852-1993$ & $1816-2012$ & $1816-2012$ & $1960-2017$ \\
N & Yes & Yes & Yes & Yes \\
Adj. R-squared & Yes & Yes & Yes & Yes \\
\hline Note: Tratian & 5476 & 13291 & 13559 & 6005 \\
& 0.94 & 0.91 & 0.87 & 0.74 \\
\hline
\end{tabular}

Note: T-statistics from country clustered standard errors in parentheses.

Right-side variables lagged by five years.

Omitted: country and year fixed effects, constant

Table 6.8: Robustness test of benchmark models, excluding countries with socialist legal origin

\begin{tabular}{lcccc}
\hline & $\begin{array}{c}\text { Model } 1 \\
\text { Ln } \\
\text { Railway } \\
\text { freight }\end{array}$ & $\begin{array}{c}\text { Model 2 } \\
\text { Ln energy } \\
\text { consump- } \\
\text { tion }\end{array}$ & $\begin{array}{c}\text { Model 3 } \\
\text { Ln iron } \\
\text { and steel } \\
\text { production }\end{array}$ & $\begin{array}{c}\text { Model 4 } \\
\text { Manu- } \\
\text { facturing } \\
\text { value added }\end{array}$ \\
\hline Stock Polyarchy $1 \%$ & -0.06 & -0.12 & -0.03 & -0.39 \\
depreciation & $(-2.49)$ & $(-7.1)$ & $(-1.47)$ & $(-3.5)$ \\
Ln GDP pc & 0.52 & 0.27 & 1.6 & 2.47 \\
& $(2.97)$ & $(1.34)$ & $(8.23)$ & $(3.39)$ \\
Ln Population & 0.49 & 1.27 & 1.05 & 2.36 \\
Constant & $(2.75)$ & $(6.57)$ & $(5.97)$ & $(3.11)$ \\
& -4.93 & -11.95 & -18.94 & -23.22 \\
Countries: & $(-2.15)$ & $(-4.61)$ & $(-8.19)$ & $(-1.91)$ \\
Years: & 89 & 162 & 162 & 159 \\
Country FE & $1852-1993$ & $1816-2012$ & $1816-2012$ & $1960-2017$ \\
Year FE & Yes & Yes & Yes & Yes \\
N & Yes & Yes & Yes & Yes \\
Adj. R-squared & 5344 & 12688 & 12701 & 5858 \\
\hline
\end{tabular}

Note: T-statistics from country clustered standard errors in parentheses.

Right-side variables lagged by five years.

Omitted: country and year fixed effects, constant 
Table 6.9: Robustness test of benchmark models, excluding all observations with the value 0 on iron and steel production

\begin{tabular}{lccc}
\hline & Model 1 & Model 2 & Model 3 \\
& \multicolumn{2}{c}{ Ln iron and steel production } \\
\hline Stock Polyarchy 1\% & -0.07 & -0.09 & -0.06 \\
depreciation & $(-4.91)$ & $(-3.81)$ & $(-3.93)$ \\
Ln GDP pc & 1.34 & & 1.71 \\
& $(4.7)$ & & $(5.51)$ \\
Ln Population & 1.09 & & 1.2 \\
& $(4.99)$ & & $(4.74)$ \\
GDP pc growth & & & 2.36 \\
& & & $(2)$ \\
Resource income \% GDP & & & -0.01 \\
Rigorous and impartial & & & $(-1.79)$ \\
public administration & & & -0.11 \\
Government ownership in & & & $(-1.49)$ \\
the economy & & & -0.08 \\
Ln time in sample & & & $(-1.7)$ \\
Constant & -17.33 & 0.9 & 0.43 \\
& $(-5.81)$ & $(1.89)$ & -21.68 \\
Countries: & 108 & 109 & $(-6.38)$ \\
Years: & $1816-2012$ & $1816-2012$ & $1816-2011$ \\
\hline Country FE & Yes & Yes & Yes \\
Year FE & Yes & Yes & Yes \\
N & 6102 & 6471 & 5340 \\
Adj. R-squared & 0.9 & 0.86 & 0.9 \\
\hline
\end{tabular}

Note: T-statistics from country clustered standard errors in parentheses. Right-side variables lagged by five years.

Omitted: country and year fixed effects, constant 



\section{Appendix for Chapter 3}

\subsection{Summary}

In this appendix I provide additional information about the data and robustness tests that are mentioned, but not displayed in tables or figures, in the paper. Section 7.2 presents relevant descriptive statistics and bivariate relationships. Section 7.3 presents different jackknife estimations in order to evaluate the stability of the results. Section 7.4 presents models that include additional covariates, and models that excludes covariates in seriatim. Section 7.5 presents robustness tests using different measures of democracy and state capacity. Section 7.6 presents models where the level of analysis is whether or not the individual letters were returned, instead of the country-level share of letters returned.

\subsection{Descriptive statistics}

Table 7.1: Descriptive statistics

\begin{tabular}{|c|c|c|c|c|c|c|}
\hline & Mean & Median & SD & Min & Max & $\mathrm{N}$ missing \\
\hline Percent letters returned & 59.31 & 70.00 & 32.88 & 0.00 & 100.00 & 0.00 \\
\hline Polyarchy centered & 0.00 & 0.02 & 0.25 & -0.54 & 0.37 & 8.00 \\
\hline Ln GDP pc PPP centered & -0.00 & 0.11 & 1.25 & -2.82 & 2.60 & 0.00 \\
\hline Impartial government officials centered & -0.00 & -0.33 & 1.43 & -2.41 & 4.05 & 8.00 \\
\hline Ln Distance from USA centered & -0.00 & 0.34 & 1.37 & -8.45 & 1.08 & 1.00 \\
\hline Ln Population centered & 0.00 & -0.03 & 1.62 & -4.62 & 4.84 & 0.00 \\
\hline Ln km2 Area Centered & 0.00 & 0.23 & 2.11 & -6.24 & 4.67 & 0.00 \\
\hline Intrastate conflict & 0.18 & 0.00 & 0.38 & 0.00 & 1.00 & 2.00 \\
\hline State ownership centered & -0.00 & 0.12 & 1.01 & -3.24 & 2.57 & 8.00 \\
\hline Latin alphabet & 0.66 & 1.00 & 0.48 & 0.00 & 1.00 & 0.00 \\
\hline Latitude & 26.86 & 24.00 & 17.05 & 0.00 & 65.00 & 6.00 \\
\hline Tropical climate & 0.31 & 0.00 & 0.41 & 0.00 & 1.00 & 15.00 \\
\hline Landlocked & 0.23 & 0.00 & 0.42 & 0.00 & 1.00 & 6.00 \\
\hline Island & 0.16 & 0.00 & 0.37 & 0.00 & 1.00 & 6.00 \\
\hline Share of european descendants & 0.33 & 0.02 & 0.42 & 0.00 & 1.00 & 11.00 \\
\hline Weighted genetic distance to Britain & 833.59 & 716.21 & 680.74 & 0.00 & 2262.39 & 6.00 \\
\hline Former European Colony & 0.58 & 1.00 & 0.50 & 0.00 & 1.00 & 6.00 \\
\hline BMR-democracy & 0.60 & 1.00 & 0.49 & 0.00 & 1.00 & 12.00 \\
\hline
\end{tabular}




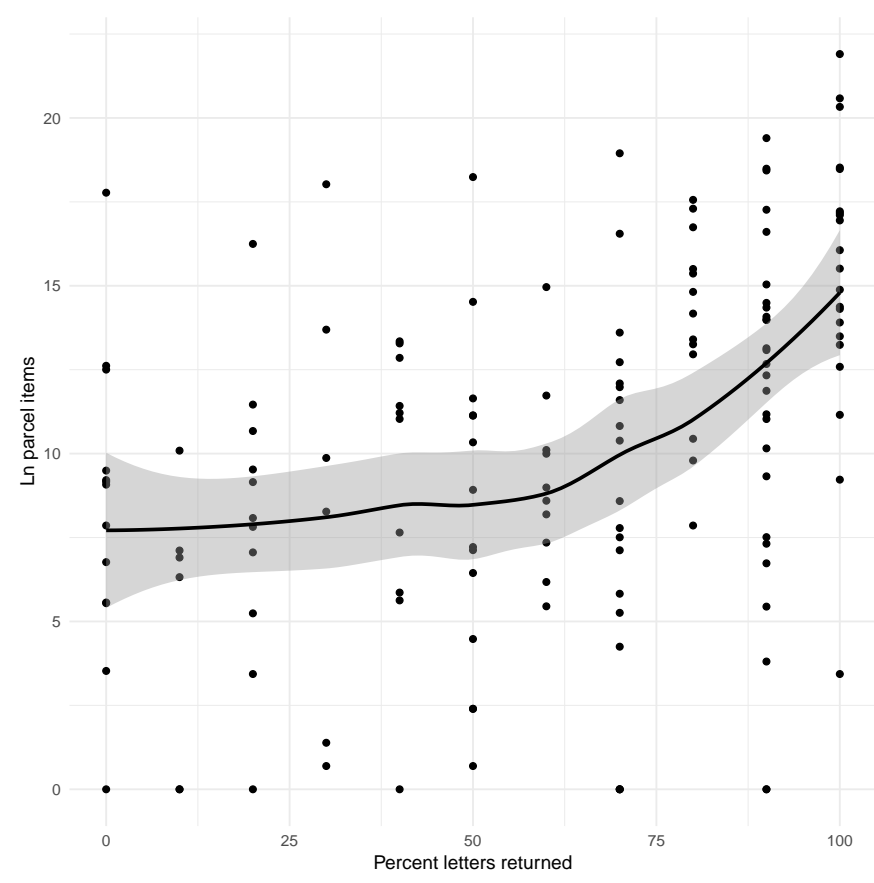

Figure 7.1: Scatterplot and local regression line of Ln domestic parcels items (imputed) +1 and the percent letters returned in the experiment

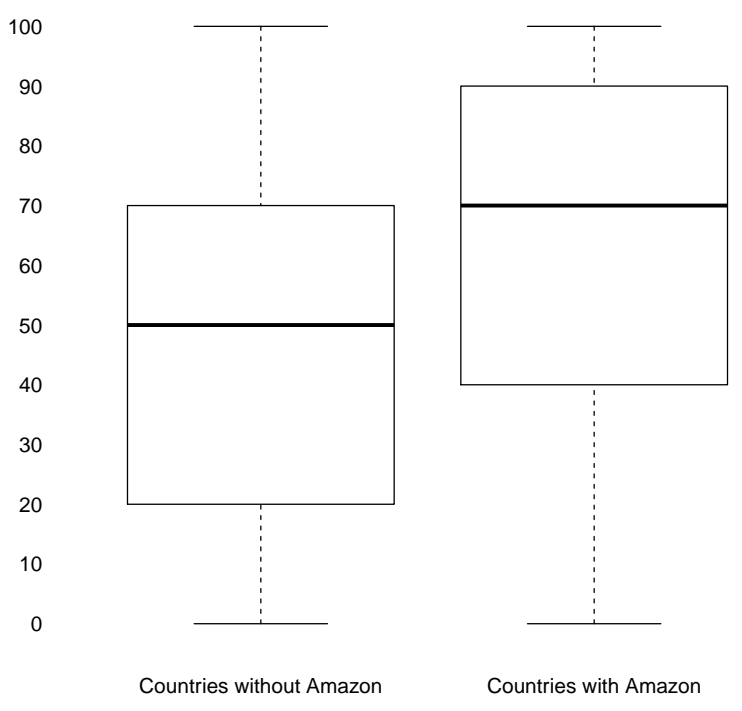

Figure 7.2: Boxplot comparison of percent responded letters between countries AmazonGlobal does and does not export to. Western Europe, North America, Australia and New Zealand are excluded. An overview of countries with Amazon-services is available at https://www . amazon. com/gp/help/customer/display.html?nodeId=201074230. 


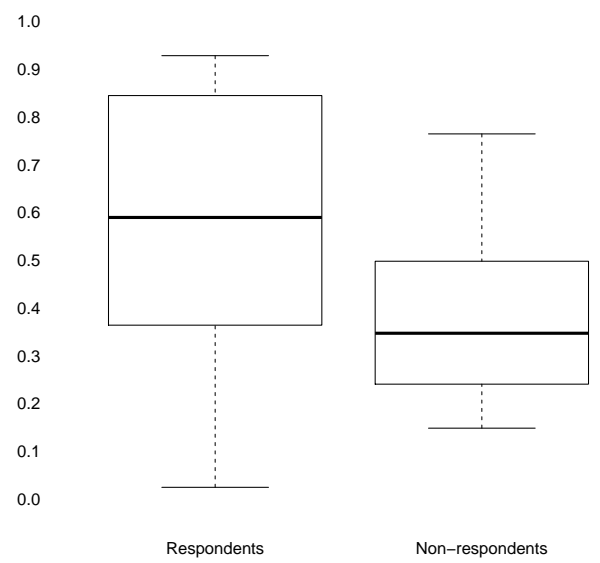

Figure 7.3: Boxplot of Polyarchy among countries that returned at least 1 letter, compared to those that returned 0 


\subsection{Robustness test: Jackknife and regional exclu- sion}

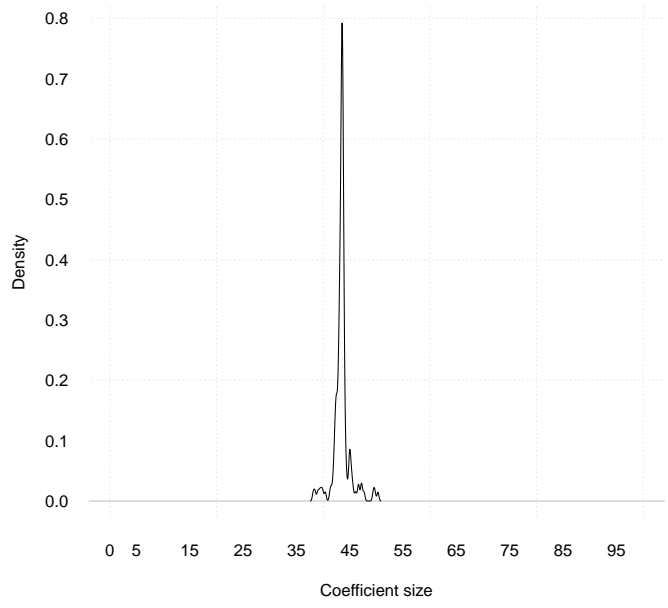

Figure 7.4: Distribution of the coefficient for Polyarchy after jackknife estimation of model 3 in Table 3.1

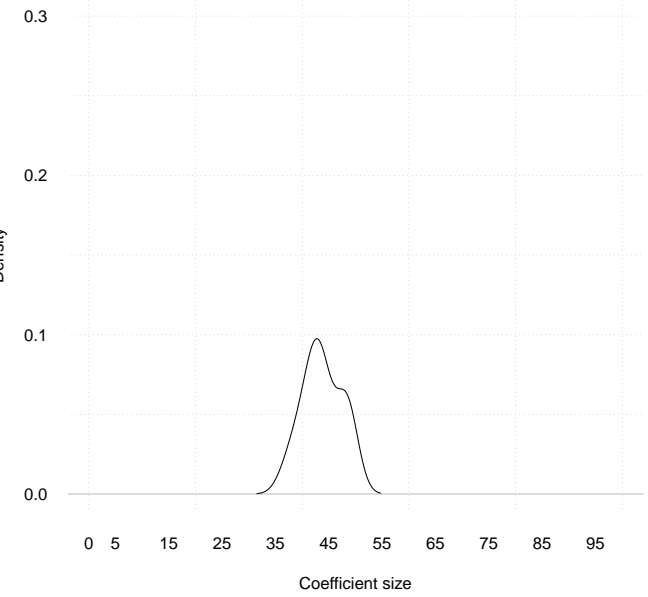

Figure 7.5: Distribution of the coefficient for Polyarchy after exclusion of individual regions when estimating the model 3 in Table 3.1 


\subsection{Robustness test: Changing the included covari- ates.}

Table 7.2: Effectiveness of postal services

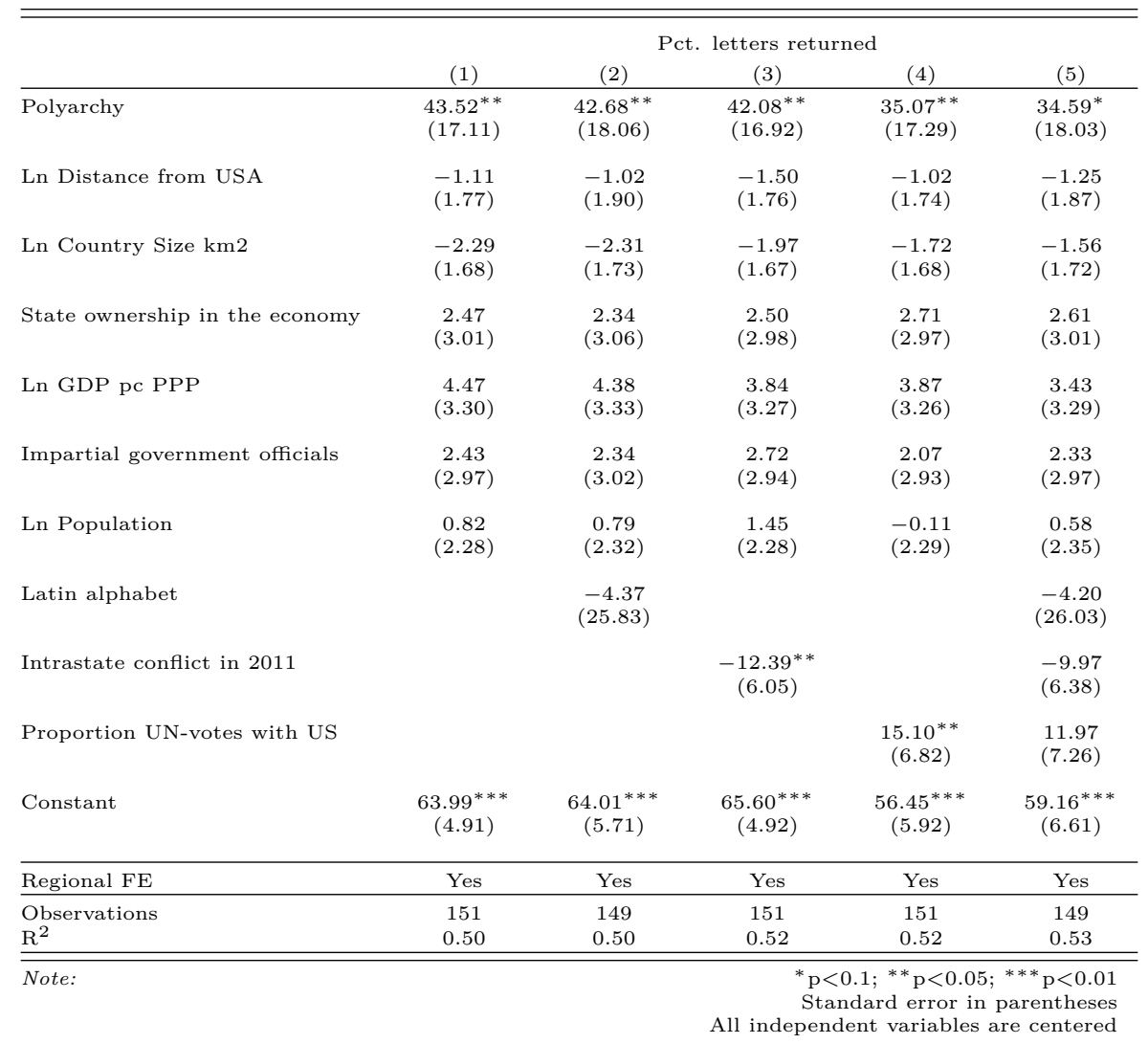


7.5 Robustness test: Alternative measures 


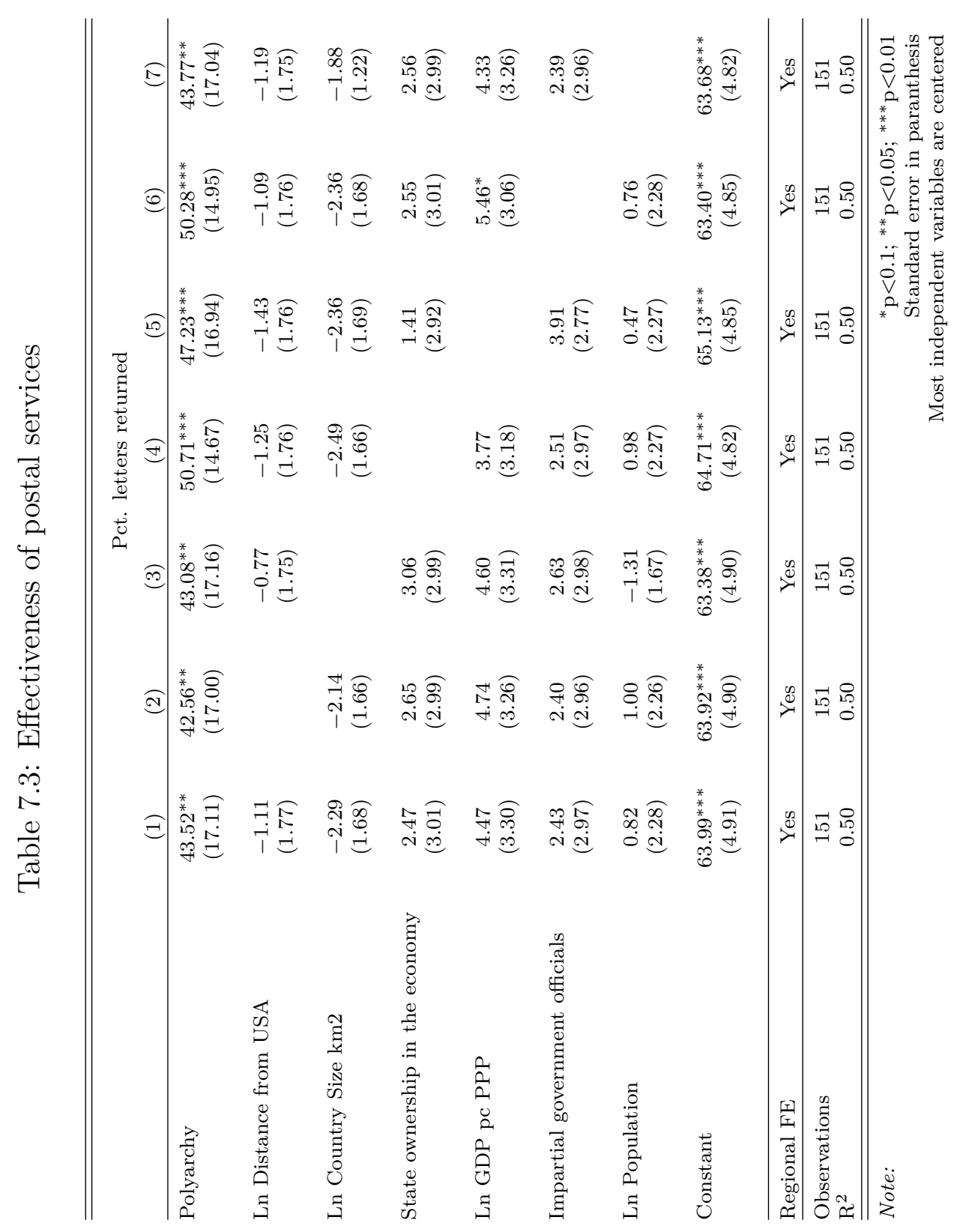


Table 7.4: Effectiveness of postal services - Alternative measures

\begin{tabular}{|c|c|c|c|c|}
\hline & $(1)$ & $(2)$ & $(3)$ & $(4)$ \\
\hline Polyarchy & $\begin{array}{r}43.5^{* *} \\
(17.1)\end{array}$ & & $\begin{array}{c}51.4^{* * *} \\
(19.4)\end{array}$ & \\
\hline BMR & & $\begin{array}{c}20.8^{* * *} \\
(6.1)\end{array}$ & & $\begin{array}{c}30.2^{* * *} \\
(7.1)\end{array}$ \\
\hline Ln Distance from USA & $\begin{array}{l}-1.1 \\
(1.8)\end{array}$ & $\begin{array}{l}-1.0 \\
(1.7)\end{array}$ & $\begin{array}{l}-1.3 \\
(1.8)\end{array}$ & $\begin{array}{l}-1.2 \\
(1.6)\end{array}$ \\
\hline Ln Country Size km² & $\begin{array}{l}-2.3 \\
(1.7)\end{array}$ & $\begin{array}{l}-1.7 \\
(1.7)\end{array}$ & $\begin{array}{l}-1.3 \\
(2.0)\end{array}$ & $\begin{array}{l}-0.5 \\
(1.8)\end{array}$ \\
\hline State ownership in the economy & $\begin{array}{c}2.5 \\
(3.0)\end{array}$ & $\begin{array}{c}2.7 \\
(2.8)\end{array}$ & $\begin{array}{c}4.3 \\
(3.6)\end{array}$ & $\begin{array}{c}3.2 \\
(3.2)\end{array}$ \\
\hline Ln GDP pc PPP & $\begin{array}{c}4.5 \\
(3.3)\end{array}$ & $\begin{array}{l}5.6^{*} \\
(3.2)\end{array}$ & $\begin{array}{c}4.1 \\
(4.5)\end{array}$ & $\begin{array}{l}8.0^{* *} \\
(3.7)\end{array}$ \\
\hline Impartial government officials & $\begin{array}{c}2.4 \\
(3.0)\end{array}$ & $\begin{array}{l}4.4^{*} \\
(2.6)\end{array}$ & & \\
\hline QoG Professionalism & & & $\begin{array}{c}0.8 \\
(4.0)\end{array}$ & $\begin{array}{c}0.9 \\
(3.7)\end{array}$ \\
\hline Ln Population & $\begin{array}{c}0.8 \\
(2.3)\end{array}$ & $\begin{array}{c}0.7 \\
(2.2)\end{array}$ & $\begin{array}{l}-1.4 \\
(2.7)\end{array}$ & $\begin{array}{l}-2.3 \\
(2.5)\end{array}$ \\
\hline Constant & $\begin{array}{c}64.0^{* * *} \\
(4.9)\end{array}$ & $\begin{array}{l}49.1^{* * *} \\
(6.4)\end{array}$ & $\begin{array}{c}62.0^{* * *} \\
(14.5)\end{array}$ & $\begin{array}{c}39.2^{* * *} \\
(13.1)\end{array}$ \\
\hline Regional FE & Yes & Yes & Yes & Yes \\
\hline $\begin{array}{l}\text { Observations } \\
\mathrm{R}^{2}\end{array}$ & $\begin{array}{l}151 \\
0.5 \\
\end{array}$ & $\begin{array}{l}147 \\
0.5\end{array}$ & $\begin{array}{l}111 \\
0.5 \\
\end{array}$ & $\begin{array}{l}108 \\
0.6\end{array}$ \\
\hline Note: & & $\begin{array}{l}{ }^{*} \mathrm{p}<0 \text {. } \\
\text { Stand } \\
\text { ependen }\end{array}$ & $\begin{array}{l}{ }^{*} \mathrm{p}<0.05 \\
\text { error in } \\
\text { riables a }\end{array}$ & $\begin{array}{l}{ }^{*} p<0.01 \\
\text { entheses } \\
\text { centered }\end{array}$ \\
\hline
\end{tabular}




\subsection{Robustness test: Letter-level analyses}

Table 7.5: Effectiveness of postal services

\begin{tabular}{|c|c|c|c|c|}
\hline & \multicolumn{4}{|c|}{ Letter returned or not } \\
\hline & $(1)$ & $(2)$ & $(3)$ & $(4)$ \\
\hline Polyarchy & $\begin{array}{c}2.08^{* * *} \\
(0.50)\end{array}$ & $\begin{array}{c}1.57^{* * *} \\
(0.53)\end{array}$ & $\begin{array}{c}1.55^{* * *} \\
(0.53)\end{array}$ & $\begin{array}{c}1.67^{* * *} \\
(0.55)\end{array}$ \\
\hline Ln Distance from USA & $\begin{array}{l}-0.06 \\
(0.07)\end{array}$ & $\begin{array}{l}-0.08 \\
(0.07)\end{array}$ & $\begin{array}{l}-0.09 \\
(0.07)\end{array}$ & $\begin{array}{l}-0.13 \\
(0.08)\end{array}$ \\
\hline Ln Distance to country capital & $\begin{array}{c}-0.05^{* * *} \\
(0.01)\end{array}$ & $\begin{array}{c}-0.05^{* * *} \\
(0.01)\end{array}$ & $\begin{array}{c}-0.03^{* * *} \\
(0.01)\end{array}$ & $\begin{array}{c}-0.03^{*} \\
(0.02)\end{array}$ \\
\hline State ownership in the economy & $\begin{array}{c}0.12 \\
(0.09)\end{array}$ & $\begin{array}{c}0.12 \\
(0.09)\end{array}$ & $\begin{array}{c}0.12 \\
(0.09)\end{array}$ & $\begin{array}{c}0.12 \\
(0.09)\end{array}$ \\
\hline Ln GDP pc PPP & $\begin{array}{c}0.21^{* *} \\
(0.09)\end{array}$ & $\begin{array}{l}0.16^{*} \\
(0.10)\end{array}$ & $\begin{array}{l}0.16^{*} \\
(0.10)\end{array}$ & $\begin{array}{c}0.08 \\
(0.11)\end{array}$ \\
\hline Impartial government officials & $\begin{array}{c}0.14 \\
(0.09)\end{array}$ & $\begin{array}{c}0.13 \\
(0.09)\end{array}$ & $\begin{array}{c}0.14 \\
(0.09)\end{array}$ & $\begin{array}{l}0.18^{*} \\
(0.10)\end{array}$ \\
\hline Ln Population & $\begin{array}{l}-0.04 \\
(0.05)\end{array}$ & $\begin{array}{l}-0.02 \\
(0.05)\end{array}$ & $\begin{array}{l}-0.03 \\
(0.06)\end{array}$ & $\begin{array}{l}-0.06 \\
(0.07)\end{array}$ \\
\hline Latin Alphabet & & $\begin{array}{c}0.83^{* * *} \\
(0.23)\end{array}$ & $\begin{array}{c}0.86^{* * *} \\
(0.24)\end{array}$ & $\begin{array}{c}0.82^{* * *} \\
(0.24)\end{array}$ \\
\hline Intrastate conflict in 2011 & & $\begin{array}{c}-0.47^{* *} \\
(0.18)\end{array}$ & $\begin{array}{c}-0.43^{* *} \\
(0.19)\end{array}$ & $\begin{array}{c}-0.37^{* *} \\
(0.19)\end{array}$ \\
\hline Proportion UN-votes with US & & $\begin{array}{l}-0.56 \\
(0.83)\end{array}$ & $\begin{array}{l}-0.50 \\
(0.85)\end{array}$ & $\begin{array}{c}0.13 \\
(0.88)\end{array}$ \\
\hline Letter sent in December & & & $\begin{array}{c}-2.70^{* * *} \\
(0.61)\end{array}$ & $\begin{array}{c}-2.64^{* * *} \\
(0.61)\end{array}$ \\
\hline Ln calibrated average nightlights & & & & $\begin{array}{c}0.16 \\
(0.17)\end{array}$ \\
\hline Average temperature & & & & $\begin{array}{c}0.16^{* * *} \\
(0.05)\end{array}$ \\
\hline Average temperature $^{2}$ & & & & $\begin{array}{c}-0.004^{* * *} \\
(0.001)\end{array}$ \\
\hline Constant & $\begin{array}{c}1.17^{* * *} \\
(0.19)\end{array}$ & $\begin{array}{c}0.86^{* * *} \\
(0.23)\end{array}$ & $\begin{array}{c}3.24^{* * *} \\
(0.63)\end{array}$ & $\begin{array}{c}2.47^{* * *} \\
(0.74)\end{array}$ \\
\hline$\underline{\text { Regional FE }}$ & Yes & Yes & Yes & Yes \\
\hline $\begin{array}{l}\text { Observations } \\
\text { Log Likelihood }\end{array}$ & $\begin{array}{c}1,510 \\
-826.79\end{array}$ & $\begin{array}{c}1,490 \\
-801.81\end{array}$ & $\begin{array}{c}1,490 \\
-782.38\end{array}$ & $\begin{array}{c}1,460 \\
-757.20\end{array}$ \\
\hline Note: & & $\begin{array}{r}{ }_{1} \\
\mathrm{St} \\
\text { Indepe }\end{array}$ & $\begin{array}{l}.1 ;{ }^{* *} \mathrm{p}<0 \\
\text { lard error } \\
\text { nt variable }\end{array}$ & $\begin{array}{l}; * * * \mathrm{p}<0.01 \\
\text { parentheses } \\
\text { are centered }\end{array}$ \\
\hline
\end{tabular}





\section{Appendix for Chapter 4}

\subsection{Summary}

In this appendix, we provide additional information about the data gathering process and the data material, before we present additional robustness tests that are mentioned, but not displayed in tables, in the paper.

The first two sections pertain to the data collection process and features of the data. The first section gives an overview of the automated data-scraping routine that we developed to gather the skyscraper data from CTBUH (2016), whereas the second section presents relevant descriptive statistics.

The following section presents robustness tests for the hypothesis that autocracies build more skyscrapers than democracies. More specifically, the third section includes various tests where we have altered the criteria for counting a building as a skyscraper, and other tests pertaining to variations in our main dependent variables. The fourth section presents model specifications where we adjust the set of control variables. We present both more parsimonious and more extensive models to investigate whether our results could be influenced by, respectively, post-treatment bias and omitted variable bias. We thereafter present tests using alternative different measures of democracy. The fifth section displays regressions using the alternative 4-year lag specification, as well as results for (different) samples that only draw on information from more recent years instead of extending the analysis back to 1900. The sixth section displays the results from the first stage of the zero-inflated negative binomial model.

The next sections presents additional tests for the hypothesis that autocracies build more wasteful skyscrapers than democracies. The seventh section displays descriptive statistics on influential observations and results from a Jackknifing exercise omitting such observations. The eighth section presents a variety of alternative Coarsened Exact Matching (CEM) specifications to those presented in the paper. The ninth section displays results from Entropy Balancing specifications. The tenth section shows CEM results at the building level when we use alternative proxies on the excessiveness of skyscrapers. The eleventh, and final, section presents results for the interaction models, where Polyarchy is interacted with, respectively, urbanization and GDP per capita. 


\subsection{Skyscraper data collection}

All data on skyscrapers have been collected from the CTBUH's website skyscrapercenter (CTBUH 2016). This was done following a 3-step procedure:

1. We downloaded the webpage for each building with a so-called "wget-loop" in a Bash script. ${ }^{1}$

2. We constructed a R-script that extracted the different pieces of information from each page. All pages have the same setup, i.e., they have identical XML structures (although the pieces of information on particular variables differ), making it possible to create a generic script for all of them that recognizes whether a particular piece of information is available for each page. While any procedure using the XMLstructure of the pages would work, this script relied on Hadley Wickham's "rvest" package in R (Wickham 2016).

3. We conducted a cleaning procedure on the information extracted. This included removing duplicate information, cleaning text (mostly related to encoding issues), and harmonizing vector-names.

All steps in this procedure are replicable. Please see https://github.com/Hax2kon/ SkyscrapersDemocracyAutocracy for all replication materials.

\footnotetext{
${ }^{1}$ Notice that step one is not mandatory, since $\mathrm{R}$ could connect to each page without downloading them first. Step 1 simply makes it possible to work offline.
} 


\subsection{Descriptive statistics and sample}

Table 8.1: Descriptive statistics for main variables

\begin{tabular}{lrrrrr}
\hline & Min & Median & Mean & Max & S.D. \\
\hline New skyscrapers & 0.00 & 0.00 & 0.23 & 70.00 & 2.01 \\
New meters of skyscrapers & 0.00 & 0.00 & 43.02 & 13221.00 & 376.80 \\
New vanity meters & 0.00 & 0.00 & 1.09 & 448.70 & 12.82 \\
Polyarchy & 0.01 & 0.31 & 0.41 & 0.94 & 0.28 \\
Ln GDP per capita & 203.41 & 2604.57 & 4468.56 & 42916.24 & 5065.15 \\
Urbanization, share & 0.02 & 0.43 & 0.45 & 0.97 & 0.22 \\
Population (here shown in 1000s) & 25.00 & 8101.23 & 32041.68 & 1297687.68 & 103471.05 \\
Total natural resource income per capita & 0.00 & 36.67 & 450.14 & 81161.85 & 2478.13 \\
\hline
\end{tabular}




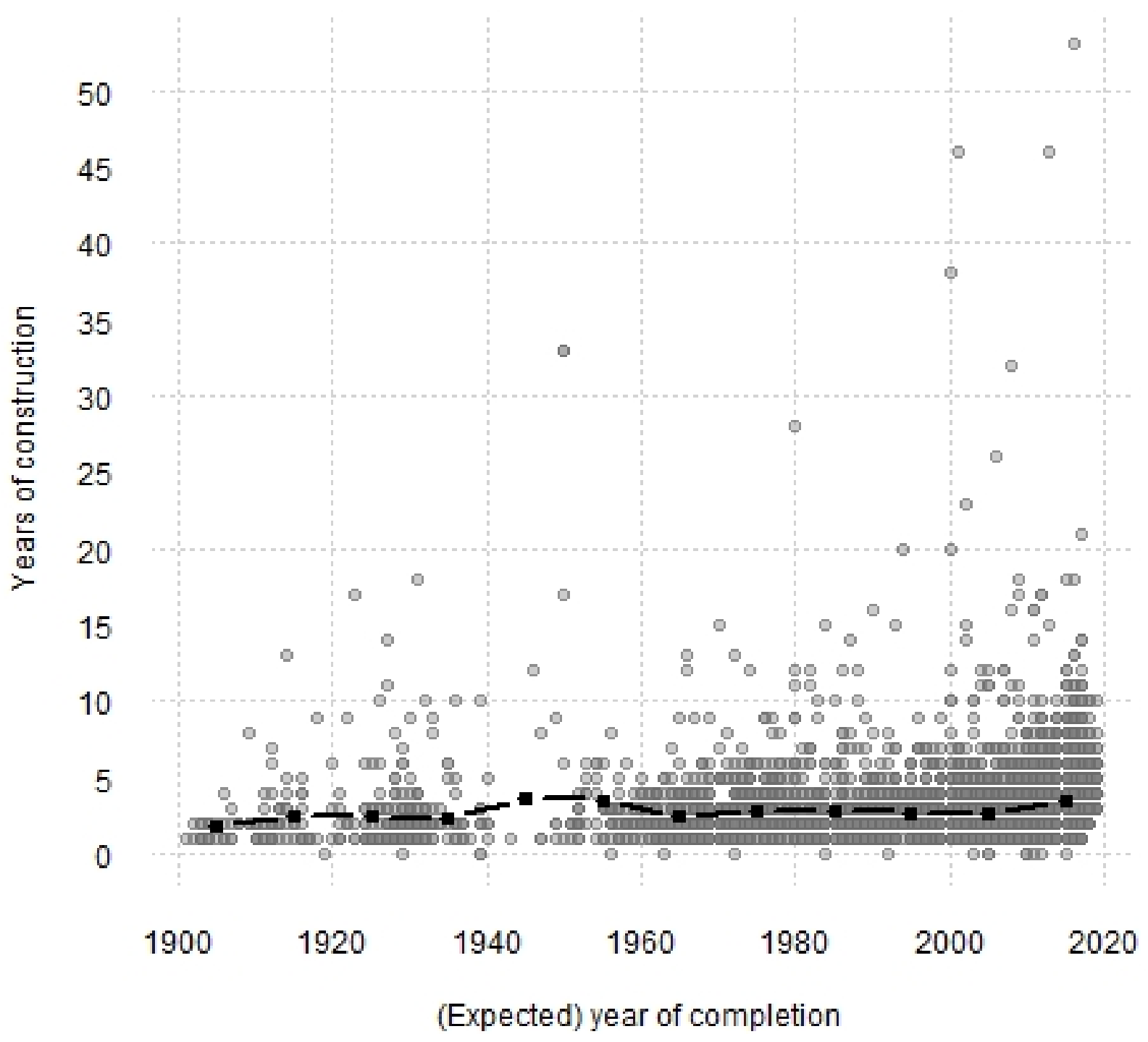

Figure 8.1: Mean construction time of building projects during the 20th century 
Table 8.2: Polyarchy and mediators: Correlation

\begin{tabular}{lrrrrr}
\hline & Polyarchy & ASI & LCE & PCI & PPSP \\
\hline Polyarchy & 1.00 & & & & \\
Alternative sources of information & 0.87 & 1.00 & & & \\
Legislative constraints on executive & 0.81 & 0.79 & 1.00 & & \\
Political Corruption Index & -0.37 & -0.27 & -0.50 & 1.00 & \\
Political Power by socioeconomic position & 0.63 & 0.47 & 0.42 & -0.35 & 1.00 \\
\hline
\end{tabular}

Table 8.3: Polyarchy and mediators: Within unit correlation

\begin{tabular}{lrrrrr}
\hline & Polyarchy & ASI & LCE & PCI & PPSP \\
\hline Polyarchy & 1.00 & & & & \\
Alternative sources of information & 0.82 & 1.00 & & & \\
Legislative constraints on executive & 0.72 & 0.73 & 1.00 & & \\
Political Corruption Index & 0.10 & 0.15 & -0.05 & 1.00 & \\
Political Power by socioeconomic position & 0.55 & 0.36 & 0.27 & 0.10 & 1.00 \\
\hline
\end{tabular}

Table 8.4: Polyarchy and mediators: Share of correlation that is within-unit

\begin{tabular}{lrrrrr}
\hline & Polyarchy & ASI & LCE & PCI & PPSP \\
\hline Polyarchy & 1.00 & & & & \\
Alternative sources of information & 0.94 & 1.00 & & & \\
Legislative constraints on executive & 0.89 & 0.93 & 1.00 & & \\
Political Corruption Index & -0.26 & -0.57 & 0.10 & 1.00 & \\
Political Power by socioeconomic position & 0.88 & 0.76 & 0.65 & -0.28 & 1.00 \\
\hline
\end{tabular}




\subsection{Alternative dependent variable specifications}

The first table included in this section replicates our main results when we set the cut-off for considering a building to be a skyscraper to $125 \mathrm{~m}$ rather than $150 \mathrm{~m}$. (We remind that the CTBUH database does not have full, global coverage for buildings shorter than $150 \mathrm{~m}$ ). The second table includes regressions counting only so-called "tall" (between $150 \mathrm{~m}$ and $300 \mathrm{~m}$ ) and "super-tall" (more than 300m) buildings, respectively. The third table shows results from when the main regressions are re-run (keeping the 150m threshold for skyscrapers), but counting also industrial structures and telecommunication masts as skyscrapers. The fourth and final table displays regressions excluding all skyscrapers that have been demolished from the baseline. 


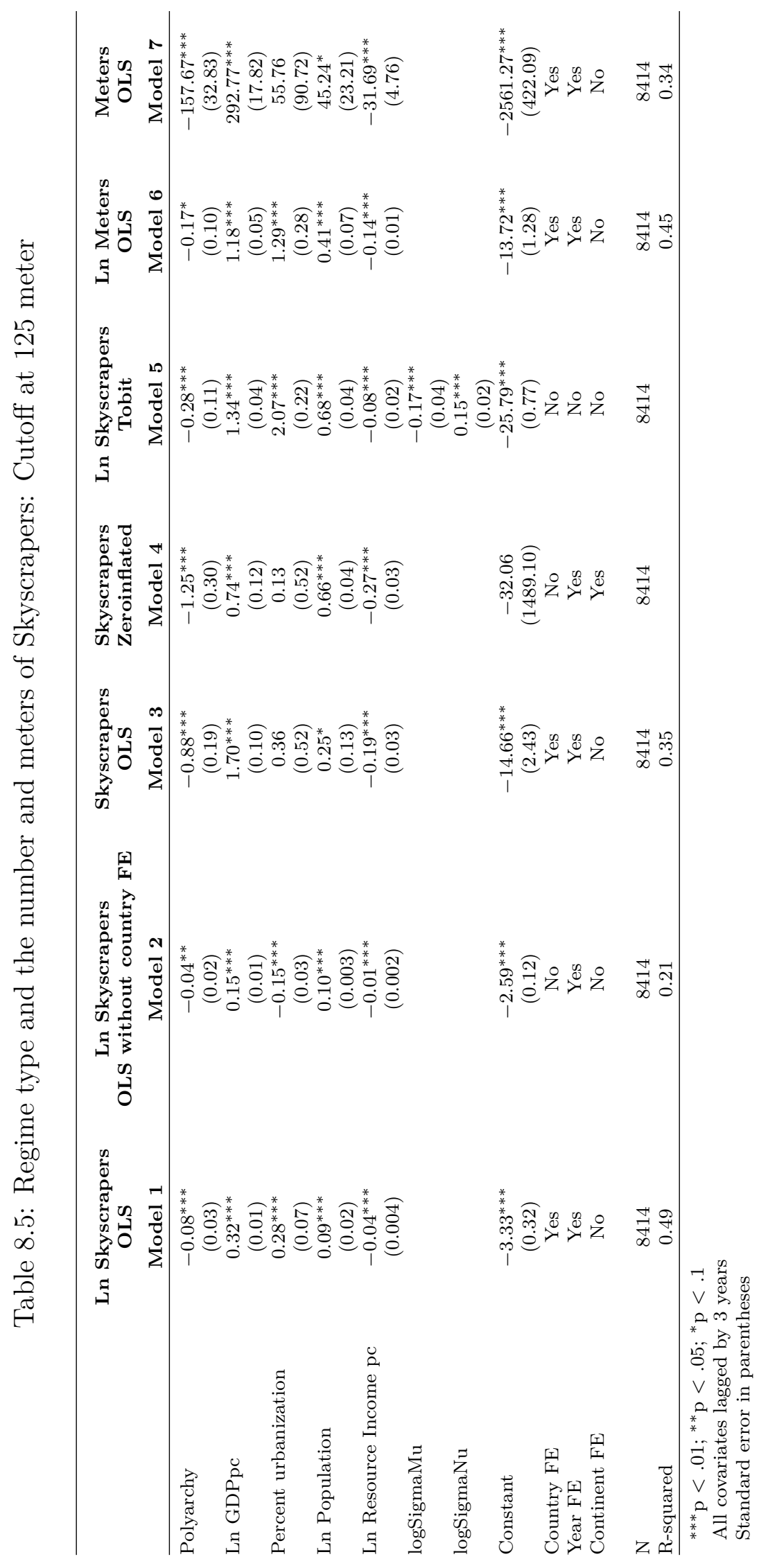


Table 8.6: Regime type and the number of tall $(150 \mathrm{~m}-300 \mathrm{~m})$ and supertall $(350 \mathrm{~m}+)$ skyscrapers

\begin{tabular}{lcc}
\hline & Tall & Supertall \\
& Model 1 & Model 2 \\
\hline Polyarchy & $-0.07^{* * *}$ & $-0.01^{* *}$ \\
& $(0.02)$ & $(0.004)$ \\
Ln GDPpc & $0.23^{* * *}$ & $0.01^{* * *}$ \\
& $(0.01)$ & $(0.002)$ \\
Percent urbanization & $0.13^{* *}$ & -0.002 \\
& $(0.06)$ & $(0.01)$ \\
Ln Population & $0.05^{* * *}$ & $0.01^{* *}$ \\
& $(0.01)$ & $(0.003)$ \\
Ln Resource Income pc & $-0.03^{* * *}$ & $-0.001^{* *}$ \\
& $(0.003)$ & $(0.001)$ \\
Constant & $-2.19^{* * *}$ & $-0.17^{* * *}$ \\
& $(0.27)$ & $(0.05)$ \\
Country FE & Yes & Yes \\
Year FE & Yes & Yes \\
& & \\
N & 8414 & 8414 \\
R-squared & 0.43 & 0.09 \\
\hline *** $<.01 ;{ }^{* *} p<.05 ;{ }^{*} p<.1$ & \\
All covariates lagged by 3 years & \\
Standard error in paranthesis &
\end{tabular}




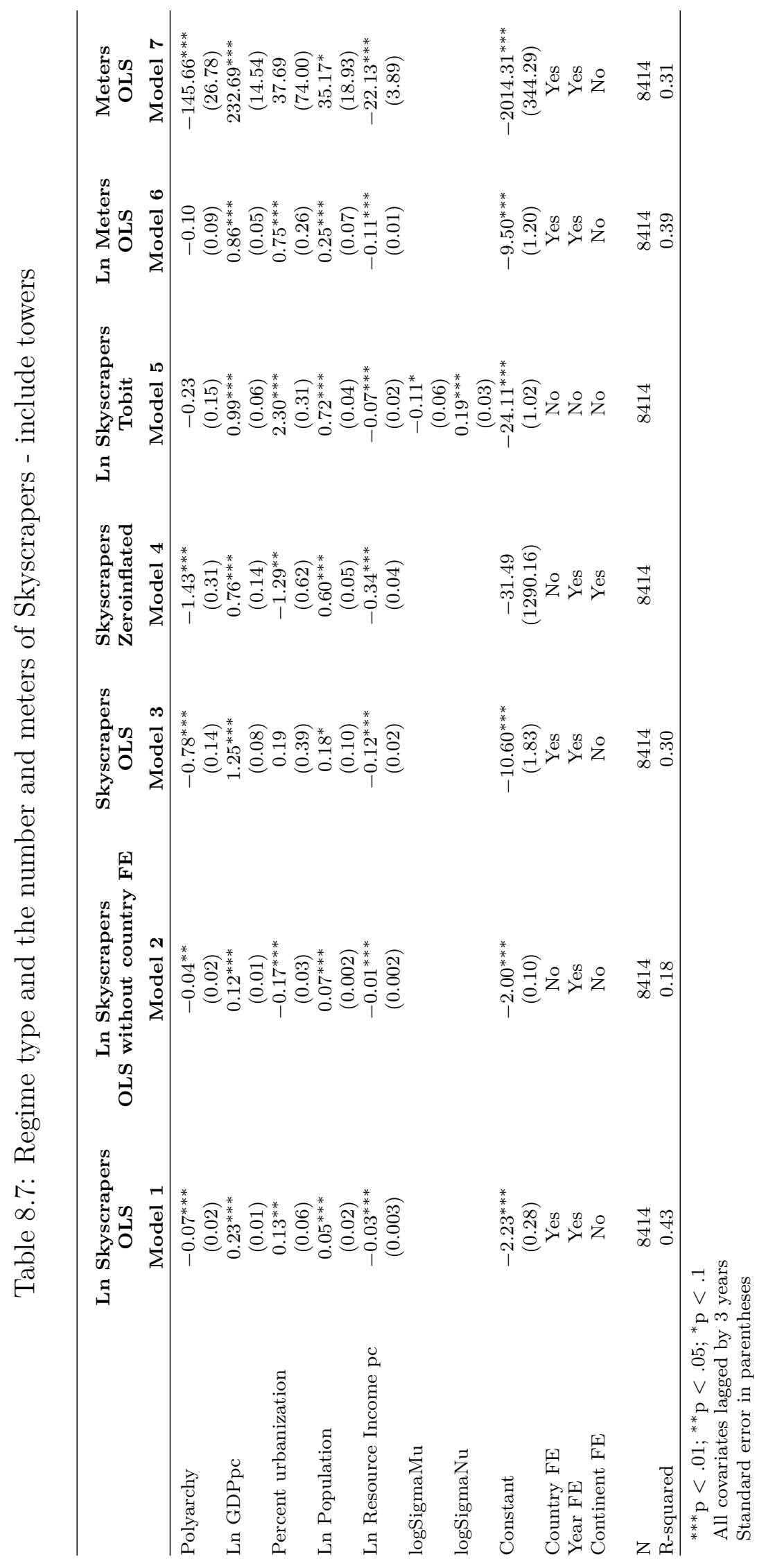




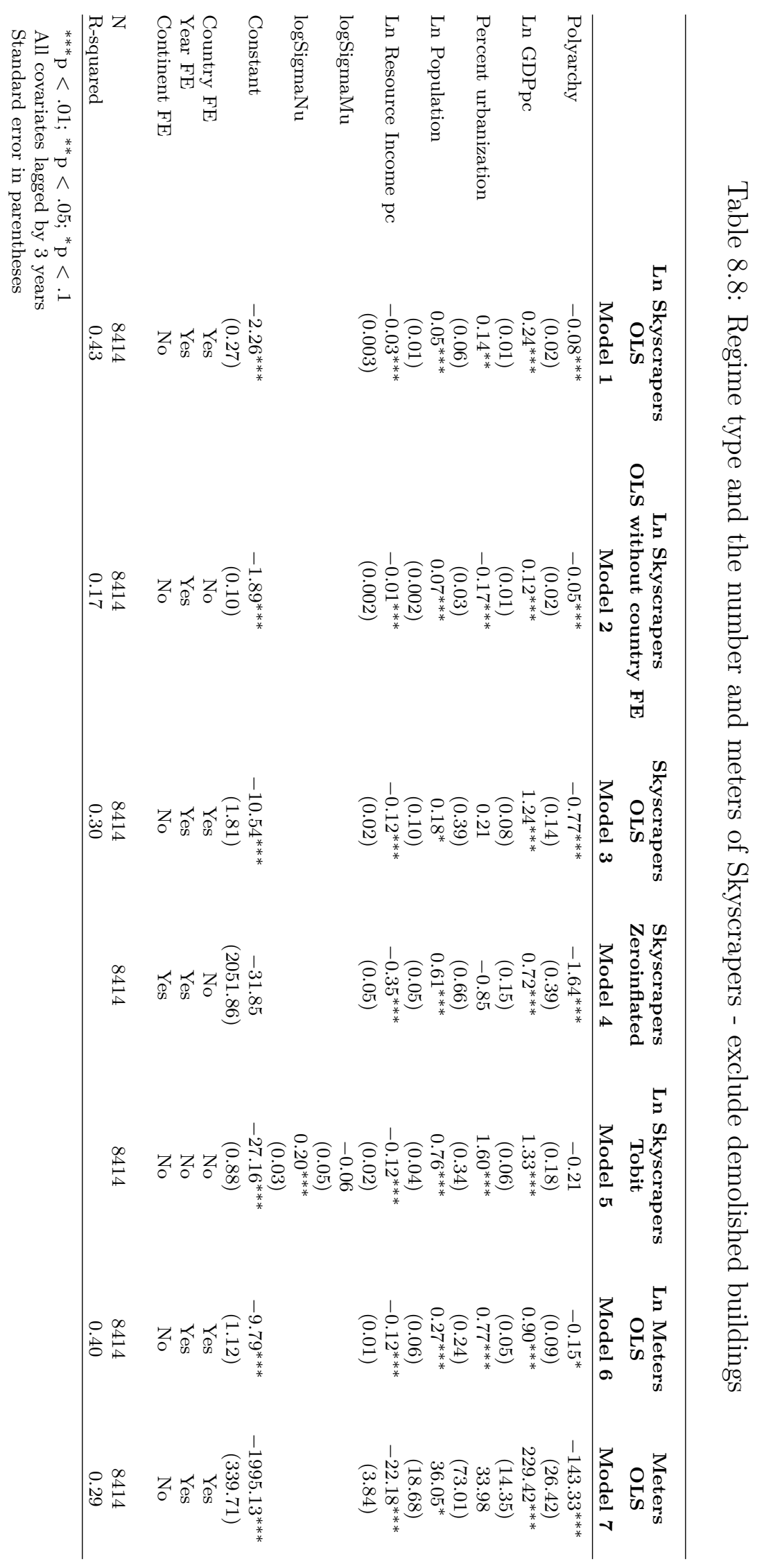


Table 8.9: Skyscrapers inside and outside the capital city

\begin{tabular}{lcccc}
\hline & Ln Skyscrapers & Ln Meters & Ln Skyscrapers & Ln Meters \\
& OLS & OLS & OLS & OLS \\
& Model 1 & Model 2 & Model 3 & Model 4 \\
\hline Polyarchy & -0.01 & $-0.19^{*}$ & $-0.09^{* * *}$ & $-0.36^{* * *}$ \\
& $(0.01)$ & $(0.10)$ & $(0.02)$ & $(0.10)$ \\
Ln GDPpc & $.12^{* * *}$ & $1.31^{* * *}$ & $0.16^{* * *}$ & $1.55^{* * *}$ \\
& $(0.01)$ & $(0.06)$ & $(0.01)$ & $(0.05)$ \\
Percent urbanization & $0.17^{* * *}$ & $3.25^{* * *}$ & 0.02 & $1.60^{* * *}$ \\
& $(0.03)$ & $(0.28)$ & $(0.05)$ & $(0.27)$ \\
Ln Population & $0.02^{* *}$ & 0.08 & $0.03^{* *}$ & $0.71^{* * *}$ \\
& $(0.01)$ & $(0.07)$ & $(0.01)$ & $(0.07)$ \\
Ln Resource Income pc & $-0.01^{* * *}$ & $-0.25^{* * *}$ & $-0.02^{* * *}$ & $-0.17^{* * *}$ \\
& $(0.002)$ & $(0.01)$ & $(0.003)$ & $(0.01)$ \\
Constant & $-0.97^{* * *}$ & $-9.33^{* * *}$ & $-1.50^{* * *}$ & $-20.50^{* * *}$ \\
& $(0.16)$ & $(1.31)$ & $(0.23)$ & $(1.28)$ \\
Country FE & Yes & Yes & Yes & Yes \\
Year FE & Yes & Yes & Yes & Yes \\
Sample: & Capital & Capital & Not capital & Not capital \\
& & & & \\
N & 8414 & 8414 & 8414 & 8414 \\
R-squared & 0.27 & 0.63 & 0.44 & 0.74 \\
\hline
\end{tabular}

${ }^{* * *} \mathrm{p}<.01 ;{ }^{* *} \mathrm{p}<.05 ;{ }^{*} \mathrm{p}<.1$

All covariates lagged by 3 years

Standard error in parentheses 


\subsection{Alternative independent variable specifications}

The first table in this section shows regressions assessing sensitivity by omitting each of the controls from the benchmark model, seriatim. The second table displays regressions adding potentially relevant controls. The third table replicates the benchmark model, but using a variety of alternative measures of democracy. The fourth table shows the 


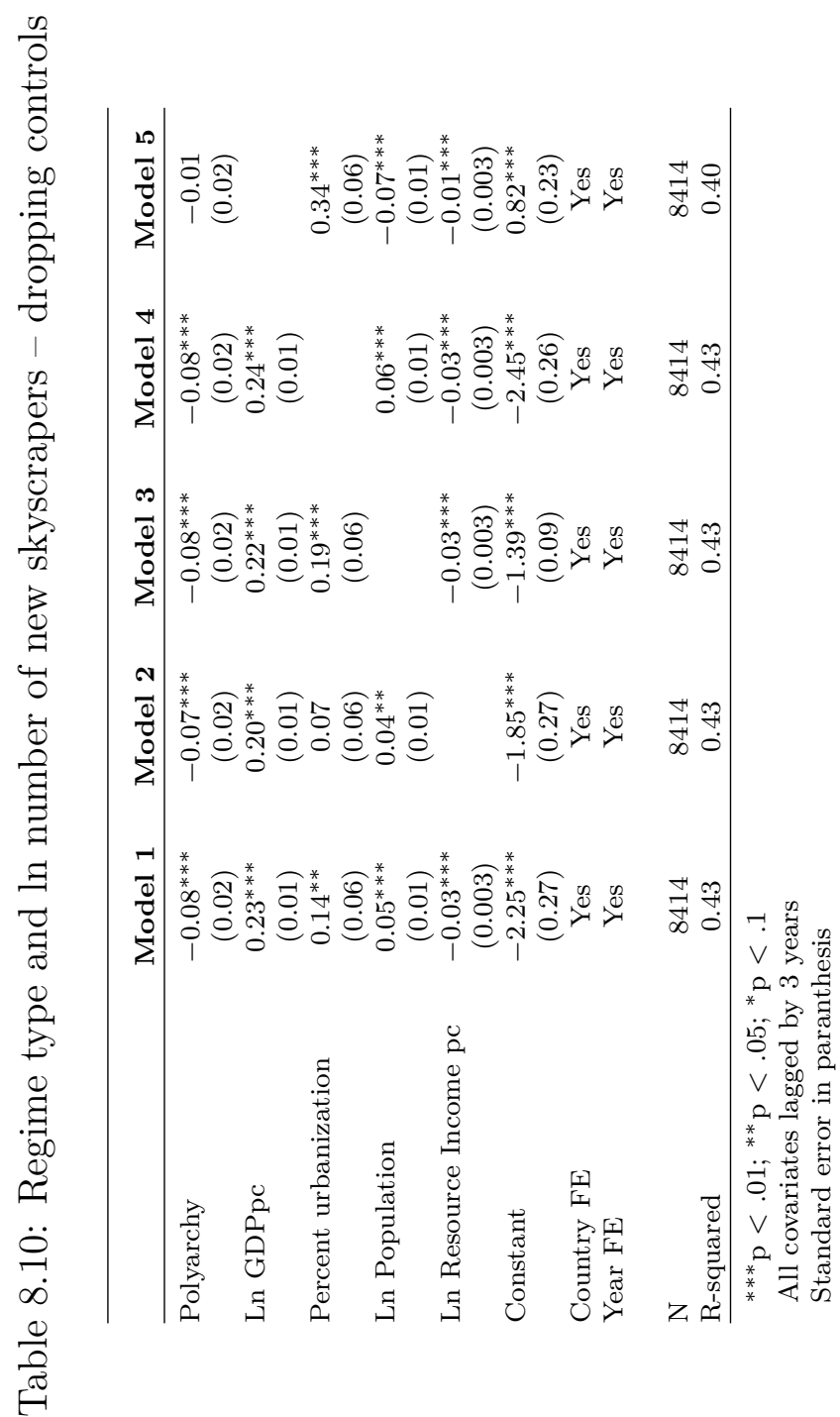




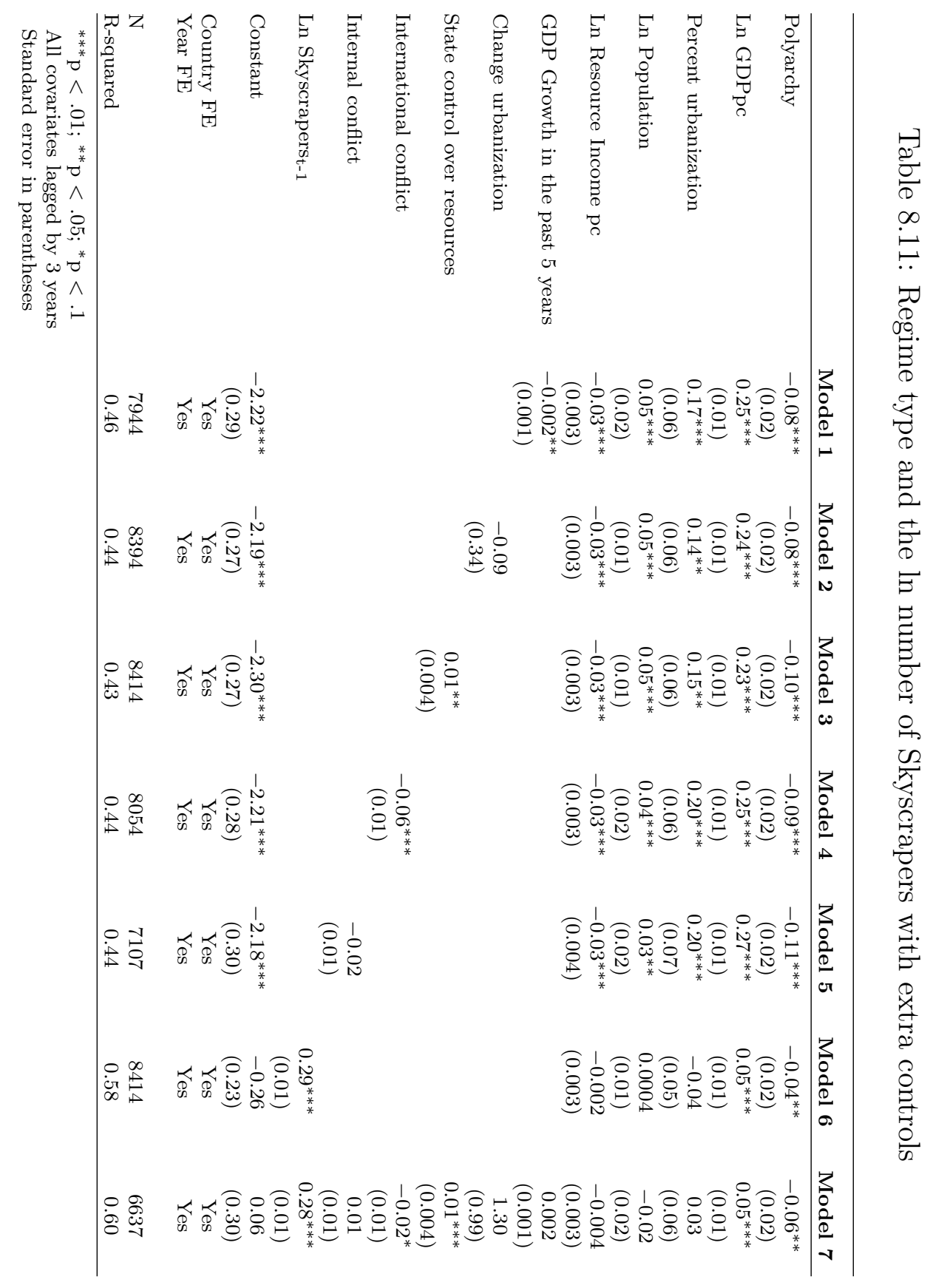




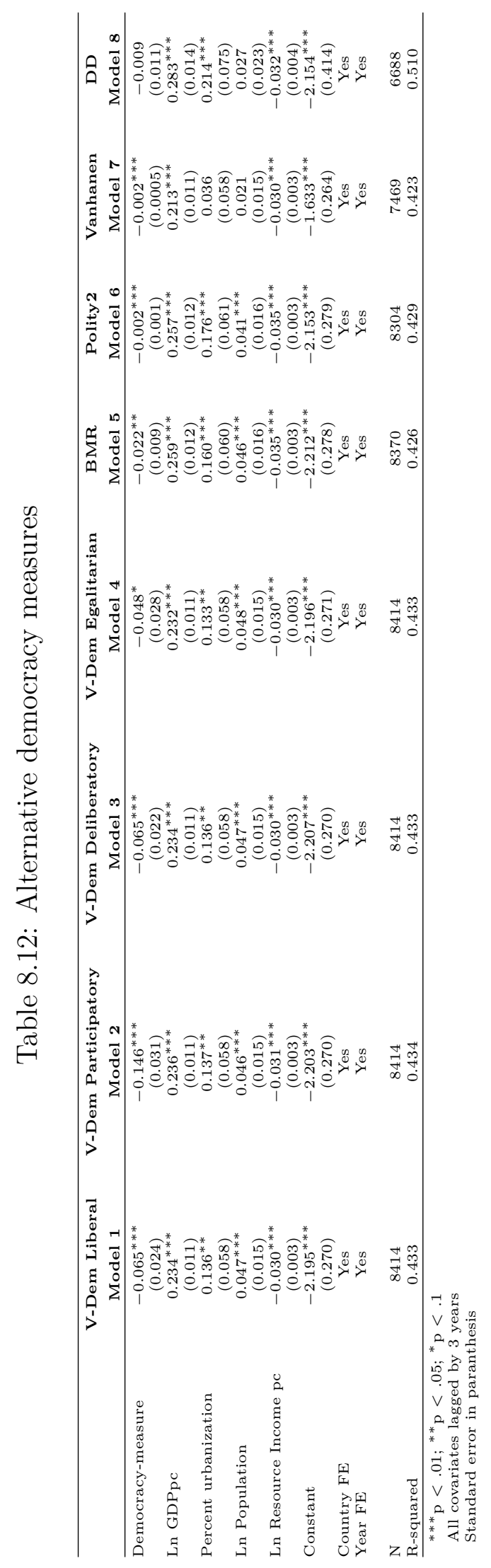




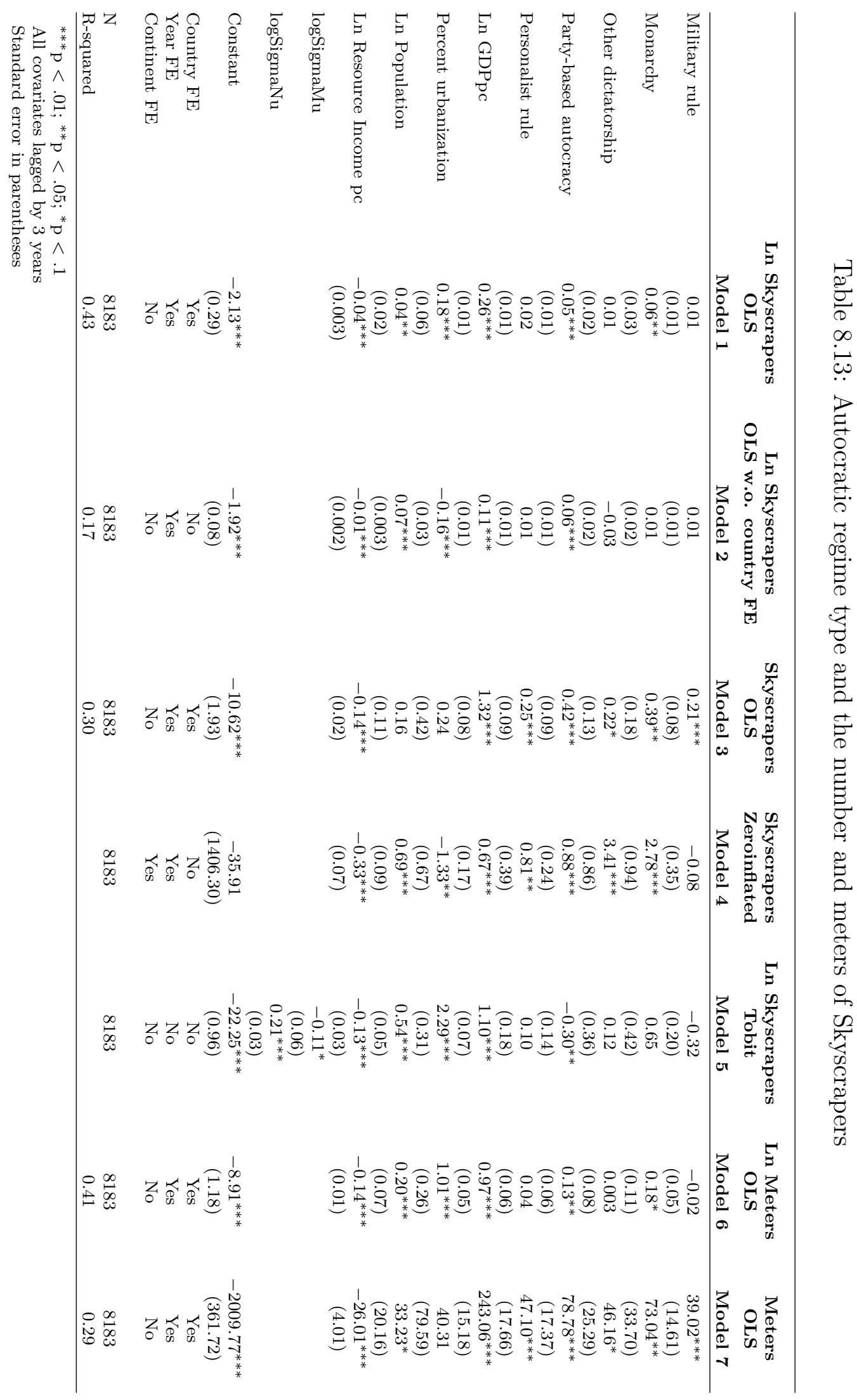


Table 8.14: Boom cycles and the number and meters of Skyscrapers

\begin{tabular}{lcccc}
\hline & Ln Skyscrapers & Skyscrapers & Ln Meters & Meters \\
& OLS & OLS & OLS & OLS \\
& Model 1 & Model 2 & Model 3 & Model 4 \\
\hline Polyarchy & $-0.08^{* * *}$ & $-0.75^{* * *}$ & $-0.16^{*}$ & $-139.13^{* * *}$ \\
& $(0.02)$ & $(0.15)$ & $(0.10)$ & $(28.76)$ \\
Standard deviation growth past 10 years & 0.002 & 0.01 & $0.01^{*}$ & 1.87 \\
& $(0.001)$ & $(0.01)$ & $(0.01)$ & $(1.57)$ \\
Ln GDPpc & $0.25^{* * *}$ & $1.40^{* * *}$ & $0.95^{* * *}$ & $259.18^{* * *}$ \\
& $(0.01)$ & $(0.09)$ & $(0.05)$ & $(16.47)$ \\
Percent urbanization & $0.25^{* * *}$ & $0.95^{* *}$ & $1.14^{* * *}$ & $170.08^{*}$ \\
& $(0.07)$ & $(0.47)$ & $(0.29)$ & $(87.66)$ \\
Ln Population & $0.05^{* *}$ & 0.18 & $0.26^{* * *}$ & 36.35 \\
& $(0.02)$ & $(0.12)$ & $(0.08)$ & $(22.83)$ \\
Ln Resource Income pc & $-0.03^{* * *}$ & $-0.16^{* * *}$ & $-0.13^{* * *}$ & $-28.89^{* * *}$ \\
& $(0.004)$ & $(0.02)$ & $(0.01)$ & $(4.44)$ \\
Constant & $-2.14^{* * *}$ & $-10.49^{* * *}$ & $-9.37^{* * *}$ & $-1997.99^{* * *}$ \\
& $(0.33)$ & $(2.18)$ & $(1.36)$ & $(409.85)$ \\
Country FE & Yes & Yes & Yes & Yes \\
Year FE & Yes & Yes & Yes & Yes \\
N & & & & 7411 \\
R-squared & 7411 & 7411 & 0.43 & 7411 \\
\hline
\end{tabular}

${ }^{* * *} \mathrm{p}<.01 ;{ }^{* *} \mathrm{p}<.05 ;{ }^{*} \mathrm{p}<.1$

All covariates lagged by 3 years

Standard error in parentheses 


\subsection{Alternative lag- and sample specifications}

The first table in this section shows the main results when we employ a 4-year rather than a 3-year lag specification for all independent variables. The three following tables show the main regressions run on delimited samples, including only years after, respectively, 1945, 1960 and 1980. 


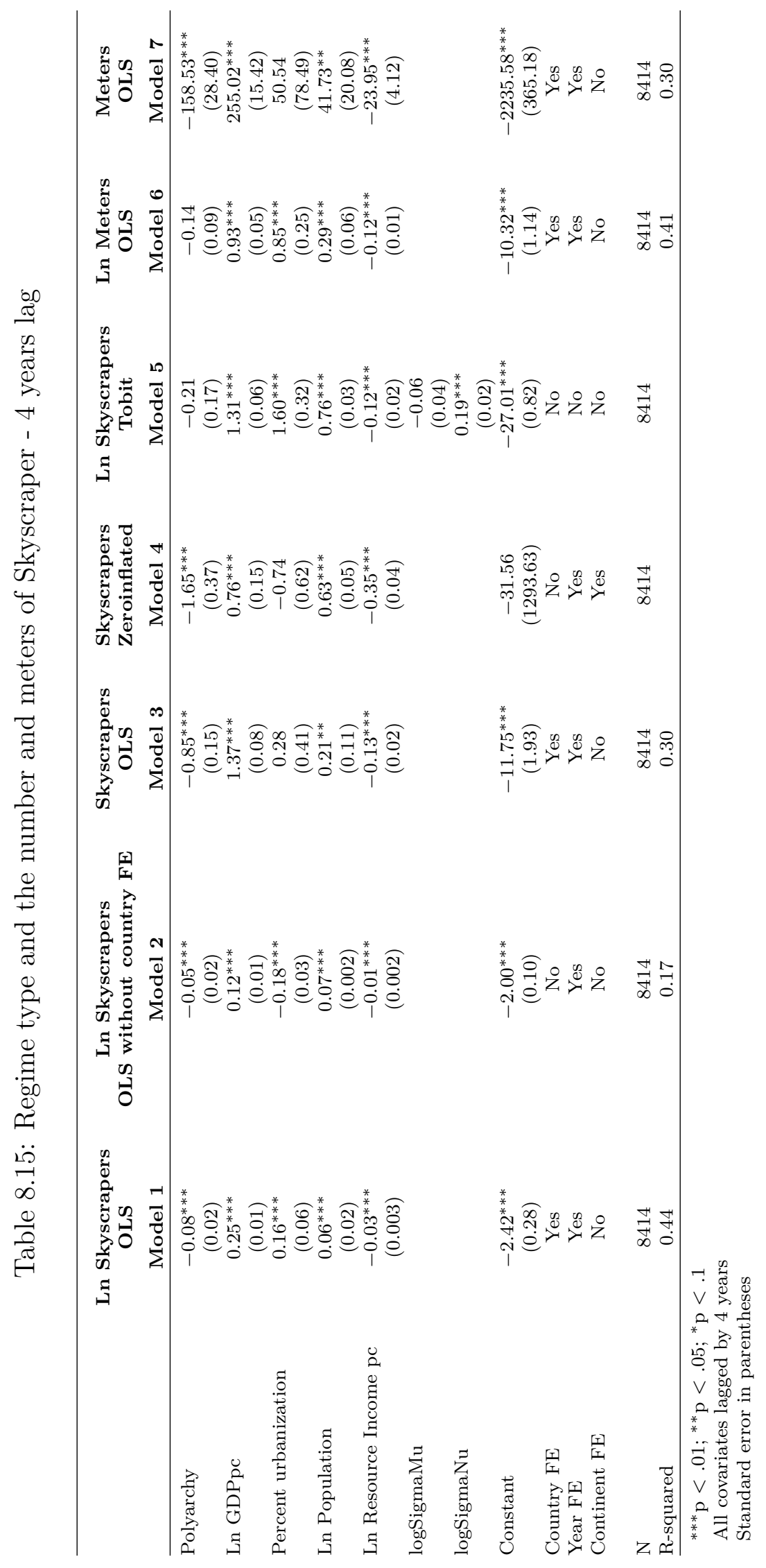




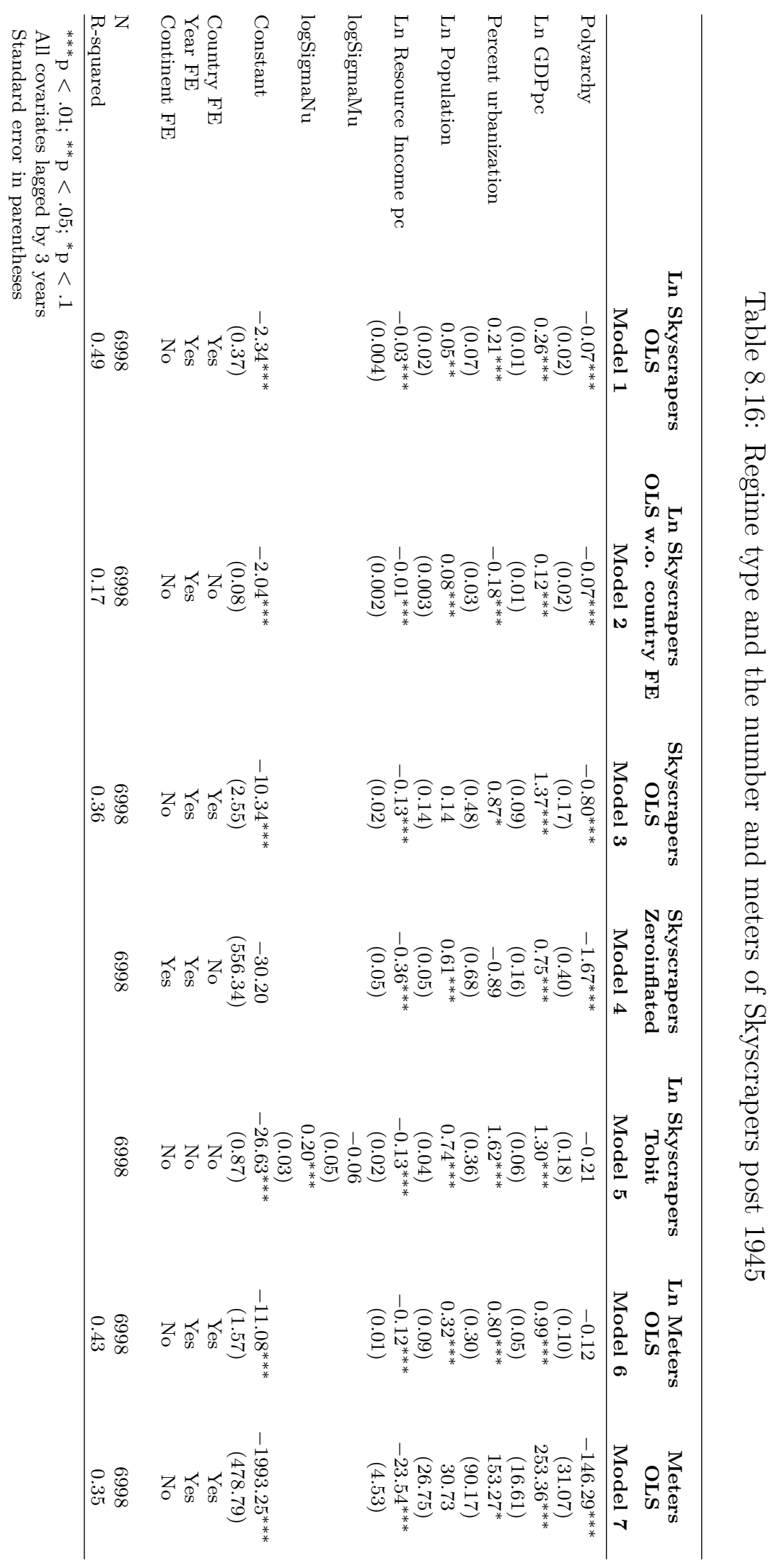




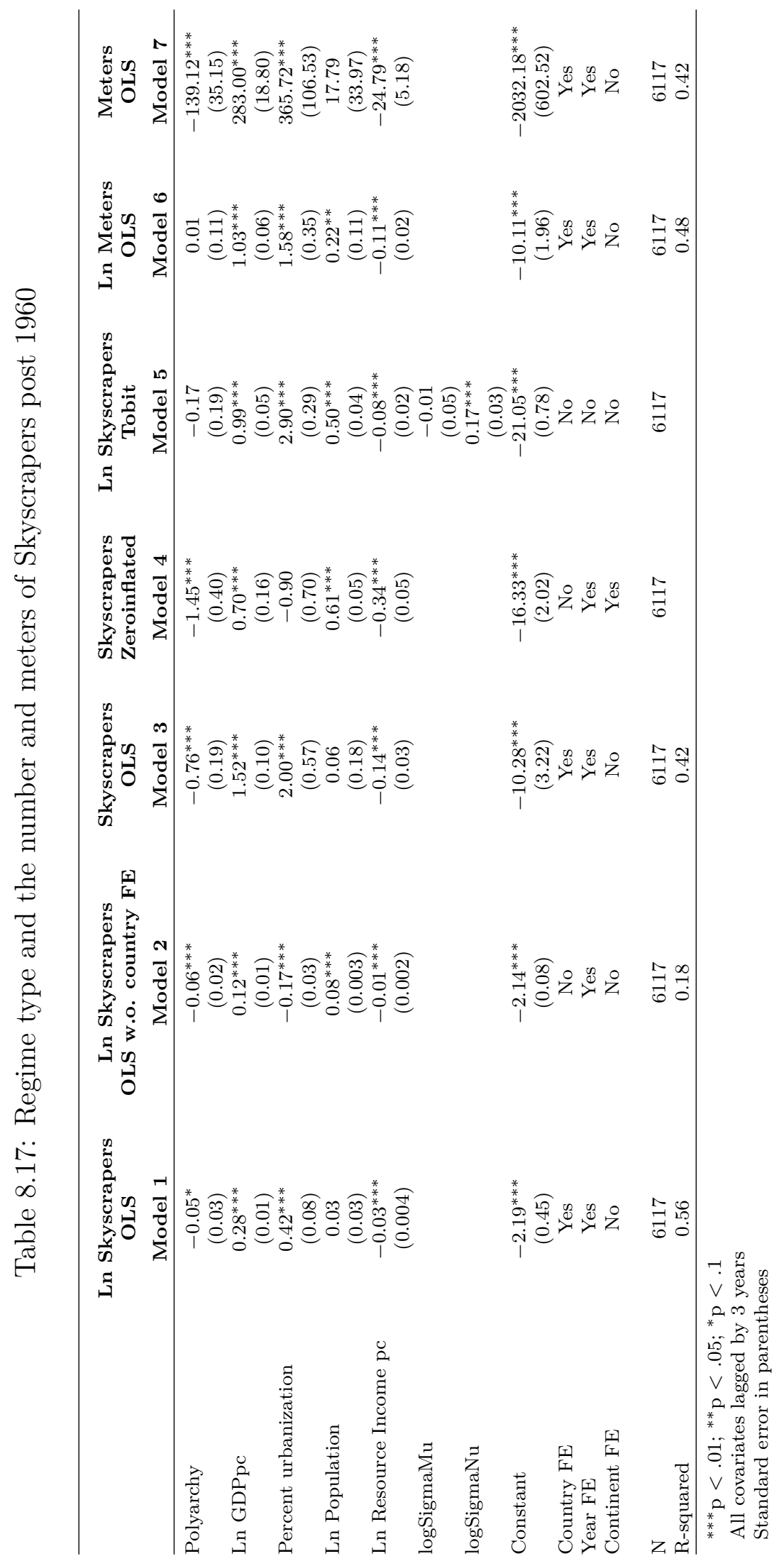




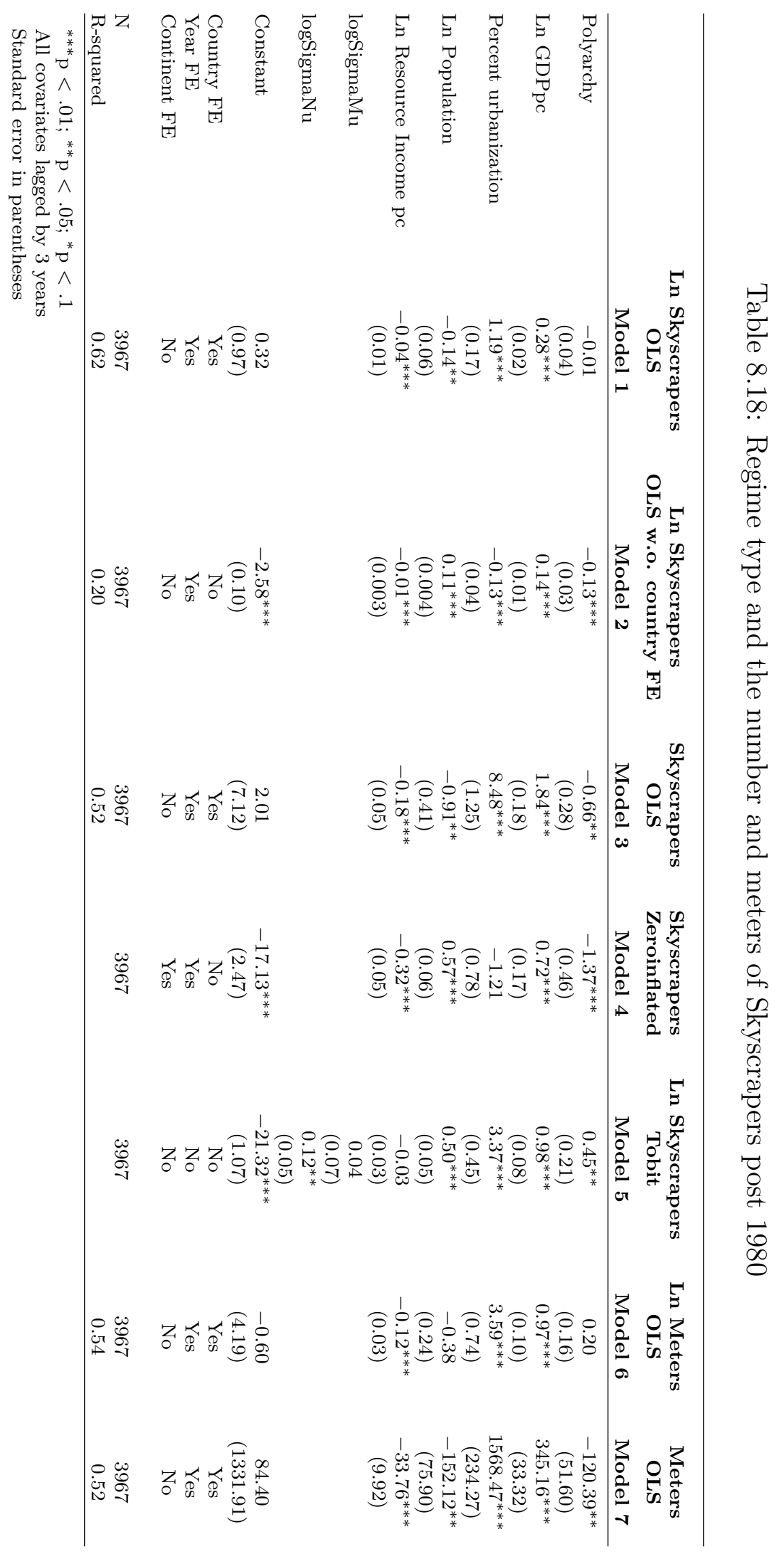




\subsection{First stage of zero-inflated negative binomial model (second stage reported as Model 5 in Table 4.1 of the paper)}

Table 8.19: First stage of zero-inflated model

\begin{tabular}{lc}
\hline Democracy-measure & -0.59 \\
& $(0.76)$ \\
Ln GDPpc & $-1.52^{* * *}$ \\
& $(0.29)$ \\
Percent urbanization & $-4.14^{* * *}$ \\
& $(1.31)$ \\
Ln Population & $-1.09^{* * *}$ \\
& $(0.12)$ \\
Ln Resource Income pc & $-0.36^{* * *}$ \\
& $(0.09)$ \\
Constant & $34.93^{* * *}$ \\
& $(4.01)$ \\
Decade FE & Yes \\
Continent FE & Yes \\
& 8414 \\
$\mathrm{~N}$ & \multicolumn{1}{c}{8} \\
\hline *** p $<.01 ;{ }^{* *} \mathrm{p}<.05 ;{ }^{*} \mathrm{p}<.1$ \\
All covariates lagged by 3 years \\
Standard error in paranthesis
\end{tabular}




\subsection{Outliers and influential observations}

This section includes, first, an illustration of the distribution on the dependent variable among democracies and dictatorships, and second, a summary of 370 Polyarchycoefficients from a jackknife-estimation, leaving out each influential observation (4 times the mean Cook's D in the sample) out, one at a time.
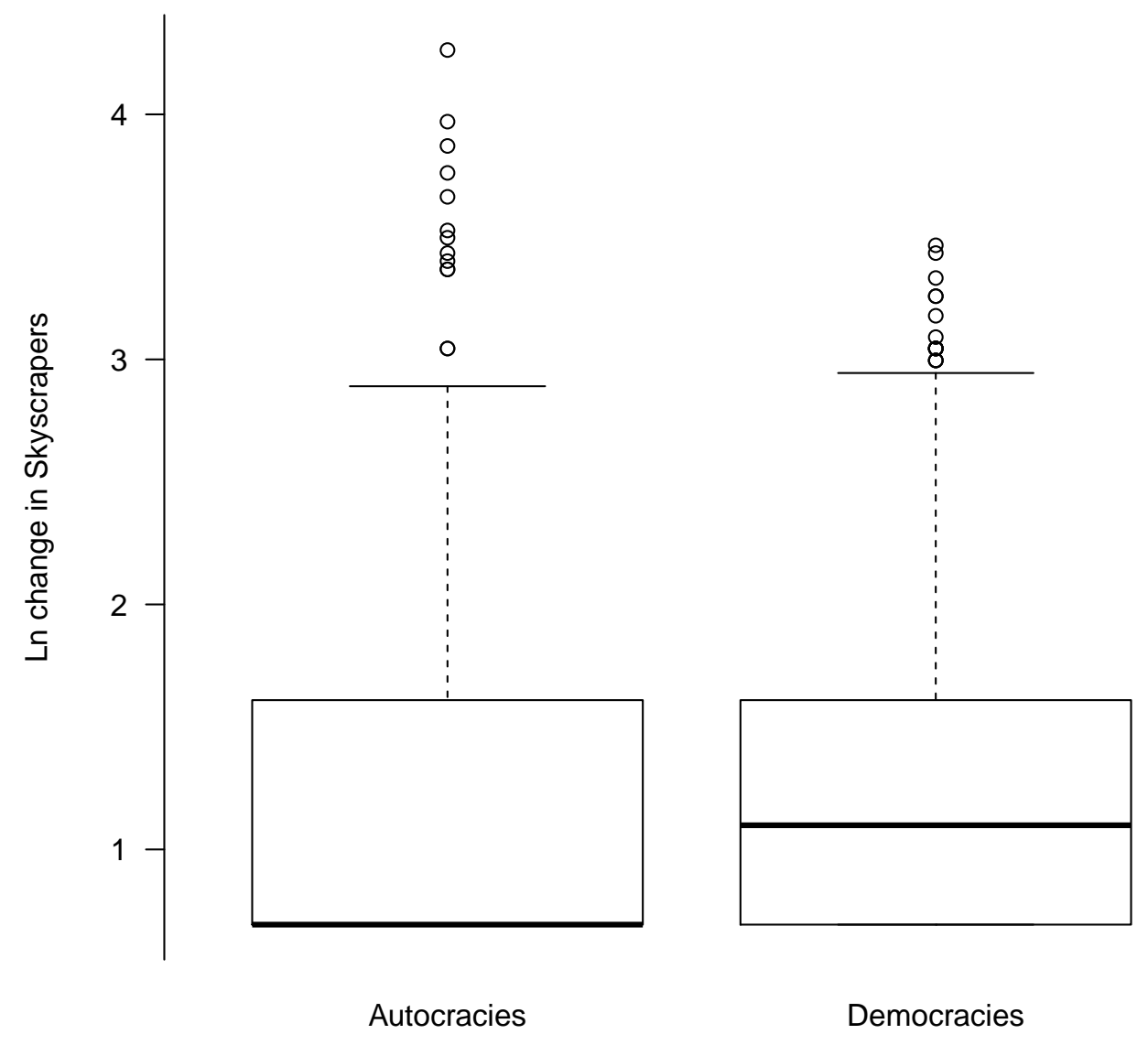

Figure 8.2: Box plots of dependent variable, $\ln (1+$ new skyscrapers in year $t)$, in autocracies and in democracies.

Notes: All 0-observations has been removed in order to better visualize the variation among countries that build skyscrapers. Autocracies are defined as countries with a value lower than or equal to the median value on Polyarchy. 


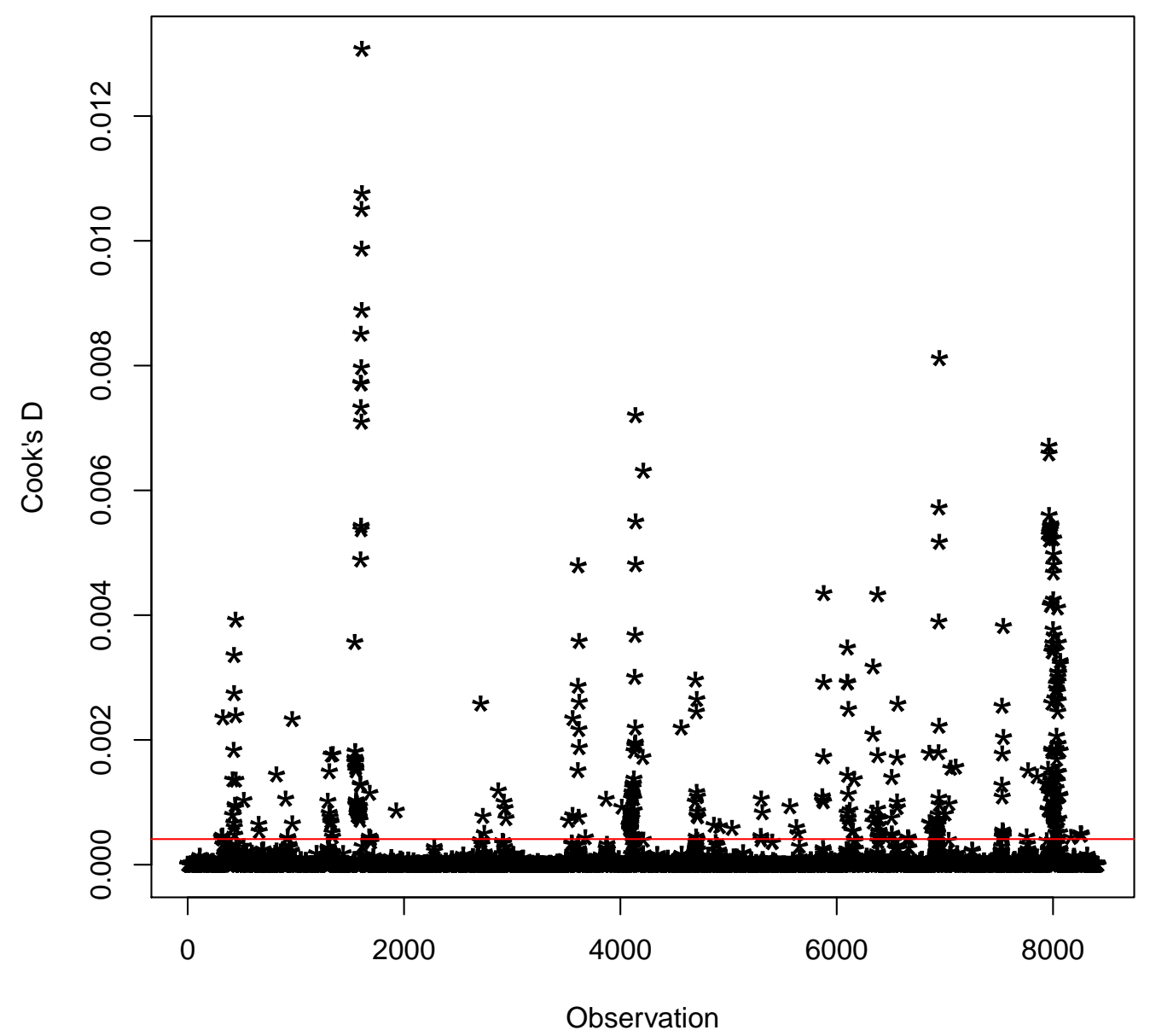

Figure 8.3: Cook's D from model 1 in table 4.1 Notes: The red line is drawn at the mean Cook's D-value. 


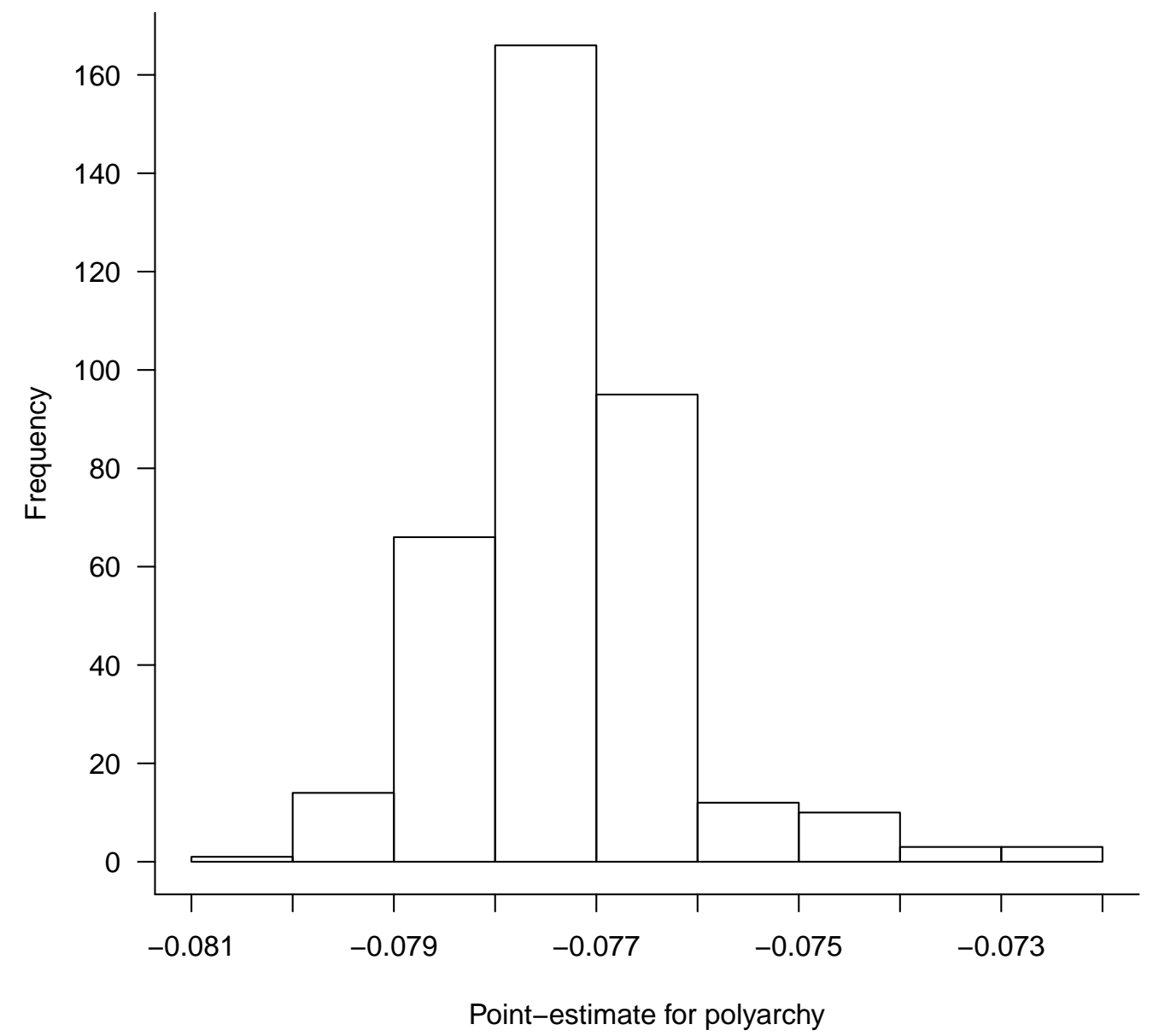

Figure 8.4: Jackknifing results for Model 1 in Table 4.1, consecutively removing each of the observations with a high Cook's D (defined more than four times the mean Cook's D in the sample) in figure 8.3. 


\subsection{Alternative mediators}

Table 8.20: Property rights

\begin{tabular}{|c|c|}
\hline Polyarchy & $\begin{array}{c}-0.11^{* * *} \\
(0.02)\end{array}$ \\
\hline Property rights index & $\begin{array}{c}0.08^{* * *} \\
(0.03)\end{array}$ \\
\hline Ln GDPpc & $\begin{array}{c}0.24^{* * *} \\
(0.01)\end{array}$ \\
\hline Percent urbanization & $\begin{array}{l}0.14^{* *} \\
(0.06)\end{array}$ \\
\hline Ln Population & $\begin{array}{c}0.05^{* * *} \\
(0.01)\end{array}$ \\
\hline Ln Resource Income pc & $\begin{array}{c}-0.03^{* * *} \\
(0.003)\end{array}$ \\
\hline Constant & $\begin{array}{c}-2.25^{* * *} \\
(0.27)\end{array}$ \\
\hline Country FE & Yes \\
\hline Year FE & Yes \\
\hline $\mathrm{N}$ & 8414 \\
\hline R-squared & 0.43 \\
\hline
\end{tabular}




\subsection{Alternative specifications for "vanity height"}

\section{Country-year analysis using different measures of vanity heights}

Table 8.21: Regime type and excessiveness of skyscrapers

\begin{tabular}{|c|c|c|c|c|}
\hline & $\begin{array}{c}\text { Ln vanity meters } \\
\text { Model } 1 \\
\end{array}$ & $\begin{array}{c}\text { Absolute vanity meters } \\
\text { Model } 2\end{array}$ & $\begin{array}{c}\text { Vanity percent } \\
\text { Model } 3 \\
\end{array}$ & $\begin{array}{c}\text { Max vanity percent } \\
\text { Model } 4\end{array}$ \\
\hline Polyarchy & $\begin{array}{c}-0.17^{* * *} \\
(0.04)\end{array}$ & $\begin{array}{c}-4.99^{* * *} \\
(1.09)\end{array}$ & $\begin{array}{l}-0.08 \\
(0.08)\end{array}$ & $\begin{array}{c}-0.17^{*} \\
(0.09)\end{array}$ \\
\hline Ln GDPpc & $\begin{array}{c}0.27^{* * *} \\
(0.02)\end{array}$ & $\begin{array}{c}6.26^{* * *} \\
(0.57)\end{array}$ & $\begin{array}{l}0.02 \\
(0.04)\end{array}$ & $\begin{array}{l}0.12^{* *} \\
(0.05)\end{array}$ \\
\hline Percent urbanization & $\begin{array}{c}0.02 \\
(0.11)\end{array}$ & $\begin{array}{l}-2.19 \\
(2.92)\end{array}$ & $\begin{array}{c}0.12 \\
(0.22)\end{array}$ & $\begin{array}{c}0.22 \\
(0.24)\end{array}$ \\
\hline Ln Population & $\begin{array}{r}0.06^{* *} \\
(0.03)\end{array}$ & $\begin{array}{c}0.97 \\
(0.77)\end{array}$ & $\begin{array}{c}0.06 \\
(0.06)\end{array}$ & $\begin{array}{c}0.07 \\
(0.06)\end{array}$ \\
\hline Ln Resource Income pc & $\begin{array}{c}-0.03^{* * *} \\
(0.01)\end{array}$ & $\begin{array}{c}-0.57^{* * *} \\
(0.15)\end{array}$ & $\begin{array}{c}-0.004 \\
(0.01)\end{array}$ & $\begin{array}{l}-0.01 \\
(0.01)\end{array}$ \\
\hline Constant & $\begin{array}{l}-2.57^{* * *} \\
(0.50)\end{array}$ & $\begin{array}{c}-55.64^{* * *} \\
(13.87)\end{array}$ & $\begin{array}{l}-1.02 \\
(1.05)\end{array}$ & $\begin{array}{l}-1.74 \\
(1.16)\end{array}$ \\
\hline Country FE & Yes & Yes & Yes & Yes \\
\hline Year FE & Yes & Yes & Yes & Yes \\
\hline $\mathrm{N}$ & 7353 & 7353 & 7353 & 7353 \\
\hline R-squared & 0.26 & 0.18 & 0.03 & 0.05 \\
\hline
\end{tabular}

${ }^{* * *} \mathrm{p}<.01 ;{ }^{* *} \mathrm{p}<.05 ;{ }^{*} \mathrm{p}<.1$

All covariates lagged by 3 years

Standard error in paranthesis

\section{CEM results, at the building level, without controls post-matching}

Table 8.22: Robustness test of skyscraper excessiveness: CEM-matching at the buildinglevel, with no post-matching controls

\begin{tabular}{lccc}
\hline & $\begin{array}{c}\text { Percent } \\
\text { Model 1 }\end{array}$ & $\begin{array}{c}\text { Ln meters } \\
\text { Model 2 }\end{array}$ & $\begin{array}{c}\text { Absolute meters } \\
\text { Model 3 }\end{array}$ \\
\hline Polyarchy above median & $-1.28^{* *}$ & $-0.17^{* * *}$ & $-4.43^{* *}$ \\
& $(0.56)$ & $(0.06)$ & $(1.74)$ \\
Constant & $20.32^{* * *}$ & $3.69^{* * *}$ & $40.54^{* * *}$ \\
& $(3.13)$ & $(0.31)$ & $(9.64)$ \\
Decade FE & No & No & No \\
Matched subclass FE & Yes & Yes & Yes \\
N & & & \\
R-squared & 592 & 592 & 592 \\
\hline
\end{tabular}

${ }^{* * *} \mathrm{p}<.01 ;{ }^{* *} \mathrm{p}<.05 ;{ }^{*} \mathrm{p}<.1$

Standard errors in parentheses 


\section{CEM results, at the building level, with continuous Polyarchy post-matching}

Table 8.23: Robustness test of skyscraper excessiveness: CEM-matching at the buildinglevel, with continuous Polyarchy

\begin{tabular}{lccc}
\hline & $\begin{array}{c}\text { Percent } \\
\text { Model 1 }\end{array}$ & $\begin{array}{c}\text { Ln meters } \\
\text { Model 2 }\end{array}$ & $\begin{array}{c}\text { Absolute meters } \\
\text { Model 3 }\end{array}$ \\
\hline Polyarchy (continuous) & $-2.12^{* * *}$ & $-0.22^{* * *}$ & -3.95 \\
& $(0.81)$ & $(0.08)$ & $(2.43)$ \\
Ln height to top occupied floor & $-2.97^{*}$ & $0.60^{* * *}$ & $30.01^{* * *}$ \\
& $(1.79)$ & $(0.17)$ & $(5.37)$ \\
Part of building-complex & $-6.64^{* * *}$ & $-0.65^{* * *}$ & $-21.69^{* * *}$ \\
& $(1.77)$ & $(0.17)$ & $(5.32)$ \\
Building function: Office & -1.89 & -0.26 & -8.52 \\
& $(2.96)$ & $(0.29)$ & $(8.89)$ \\
Building function: Residential & -1.07 & -0.01 & -6.41 \\
& $(2.25)$ & $(0.22)$ & $(6.76)$ \\
Constant & $32.64^{* * *}$ & 0.44 & $-111.87^{* * *}$ \\
& $(10.29)$ & $(1.00)$ & $(30.88)$ \\
Decade FE & Yes & Yes & Yes \\
Matched subclass FE & Yes & Yes & Yes \\
& & & 592 \\
$\mathrm{~N}$ & 592 & 592 & 0.21 \\
R-squared & 0.19 & 0.20 & \\
\hline$* * * p<.01 ;{ }^{* *} \mathrm{p}<.05 ;{ }^{*} \mathrm{p}<.1$ & & & \\
Standard errors in parentheses & & &
\end{tabular}




\section{CEM results, at the building level, including GDP per capita as matching and control variable}

Table 8.24: Robustness test of skyscraper excessiveness: CEM-matching at the buildinglevel and GDP

\begin{tabular}{|c|c|c|c|}
\hline & $\begin{array}{l}\text { Percent } \\
\text { Model } 1\end{array}$ & $\begin{array}{l}\text { Ln meters } \\
\text { Model } 2 \\
\end{array}$ & $\begin{array}{c}\text { Absolute meters } \\
\text { Model } 3\end{array}$ \\
\hline Polyarchy above median & $\begin{array}{l}-0.96 \\
(1.57)\end{array}$ & $\begin{array}{l}-0.06 \\
(0.16)\end{array}$ & $\begin{array}{l}-2.53 \\
(4.75)\end{array}$ \\
\hline Ln GDP per capita & $\begin{array}{l}1.45 \\
(2.04)\end{array}$ & $\begin{array}{c}0.22 \\
(0.21)\end{array}$ & $\begin{array}{c}4.23 \\
(6.18)\end{array}$ \\
\hline Ln height to top occupied floor & $\begin{array}{l}5.81^{*} \\
(3.37)\end{array}$ & $\begin{array}{c}1.42^{* * *} \\
(0.34)\end{array}$ & $\begin{array}{c}59.37^{* * *} \\
(10.21)\end{array}$ \\
\hline Part of building-complex & $\begin{array}{c}-10.01^{* * *} \\
(2.86)\end{array}$ & $\begin{array}{c}-1.24^{* * *} \\
(0.29)\end{array}$ & $\begin{array}{c}-31.83^{* * *} \\
(8.66)\end{array}$ \\
\hline Building function: Office & $\begin{array}{c}-9.09^{* *} \\
(4.25)\end{array}$ & $\begin{array}{c}-1.28^{* * *} \\
(0.43)\end{array}$ & $\begin{array}{c}-30.91^{* *} \\
(12.87)\end{array}$ \\
\hline Building function: Residential & $\begin{array}{c}-4.98^{*} \\
(2.87)\end{array}$ & $\begin{array}{l}-0.43 \\
(0.29)\end{array}$ & $\begin{array}{c}-20.02^{* *} \\
(8.69)\end{array}$ \\
\hline Constant & $\begin{array}{l}-21.84 \\
(31.48)\end{array}$ & $\begin{array}{l}-5.18 \\
(3.19)\end{array}$ & $\begin{array}{c}-287.63^{* * *} \\
(95.38)\end{array}$ \\
\hline Decade FE & Yes & Yes & Yes \\
\hline Matched subclass FE & Yes & Yes & Yes \\
\hline $\mathrm{N}$ & 127 & 127 & 127 \\
\hline R-squared & 0.40 & 0.51 & 0.54 \\
\hline
\end{tabular}




\section{CEM results, matching on height to occupied floor and GDP per capita}

Table 8.25: Robustness test of skyscraper excessiveness: CEM-matching on height to top occupied floor and GDP per capita

\begin{tabular}{lccc}
\hline & $\begin{array}{c}\text { Percent } \\
\text { Model 1 }\end{array}$ & $\begin{array}{c}\text { Ln meters } \\
\text { Model 2 }\end{array}$ & $\begin{array}{c}\text { Absolute meters } \\
\text { Model 3 }\end{array}$ \\
\hline Polyarchy above median & $-4.03^{* * *}$ & $-0.31^{* * *}$ & $-8.18^{* * *}$ \\
& $(0.69)$ & $(0.06)$ & $(1.97)$ \\
Ln GDP per capita & $2.97^{* * *}$ & $0.29^{* * *}$ & $5.66^{* *}$ \\
& $(0.98)$ & $(0.09)$ & $(2.79)$ \\
Ln height to top occupied floor & $-5.20^{* *}$ & 0.33 & $28.58^{* * *}$ \\
& $(2.48)$ & $(0.23)$ & $(7.03)$ \\
Constant & 11.48 & -1.48 & $-177.29^{* * *}$ \\
& $(16.47)$ & $(1.52)$ & $(46.69)$ \\
Decade FE & Yes & Yes & Yes \\
Matched subclass FE & Yes & Yes & Yes \\
& & & \\
N & 273 & 273 & 273 \\
R-squared & 0.26 & 0.42 & 0.39 \\
\hline
\end{tabular}

${ }^{* * *} \mathrm{p}<.01 ;{ }^{* *} \mathrm{p}<.05 ;{ }^{*} \mathrm{p}<.1$

Standard errors in parentheses 
CEM results, split samples for skyscrapers inside and outside capitals 


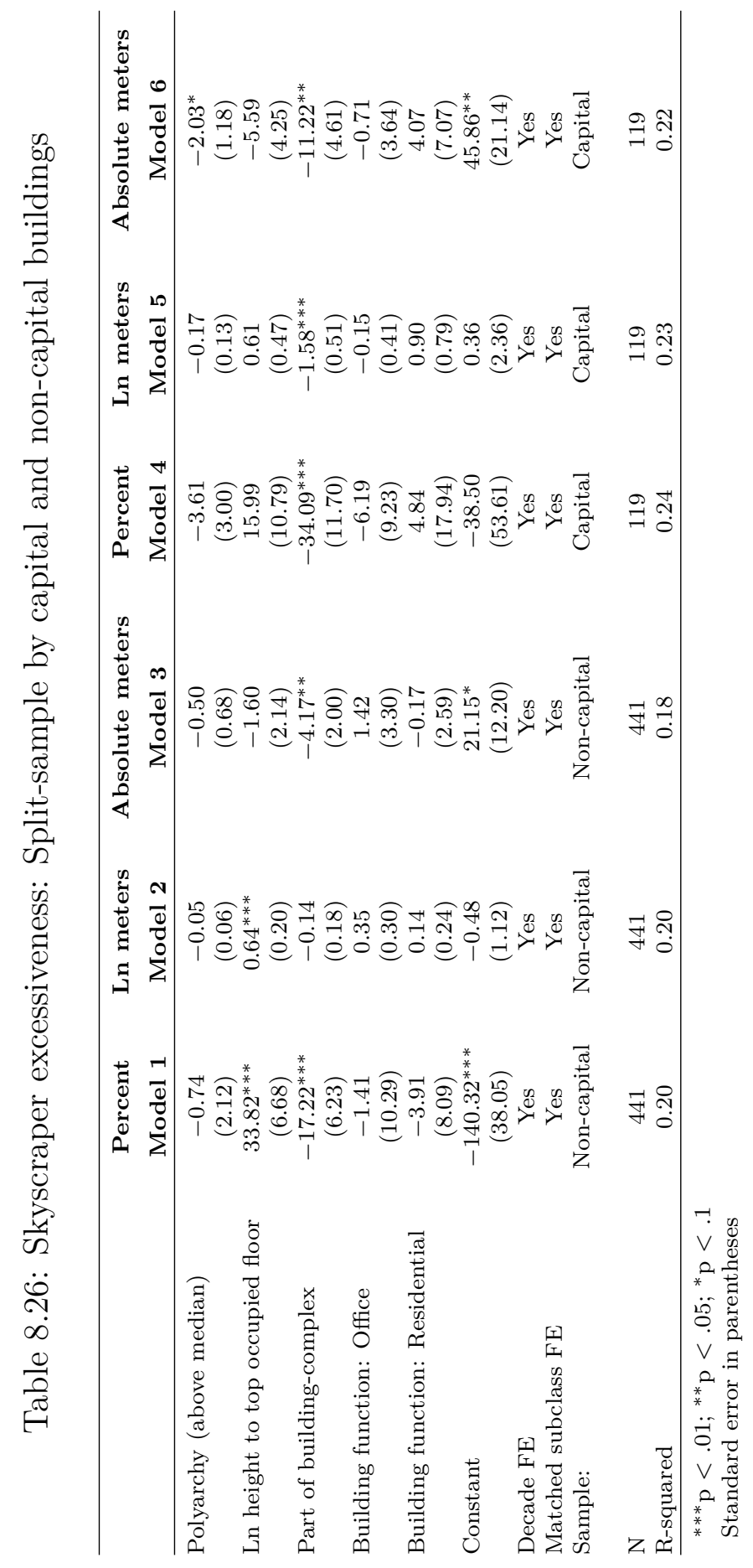




\subsection{Robustness test of skyscraper excessiveness: En- tropy Balancing models}

Table 8.27: Robustness test of skyscraper excessiveness: Entropy Balancing

\begin{tabular}{lccc}
\hline & $\begin{array}{c}\text { Percent } \\
\text { Model 1 }\end{array}$ & $\begin{array}{c}\text { Ln meters } \\
\text { Model 2 }\end{array}$ & $\begin{array}{c}\text { Absolute meters } \\
\text { Model 3 }\end{array}$ \\
\hline Polyarchy above median & $-4.19^{* *}$ & $-0.39^{* *}$ & -7.33 \\
& $(1.73)$ & $(0.18)$ & $(5.07)$ \\
Ln GDP per capita & 0.64 & 0.02 & 0.64 \\
& $(1.06)$ & $(0.11)$ & $(3.12)$ \\
Ln height to top occupied floor & $-3.88^{* * *}$ & $0.49^{* * *}$ & $22.84^{* * *}$ \\
& $(1.43)$ & $(0.15)$ & $(4.18)$ \\
Urbanization & 5.29 & 0.52 & 9.56 \\
& $(3.81)$ & $(0.39)$ & $(11.17)$ \\
Part of building-complex & $-3.62^{* * *}$ & $-0.38^{* * *}$ & $-9.54^{* * *}$ \\
& $(0.75)$ & $(0.08)$ & $(2.20)$ \\
Building function: Office & -0.05 & -0.01 & -0.38 \\
& $(1.20)$ & $(0.12)$ & $(3.51)$ \\
Building function: Residential & $-3.19^{* * *}$ & $-0.28^{* *}$ & $-8.31^{* *}$ \\
& $(1.17)$ & $(0.12)$ & $(3.42)$ \\
Constant & $40.17^{* * *}$ & 1.27 & $-68.69^{*}$ \\
& $(11.93)$ & $(1.22)$ & $(35.00)$ \\
Year FE & Yes & Yes & Yes \\
& & & \\
$\mathrm{N}$ & 430 & 430 & 430 \\
R-squared & 0.36 & 0.34 & 0.41 \\
\hline
\end{tabular}

${ }^{* * *} \mathrm{p}<.01 ;{ }^{* *} \mathrm{p}<.05 ;{ }^{*} \mathrm{p}<.1$

Standard errors in parentheses 
Table 8.28: Robustness test of skyscraper excessiveness: Entropy Balancing, using Boix, Miller, Rosato regime measure

\begin{tabular}{lccc}
\hline & Percent & Ln meters & Absolute meters \\
& Model 1 & Model 2 & Model 3 \\
\hline BMR & $-7.51^{* *}$ & $-0.74^{* *}$ & $-16.63^{*}$ \\
& $(3.08)$ & $(0.31)$ & $(8.71)$ \\
Ln GDP per capita & 1.72 & 0.17 & 2.30 \\
& $(2.08)$ & $(0.21)$ & $(5.89)$ \\
Ln height to top occupied floor & $-4.74^{* *}$ & $0.48^{* *}$ & $24.38^{* * *}$ \\
& $(1.93)$ & $(0.19)$ & $(5.47)$ \\
Urbanization & 9.01 & 0.75 & 23.03 \\
& $(7.22)$ & $(0.72)$ & $(20.42)$ \\
Part of building-complex & $-4.60^{* * *}$ & $-0.45^{* * *}$ & $-11.19^{* * *}$ \\
& $(1.16)$ & $(0.12)$ & $(3.29)$ \\
Building function: Office & -1.32 & -0.13 & -3.48 \\
& $(1.73)$ & $(0.17)$ & $(4.90)$ \\
Building function: Residential & $-5.15^{* * *}$ & $-0.51^{* * *}$ & $-13.11^{* * *}$ \\
& $(1.71)$ & $(0.17)$ & $(4.84)$ \\
Constant & $44.02^{* *}$ & 1.07 & -71.98 \\
& $(17.49)$ & $(1.75)$ & $(49.47)$ \\
Year FE & Yes & Yes & Yes \\
& & & 256 \\
$\mathrm{~N}$ & 256 & 256 & 0.50 \\
R-squared & 0.43 & 0.42 & \\
\hline ***p $<.01 ; * * \mathrm{p}<.05 ;{ }^{*} \mathrm{p}<.1$ & & & \\
Standard errors in parantheses & & &
\end{tabular}




\subsection{Alternative proxies of skyscraper excessiveness (Height/ground-floor area and Height/number of floors). CEM results, with building as unit of analysis.}

Table 8.29: CEM-matching at the building-level: Alternative proxies of the excessiveness of skyscrapers

\begin{tabular}{lcc}
\hline & Height / GFA & Height / Floors \\
& Model 1 & Model 2 \\
\hline Polyarchy (above or below median) & $-0.0004^{* *}$ & $-0.12^{* *}$ \\
Constant & $(0.0002)$ & $(0.06)$ \\
& 0.002 & $4.65^{* * *}$ \\
matched subclass FE & $(0.001)$ & $(0.42)$ \\
N & Yes & Yes \\
R-squared & 318 & 544 \\
\hline
\end{tabular}

*** $\mathrm{p}<.01 ;{ }^{* *} \mathrm{p}<.05 ;{ }^{*} \mathrm{p}<.1$

All covariates lagged by 3 years

Standard error in paranthesis 


\subsection{Interaction between Polyarchy and Urbaniza- tion/GDP per capita}

This section includes, first, a table with the model (Model 1) that was used for generating Figure 4 of the paper, pertaining to the interactive effects of urbanization and regime type on $\ln ($ skyscrapers +1$)$. The second column of this table displays a robustness tests run with $\ln$ (number of skyscraper meters +1 ) as the dependent variable. The next table displays equivalent interaction models, but now interacting Polyarchy with ln GDP per capita rather than Urbanization. The accompanying figure displays the interaction results from the first of those models graphically.

Table 8.30: Interaction models: Regime type and urbanization

\begin{tabular}{|c|c|c|}
\hline & $\begin{array}{c}\text { ln number of skyscraper } \\
\text { Model } 1\end{array}$ & $\begin{array}{c}\text { ln meters of skyscrapers } \\
\text { Model } 2 \\
\end{array}$ \\
\hline Polyarchy & $\begin{array}{c}-0.28^{* * *} \\
(0.04)\end{array}$ & $\begin{array}{c}-1.24^{* * *} \\
(0.18)\end{array}$ \\
\hline $\ln$ GDPpc & $\begin{array}{c}0.23^{* * *} \\
(0.01)\end{array}$ & $\begin{array}{c}0.88^{* * *} \\
(0.05)\end{array}$ \\
\hline Percent urbanization & $\begin{array}{l}-0.002 \\
(0.06)\end{array}$ & $\begin{array}{c}0.02 \\
(0.26)\end{array}$ \\
\hline ln Population & $\begin{array}{c}0.08^{* * *} \\
(0.02)\end{array}$ & $\begin{array}{c}0.41^{* * *} \\
(0.06)\end{array}$ \\
\hline ln Resource Income pc & $\begin{array}{c}-0.03^{* * *} \\
(0.003)\end{array}$ & $\begin{array}{c}-0.11^{* * *} \\
(0.01)\end{array}$ \\
\hline Polyarchy*Urbanization & $\begin{array}{c}0.39^{* * *} \\
(0.07)\end{array}$ & $\begin{array}{c}2.06^{* * *} \\
(0.30)\end{array}$ \\
\hline Intercept & $\begin{array}{c}-2.62^{* * * *} \\
(0.28)\end{array}$ & $\begin{array}{c}-11.67^{* * *} \\
(1.15)\end{array}$ \\
\hline Country FE & Yes & Yes \\
\hline Year FE & Yes & Yes \\
\hline $\mathrm{N}$ & 8414 & 8414 \\
\hline R-squared & 0.44 & 0.41 \\
\hline
\end{tabular}


Table 8.31: Interaction models: Regime type and ln GDP per capita

\begin{tabular}{lcc}
\hline & $\begin{array}{c}\text { Ln Skyscrapers } \\
\text { Model 1 }\end{array}$ & $\begin{array}{c}\text { Ln Meters } \\
\text { Model 2 }\end{array}$ \\
\hline Polyarchy & $-0.87^{* * *}$ & $-4.41^{* * *}$ \\
& $(0.13)$ & $(0.55)$ \\
Ln GDPpc & $0.19^{* * *}$ & $0.67^{* * *}$ \\
& $(0.01)$ & $(0.05)$ \\
Percent urbanization & $0.17^{* * *}$ & $0.94^{* * *}$ \\
& $(0.06)$ & $(0.24)$ \\
Ln Population & $0.09^{* * *}$ & $0.49^{* * *}$ \\
& $(0.02)$ & $(0.07)$ \\
Ln Resource Income pc & $-0.03^{* * *}$ & $-0.11^{* * *}$ \\
& $(0.003)$ & $(0.01)$ \\
Polyarchy x Ln GDP per Capita & $0.10^{* * *}$ & $0.52^{* * *}$ \\
& $(0.02)$ & $(0.07)$ \\
Constant & $-2.59^{* * *}$ & $-11.53^{* * *}$ \\
& $(0.28)$ & $(1.14)$ \\
Country FE & Yes & Yes \\
Year FE & Yes & Yes \\
N & & \\
R-squared & 8414 & 8414 \\
***p $<.01 ; * * p<.05 ;{ }^{*} p<.1$ & 0.44 & 0.41 \\
All covariates lagged by 3 years & & \\
Standard error in paranthesis & &
\end{tabular}

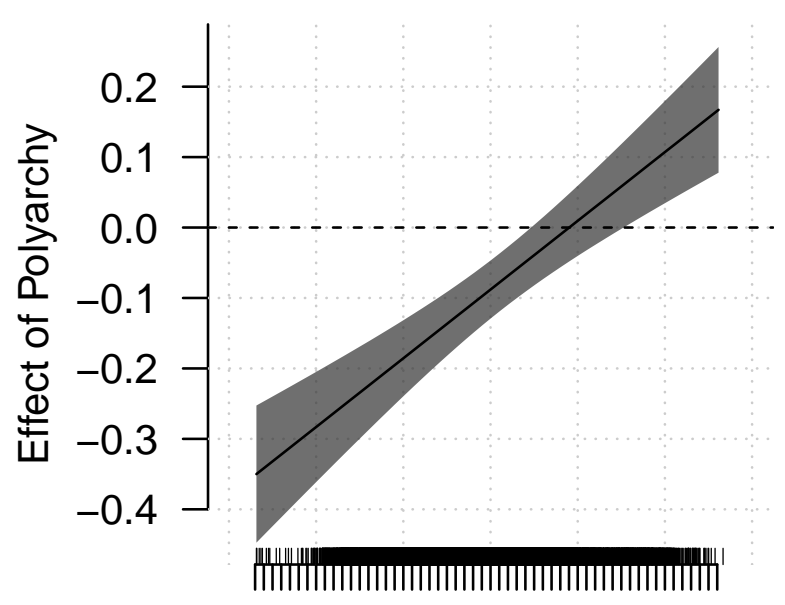

$\begin{array}{lllll}5.3 & 6.4 & 7.5 & 8.6 & 9.7\end{array}$

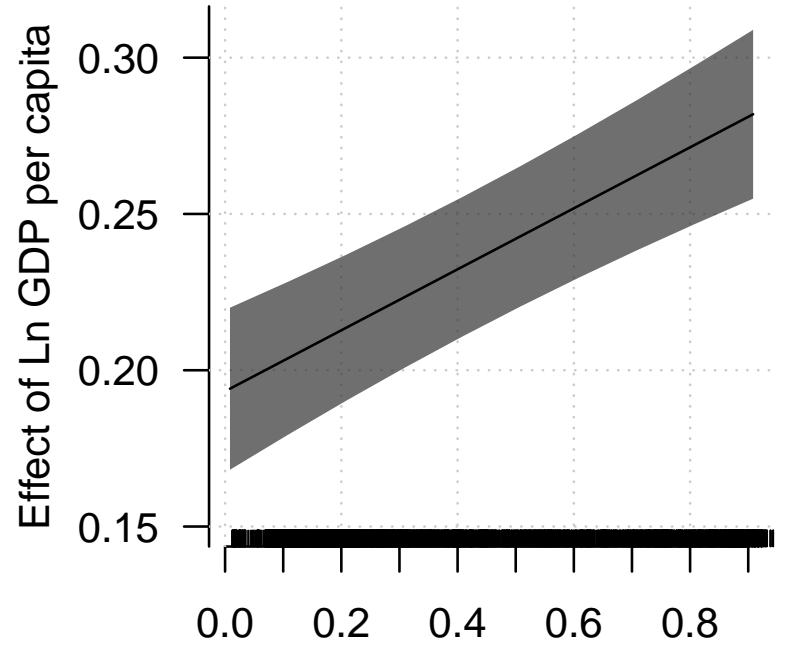

Level of Polyarchy

Figure 8.5: Marginal effects: Interaction between Polyarchy and ln GDP per capita.

Notes: Point estimates and 95 percent confidence intervals are based on Model 1 of Appendix Table A.15, with $\ln ($ skyscrapers +1$)$ as dependent variable. 


\section{Appendix for Chapter 5}

\section{$9.1 \quad$ Summary}

In this appendix, I present additional robustness tests that are mentioned, but not displayed in tables or figures, in the paper.

Section 9.2 presents relevant descriptive statistics. Section 9.3 present different robustness tests evaluating the stability of the results across different sub-samples, estimated with different jackknife-techniques. Section 9.4 present analyses where the dependent variable is instead measured as whether or not each project was located closer than $\mathrm{K}$ $\mathrm{km}$ to the birthplace of the HOS, where K takes each integer value between 2 and 200 . Section 9.5 presents analyses that instead use the PRIO-GRID data set to investigate the sum of projects in each grid each year. Section 9.6 present the results from figure 5.4 in a table-format. Section 9.7 evaluates the robustness of the results presented in figure 5.3 across different measures of democracy. Section 9.8 present the results from figure 5.6 in a table-format. Section 9.9 present the results from figure 5.5 in a table-format. 


\subsection{Descriptive statistics}

Table 9.1: Descriptive statistics: Numeric variables

\begin{tabular}{|c|c|c|c|c|c|c|}
\hline & Min. & 1st Qu. & Median & Mean & 3rd Qu. & Max. \\
\hline Meters to leader birthplace & 167.74 & 103904.33 & 235412.38 & 304244.76 & 459003.44 & 1448074.55 \\
\hline Impartial bureaucracy & -2.31 & -0.61 & 0.31 & 0.09 & 0.51 & 2.85 \\
\hline Polyarchy & 0.12 & 0.34 & 0.45 & 0.46 & 0.57 & 0.83 \\
\hline HOS days in office & 1.00 & 1106.00 & 2370.00 & 3527.99 & 5844.00 & 15009.00 \\
\hline Number of conflict-events & 0.00 & 0.00 & 0.00 & 13.31 & 9.00 & 296.00 \\
\hline GDP per capita & 214.16 & 729.45 & 1020.02 & 1532.46 & 1506.86 & 22048.51 \\
\hline Population & 82634.00 & 9209996.00 & 18659940.00 & 24296560.22 & 35816784.00 & 154728896.00 \\
\hline
\end{tabular}

Table 9.2: Descriptive statistics: Categorical variables

\begin{tabular}{lrr}
\hline & 0 & 1 \\
\hline Presidential election next year & 1650 & 312 \\
Parliamentary election next year & 1610 & 352 \\
HOS selected by legislature & 1703 & 259 \\
HOS elected & 419 & 1543 \\
BMR-Democracy & 1313 & 649 \\
\hline
\end{tabular}

Table 9.3: Descriptive statistics: GRID-data

\begin{tabular}{lrrrrrr}
\hline & Min. & 1st Qu. & Median & Mean & 3rd Qu. & Max. \\
\hline Nightlight intensity & 0.00 & 0.03 & 0.03 & 0.04 & 0.04 & 0.94 \\
Pct. urban population & 0.00 & 0.00 & 0.00 & 0.12 & 0.03 & 22.39 \\
Cell-size (land-area in cell) & 213.39 & 2772.31 & 2943.94 & 2831.53 & 3041.76 & 3091.07 \\
Kilometers to capital & 3.99 & 319.38 & 544.48 & 634.99 & 906.28 & 1947.95 \\
Population density & 0.00 & 0.95 & 6.53 & 28.86 & 22.48 & 4649.87 \\
Conflict events in cell & 0.00 & 0.00 & 0.00 & 0.09 & 0.00 & 245.00 \\
\hline
\end{tabular}




\subsection{Jackknife resamplings}

I do three different jackknife-type of estimations, all using model 3 from table 5.1. First, in figure 9.1, I leave out each HOS in a consecutive manner for each iteration. The resulting graphic is the distribution of the coefficients for presidential and parliamentary elections. Second, I do the same procedure, but instead leave out each country in consecutive manner. The resulting distributions are illustrated in figure 9.2. Third, I do a proper jackknife resampling, and leave out each individual observation in a consecutive manner. This is figure 9.3.

-..- Presidential election

— Parliamentary election

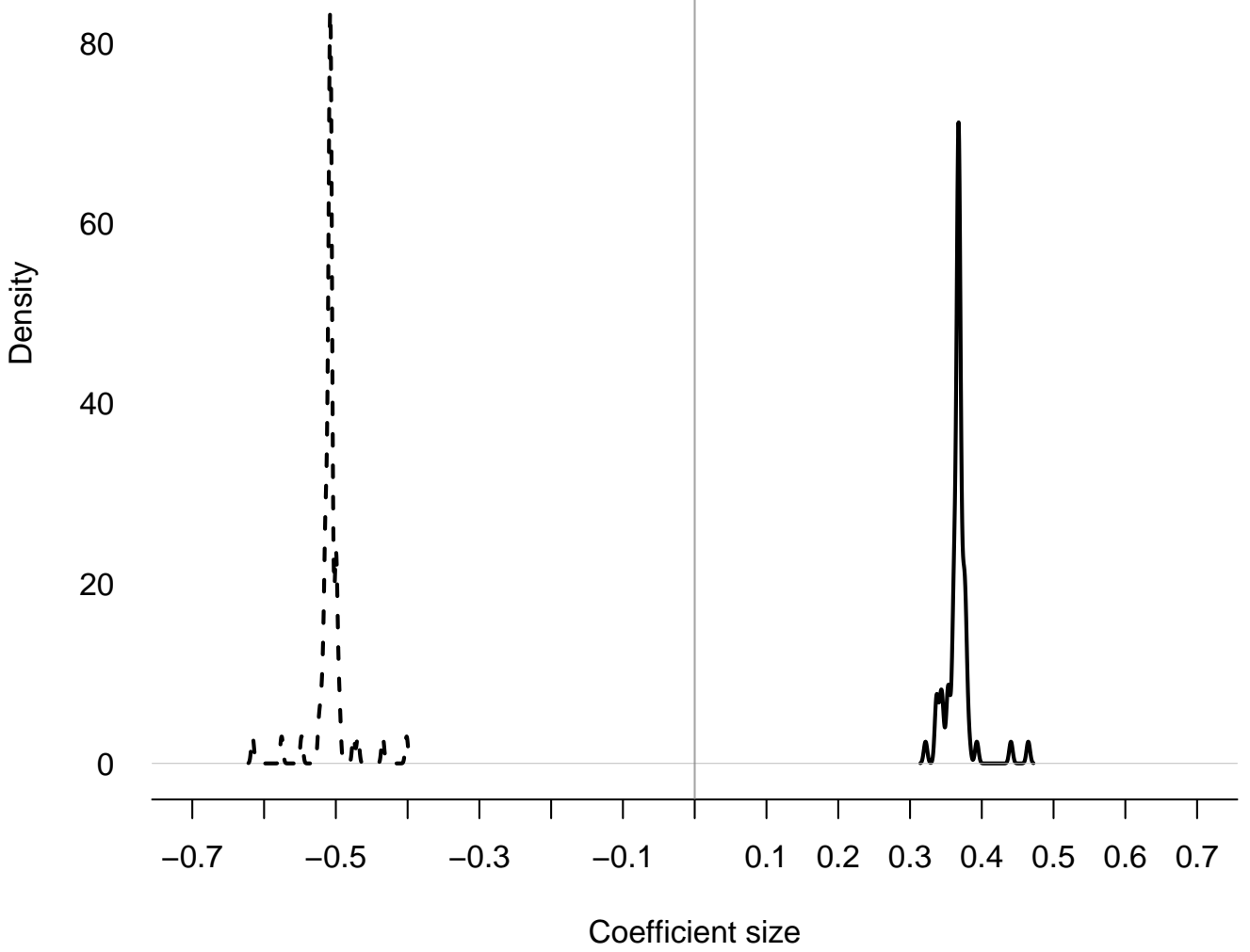

Figure 9.1: Leave-one-leader-out from Model 3 in Table 5.1. Shows the distribution of the coefficients for presidential and parliamentary elections across the different subsamples. 


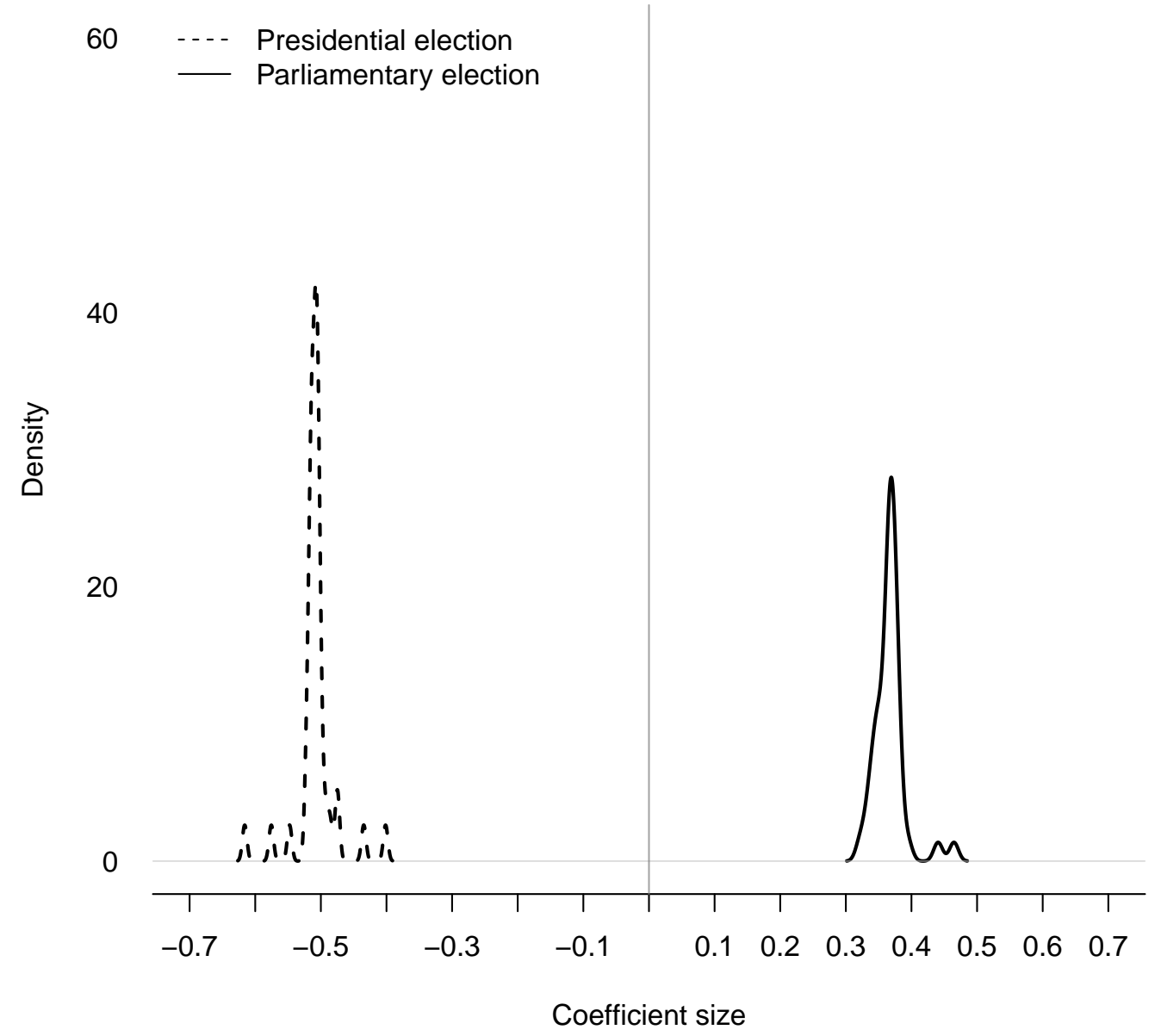

Figure 9.2: Leave-one-country-out from Model 3 in Table 5.1. Shows the distribution of the coefficients for presidential and parliamentary elections across the different subsamples. 


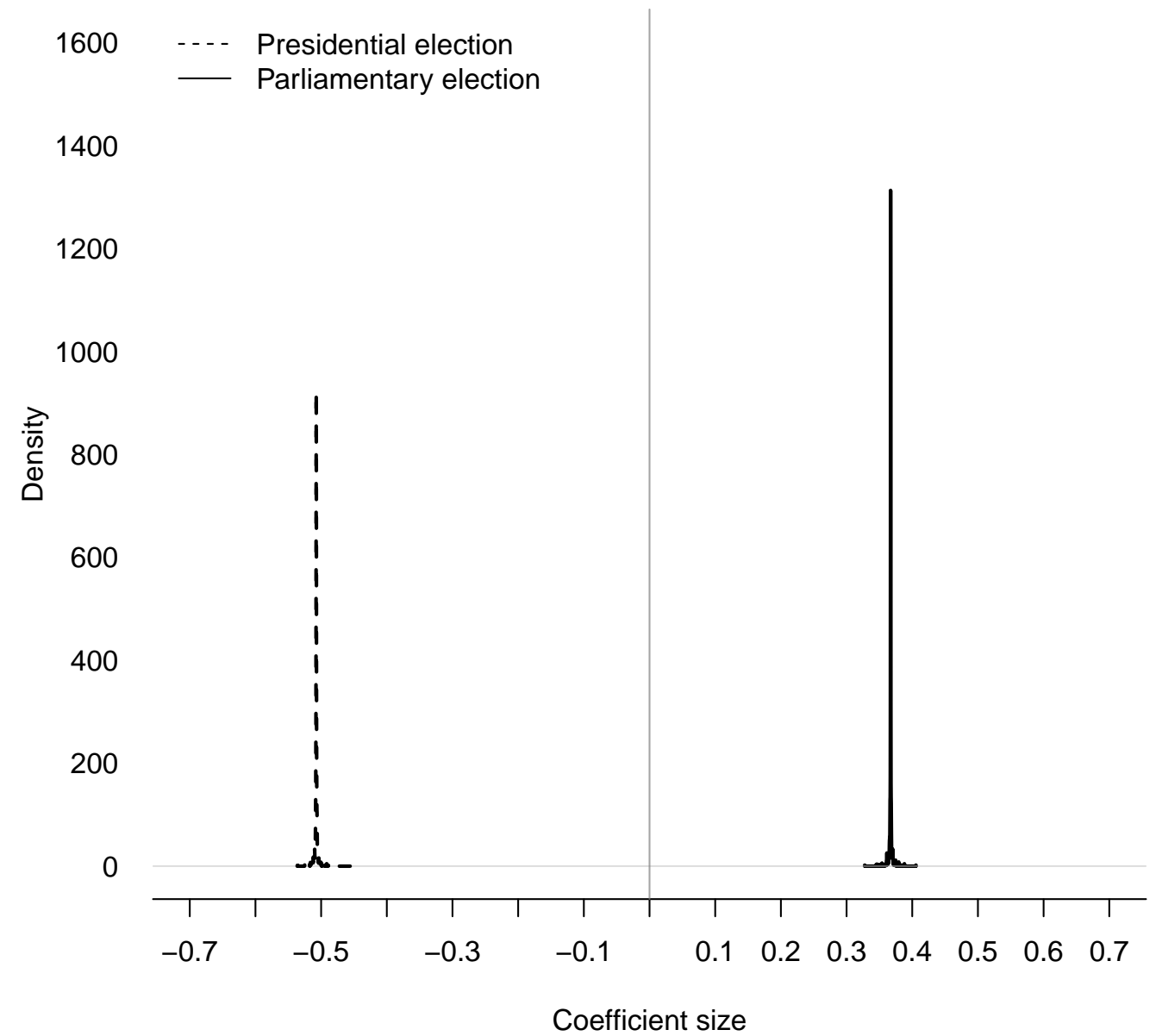

Figure 9.3: Leave-one-observation-out from Model 3 in Table 5.1. Shows the distribution of the coefficients for presidential and parliamentary elections across the different subsamples. 


\subsection{Binomial cut-off of distance}

In these analyses, I run a logistic regression where the dependent variable is whether or not each project was located closer than $\mathrm{K} \mathrm{km}$ to the birthplace of the HOS, where $\mathrm{K}$ increases by $1 \mathrm{~km}$ for each iteration, up to $200 \mathrm{~km}$. The model is otherwise similar to model 3 in table 5.1 .

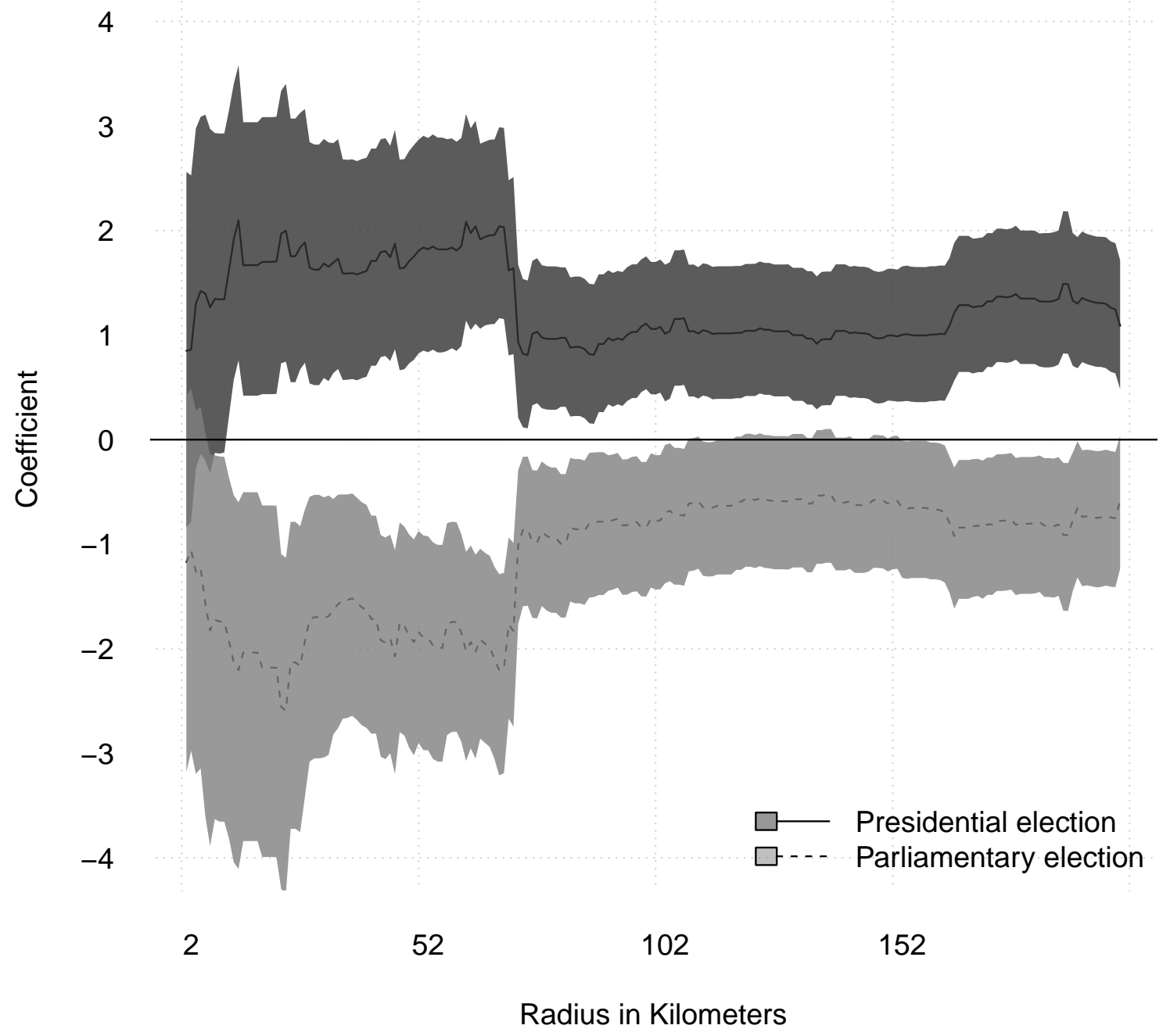

Figure 9.4: Investigating different cut-off points for home area. Each point along the $\mathrm{X}$-axis represent an individual logistic regression. The value on the $\mathrm{X}$-axis indicates the threshold radius for what constitues the "home area" of the HOS. The model is otherwise similar to model 3 in table 5.1. 


\subsection{PRIO-GRID}

In these analyses, each project is mapped to a grid in the PRIO-GRID dataset, and the sum of projects for each grid each year is then calculated. I then run two models with this dependent variable. First, the effect of the distance from the grid-centroid to the birthplace of the HOS interacted with whether or not there is a presidential election next year, and whether or not there is a parliamentary election next year. This is model 1 in table 9.4, with marginal effect illustrated in 9.5. Second, model 2 estimates the effect of being the grid-cell where the HOS was born, interacted with whether or not there is a presidential election next year, and whether or not there is a parliamentary election next year. The marginal effects are illustrated in figure 9.6.

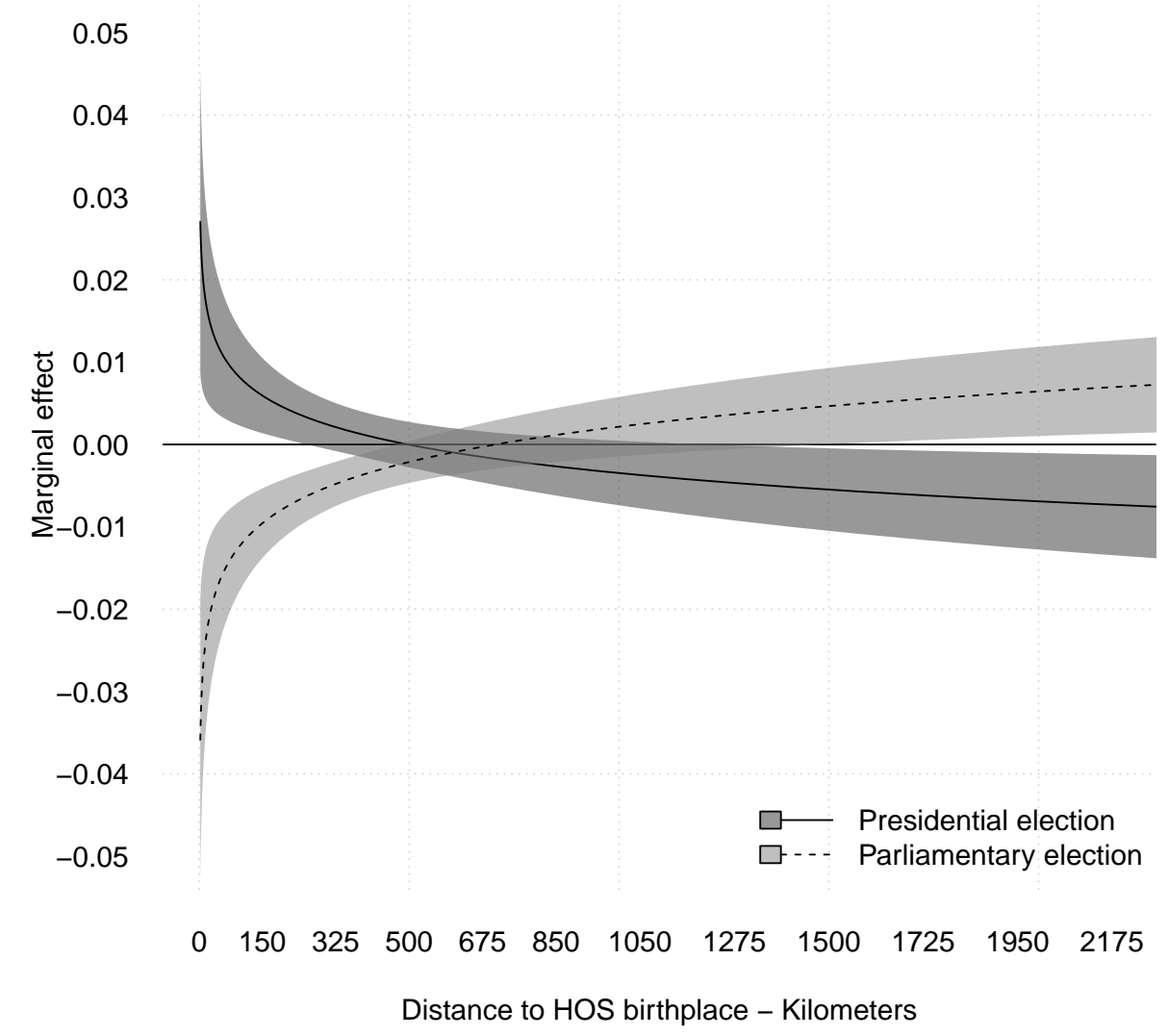

Figure 9.5: Marginal effects of elections on the number of investment projects in the grid given distance the distance from the grid-centroid to the birthplace of the HOS. 


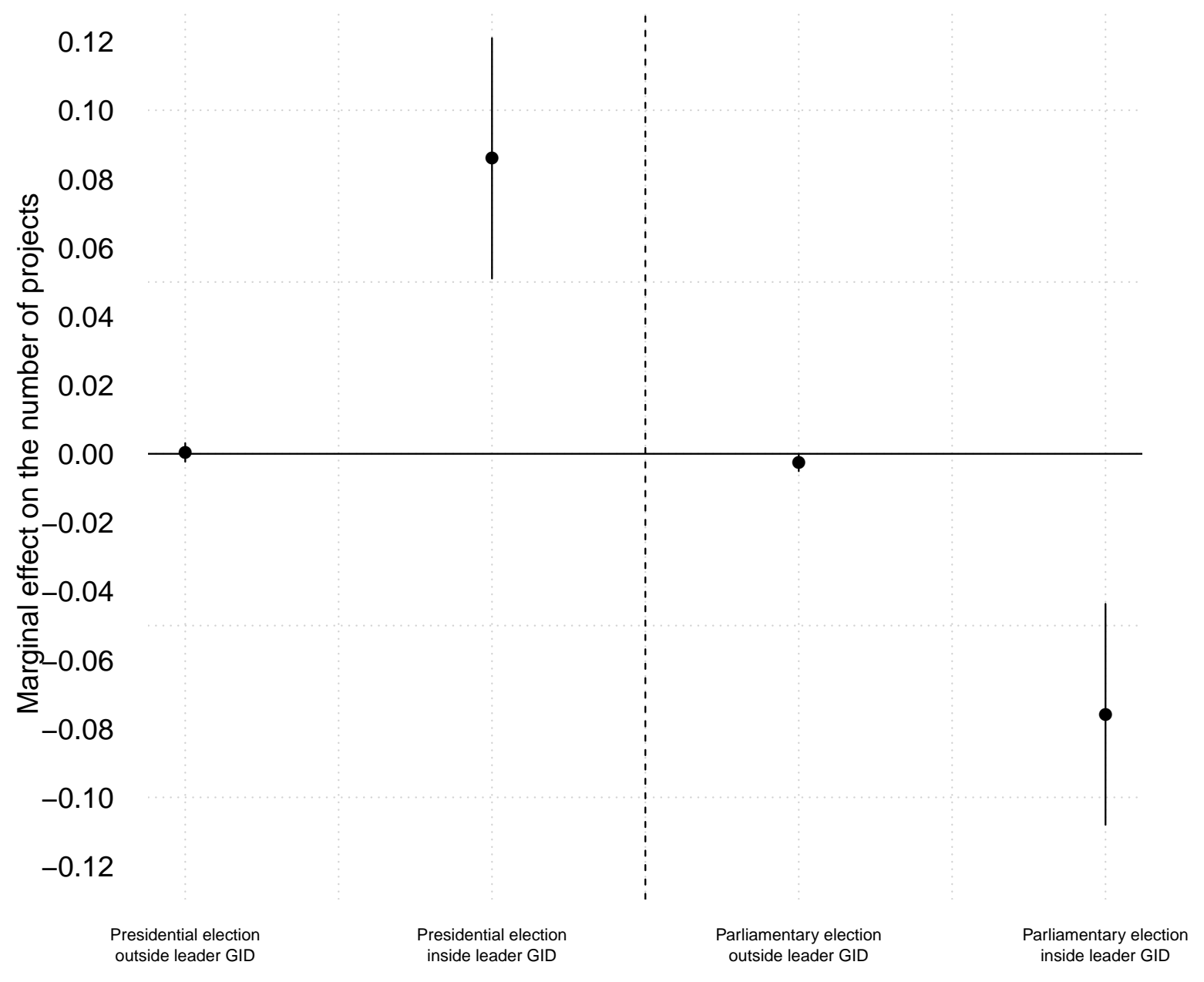

Figure 9.6: Marginal effects of elections given whether it is the cell where the HOS was born. 
Table 9.4: Effect of elections on the number of investment projects in geographical gridcells

\begin{tabular}{|c|c|c|}
\hline & Model 1 & Model 2 \\
\hline Ln distance to HOS birthplace & $\begin{array}{r}0.001 \\
(0.809)\end{array}$ & \\
\hline Birthplace GRID-cell & & $\begin{array}{r}-0.109 \\
(-8.524)\end{array}$ \\
\hline Presidential election next year & $\begin{array}{r}0.065 \\
(2.864)\end{array}$ & $\begin{array}{r}0 \\
(0.289)\end{array}$ \\
\hline Parliamentary election next year & $\begin{array}{r}-0.083 \\
(-3.958)\end{array}$ & $\begin{array}{r}-0.003 \\
(-1.991)\end{array}$ \\
\hline Ln distance $*$ Presidential election & $\begin{array}{r}-0.005 \\
(-2.842)\end{array}$ & \\
\hline Ln distance $*$ Parliamentary election & $\begin{array}{r}0.006 \\
(3.826)\end{array}$ & \\
\hline Birthplace * Presidential election & & $\begin{array}{r}0.086 \\
(4.781)\end{array}$ \\
\hline Birthplace * Parliamentary election & & $\begin{array}{r}-0.073 \\
(-4.453)\end{array}$ \\
\hline Impartial bureaucracy & $\begin{array}{l}-0.003 \\
(-2.03)\end{array}$ & $\begin{array}{r}-0.003 \\
(-2.094)\end{array}$ \\
\hline Polyarchy & $\begin{array}{r}0.062 \\
(5.736)\end{array}$ & $\begin{array}{r}0.061 \\
(5.656)\end{array}$ \\
\hline HOS selected by legislature & $\begin{array}{r}-0.012 \\
(-4.505)\end{array}$ & $\begin{array}{r}-0.012 \\
(-4.479)\end{array}$ \\
\hline HOS elected & $\begin{array}{r}-0.007 \\
(-3.101)\end{array}$ & $\begin{array}{r}-0.007 \\
(-3.086)\end{array}$ \\
\hline Ln GDP per capita & $\begin{array}{r}-0.004 \\
(-1.782)\end{array}$ & $\begin{array}{r}-0.004 \\
(-1.723)\end{array}$ \\
\hline Ln days in office & $\begin{array}{r}0.001 \\
(1.414)\end{array}$ & $\begin{array}{r}0.001 \\
(1.476)\end{array}$ \\
\hline Nightlight intensity & $\begin{array}{r}-1.424 \\
(-19.892)\end{array}$ & $\begin{array}{r}-1.422 \\
(-19.871)\end{array}$ \\
\hline Pct. urban population & $\begin{array}{r}0.075 \\
(15.719)\end{array}$ & $\begin{array}{r}0.074 \\
(15.53)\end{array}$ \\
\hline Cell-size & $\begin{array}{r}0 \\
(-0.168)\end{array}$ & $\begin{array}{r}0 \\
(-0.12)\end{array}$ \\
\hline Ln distance to capital & $\begin{array}{r}-0.008 \\
(-0.795)\end{array}$ & $\begin{array}{r}-0.008 \\
(-0.826)\end{array}$ \\
\hline Population density & $\begin{array}{r}0.002 \\
(57.867)\end{array}$ & $\begin{array}{r}0.002 \\
(57.977)\end{array}$ \\
\hline Ln conflict events in cell & $\begin{array}{l}-0.002 \\
(-0.77)\end{array}$ & $\begin{array}{r}-0.002 \\
(-0.655)\end{array}$ \\
\hline Constant & $\begin{array}{r}0.063 \\
(0.408) \\
\end{array}$ & $\begin{array}{r}0.073 \\
(0.473) \\
\end{array}$ \\
\hline Cell FE & Yes & Yes \\
\hline Year FE & Yes & Yes \\
\hline $\mathrm{N}:$ & 148715 & 148715 \\
\hline Cells: & 10273 & 10273 \\
\hline
\end{tabular}


9.6 Table presenting results from models investigating different leads and lags of elections 
Table 9.5: Elections and investment allocation: investigating timing

\begin{tabular}{|c|c|}
\hline & Dependent variable: \\
\hline & Ln meters to HOS birthplace \\
\hline Presidential election lead 2 & $\begin{array}{c}0.01 \\
(0.13)\end{array}$ \\
\hline Presidential election lead 1 & $\begin{array}{c}-0.44^{* *} \\
(0.15)\end{array}$ \\
\hline Presidential election & $\begin{array}{l}-0.14 \\
(0.17)\end{array}$ \\
\hline Presidential election lag 1 & $\begin{array}{c}0.08 \\
(0.16)\end{array}$ \\
\hline Presidential election lag 2 & $\begin{array}{c}0.11 \\
(0.14)\end{array}$ \\
\hline Parliamentary election lead 2 & $\begin{array}{c}0.17 \\
(0.15)\end{array}$ \\
\hline Parliamentary election lead 1 & $\begin{array}{l}0.43^{*} \\
(0.17)\end{array}$ \\
\hline Parliamentary election & $\begin{array}{c}0.23 \\
(0.17)\end{array}$ \\
\hline Parliamentary election lag 1 & $\begin{array}{l}-0.03 \\
(0.16)\end{array}$ \\
\hline Parliamentary election lag 2 & $\begin{array}{l}-0.02 \\
(0.15)\end{array}$ \\
\hline Impartial bureaucracy & $\begin{array}{l}-0.30 \\
(0.21)\end{array}$ \\
\hline Polyarchy & $\begin{array}{l}-0.85 \\
(1.11)\end{array}$ \\
\hline Ln days in office & $\begin{array}{l}-0.05 \\
(0.06)\end{array}$ \\
\hline HOS selected by legislature & $\begin{array}{l}0.71^{\dagger} \\
(0.39)\end{array}$ \\
\hline HOS elected & $\begin{array}{c}0.31 \\
(0.34)\end{array}$ \\
\hline Ln number of conflict-events & $\begin{array}{c}0.01 \\
(0.05)\end{array}$ \\
\hline Ln GDP per capita & $\begin{array}{c}0.20 \\
(0.58)\end{array}$ \\
\hline Ln population & $\begin{array}{c}0.28 \\
(2.08)\end{array}$ \\
\hline Constant & $\begin{array}{c}7.35 \\
(30.99)\end{array}$ \\
\hline $\begin{array}{l}\text { Country FE } \\
\text { Year FE } \\
\text { Leader FE } \\
\end{array}$ & $\begin{array}{l}\text { No } \\
\text { Yes } \\
\text { Yes }\end{array}$ \\
\hline $\begin{array}{l}\text { Observations } \\
\mathrm{R}^{2}\end{array}$ & $\begin{array}{c}1,593 \\
0.42\end{array}$ \\
\hline
\end{tabular}




\subsection{Democracy versus autocracy: Alternative data}

In the following models, I re-estimate the split-sample model in figure 5.3, but change the definition of democracy. The effects illustrated in figure 9.7 uses the DD-variable from (Cheibub, Gandhi, and Vreeland 2010), while those illustrated in figure 9.8 uses a split based on the median value on Polyarchy.

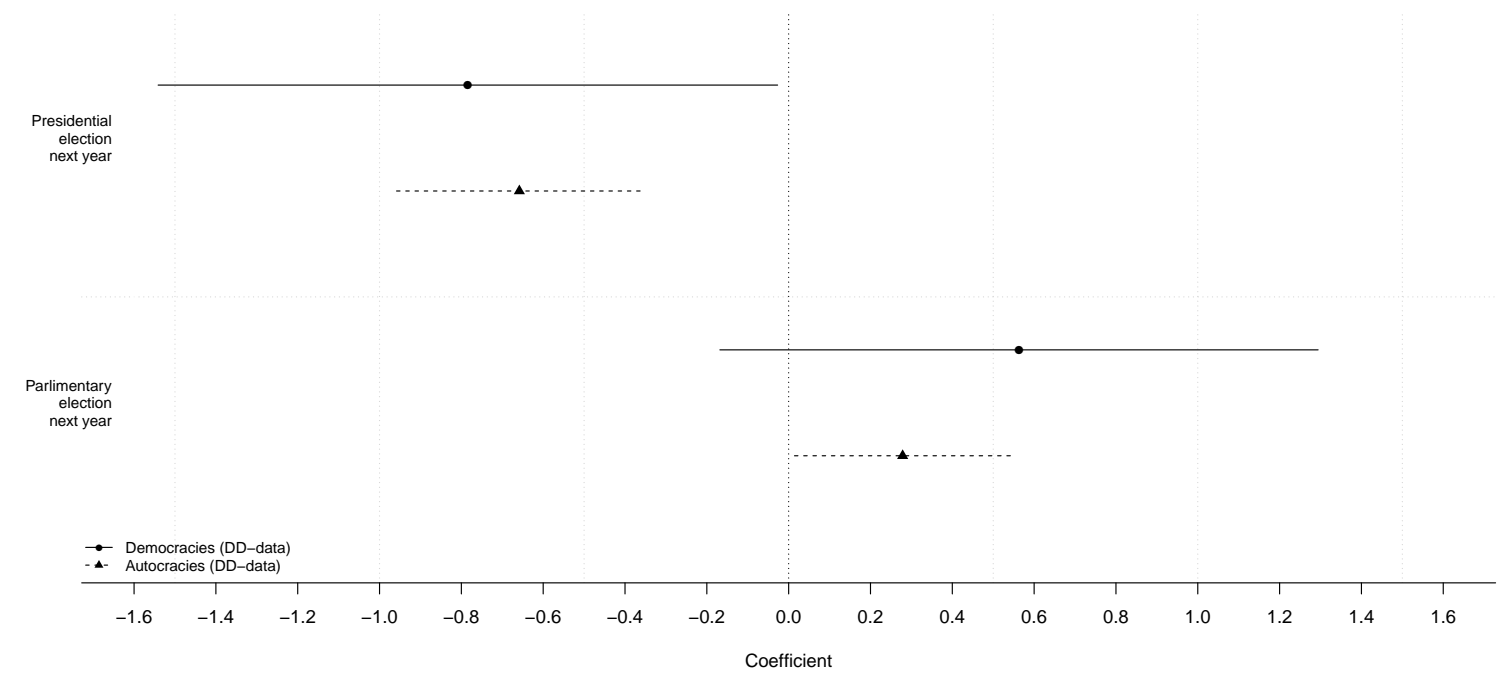

Figure 9.7: The estimated effect and corresponding 95\% confidence interval of parliamentary and presidential elections on the distance between HOS' birthplace and investment location, split by median value on polyarchy. Except for excluding the control for Polyarchy, the model is similar to model 3 in table 5.1. Control variables are left out of the illustration. 


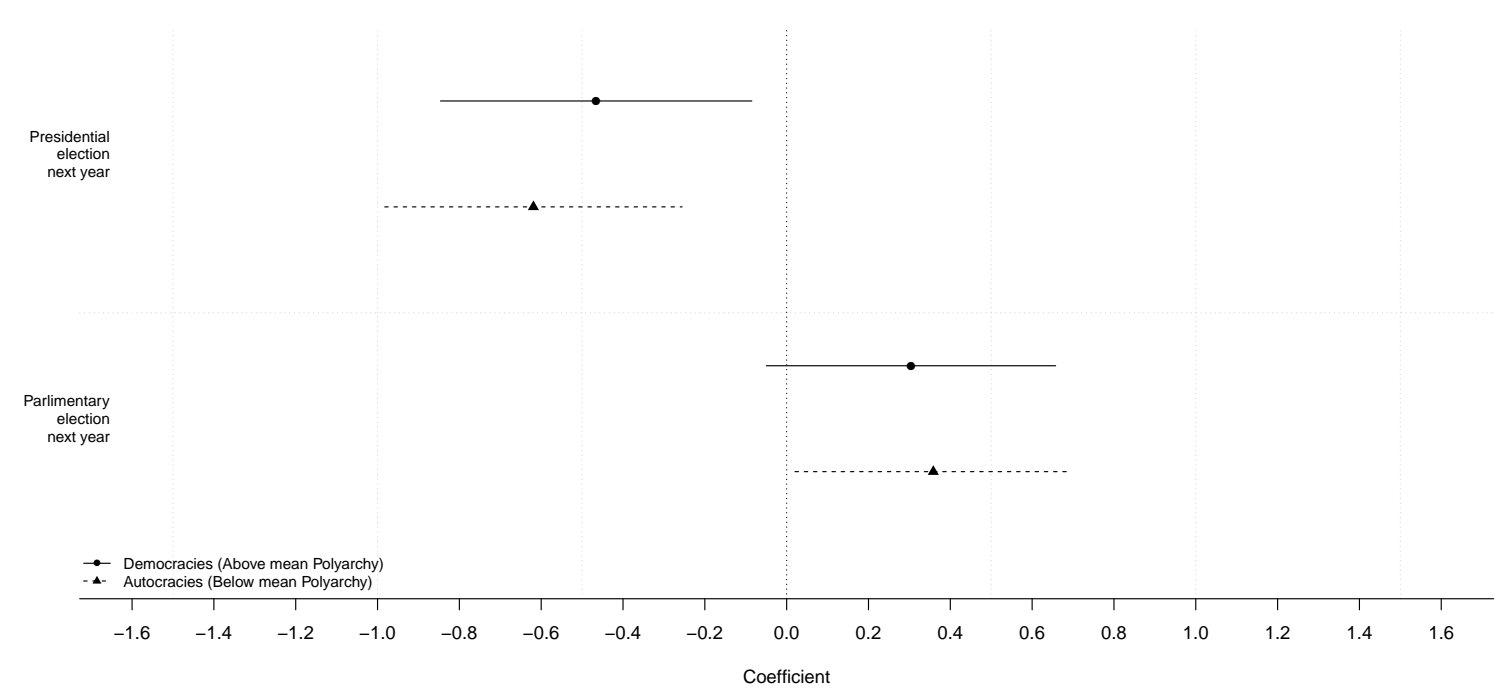

Figure 9.8: The estimated effect and corresponding 95\% confidence interval of parliamentary and presidential elections on the distance between HOS' birthplace and investment location, split by DD measure on democracy and autocracy.. Except for excluding the control for Polyarchy, the model is similar to model 3 in table 5.1. Control variables are left out of the illustration. 


\section{Table presenting results from the models comparing democracy and autocracy}

Table 9.6: Elections and investment allocation: comparing democracies and autocracies

\begin{tabular}{|c|c|c|c|c|c|c|}
\hline & \multicolumn{6}{|c|}{ Dependent variable: } \\
\hline & \multicolumn{6}{|c|}{ Ln meters to HOS birthplace } \\
\hline & $(1)$ & $(2)$ & (3) & $(4)$ & $(5)$ & $(6)$ \\
\hline Presidential election next year & $\begin{array}{c}-0.52^{\dagger} \\
(0.31)\end{array}$ & $\begin{array}{c}-0.56^{* * *} \\
(0.14)\end{array}$ & $\begin{array}{c}-0.47^{*} \\
(0.19)\end{array}$ & $\begin{array}{c}-0.62^{* * *} \\
(0.19)\end{array}$ & $\begin{array}{c}-0.78^{*} \\
(0.39)\end{array}$ & $\begin{array}{c}-0.66^{* * *} \\
(0.15)\end{array}$ \\
\hline Parliamentary election next year & $\begin{array}{l}0.51^{\dagger} \\
(0.30)\end{array}$ & $\begin{array}{c}0.35^{* *} \\
(0.13)\end{array}$ & $\begin{array}{l}0.30^{\dagger} \\
(0.18)\end{array}$ & $\begin{array}{l}0.36^{*} \\
(0.17)\end{array}$ & $\begin{array}{c}0.56 \\
(0.37)\end{array}$ & $\begin{array}{l}0.28^{*} \\
(0.13)\end{array}$ \\
\hline Impartial bureaucracy & $\begin{array}{c}0.92 \\
(0.65)\end{array}$ & $\begin{array}{c}-0.77^{*} \\
(0.32)\end{array}$ & $\begin{array}{c}0.05 \\
(0.35)\end{array}$ & $\begin{array}{l}-0.43 \\
(0.38)\end{array}$ & $\begin{array}{c}0.31 \\
(0.53)\end{array}$ & $\begin{array}{c}-0.59^{\dagger} \\
(0.34)\end{array}$ \\
\hline Ln days in office & $\begin{array}{l}-0.08 \\
(0.09)\end{array}$ & $\begin{array}{l}-0.05 \\
(0.10)\end{array}$ & $\begin{array}{l}-0.04 \\
(0.06)\end{array}$ & $\begin{array}{c}0.16 \\
(0.31)\end{array}$ & $\begin{array}{l}-0.08 \\
(0.09)\end{array}$ & $\begin{array}{l}-0.06 \\
(0.11)\end{array}$ \\
\hline HOS selected by legislature & $\begin{array}{l}14.32^{\dagger} \\
(8.07)\end{array}$ & $\begin{array}{l}0.84^{*} \\
(0.40)\end{array}$ & $\begin{array}{c}-0.61 \\
(10.55)\end{array}$ & $\begin{array}{l}0.81^{\dagger} \\
(0.47)\end{array}$ & $\begin{array}{c}-10.49^{*} \\
(4.20)\end{array}$ & $\begin{array}{c}0.62 \\
(0.42)\end{array}$ \\
\hline HOS elected & $\begin{array}{l}-0.85 \\
(0.76)\end{array}$ & $\begin{array}{c}0.46 \\
(0.35)\end{array}$ & $\begin{array}{c}0.58 \\
(5.48)\end{array}$ & $\begin{array}{c}0.18 \\
(0.47)\end{array}$ & $\begin{array}{l}-0.45 \\
(0.83)\end{array}$ & $\begin{array}{c}0.34 \\
(0.35)\end{array}$ \\
\hline Ln number of conflict-events & $\begin{array}{l}-0.08 \\
(0.08)\end{array}$ & $\begin{array}{l}-0.02 \\
(0.06)\end{array}$ & $\begin{array}{l}-0.05 \\
(0.06)\end{array}$ & $\begin{array}{l}-0.02 \\
(0.08)\end{array}$ & $\begin{array}{l}-0.12 \\
(0.09)\end{array}$ & $\begin{array}{c}0.01 \\
(0.07)\end{array}$ \\
\hline Ln GDP per capita & $\begin{array}{c}-7.07^{* *} \\
(2.37)\end{array}$ & $\begin{array}{c}0.52 \\
(0.73)\end{array}$ & $\begin{array}{c}1.55 \\
(1.34)\end{array}$ & $\begin{array}{c}0.04 \\
(0.89)\end{array}$ & $\begin{array}{l}-3.38 \\
(2.51)\end{array}$ & $\begin{array}{c}0.13 \\
(0.71)\end{array}$ \\
\hline Ln population & $\begin{array}{l}-4.59 \\
(4.33)\end{array}$ & $\begin{array}{l}-1.76 \\
(3.26)\end{array}$ & $\begin{array}{c}0.29 \\
(3.19)\end{array}$ & $\begin{array}{c}0.04 \\
(3.95)\end{array}$ & $\begin{array}{l}-10.35 \\
(6.57)\end{array}$ & $\begin{array}{l}-1.40 \\
(3.51)\end{array}$ \\
\hline Constant & $\begin{array}{c}137.21^{\dagger} \\
(76.13)\end{array}$ & $\begin{array}{c}34.54 \\
(47.83)\end{array}$ & $\begin{array}{c}-3.71 \\
(49.15)\end{array}$ & $\begin{array}{c}8.69 \\
(57.81)\end{array}$ & $\begin{array}{l}203.34^{\dagger} \\
(112.48)\end{array}$ & $\begin{array}{c}32.01 \\
(52.31)\end{array}$ \\
\hline Country FE & No & No & No & No & No & No \\
\hline Year FE & Yes & Yes & Yes & Yes & Yes & Yes \\
\hline Leader FE & Yes & Yes & Yes & Yes & Yes & Yes \\
\hline Sample & $\begin{array}{c}\text { BMR } \\
\text { democracy }\end{array}$ & $\begin{array}{c}\text { BMR } \\
\text { autocracy }\end{array}$ & $\begin{array}{l}\text { Polyarchy } \\
\text { democracy }\end{array}$ & $\begin{array}{l}\text { Polyarchy } \\
\text { autocracy }\end{array}$ & $\begin{array}{c}\text { DD } \\
\text { democracy }\end{array}$ & $\begin{array}{c}\text { DD } \\
\text { autocracy }\end{array}$ \\
\hline Observations & 540 & 1,053 & 822 & 771 & 420 & 880 \\
\hline $\mathrm{R}^{2}$ & 0.40 & 0.44 & 0.45 & 0.41 & 0.46 & 0.42 \\
\hline
\end{tabular}




\subsection{Table presenting results from models investigat- ing different electoral formulas.}

Table 9.7: Elections and investment allocation: comparing electoral formulas

\begin{tabular}{|c|c|}
\hline & Dependent variable: \\
\hline & Ln meters to HOS birthplace \\
\hline Presidential election next year & $\begin{array}{c}-0.58^{* * *} \\
(0.13)\end{array}$ \\
\hline Parliamentary majoritarian election next year & $\begin{array}{c}0.54^{* * *} \\
(0.15)\end{array}$ \\
\hline Parliamentary mixed or PR election next year & $\begin{array}{c}0.16 \\
(0.15)\end{array}$ \\
\hline Impartial bureaucracy & $\begin{array}{l}-0.33 \\
(0.20)\end{array}$ \\
\hline Polyarchy & $\begin{array}{l}-1.20 \\
(1.10)\end{array}$ \\
\hline Ln days in office & $\begin{array}{l}0.82^{*} \\
(0.38)\end{array}$ \\
\hline HOS selected by legislature & $\begin{array}{c}0.39 \\
(0.33)\end{array}$ \\
\hline HOS elected & $\begin{array}{l}-0.001 \\
(0.04)\end{array}$ \\
\hline Ln number of conflict-events & $\begin{array}{c}0.32 \\
(0.55)\end{array}$ \\
\hline Ln GDP per capita & $\begin{array}{l}-0.24 \\
(1.97)\end{array}$ \\
\hline Ln population & $\begin{array}{l}14.93 \\
(29.45)\end{array}$ \\
\hline $\begin{array}{l}\text { Country FE } \\
\text { Year FE } \\
\text { Leader FE }\end{array}$ & $\begin{array}{l}\text { No } \\
\text { Yes } \\
\text { Yes }\end{array}$ \\
\hline $\begin{array}{l}\text { Observations } \\
\mathrm{R}^{2}\end{array}$ & $\begin{array}{c}1,593 \\
0.42\end{array}$ \\
\hline
\end{tabular}




\subsection{Table presenting results from placebo tests.}

Table 9.8: Placebo table of elections and investment allocation

\begin{tabular}{lcc}
\hline \hline & \multicolumn{2}{c}{ Dependent variable: } \\
\cline { 2 - 3 } & \multicolumn{2}{c}{ Ln meters to birthplace } \\
& $(1)$ & $(2)$ \\
\hline Presidential election next year & 0.08 & \\
& $(0.30)$ & \\
Parliamentary election next year & 0.24 & \\
& $(0.22)$ & 0.02 \\
Placebo presidential election next year & & $(0.07)$ \\
& & 0.02 \\
Placebo parliamentary election next year & & $(0.06)$ \\
& & $12.20^{* * *}$ \\
Constant & $13.39^{* * *}$ & $(0.28)$ \\
& $(0.28)$ & \\
\hline Year FE & & Yes \\
Leader FE & Yes & 2,108 \\
Observations & Yes \\
$\mathrm{R}^{2}$ & 72 & 0.48 \\
\hline \hline Note: & 0.98 & ${ }^{*} \mathrm{p}<0.1 ;{ }^{* *} \mathrm{p}<0.05 ;{ }^{* * *} \mathrm{p}<0.01$ \\
\end{tabular}




\section{Bibliography}

Acemoglu, Daron, Simon Johnson, and James A. Robinson (2001). "The Colonial Origins of Comparative Development: An Empirical Investigation." American Economic Review 91 (5), pp. 1369-1401.

Acemoglu, Daron, Suresh Naidu, Pascual Restrepo, and James A. Robinson (2019). "Democracy Does Cause Growth." Journal of Political Economy 127 (1), pp. 47100.

Acemoglu, Daron and James A. Robinson (2006). Economic Origins of Dictatorship and Democracy. New York: Cambridge University Press.

Acemoglu, Daron and James A. Robinson (2012). Why Nations Fail: The Origins of Power, Prosperity and Poverty. Paperback. London: Profile Books.

Ades, Alberto F. and Edward L. Glaeser (1995). "Trade and Circuses: Explaining Urban Giants." Quarterly Journal of Economics 110 (1), pp. 195-227.

Adler, Nicole, Eric Pels, and Chris Nash (2010). "High-speed rail and air transport competition: Game engineering as tool for cost-benefit analysis." Transportation Research Part B: Methodological 44 (7), pp. 812-833.

Aidt, Toke S. and Peter Jensen (2014). "Workers of the world, unite! Franchise extensions and the threat of revolution in Europe, 1820-1938." European Economic Review 72 (C), pp. $52-75$.

Aidt, Toke, Martin Daunton, and Jayasri Dutta (2010). "The Retrenchment Hypothesis and the Extension of the Franchise in England and Wales." Economic Journal 120 (547), pp. 990-1020.

Aidt, Toke, Jayasri Dutta, and Elena Loukoianova (2006). "Democracy comes to Europe: Franchise extension and fiscal outcomes 1830-1938." European Economic Review 50 (2), pp. 249-283.

Aldrich, Daniel P. (2008). Site Fights: Divisive Facilities and Civil Society in Japan and the West. Ithaca: Cornell University Press.

Aleem, Irfan (1990). "Imperfect information, screening, and the costs of informal lending: A study of rural credit market in Pakistan." The World Bank Economic Review 4 (3), pp. 329-349.

Amsden, Alice (1989). Asia's next giant: South Korea and late industrialization. New York: Oxford University Press.

Anckar, Carsten and Cecilia Fredriksson (2018). "Classifying Political Regimes 1800-2016: A typology and a new dataset." European Political Science, pp. 1-13.

Ansell, Ben (2008). "Traders, teachers, and tyrants: Democracy, globalization, and public investment in education." International Organization 62 (2), pp. 289-322.

Ansell, Ben W. and David J. Samuels (2014). Inequality and Democratization: An EliteCompetition Approach. New York: Cambridge University Press.

Ansolabehere, Stephen, Alan Gerber, and James Snyder (2002). "Equal Votes, Equal Money: Court-Ordered Redistricting and Public Expenditures in the American States." The American Political Science Review 96 (4), pp. 767-777. 
Baldwin, Kate (2013). "Why Vote with the Chief? Political Connections and Public Goods Provisions in Zambia." American Journal of Political Science 57 (4), pp. 794-809.

Banerjee, Abhijit V. and Esther Duflo (2011). Poor Economics: A Radical Rethinking of the Way to Fight Global Poverty. London: Penguin Books.

Bardhan, Pranab K. (2012). Awakening giants, feet of clay: Assessing the economic rise of China and India. Princeton: Princeton University Press.

Barkan, Joel D. (1995). "Elections in agrarian societies." Journal of Democracy 6 (4), pp. $106-116$.

Barr, Jason (2012). "Skyscraper height." Journal of Real Estate Finance and Economics 45 (3), pp. 723-753.

Beaulieu, Emily and Susan D Hyde (2009). "In the Shadow of Democracy Promotion. Strategic Manipulation, international observers, and Election Boycotts." Comparative Political Studies 42 (3), pp. 392-415.

Beetham, David (1992). "Liberal Democracy and the Limits of Democratization." Political Studies 40 (S1), pp. 40-53.

Behrens, Christiaan and Eric Pels (2012). "Intermodal competition in the London-Paris passenger market: High-speed Rail and air transport." Journal of Urban Economics 71 (3), pp. 278-288.

Besley, Timothy (2006). Principled Agents? The political economy of good government. Oxford: Oxford University Press.

Bhasin, Tavishi and Jennifer Gandhi (2013). "Timing and targeting of state repression in authoritarian elections." Electoral Studies 32 (4), pp. 620-631.

Blaydes, Lisa (2010). Election and Distributive Politics in Mubarak's Egypt. Cambridge: Cambridge University Press.

Bloom, David E., Jeffrey D. Sachs, Paul Collier, and Christopher Udry (1998). "Geography, Demography, and Economic Growth in Africa." Brookings Papers on Economic Activity 1998 (2), pp. 207-295.

Boese, Vanessa A. (2019). "How (not) to measure democracy." International Area Studies Review 22 (2), pp. 95-127.

Boix, Carles (2003). Democracy and Redistribution. Princeton: Princeton University Press.

Boix, Carles, Michael Miller, and Sebastian Rosato (2013). "A complete data set of political regimes, 1800-2007." Comparative Political Studies 46 (12), pp. 1523-1554.

Boix, Carles and Milan W. Svolik (2013). "The foundations of limited authoritarian government: institutions, commitment, and power-sharing in dictatorships." Journal of Politics 75 (2), pp. 300-316.

Bolt, Jutta, Robert Inklaar, Herman de Jong, and Jan Luiten van Zanden (2018). "Rebasing 'Maddison': New income comparisons and the shape of long-run economic development." Maddison Project Working paper 10.

Bolt, Jutta and Jan Luiten van Zanden (2014). "The Maddison Project: Collaborative Research on Historical National Accounts." The Economic History Review 67 (3), pp. 627-651. 
British Petroleum (2018). BP Energy Outlook, 2018 Edition. Retrieved from https : //www.bp.com/content/dam/bp/en/corporate/pdf/energy-economics/energyoutlook/bp-energy-outlook-2018.pdf [Last visited 17-08-2018].

Brown, David and Wendy Hunter (2004). "Democracy and Human Capital Formation." Comparative Political Studies 37 (7), pp. 842-864.

Brown, David and Ahmed Mushfiq Mobarak (2009). "The Transforming Power of Democracy: Regime Type and the Distribution of Electricity." Annual Political Science Review 103 (2), pp. 193-213.

Bueno de Mesquita, Bruce, James D. Morrow, Randolph M. Siverson, and Alistair Smith (1999). "An Institutional Explanation of the Democratic Peace." American Political Science Review 93 (4), pp. 791-807.

Bueno de Mesquita, Bruce, James D. Morrow, Randolph M. Siverson, and Alistair Smith (2004). "Testing Novel Implications From The Selectorate Theory of War." World Politics 56, pp. 363-388.

Bueno de Mesquita, Bruce, Alistair Smith, Randolph M. Siverson, and James D. Morrow (2003). The Logic of Political Survival. Cambridge, Ma.: Cambridge, Ma: MIT Press.

Bunce, Valerie J. and Sharon Lee Wolchik (2010). "Defeating Dictators: Electoral Change and Stability in Competitive Authoritarian Regime." World Politics 62 (1), pp. 43-86.

Burgess, Robin, Remi Jedwab, Edward Miguel, Ameet Morjaria, and Gerard Padró Miquel (2015). "The Value of Democracy: Evidence from Road Building in Kenya." American Economic Review 105 (6), pp. 1817-1851.

Burgess, Robin and Rohini Pande (2005). "Do rural banks matter? Evidence from the Indian social banking experiment." American Economic Review 95 (3), pp. 780-795.

Burnett, Craig M. and Vladimir Kogan (2017). "The Politics of Potholes: Service Quality and Retrospective Voting in Local Elections." The Journal of Politics 79 (1), pp. 302314.

Cain, Bruce, John A. Ferejohn, and Morris Fiorina (1990). The Personal Vote: Constituency Service and Electoral Independence. Harvard University Press.

Carbone, Giovanni (2009). "The Consequences of Democratization." Journal of Democracy 20 (2), pp. 123-137.

Cederman, Lars-Erik, Kristian Skrede, and Simon Hug (2013). "Elections and Ethnic Civil War." Comparative Political Studies 46 (3), pp. 387-417.

Central Intelligence Agency (2017). The World Factbook 2016-17. Available from https: //www.cia.gov/library/publications/the-world-factbook/index.html [Last visited 16-06-2019].

Chambers, Paul and Napisa Waitoolkiat, eds. (2017). Khaki Capital: The Political Economy of the Military in Southeast Asia. Copenhagen: Nordic Institute of Asian Studies Press.

Chan, Alfred N. (2001). Mao's Crusade: Politics and Policy Implementation in China's Great Leap Forward. Oxford: Oxford University Press. 
Chang, Eric C. C., Mark Andreas Kayser, Drew A. Linzer, and Ronald Rogowski (2010). Electoral Systems and the Balance of Consumer-Producer Power. Cambridge: Cambridge University Press.

Charron, Nicholas and Victor Lapuente (2010). "Does democracy produce quality of government." European Journal of Political Research 49 (4), pp. 471-495.

Chauvet, Lisa and Paul Collier (2009). "Election and economic policy in developing countries." Economic Policy 24 (59), pp. 509-550.

Cheibub, José Antonio, Jennifer Gandhi, and James Raymond Vreeland (2010). "Democracy and dictatorship revisited." Public Choice 143 (1), pp. 67-101.

Chiozza, Giacomo and H. E. Goemans (2004). "International Conflict and the Tenure of Leaders: Is War Still Ex Post Inefficient?" American Journal of Political Science 48 (3), pp. 604-619.

Chong, Alberto, Rafael La Porta, Florencio Lopez-de-Silanes, and Andrei Shleifer (2014). "Letter Grading Government Efficiency." Journal of the European Economic Association 12 (2), pp. 277-299.

Clark, Gregory (2007). A Farewell to Alms: A Brief Economic History of the World. NJ: Princeton University Press.

Clavert, Randall (1995). "Rational actors, equilibrium, and social institutions." Explaining social institutions. Ed. by Jack Knight and Itai Sened. Ann Arbor: University of Michigan Press. Chap. 3, pp. 57-95.

Comin, Diego and Bart Hobijn (2009). "The CHAT Dataset." NBER Working Paper 15319.

Condorcet, Nicolas de (2014). Essai sur l'application de l'analyse à la probabilité des décisions rendues à la pluralité des voix. Cambridge Library Collection - Mathematics. Cambridge University Press.

Coppedge, Michael, John Gerring, Carl Henrik Knutsen, Staffan I. Lindberg, Svend-Erik Skaaning, Jan Teorell, David Altman, Michael Bernhard, Agnes Cornell, Steven M. Fish, Haakon Gjerløw, Adam Glynn, Allen Hicken, Joshua Krusell, Anna Lührman, Kyle L. Marquardt, Kelly McMann, Valeriya Mechkova, Moa Olin, Pamela Paxton, Daniel Pemstein, Brigitte Seim, Rachel Sigman, Rachel Sigman, Jeffrey Staton, Aksel Sundtröm, Eitan Tzelgov, Luca Uberti, Yi-ting Wang, Tore Wig, and Daniel Ziblatt (2018). V-Dem Codebook v8. Retrieved from https : //www.v-dem . net/en/data/ data-version-8/ [Last visited 16-06-2019]. Varieties of Democracy (V-Dem).

Coppedge, Michael, John Gerring, Carl Henrik Knutsen, Staffan I. Lindberg, Jan Teorell, Kyle L. Marquardt, Juraj Medzihorsky, Daniel Pemstein, Josefine Pernes, Johannes von Römer, Natalia Stepanova, Eitan Tzelgov, Yi-ting Wang, and Steven Wilson (2019). V-Dem Methodology v9. Available from https : / www.v-dem.net/en/ reference/version-9-apr-2019/. Varieties of Democracy (V-Dem).

Coppedge, Michael, John Gerring, Staffan I. Lindberg, Svend-Erik Skaaning, Jan Teorell, David Altman, Michael Bernhard, Steven M. Fish, Adam Glynn, Allen Hicken, Carl Henrik Knutsen, Kyle L. Marquardt, Kelly McMann, Valeriya Mechkova, Pamela Paxton, Daniel Pemstein, Laura Saxer, Brigitte Seim, Rachel Sigman, and Jeffrey 
Staton (2017). V-Dem Codebook v\%. Retrieved from https://www.v-dem.net/en/ reference/version-7-may-2017/ [Last visited 16-06-2019]. Varieties of Democracy (V-Dem).

Coppedge, Michael, John Gerring, Staffan I. Lindberg, Svend-Erik Skaaning, Jan Teorell, David Altman, Michael Bernhard, Steven M. Fish, Adam Glynn, Allen Hicken, Carl Henrik Knutsen, Kelly McMann, Valeriya Mechkova, Farhad Miri, Pamela Paxton, Daniel Pemstein, Rachel Sigman, Jeffrey Staton, and Brigitte Zimmerman (2016). V-Dem Country-Year Dataset 6.1. Available from https://www.v-dem . net [Last visited 16-06-2019]. Varieties of Democracy (V-Dem).

Cox, Gary W. (2009). "Authoritarian elections and leadership succession, 1975-2004."

Available at: https://ssrn. com/abstract=1449034 [Last visited 16-06-2019].

Croicu, Mihai and Ralph Sundberg (2017). UCDP GED Codebook version 18.1. Retrieved from http : //ucdp.uu. se/downloads/ged/ged181.pdf [Last visited 16-06-2019]. Department of Peace and Conflict Research, Uppsala University.

CTBUH (2013). "Tall Building in Numbers." CTBUH Journal 3, pp. 42-43.

CTBUH (2016). The Skyscraper Center. The Global Tall Building Database of the CT-

$B U H$. Available from http: //www . skyscrapercenter.com/. Council of Tall Buildings and Urban Habitats.

Cummings, Bruce (1984). "The Origins and Development of the Northeast Asian Political

Economy: Industrial Sectors, Product Cycles and Political Consequences." Industrial Organization 38 (1), pp. 1-40.

Dahl, Robert A. (1971). Polyarchy: Political Participation and Opposition. New Haven, CT: Yale University Press.

Dahl, Robert A. (1989). Democracy and its Critics. New Haven: Yale University Press.

Dahl, Robert A. (1998). On democracy. New Haven: Yale University Press.

Dahl, Robert A. and Edward R. Tufte (1973). Size and Democracy. Stanford Paperbacks. Stanford University Press.

Dahlström, Carl, Jan Teorell, Stefan Dahlberg, Felix Hartmann, Annika Lindberg, and Marina Nistotskaya (2015). The QoG Expert Survey Dataset II. Retrieved from https: //qog.pol.gu.se/data/datadownloads/qogexpertsurveydata [Last visited 16-062019]. University of Gothenburg: The Quality of Government Institute.

Dahlum, Sirianne and Carl Henrik Knutsen (2017). "Do Democracies Provide Better Education? Revisiting the Democracy-Human Capital Link." World Development 94, pp. 186-199.

Davenport, Christian (1997). "From ballots to bullets: an empirical assessment of how national elections influence state uses of political repression." Electoral Studies 16 (4), pp. $517-540$.

Davenport, Christian (2007). "State repression and political order." Annual Review of Political Science 10, pp. 1-23.

Davies, Robert William, Mark Harrison, and Stephen G. Wheatcroft, eds. (1994). The Economic Transformation of the Soviet Union, 1913-1945. Cambridge: Cambridge University Press. 
De Luca, Giacomo, Roland Hodler, Paul A. Raschky, and Michele Valsecchi (2018). "Ethnic favoritism: An axiom of politics?" Journal of Development Economics 132, pp. 115-129.

Delaney, Kevin J. and Rick Eckstein (2003). Public Dollars, Private Stadiums: The Battle Over Building Sports Stadiums. New Brunswick, NJ: Rutgers University Press. 248 pp.

Dellepiane-Avellaneda, Sebastian (2010). "Review Article: Good Governance, Institutions and Economic Development: Beyond the Conventional Wisdom." British Journal of Political Science 40 (1), pp. 195-224.

Deyo, Frederick, ed. (1987). The Political Economy of the New Asian Industrialism. Ithaca, NY: Cornell University Press.

Donaghy, Maureen M. (2011). "Do Participatory Governance Institutions Matter? Municipal Councils and Social Housing Programs in Brazil." Comparative Politics 44 (1), pp. 83-102.

Dorsch, Michael T. and Paul Maarek (2019). "Democratization and the Conditional Dynamics of Income Distribution." American Political Science Review, pp. 1-20.

Doucouliagos, Hristos and Mehmet Ali Ulubaşoğlu (2008). "Democracy and Economic Growth: A Meta-Analysis." American Journal of Political Science 52 (1), pp. 61-83.

Downs, Anthony (1957). "An Economic Theory of Political Action in a Democracy." Journal of Political Economy 65 (2), pp. 135-150.

Dreher, Axel and Andreas Fuchs (2016). "Rogue aid? An empirical analysis of China's aid allocation." Canadian Journal of Economics 48 (3), pp. 988-1023.

Dreher, Axel, Andreas Fuchs, Roland Hodler, Bradley C. Parks, Paul A. Raschky, and Michael J. Tierney (2016a). "Aid on Demand: African Leaders and the Geography of China's Foreign Assistance." Working Paper 3 Revisited. Retrieved from http: / / docs . aiddata . org / ad4 / files / inline / wp3__ _revised_working _ paper _ series_dreher_et_al_2016_october.pdf [Last visited 16-06-2019].

Dreher, Axel, Andreas Fuchs, Bradley Parks, Austin Strange, and Michael J. Tierney (2016b). "Apples and Dragon Fruits: The Determinants of Aid and Other Forms of State Financing from China to Africa." Working paper. Retrieved from http : //docs . aiddata.org/ad4/pdfs/wps15_apples_and_dragon_fruits . pdf [Last visited 16-06-2019].

Easterly, William and Ross Levine (2016). "The European origins of economic development." Journal of Economic Growth 21 (3), pp. 225-257.

Engerman, Stanley L., Kenneth L. Sokoloff, Miguel Urquiola, and Daron Acemoglu (2002). "Factor Endowments, Inequality, and Paths of Development among New World Economies." Economía 3 (1), pp. 41-109.

Evans, Peter (1995). Embedded Autonomy: States and Industrial Transformation. Princeton, NJ: Princeton University Press.

Fariss, Christopher J., Charles D. Crabtree, Therese Anders, Zachary M. Jones, Fridolin J. Linder, and Jonathan N. Markowitz (2017). "Latent Estimation of GDP, GDP per capita, and Population from Historic and Contemporary Sources." Working paper. 
Faust, Jörg (2007). "Democracy's Dividend: Political Order and Economic Productivity." World Political Science Review 3 (2), pp. 2363-4782.

Fearon, James (2011). "Self-Enforcing Democracy." The Quarterly Journal of Economics $126(4)$.

Fearon, James D. (1998). "Bargaining, Enforcement, and International Cooperation." International Organization 52 (2), pp. 269-305.

Fearon, James D. (1999). "Electoral Accountability and the Control of Politicians: Selecting Good Types versus Sanctioning Poor Performance." Democracy, Accountability, and Representation. Ed. by Adam Przeworski, Susan C. Stokes, and Bernard Manin. New York: Cambridge University Press. Chap. 2.

Ferejohn, John A. (1974). Pork Barrel Politics: Rivers and Harbors Legislation, 19471968. Stanford: Stanford University Press.

Ferejohn, John A. (1986). "Incumbent performance and electoral control." Public Choice $50(1-3)$, pp. 5-25.

Fisher, Ronald (1955). "Statistical Methods and Scientific Induction." Journal of the Royal Statistical Society. Series B (Methodological) 12 (1), pp. 69-78.

Fiva, Jon, Askill Halse, and Daniel M. Smith (2018). "Local Candidates and Distributive Politics under Closed-list Proportional Representation." CESifo Working Paper No. 7039. Retrieved from http://www.cesifo-group.de/DocDL/cesifo1_wp7039.pdf [Last visited 16-06-2019].

Franck, Raphael and Ilia Rainer (2012). "Does the Leaders' Ethnicity Matter? Ethnic Favoritism, Education, and Health in Sub-Saharan Africa." American Political Science Review 106 (2), pp. 294-325.

Fravel, Taylor M. (2019). Active Defense: China's Military Strategy Since 1949. Princeton: Princeton University Press.

Fukuyama, Francis (2015). Political Order and Political Decay: From the Industrial Revolution to the Globalization of Democracy. New York: Macmillan Publishers USA.

Funk, Patricia and Christina Gathmann (2013). "How do electoral systems affect fiscal policy? Evidence from cantonal parliaments, 1890-2000." Journal of the European Economic Association 11 (5), pp. 1178-1203.

Gagliarducci, Stefano, Tommaso Nannicini, and Paolo Naticchiono (2011). "Electoral Rules and Politicians' Behavior: A Micro Test." American Economic Journal: Economic Policy 3 (3), pp. 144-174.

Galor, Oded and Omer Moav (2006). "Das Human-Kapital: A Theory of the Demise of the Class Structure." Review of Economic Studies 73, pp. 85-117.

Galtung, Johan (1996). "On the Social Costs of Modernization. Social Disintegration, Atomie/Anomie and Social Development." Development and Change 27 (2), pp. 379413.

Gandhi, Jennifer (2008a). "Dictatorial Institutions and their Impact on Economic Growth." European Journal of Sociology 49 (1), pp. 3-30.

Gandhi, Jennifer (2008b). Political institutions under dictatorship. New York: Cambridge University Press. 
Gandhi, Jennifer and Ellen Lust-Okar (2009). "Elections Under Authoritarianism." Annual Review of Political Science 12 (1), pp. 403-422.

Gandhi, Jennifer and Adam Przeworski (2006). "Cooperation, Cooptation and Rebellion Under Dictatorships." Economics and Politics 18 (1), pp. 1-26.

Gandhi, Jennifer and Adam Przeworski (2007). "Authoritarian Institutions and the Survival of Autocrats." Comparative Political Studies 40 (11), pp. 1279-1301.

Geddes, Barbara, Joseph Wright, and Erica Frantz (2014). "Autocratic Breakdown and Regime Transition: A New Data Set." Perspectives on Politics 12 (2), pp. 313-331.

Gehlbach, Scott and Philip Keefer (2011). "Investment without democracy: ruling-party institutionalization and credible commitment in autocracies." Journal of Comparative Economics 39 (2), pp. 123-139.

Gehlbach, Scott and Alberto Simpser (2014). "Electoral Manipulation as Bureaucratic Control." American Journal of Political Science 59 (1), pp. 212-224.

Gehlbach, Scott, Konstantin Sonin, and Milan W. Svolik (2016). "Formal models of nondemocratic politics." Annual Review of Political Science 19, pp. 565-584.

Gereffi, Gary and Donald L. Wyman (1990). Manufacturing Miracles: Paths of Industrialization in Latin America and East Asia. Princeton, NJ: Princeton University Press.

Gerring, John, Philip Bond, William T. Barndt, and Carola Moreno (2005). "Democracy and economic growth: A historical perspective." World Politics 57 (3), pp. 323-364.

Gerring, John, Carl Henrik Knutsen, Svend-Erik Skaaning, Jan Teorell, Matthew Maguire, Michael Coppedge, and Staffan Lindberg (2016). "Electoral Democracy and Human Development." V-Dem Working Paper No. 9.

Gerring, John, Strom C. Thacker, and Rodrigo Alfaro (2012). "Democracy and Human Development." Journal of Politics 74 (1), pp. 1-17.

Gerschenkron, Alexander (1962). Economic Backwardness in Historical Perspective. Cambridge: Belknap Press.

Gibler, Douglas M. (2007). "Bordering on Peace: Democracy, Territorial Issues, and Conflict." International Studies Quarterly 51, pp. 509-532.

Glaeser, Edward L., Rafael LaPorta, Florencio López-de-Silanes, and Andrei Shleifer (2004). "Do Institutions Cause Growth?" Journal of Economic Growth 9 (3), pp. 271303.

Goldstone, Jack. (2009). Why Europe? The Rise of the West in World History, 1500-1850. New York: McGraw-Hill.

Gordon, Sanford C. and Hannah K. Simpson (2018). "The Birth of Pork: Local Appropriations in America's First Century." American Political Science Review 112 (3), pp. 564-579.

Greif, Avner and Christopher Kingston (2011). "Institutions: Rules or Equilibria?" Political Economy of Institutions, Democracy and Voting. Ed. by Norman Schofield and Gonzalo Caballero. Berlin: Springer. Chap. 2, pp. 13-44.

Greif, Avner and David D. Laitin (2004). "A Theory of Endogenous Institutional Change." American Political Science Review 98 (4), pp. 633-652. 
Guardado, Jenny and Leonard Wantchékon (2018). "Do electoral handouts affect voting behavior?" Electoral Studies 53, pp. 139-149.

Guiffrey, Jules (1901). Comptes des bâtiments du Roi sous le règne de Louis XIV. Tome deuxième, Colbert et Louvois, 1681-168\%. Ed. by Imprimerie nationale (Paris). Jules Guiffrey.

Haber, Stephen and Victor Menaldo (2011). "Do natural resources fuel authoritarianism? A reappraisal of the resource curse." American Political Science Review 105 (1), pp. 126.

Hachigian, Nina (2002). "The Internet and Power in One-Party East Asian States." The Washington Quarterly 25 (3), pp. 41-58.

Hafner-Burton, Emilie, Susan D Hyde, and Ryan S. Jablonski (2014). "When Do Governments Resort to Election Violence?" British Journal of Political Science 44 (1), pp. 149-179.

Haggard, Stephan (1990). Pathways from the Periphery: The Politics of Growth in the Newly Industrializing Countries. Ithaca: Cornell University Press.

Haggard, Stephan and Robert A. Kaufman (2012). "Inequaliy and Regime Change: Democratic Transitions and the Stability of Democratic Rule." American Political Science Review 106 (3), pp. 495-516.

Hainmueller, Jens (2011). "Entropy Balancing for Causal Effects: A Multivariate Reweighting Method to Produce Balanced Samples in Observational Studies." Political Analysis 20 (1), pp. 25-46.

Hajnal, John (1965). "European Marriage Patterns in Perspective." Population in history: Essays in historical damography. Ed. by David Victor Glass and David Edward Charles Eversley. Chicago: Aldine Publishing Company.

Hardin, Garrett (1968). "The Tragedy of the Commons." Science 162 (3859), pp. 12431248.

Harding, Robin (2015). "Attribution and Accountability: Voting for Roads in Ghana." World Politics 67 (4), pp. 656-689.

Harding, Robin and David Stasavage (2014). "What Democracy Does (and Doesn't Do) for Basic Services: School Fees, School Inputs, and African Elections." The Journal of Politics 76 (1), pp. 229-245.

Hariri, Jacob Gerner (2015). "Foreign Aided: Why Democratization Brings Growth When Democracy Does Not." English. British Journal of Political Science 45 (1), pp. 53-71.

Harms, Philipp and Stefan Zink (2003). "Limits to redistribution in a democracy: a survey." European Journal of Political Economy 19 (4), pp. 651-668.

Helmke, Gretchen and Frances Rosenbluth (2009). "Regimes and the Rule of Law: Judicial Independence in Comparative Perspective." Annual Review of Political Science 12, pp. 345-366.

Hodler, Roland and Paul A. Raschky (2014). "Regional Favoritism." The Quarterly Journal of Economics 129 (2), pp. 995-1033. 
Holkeboer, Christian B. and James R. Vreeland (2013). "Calling Democracies and Dictatorships: The Effect of Political Regime on Long-Distance Rates." Kyklos 66 (3), pp. $417-437$.

Hollenbach, Florian M. (2019). "Elite Interests and public spending: Evidence from Prussian Cities." The Review of International Organizations, pp. 1-23.

Hollyer, James R, B Peter Rosendorff, and James Raymond Vreeland (2011). "Democracy and transparency." Journal of Politics 73 (4), pp. 1191-1205.

Hollyer, James R, B Peter Rosendorff, and James Raymond Vreeland (2014). "Measuring transparency." Political analysis 22 (4), pp. 413-434.

Huntington, Samuel P. (1968). Political Order in Changing Societies. Yale University Press.

Iacus, Stefano M., Gary King, and Guiseppe Porro (2012). "Causal Inference without Balance Checking: Coarsened Exact Matching." Political Analysis 20 (1), pp. 1-24.

International Consortium of Investigative Journalists (2016). Panama Papers. Available from https://www.icij.org/investigations/panama-papers/ [Last visited 1606-2019].

Isaksson, Ann-Sofie and Andreas Kotsadam (2018). "Chinese aid and local corruption." Joural of Public Economics 159, pp. 146-159.

Jackman, Robert W. (1974). "Political Democracy and Social Equality: A Comparative Analysis." American Sociological Review 39 (1), pp. 29-45.

Jensen, Nathan M., Edmund Malesky, and Stephen Weymouth (2014). "Unbundling the relationship between authoritarian legislatures and political risk." British Journal of Political Science 44 (3), pp. 655-684.

Jerven, Morten (2013). Poor Numbers. How We Are Misled by African Development Statistics and What to Do aout It. Cornell University Press: Ithaca and London.

Jones, Eric (1981). The European Miracle: Environments, Economics and Geopolitics in the History of Europe and Asia. Cambridge: Cambridge University Press.

Kadt, Daniel de and Stephen B. Wittels (2019). "Democratization and Economic Output in Sub-Saharan Africa." Political Science Research and Methods 7 (1), pp. 63-84.

Kamarck, Andrew M. (1976). The Tropics and Economic Development. Baltimore and London: John Hopkins University Press.

Kasara, Kimuli (2007). "Tax Me if You Can: Ethnic Geography, Democracy, and the Taxation of Agriculture in Africa." American Political Science Review 101 (1), pp. 159 172.

Keefer, Philip and Stephen Knack (2007). "Boondoggles, Rent-Seeking, and Political Checks and Balances: Public Investment Under Unaccountable Governments." Review of Economics and Statistics 89 (3), pp. 566-572.

Kenworthy, Lane and Leslie McCall (2008). "Inequality, Public Opinion and Redistribution." Socio-Economic Review 6 (1), pp. 35-68.

King, Gary, Robert O. Keohane, and Sidney Verba (1994). Designing Social Inquiry: Scientific Inference in Qualitative Research. NJ: Princeton University Press. 
King, Gary, Christopher Lucas, and Richard Nielsen (2016). "The Balance-Sample Size Frontier in Matching Methods for Causal Inference." American Journal of Political Science 61 (2), pp. 473-489.

King, Gary, Jennifer Pan, and Margaret E. Roberts (2013). "How Censorship in China Allows Government Criticism but Silences Collective Expression." American Political Science Review 107 (2), pp. 1-8.

King, Gary, Jennifer Pan, and Margaret E. Roberts (2017). "How the Chinese Government Fabricates Social Media Posts for Strategic Distraction, not Engaged Argument." American Political Science Review 111 (3), pp. 484-501.

Knutsen, Carl Henrik (2010). "Measuring Effective Democracy." International Political Science Review 31 (2), pp. 109-128.

Knutsen, Carl Henrik (2011). "Democracy, Dictatorship and Protection of Property Rights." Journal of Development Studies 47 (1), pp. 164-182.

Knutsen, Carl Henrik (2012). "Democracy and economic growth: A survey of arguments and results." International Area Studies Review 15 (4), pp. 393-415.

Knutsen, Carl Henrik (2013). "Democracy, State Capacity, and Economic Growth." World Development 43, pp. 1-18.

Knutsen, Carl Henrik (2015). "Why democracies outgrow autocracies in the long run: Civil liberties, information flows and technological change." Kyklos 68 (3), pp. 357384.

Knutsen, Carl Henrik, John Gerring, Svend-Erik SKaaning, Jan Teorell, Matthew Maguire, Michael Coppedge, and Staffan I. Lindberg (2019a). "Economic development and democracy: An electoral connection." European Journal of Political Research 58 (1), pp. 292-314.

Knutsen, Carl Henrik, Håvard Mokleiv Nygård, and Tore Wig (2017). "Autocratic Elections: Stabilizing Tool or Force for Change?" World Politics 69 (1), pp. 98-143.

Knutsen, Carl Henrik and Magnus Rasmussen (2017). "The Autocratic Welfare State: Old-Age Pensions, Credible Commitments, and Regime Survival." Comparative Political Studies, pp. 1-37.

Knutsen, Carl Henrik, Jan Teorell, Tore Wig, Agnes Cornell, John Gerring, Haakon Gjerløw, Svend-Erik Skaaning, Daniel Ziblatt, Kyle L. Marquardt, Dan Pemstein, and Brigitte Seim (2019b). "Introducing the Historical Varieties of Democracy dataset: Political Institutions in the long 19th Century." Journal of Peace Research 56 (3), pp. 440-451.

Kohli, Atul (2004). State-Directed Development: Political Power and Industrialization in the Global Periphery. Cambridge: Cambridge University Press.

Koistinen, Paul A. C. (1980). The Military-Industrial Complex: A Historical Perspective. Praeger.

Kollman, Ken, Allan Hicken, Daniel Caramani, David Becker, David Lublin, Joel Selway, and Fabricio Vasselai (2019). "GeoReferenced Electoral Districts Datasets." Produced and distributed by Ann Arbor, MI: Center for Political Studies, University 
of Michigan. Available from http://www . electiondataarchive.org [Last visited 16-06-2019].

Kramon, Eric (2013). "Vote Buying and Accountability in Democratic Africa." Available from https: / / escholarship.org/uc/item/1490x02z [Last visited 16-06-2019]. PhD thesis. University of California, Los Angeles.

Kramon, Eric (2016). "Electoral Handouts as Information: Explaining Unmonitored Vote Buying." World Politics 68 (3), pp. 454-498.

Kramon, Eric and Daniel N. Posner (2013). "Who Benefits from Distributive Politics? How the Outcome One Studies Affects the Answer One Gets." Perspectives on Politics 11 (02), pp. 461-474.

Krieckhaus, Jonathan (2004). "The Regime Debate Revisted: A Sensitivity Analysis of Democracy's Economic Effect." British Journal of Political Science 34 (4), pp. 635655.

Kuran, Timur (1989). "Sparks and Prairie Fires: A Theory of Unanticipated Political Revolution." Public Choice 61 (1), pp. 41-74.

Kuran, Timur (1991). "Now Out of Never: The Element of Surprise in the East European Revolution of 1989." World Politics 44 (1), pp. 7-48.

La Porta, Rafael, Florencio Lopez-de-Silanes, Andrei Shleifer, and Robert W. Vishny (1999). "The Quality of Government." Journal of Law, Economics, E Organization 15 (1), pp. 222-279.

Lake, David A. and Matthew A. Baum (2001). "The Invisible Hand of Democracy: Political Control and the Provision of Public Services." Comparative Political Studies 35 (6), pp. 587-621.

Landes, David (1998). The Wealth and Poverty of Nations. London: Little.

Lee, Cheol-Sung (2005). "Income Inequality, democracy, and public sector size." American Sociological Review 70 (1), pp. 158-181.

Leftwich, Adrian (2000). States of development: On the Primacy of Politics in Development. Cambridge: Polity Press.

Lehne, Jonathan, Jacob N. Shapiro, and Oliver Vanden Eynde (2018). "Building connections: Political corruption and road construction in India." Journal of Development Economics 131, pp. 62-78.

Levitsky, Steven and Lucan A Way (2010). Competitive Authoritarianism: Hybrid Regimes after the Cold War. Cambridge: Cambridge University Press.

Lindberg, Staffan I., ed. (2009). Democratization by Elections. A New Mode of Transition. Baltimore: Johns Hopkins University Press.

Lindert, Peter H. (2004). Growing Public: Social Spending and Economic Growth since the Eighteenth Century. Cambridge: Cambridge University Press.

Little, Andrew T (2015). "Fraud and Monitoring in non-competitive Elections." Political Science Research and Methods 3 (1), pp. 21-41.

Little, Andrew T. (2017). "Are non-competitive elections good for citizens?" Journal of Theoretical Politics 29 (1), pp. 214-242. 
Lott, John R. Jr. and Lawrence Kenny (1999). "Did Women's Suffrage Change the Size and Scope of Government?" Journal of Political Economy 107 (6), pp. 1163-1198.

Lührman, Anna, Kyle Marquardt, and Valeriya Mechkova (2017). "Constraining Governments: New Indices of Vertical, Horizontal and Diagonal Accountability." V-Dem Working Paper 2017:46.

Lust-Okar, Ellen (2006). "Elections under authoritarianism: Preliminary lessons from Jordan." Democratization 13 (3), pp. 456-471.

Macho-Stadler, Inés and David Pérez-Castrillo (1997). An Introduction to the Economics of Information. Oxford: Oxford University Press.

Magaloni, Beatriz (2006). Voting for autocracy: Hegemonic party survival and its demise in Mexico. New York: Cambridge University Press.

Malesky, Edmund and Paul Schuler (2011). "The Single-Party Dictator's Dilemma: Information in elections without opposition." Legislative Studies Quarterly 36 (4), pp. 491530 .

Manning, Patrick (2010). "African Population Projections 1850-1960." The Demographies of Empire: The Colonial Order and the Creation of Knowledge. Ed. by Dennis D. Cordell and Gregory Maddox. Athens: Ohio University Press, pp. 245-275.

Mark, Monica (2015). "Yamoussoukro's Notre-Dame de la Paix, the world's largest basilica - A history of cities in 50 buildings, day 37." The Guardian. Retrieved from https: //www . theguardian . com/cities/2015/may/15/yamoussoukro-notre-dame-dela-paix-ivory-coast-worlds-largest-basilica-history-of-cities-in-50buildings-day-37 [Last visited 16-06-2019].

Martin, Shane (2016). "Policy, Office and Votes: The Electoral Value of Ministerial Office." British Journal of Political Science 46 (2), pp. 281-296.

Martina, Michael (2017). "Exclusive: In China, the Party's push for influence inside foreign firms stir fears." Reuters. Retrieved from https://www.reuters.com/article/ us - china-congress - companies / exclusive-in-china-the-partys-push-forinfluence-inside-foreign-firms-stirs-fears-idUSKCN1B40JU [Last visited 16-06-2019].

Martinez, Luis R. (2018). "How Much Should We Trust Dictator's GDP Estimates?" Working Paper. Retrieved from https://ssrn. com/abstract=3093296 [Last visited 16-06-2019].

Masters, William A. and Margaret S. McMillan (2001). "Climate and Scale in Economic Growth." Journal of Economic Growth 6 (3), pp. 167-186.

Mauro, Paolo, Rafael Romeu, Ariel Binder, and Asad Zaman (2015). "A modern history of fiscal prudence and profligacy." Journal of Monetary Economics 76 (C), pp. 55-70.

McCubbins, Mathew D. and Frances Rosenbluth (1995). "Party provision for personal politics: Dividing the vote in Japan." Structure and policy in Japan and the United States. Ed. by Peter F. Cowhey and Matthew D. McCubbins. New York: Cambridge University Press, pp. 33-55.

McDowell, Christopher, ed. (1996). Understanding Impoverishment. The Consequences of Development-induced Displacement. Oxford: Berghahn Books. 
McElreath, Richard (2015). Statistical Rethinking. A Bayesian Course with examples in $R$ and Stan. USA: CRC Press.

Meltzer, Allan H. and Scott F. Richard (1981). "A Ration Theory of the Size of Government." The Journal of Political Economy 89 (5), pp. 914-927.

Meredith, Martin (2011). The Fate of Africa: A History of the Continent Since Independence. NY: PublicAffairs.

Miller, Michael K. (2015a). "Democratic Pieces: Autocratic Elections and Democratic Development since 1815." British Journal of Political Science 45 (3), pp. 501-530.

Miller, Michael K. (2015b). "Elections, Information, and Policy Responsiveness in Autocratic Regimes." Comparative Political Studies 48 (6), pp. 691-727.

Miller, Michael K. (2015c). "Electoral authoritarianism and human development." Comparative Political Studies 48 (12), pp. 1526-1562.

Min, Brian (2015). Power and the Vote: Elections and Electricity in the Developing World. Cambridge: Cambridge University Press.

Mobarak, Ahmed Mushfiq (2005). "Democracy, Volatility, and Economic Development." Review of economics and Statistics 87 (2), pp. 348-361.

Moe, Terry (1990). "Political Institutions: The Neglected Side of the Story." Jounral of Law, Economics, and Organization 6 (Special Issue), pp. 213-253.

Mokyr, Joel (2017). A Culture of Growth: Origins of the Modern Economy. Princeton: Princeton University Press.

Morgan, Stephen L. and Christopher Winship (2015). Counterfactuals and causal inference. Methods and principles for social research. Second. NY: Cambridge University Press.

Müller, Wolfgang C. and Kaare Strøm, eds. (1999). Policy, Office, or Votes? How political parties in western europe make hard decisions. UK: Cambridge University Press.

Mulligan, Casey B., Richard Gil, and Xavier Sala-i-Martin (2004). "Do Democracies Have Different Public Policies than Nondemocracies?" Journal of Economic Perspective 18 (1), pp. 51-74.

Munck, Gerardo L. and Jay Verkuilen (2002). "Conceptualizing and Measuring Democracy." Comparative Political Studies 35 (1), pp. 5-34.

Murphy, Kevin M., Andrei Shleifer, and Robert W. Vishny (1989). "Industrialization and the Big Push." Journal of Political Economy 97 (5), pp. 1003-1026.

Myrdal, Gunnar (1968). Asian Drama: An Inquiry into the Poverty of Nations. New York: Twientieth Century Fund.

Naughton, Barry and Kellee S. Tsai (2015). State capitalism, institutional adaptation, and the Chinese miracle. Cambridge: Cambridge University Press.

Nelson, Joan M. (2007). "Election, Democracy and Social Services." Studies in Comparative International Development 41 (4), pp. 79-97.

Nielsen, Kenneth Bo (2010). "Contesting India's development? Industrialisation, land acquisition and protest in West Bengal." Forum for Development Studies 37 (2), pp. 145170. 
North, Douglass C. (1990). Institutions, Institutional Change and Economic Performance. Cambridge: Cambridge University Press.

North, Douglass C. and Robert Paul Thomas (1973). The Rise of the Western World: A New Economic History. Cambridge: Cambridge University Press.

North, Douglass C. and Barry R. Weingast (1989). "Constitutions and Commitment: The Evolution of Institutions in Governing Public Choice in Seventeenth-Century England." The Journal of Economic History 49 (4), pp. 803-832.

O'Donnell, Guillermo A. (1988). Bureaucratic authoritarianism: Argentina, 1966-1973, in comparative perspective. Berkeley: University of California Press.

Olken, Benjamin (2007). "Monitoring Corruption: Evidence From a Field Experiment in Indonesia." Journal of Political Economy 115 (2), pp. 200-249.

Olson, Mancur (1971). The Logic of Collective Action. Public Goods and the Theory of Groups. Cambridge: Harvard University Press.

Olson, Mancur (1993). "Dictatorship, Democracy, and Development." American Political Science Review 87 (3), pp. 567-576.

Pemstein, Daniel, Kyle L. Marquardt, Eitan Tzelgov, Yi-ting Wang, Joshua Krussel, and Farhad Miri (2018). "The V-Dem Measurement Model: Latent Variable Analysis for Cross-National and Cross-Temporal Expert-Coded Data." V-Dem Working Paper 2018:21.

Pemstein, Daniel, Kyle L. Marquardt, Eitan Tzelgov, Yi-ting Wang, and Farhad Miri (2015). "The V-Dem Measurement Model: Latent Variable Analysis for Cross-National and Cross-Temporal Expert-Coded Data." V-Dem Working Paper.

Persson, Tove Ahlbom and Marina Povitkina (2017). "Gimme Shelter": The Role of Democracy and Institutional Quality in Disaster Preparedness." Political Research Quarterly 70 (4), pp. 833-847.

Pierskalla, Jan H. and Audrey Sacks (2018). "Unpaved Road Ahead: The Consequences of Election Cycles for Capital Expenditures." Journal of Politics 80 (2), pp. 510-524.

Pomeranz, Kenneth (2000). The Great Divergence: China, Europe and the Making of the Modern World Economy. Princeton: Princeton University Press.

Pomeranz, Kenneth and Steven Topik (2014). The World that Trade Created: Society, Culture and the World Economy, 1400 to the present. UK: Routledge.

Priest, Geroge L. (1975). "The History of The Postal Monopoly In the United States." Journal of Law and Economics 18 (1), pp. 33-80.

Przeworski, Adam (1991). Democracy and the Market: Political and Economic Reforms in Eastern Europe and Latin America. Cambridge: Cambridge University Press.

Przeworski, Adam (2000). States and Markets: A Primer in Political Economy. Cambridge: Cambridge University Press.

Przeworski, Adam (2004). "Institutions matter?" Government and Opposition 39 (4), pp. 527-540.

Przeworski, Adam (2010). Democracy and the Limits of Self-Government. Cambridge: Cambridge University Press. 
Przeworski, Adam, Michael E. Alvarez, José Antonio Cheibub, and Fernando Limongi (2000). Democracy and Development. Political Institutions and Well-Being in the World, 1950-1990. Cambridge: Cambridge University Press.

Przeworski, Adam and Fernando Limongi (1993). "Political Regimes and Economic Growth." The Journal of Economic Perspectives 7 (3), pp. 51-69.

Przeworski, Adam, Susan C. Stokes, and Bernard Manin, eds. (1999). Democracy, Accountability, and Representation. New York: Cambridge University Press.

Putterman, Louis (1997). "Why Have the Rabble not Redistributed the Wealth." Property Relations, Incentives and Welfare. Ed. by John E. Roemer. UK: Palgrave Macmillan. Chap. 13.

Rakner, Lise and Nicolas van de Walle (2009). "Democratization by Elections? Opposition Weakness in Africa." Journal of Democracy 20 (3), pp. 108-121.

Rappaport, Jordan and Jeffrey D. Sachs (2003). "The United States as a Coastal Nation." Journal of Economic Growth 8 (1), pp. 5-46.

Riker, William (1982). LIberalism against Populism. Prospect Heights, IL: Waveland Press.

Riker, William H. (1980). "Implications from the Disequilibrium of Majority Rule for the Study of Institutions." American Political Science Review 74 (2), pp. 432-446.

Robinson, James and Ragner Torvik (2005). "White Elephants." Journal of Political Economy 89 (2), pp. 197-210.

Robison, Richard (1988). "Authoritarian States, capital-owning classes and the politics of newly industrializing countries: The case of Indonesia." World Politics 41 (1), pp. 5274.

Rock, Michael (2009). "Corruption and Democracy." Journal of Development Studies 45 (1), pp. 55-75.

Rodrigìuez, Francisco C. (1999). "Does Distributional Skewness Lead to Redistribution? Evidence from the United States." Economics and Politics.

Rodrik, Dani (1999). "Democracies Pay Higher Wages." The Quarterly Journal of Economics 114 (3), pp. 707-738.

Rodrik, Dani (2008). One Economics, Many Recipes. Princeton: Princeton University Press.

Rogowski, Jon C. (2016). "Presidential Influence in an Era of Congressional Dominance." American Political Science Review 110 (2), pp. 325-341.

Rogowski, Jon C., John Gerring, Matthew Maguire, and Lee Cojocary (2018). "Public Infrastructure and Economic Development: Evidence from Postal Systems."

Working paper. Available from https://scholar .harvard.edu/rogowski/research [Last visited 16-06-2019].

Román, Concepción, Raquel Espino, and Juan Carlos Martín (2007). "Competition of high-speed train with air transport: The case of Madrid-Barcelona." Journal of Air Transport Management 13 (5), pp. 277-284.

Romer, Thomas and Howard Rosenthal (1978). "Political resource allocation, controlled agendas, and the status quo." Public Choice 33 (4), pp. 27-43. 
Rosenstein-Rodan, Paul N. (1943). "Problems of Industrialisation of Eastern and Southeastern Europe." Economic Journal 53, pp. 202-211.

Rosling, Hans, Ola Rosling, and Anna Rosling Rönnlund (2018). Factfulness:Ten Resasons We're Wrong About the World-and Why Things Are Better Than You Think. UK: Sceptre.

Ross, Michael (2006). "Is Democracy Good for the Poor?" American Journal of Political Science 50 (4), pp. 860-874.

Ross, Michael L. (2012). The Oil Curse: How Petroleum Wealth Shapes the Development of Nations. NJ: Princeton University Press.

Rothstein, Bo and Jan Teorell (2008). "What Is Quality of Government? A Theory of Impartial Government Institutions." Governance 21 (2), pp. 165-190.

Rowley, Charles, Robert D. Tollison, and Gordon Tullock, eds. (1988). The Political Economy of Rent-Seeking. Springer US.

Rubin, Donald B. (2005). "Causal Inference Using Potential Outcomes: Design, Modeling, Decisions." Journal of the American Statistical Association 100, pp. 322-331.

Rundlett, Ashlea and Milan W. Svolik (2016). "Deliver the vote! Micromotives and macrobehavior in electoral fraud." Americal Political Science Review 110 (1), pp. 180197.

Sachs, Jeffrey D. (2001). "Tropical Underdevelopment."

Working paper. Available from https://www.nber.org/papers/w8119 [Last visited 16-06-2019].

Saiz, Albert (2006). "Dictatorships and Highways." Regional Science and Urban Economics 36 (2), pp. 187-206.

Sandler, Todd (1992). Collective Action. Theory and Applications. Ann Arbor: University of Michigan Press.

Sargeson, Sally (2013). "Violence as Development: Land Expropriation and China's Urbanization." Journal of Peasant Studies 40 (6), pp. 1063-1085.

Sarkees, Meredith and Frank Wayman (2010). Resort to War: 1816 - 2007. Washington DC: CQ Press.

Schedler, Andreas (1999). "Conceptualizing Accountability." Self-Restraining State - Power and Accountability in New Democracies. Ed. by Andreas Schedler, Larry Diamond, and Marc F. Plattner. Boulder: Rienner Publishers. Chap. 2, pp. 13-29.

Schedler, Andreas (2009). "Electoral Authoritarianism." The SAGE Handbook of Comparative Politics. Ed. by Todd Landman and Neil Robinson. London: SAGE Publications Ltd. Chap. 20, pp. 380-393.

Scheve, Kenneth and David Stasavage (2009). "Institutions, Partisanship and Inequality in the Long Run." World Politics 61 (2), pp. 215-253.

Scheve, Kenneth and David Stasavage (2017). "Wealth Inequality and Democracy." $A n$ nual Review of Political Science 20 (1), pp. 451-468.

Schumpeter, Joseph A. (1942). Capitalism, Socialism \& Democracy. New York: Routledge, 1992. 
Schweinitz, Karl. de (1959). "Industrialization, labor controls, and democracy." Economic Development and Cultural Change 7 (4), pp. 385-404.

Sen, Amartya (1999). "Democracy as a Universal Value." Journal of Democracy 10.

Shandra, John M., Jenna Nobles, Bruce London, and John B. Williamson (2004). "Dependency, democracy, and infant mortality: a quantitative, cross-national analysis of less developed countries." Social Science 8 Medicine 59 (2), pp. 321-333.

Shearer, David R. (1996). Industry, State, and Society in Stalin's Russia, 1926-1934. Ithaca: Cornell University Press.

Shepsle, Kenneth A. and Mark S. Boncheck (1996). Analyzing Politics: Rationality, Behavior, and Institutions. New York: W. W. Norton \& Company.

Simpser, Alberto (2013). Why governments and parties manipulate elections: Theory, practice, and implications. New York: Cambridge University Press.

Sirowy, Larry and Alex Inkeles (1990). "The Effects of Democracy on Economic Growth and Inequality: A review." Studies In Comparative International Development 25 (1), pp. 126-157.

Skaaning, Svend-Erik, John Gerring, and Henrikas Bartusevičius (2015). "A Lexical Index of Electoral Democracy." Comparative Political Studies 48 (12), pp. 1491-1525.

Skidmore, Thomas E. (1990). The Politics of Military Rule in Brazil, 1964-1985. New York: Oxford University Press.

Skocpol, Theda (1985). "Bringing the State Back In." Bringing the State Back In. Ed. by Peter B. Evans, Dietrich Rueschmeyer, and Thedas Skocpol. Cambridge: Cambridge University Press. Chap. 1, pp. 3-38.

Smelser, Neil J. (1959 [2011]). Social change in the British industrial revolution: An application of theory to the British cotton industry. London: Routledge.

Smith, Hazel (2015). North Korea: Markets and Military Rule. Cambridge: Cambridge University Press.

Spolaore, Enrico and Romain Wacziarg (2013). "How Deep Are the Roots of Economic Development?" Journal of Economic Literature 51 (2), pp. 325-369.

Stasavage, David (2005). "Democracy and Education Spending in African." American Journal of Political Science 49 (2), pp. 343-358.

State Council (2014). "China's Foreign Aid. Beijing: White Paper."

Retrieved from http://english.gov.cn/archive/white_paper/2014/08/23/ content_281474982986592.htm [Last visited 16-06-2019].

Staton, Jeffrey and Georg Vanberg (2008). "The Value of Vagueness: Delegation, Defiance, and Judicial Opinions." American Journal of Political Science 52 (3), pp. 504-519.

Stokes, Susan C., Thad Dunning, Marcelo Nazareno, and Valeria Brusco (2014). Brokers, Voters, and Clientelism. The Puzzle of Distributive Politics. Cambridge: Cambridge University Press.

Strange, Austin M., Axel Dreher, Andreas Fuchs, Bradley Parks, and Michael J. Tierney (2017). "Tracking Underreported Fincacial Flows: China's Development Finance and the Aid-Conflict Nexus Revisited." Journal of Conflict Resolution 61 (5), pp. 935-963. 
Sundberg, Ralph and Erik Melander (2013). "Introducing the UCDP Georeferenced Event Dataset." Journal of Peace Research 50 (4), pp. 523-532.

Svolik, Milan W. (2012). The Politics of Authoritarian Rule. Cambridge: Cambridge Univerisity Press.

Tajima, Yuhki, Krislert Samphantharak, and Kai Ostwald (2018). "Ethnic Segregation and Public Goods: Evidence from Indonesia." American Political Science Review 112 (3), pp. 637-653.

Tang, John P. (2014). "Railroad expansion and industrialization: evidence from Meiji Japan." The Journal of Economic History 74 (3), pp. 1341-1378.

Tavares, Jose and Romain Wacziarg (2001). "How democracy affects growth." European Economic Review 45 (8), pp. 1341-1378.

Teorell, Jan, Michael Coppedge, Staffan I. Lindberg, and Svend-Erik Skaaning (2018). "Measuring Polyarchy Across the Globe, 1900-2017." Studies in Comparative International Development, pp. 1-25.

Teroell, Jan, Stefan Dahlberg, Bo Rothstein, Anna Khomenko, and Richard Svensson (2017). The Quality of Government Standard Dataset, version Jan17. University of Gothenburg: The Quality of Government Institute.

The World Bank (2010). World Development Indicators. Retrieved from http://data. worldbank . org / data - catalog / world-development-indicators [14-08-2018]. Washington, D.C.: The World Bank (producer and distributor).

Thompson, Edward P. (1966). The making of the English working class. New York: Vintage.

Tipton, Elise K. (2008). Modern Japan: A social and political history. London: Routledge. Tollefsen, Andreas Forø, Karim Bahgat, Jonas Nordkvelle, and Halvard Buhaug (2012). "PRIO-GRID: A unified spatial data structure." Journal of Peace Research 49 (2), pp. 363-374.

Tollefsen, Andreas Forø, Karim Bahgat, Jonas Nordkvelle, and Halvard Buhaug (2015). PRIO-GRID v.2.0 Codebook. Peace Research Institute Oslo.

Treisman, Daniel (2007). "What Have We Learned About the Causes of Corruption from Ten Years of Cross-National Empirical Research?" Annual Review of Political Science 10, pp. 211-244.

Tull, Denis (2006). "China's Engagement in Africa: Scope, Significance and Consequences." Journal of Modern African Studies 44 (3), pp. 459-479.

United Nations, European Commission, International Monetary Fund, Organisation for Economic Co-operation and Development and World Bank. (2009). System of National Accounts 2008. New York: United Nations.

UPU (2011). Annual Report 2011. Actions to strengthen the global postal network. Retrieved from http : / / news . upu . int / fileadmin / user_upload / PDF / Reports / 2011AnnualReportEn.pdf [Last visited 16-06-2019]. Universal Postal Union.

van de Walle, Nicholas (2003). "Presidentialism and clientelism in Africa's emerging party systems." The Journal of Modern African Studies 41 (2), pp. 297-321. 
Wade, Robert (2003). Governing the Market: Economic Theory and the Role of Government in East Asian Industrialization. Princeton: Princeton University Press.

Wantchékon, Leonard (2003). "Clientelism and Voting Behavior." World Politics 55, pp. 399-422.

Wavro, Geoffrey (2003). The Franco-Prussian War: The German Conquest of France in 1870-1871. Cambridge: Cambridge University Press.

Weidmann, Nils B., Doreen Kuse, and Kristian Skrede Gleditsch (2010). "The Geography of the International System: The CShapes Dataset." International Interactions 36 (1), pp. 86-106.

Wickham, Hadley (2016). Package 'rvest'. Available from https://cran.r-project. org/web/packages/rvest/rvest.pdf.

Wig, Tore and Espen Geelmuyden Rød (2014). "Cues to Coup Plotters. Elections as Coup Triggers in Dictatorships." Journal of Conflict Resolution 60 (5), pp. 787-812.

Wikipedia (n.d.). Shwedagon Pagoda. Retrieved from https : / / en . wikipedia.org / wiki/Shwedagon_Pagoda [Last visited 16-06-2019].

Williams, Martin J. (2017). "The Political Economy of Unfinished Development Projects: Corruption, Clientelism, or Collective Choice?" American Political Science Review 111 (4), pp. 705-723.

Wintrobe, Ronald (1998). The Political Economy of Dictatorship. Cambridge: Cambridge University Press.

Woo-Cumings, Meredith, ed. (1999). The Developmental State. Ithaca, NY: Cornell University Press.

Woo, Ae sil and Courtenay R. Conrad (2019). "The Differential Effects of "Democratic" Institutions on Dissent in Dictatorships." Journal of Politics 81 (2).

Wright, Joseph (2008). "Do Authoritarian Institutions Constrain? How Legislatures Affect Economic Growth and Investment." American Journal of Political Science 52 (2), pp. 322-343.

Yamamura, Kozo (1977). "Success Illgotten? The Role of Meiji Militarism in Japan's Technological Progress." The Journal of Economic History 37 (1), pp. 113-135.

Young, Alwyn (1995). "The Tyranny of Numbers: Confronting the Statistical Realities of the East Asian Growth Experience." Quarterly Journal of Economics 110 (3), pp. 641680.

Zaslavsky, Victor and Robert J Brym (1978). "The functions of elections in the USSR." Soviet Studies XXX (3), pp. 362-371. 